\title{
Rett Syndrome : 1954-2004
}

Citation for published version (APA):

Smeets, E. E. J. (2005). Rett Syndrome : 1954-2004. [Doctoral Thesis, Maastricht University]. https://doi.org/10.26481/dis.20050601es

Document status and date:

Published: 01/01/2005

DOI:

10.26481/dis.20050601es

Document Version:

Publisher's PDF, also known as Version of record

\section{Please check the document version of this publication:}

- A submitted manuscript is the version of the article upon submission and before peer-review. There can be important differences between the submitted version and the official published version of record.

People interested in the research are advised to contact the author for the final version of the publication, or visit the DOI to the publisher's website.

- The final author version and the galley proof are versions of the publication after peer review.

- The final published version features the final layout of the paper including the volume, issue and page numbers.

Link to publication

\footnotetext{
General rights rights.

- You may freely distribute the URL identifying the publication in the public portal. please follow below link for the End User Agreement:

www.umlib.nl/taverne-license

Take down policy

If you believe that this document breaches copyright please contact us at:

repository@maastrichtuniversity.nl

providing details and we will investigate your claim.
}

Copyright and moral rights for the publications made accessible in the public portal are retained by the authors and/or other copyright owners and it is a condition of accessing publications that users recognise and abide by the legal requirements associated with these

- Users may download and print one copy of any publication from the public portal for the purpose of private study or research.

- You may not further distribute the material or use it for any profit-making activity or commercial gain

If the publication is distributed under the terms of Article $25 \mathrm{fa}$ of the Dutch Copyright Act, indicated by the "Taverne" license above, 


\section{RETT SYNDROME}

$1954-2004$ 
To watch, to measure and to compare. 


\title{
RETT SYNDROME
}

\author{
$1954-2004$
}

\author{
Proefschrift
}

ter verkrijging van de graad van doctor aan de Universiteit Maastricht, op gezag van de Rector Magnificus, Prof. mr. G.P.M.F. Mols,

volgens het besluit van het College van Decanen, in het openbaar te verdedigen, op woensdag 1 juni 2005 om 16.00 uur door

Eric E.J. Smeets

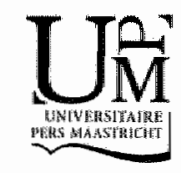




\section{PROMOTORES}

Prof. dr. C.T.R.M. Schrander-Stumpel

Prof dr. J.P. Frijns

\section{BEOORDELINGSCOMMISSIE}

Prof. dr. M. Daemen (voorzitter)

Prof. dr. P. Casaer, Universiteit Leuven

Prof. em. dr. B. Hagberg, Universiteit Goteborg

Prof. dr. H. Vles

Prof. dr. E. Zimmerman

ISBN $905278 \quad 4639$

(c) 2005 E.J Smeets, Maastricht 
PART I GENERAL INTRODUCTION 7

A. About mental retardation and developmental delay 9

Definition and classification

Prevalence

Why investigate the causes of mental retardation/developmental delay?

How to evaluate mental retardation/developental delay?

How to investigate the etiology of mental retardation?

Causes of mental retardation

B. Aims of the study

17

PART II RETT SYNDROME (1954-2004) 17

A. Rett syndrome, a developmental disorder of the brain 19

History

Prevalence

Clinical features and diagnostic criteria

Etiology, pathogenesis and genetics

B. The Leuven - Maastricht experience

Materials and methods

Results

Discussion

General remarks

Grouping by MECP2 mutation types

Grouping by long-term disorder profile

Conclusion

C. Management of Rett syndrome

69

Growth and feeding

Development and behavior

Epillepsy

Deformation

Orodental

Gastro-intestinal

Cardiovascular

Ophtalmologic

Abnormal breathing

D. General conclusions and future perspectives 
1. Rett Syndrome in Adolescent and Adult Females: Clinical and Molecular Genetic Findings.

2. Rett syndrome in females with CTS hot spot deletions: A disorder profile.

3. Apprcach and Management of Severe Abnormal Breathing in Rett Syndrome: a Case Report.

4. The development of visual- and auditory processing in Rett syndrome: An ERP study.

5. Gross rearrangements in the MECP2 gene in three patients with Rett syndrome: implications for routine diagnosis of Rett syndrome.

6. Neurodevelopmental disorders in males related to the gene causing Rett syndrome in females (MECP2).

\section{Summary 153}

Samenvatting 154

Curriculum Vitae 155

List of publications $\quad 156$

Dankwoord 159 
A. About mental retardation and developmental delay

B. Aims of the study 



\section{A. About developmental delay and mental retardation}

\section{DEFINITION AND CLASSIFICATION}

Mental retardation (MR) can be defined as a lifelong human disability characterized by a significant impairment of cognitive and adaptive skills, with onset before 18 years. Although dissociation of mental and motor developmental capacities is often difficult in the absence of true motor dysfunction the condition is called mental retardation. Developmental delay (DD) is used to describe the retardation in postural, motor and social adaptive behavior, including delay in speech development, in infants and children.

According to the definition of the American Psychiatric Association (1994) "Mental retardation refers to substantial limitations in present functioning. It is characterized by significantly sub-average intellectual functioning, existing concurrently with related limitations in two or more of the following adaptive skill areas: communication, self-care, home living. saciall skills, community use, self-direction, health and safety, functional academics, leisure and work."

Adaptive behavior refers to how effectively individuals learn to cope with everyday life demands, and how well they meet the standards of personal independence expected of someone of that particular age and socio-economic background.

Adaptive skills may be influenced by various factors such as personality, motivation, educational, social and vocational opportunities and the general medical conditions and mental disorders that may coexist with mental retardation.

When mental retardation is consistently associated with somatic, neurological or behavioral manifestations, it is termed as 'syndromal' mental retardation. Such cases generally have a single, specific, and inheritable or environmental cause. In the absence of somatic, neurological, or behavioral manifestations, the mental retardation is called non-syndromic or non «pecific.

Intelligence is measured in standardized tests as the ratio between mental age and chronological age multiplied by a 100 (Eysenck and Evans, 1996) resulting in the intelligence quotient (IQ). According to the IQ level MR is subdivided as follows (WHO, 1980):

Terminology

IQ level

- Borderline $\quad 70-85$

- Mild $\quad 50-70$

- Moderate $\quad 35-50$

- Severe $\quad 20-35$

- Profound $<20$

In the general population $95 \%$ has a full-scale intelligence quotients of $25 \mathrm{D}$ above or below the mean of 100 following approximately the Gaussian distribution (Dingman and Tarjan, 1960; Moser and Wolf, 1971). In about 2,5 -3\% of the population intelligence is $>2$ SD below the mean of 100 and consist mostly of individuals with full-scale intelligence quotients scores between 50 and 70 . Psychosocial and familial components are usually present in this group. In individuals with moderate to severe long-term impairment of biological or environmental nature, the major contribution to the intellectual disability is determined by multiple biological and genetic factors (Moser and Wolf, 1971). 


\section{PREVALENCE}

The prevalence of mental retardation is estimated to occur in $2-3 \%$ of the general population in Western countries (Schaefer and Bodensteiner, 1992; Curry et all. 1997). About $85 \%$ are mildly, $10 \%$ moderately, 3 to $4 \%$ severely and 1 to $2 \%$ profoundly mentally retarded (DSM-IV, American Psychiatric Association, 1994). However, a lower general prevalence of $1-1.5 \%$ has been reported with a prevalence of $0.5 \%$ in persons with an $\mathbb{R}$ below or at 50 (Matilainen et al., 1995; Roeleveld et al., 1997; Chelly and Mandel, 2001). In a population of school-aged children the prevalence of mental retardation is $3 \%$. Severe mental retardation with an $1 \mathrm{Q}<50$ is present in $0.4 \%$ (ranges $0.26-0.73 \%$ ) (Roeleveld et al. 1997), while the prevalence of mild mental retardation varies between and $0.4-8 \%$ depending on the cohort that is studied (Roeleveld et al., 1997).

The fact that mental retardation is more prevalent in males (sex ratio of around 1.5:1) is explained by the biological difference of males and females in the number of $X$ chromosomes and by now well established $X$-linked single-gene mutations. The overall prevalence of $X$-linked mental retardation (with or without syndromic forms) has been estimated at 1.66/1000 males (Turner et al., 1996a; Turner, 1996b; Crawford et al., 1999; Mandel and Chelly, 2004).

\section{WHY INVESTIGATE THE CAUSES OF MENTAL RETARDATION?}

The reasons why mental retardation/developmental delay is investigated are obvious (Bataglia and Carey, 2003). The presence of mental retardation restricts the affected individual and his family in all activities of daily living. The impact on public health and society is easily recognized in the lifelong costs and the loss in productivity associated with these different degrees of limitations in self-care and self-direction with subsequent needs for supervision, support and protection. Parents and families need to know the answers to important questions: what is going on? How did it happen? Were will it go to? is there anything worse we can expect? What can we do to make it better? is there a possible treatment? Do we have a recurrence risk? If so, what are our reproductive options? What are the potential recurrence risks for the sibs and/or do we need to inform the rest of the family? Are there similar families to meet? For the affected individual early diagnosis avoids costly and needless investigations and options for treatment and (preventive) management can be explored. Diagnostic information and guidance can be offered to the primary care physician, to other medical specialists, to schools, to therapists and to other non-medical care providers.

Finally, research based on clinical grounds is only possible with well defined groups of people with a same diagnosis. The benefits for the individual patient as well as for the parents and family are listed in table 1. 
For the individual

Prescription of appropriate therapies and referrals and avoidance of unnecessary examinations, medical and non medical.

Planning of preventive management of associated complications or functional disabilities that may co-exist.

Early (educational) intervention and educational planning.

For the parents/relatives

Referral to appropriate medical and social services.

Genetic counselling.

Carrier testing, prenatal and pre-implantation diagnosis.

Educational guidance and emotional support.

Referral to support groups and family networking.

\section{HOW TO EVALUATE MENTAL RETARDATION/DEVELOPMENTAL DELAY?}

Developmental delay can be evaluated through the different developmental scales that estimate the infant's or preschool child's motor and social adaptive behavior and speech development. Such evaluations made at intervals of several months result in a developmental quotient (DQ) that is diverging from the norm with advancing age. In case of a milder delay in psychomotor development (e.g. transient hypotonia, mild speech delay) the infant or child is given the benefit of the doubt that he or she might return to normal. An insidious or obvious stagnation and eventual regression in development are objectively documented in this way. Mental retardation will subsequently be diagnosed in terms of an intelligence quotient during school years through assessment with one or more of the standardized, individually administered tests.

\section{HOW TO INVESTIGATE THE ETIOLOGY OF MENTAL RETARDATION?}

A carefull medical and paramedical evaluation of the person is required, if possible in a multidisciplinary setting. Psychological testing and data on motor adaptive behavior and language development belong to the overall assessment.

Based on a full clinical history, the family history and the physical examination, a differential diagnosis is made. Specific attention is given to minor malformations and dysmorphic features, which may point to a specific clinically recognizable syndrome. In general, (genetic) laboratory testing or additional medical examinations are needed to make or to confirm a diagnosis or to exclude other more common causes. Several guidelines or protocols for the investigation of mental retardation exist (e.g. Curry et al., 1997; Shevell et al., 2003).

\section{ETIOLOGY OF MENTAL RETARDATION}

Being a disorder of central mervous system development, maturation and function, MR may result from genetic influences, environmental influences, or a combination of both (Bataglia et al., 1999). Investigating its cause has always been a great challenge for the medical profession (Hamel, 1999; van Karnebeek et al., 2005). The last decade's science has witnessed important advances in diagnostic evaluation and management of people with mental retardation. Dysmorphology, developmental neurology and psychology have largely enhanced the knowledge about clinical and behavioral developmental patterns in different conditions and recognizable syndromes with mental retardation. New and finer techniques in 
cytogenetic and molecular genetic analysis (e.g. fuorescence in situ hybridization, subtelomeric screening, chromosome-micro-dissection, comparative genomic hybridization/micro-arrays, and the expanding possibilities of DNA analysis) link more and more clinically recognizable syndromes to chromosomal microdeletions, rearrangements and single-gene mutations in autosomes as well as on the X-chromosome (Shoichet et al., 2003; Stromme et al., 2002). Many disorder-related genes have been identified in recent years. This is reflected by the finding in Online Mendelian Inheritance in Man (OMIM) of over 1.000 entries upon a search for "mental retardation".

Mutations in X-linked genes are likely to account for the observation that more males than females are affected by mental retardation. Fragile $X$ syndrome (Martin \& Bell, 1943; Lubs, 1969 ) is the most common genetic cause in this group, with an estimated prevalence of $1 / 4000$ to $1 / 6000$ males (Turner et al. 1996a; de Vries, 1997). Collaborative work on syndromic and non-specific $X$-linked mental retardation (XLMR) identified more and more causative $X$-linked genes (Claes et al., 1997; Frints et al., 2002; Stromme et al., 2002; Shoichet et al., 2003). Some of these genes are involved in chromatin remodeling, e.g. the ATRX syndrome (Stayton et al., 1994; Gibson et al., 2000), the Coffin-Lowry syndrome (Coffin et al., 1966; Trivier et al., 1996), and Rett syndrome (Amir et al., 1999; Martinowich et al., 2003). Others act as signal transduction pathways in neuronal cells in individuals with non-specific XLMR (Chelly and Mandel, 2001). Technical advances in biochemistry have lead to a better understanding and design of metabolic pathways. New techniques of neuroimaging (e.g. in vivo proton magnetic resonance spectroscopy) have opened a whole new window upon brain development and functioning. Clinical neurophysiology and neonatal intensive care has produced exciting advances in understanding the vascular origin of brain damage in prematurelly born infants (Hunt et al., 2002) contributing to a preventive treatment and a better outcome in these neonates at risk for vascular accidents.

In large etiological surveys the percentage of both genetic and environmental causes of mental retardation varies according to the population studied (Curry et al.. "1997; van Buggenhout et al., 2001). An example of these data is given in table 2.

Excluding Down syndrome, and working according to a protocol as suggested by Curry et al. (1997) a causal diagnosis could be made in $42 \%$ of cases and a pathogenic cause in another $39 \%$ (Battaglia et al., 1999). The recognition of several syndromes and chromosome abnormalities that present with a specific physical and/or behavioral phenotype evolving over time has further enhanced the diagnostic yield. Single gene mutations or microdeletions may well be responsible for a growing number of syndromic and metabolic conditions. However, in spite of all efforts made, absence of an actual cause is still the case in at least half of the patients putting forward a big challenge for (future) research.

Table 2. Causes of Mental retardation in Literature Survey*

\begin{tabular}{ll}
\hline Chromosome abnormalities & $(\%)$ \\
Recognizable syndromes & $4-28$ \\
Monogenetic conditions & $3-7$ \\
Structural central nervous system abnormalities & $5-19$ \\
Complications of prematurity & $7-17$ \\
Environmental/teratogenic causes & $2-10$ \\
"Cultural-familial" mental retardation & $5-13$ \\
Unknown & $3-12$ \\
\hline *According to Curry et al. (1997). & $30-50$ \\
\hline
\end{tabular}

Through the follow up of children and adults with an established diagnosis, valuable data on changes in time can be collected. These changes include not only facial features, but also 
specific age related medical manifestations and eventual changes in cognitive profle and/or in behavioral characteristics.

Behaviors unique to a single syndrome, eg. distinctive behaviors occurring almost without exception in individuals with a given syndrome are rare. Flint and Yule (1994) referred to the Prader-Will syndrome (PWS), where severe and persistent overeating is associated with an abnormality of expression of maternally imprinted genes located on the proximal long arm of chromosome 15 (15q11-13). Other examples are the Lesch-Nyhan syndrome, where severe self-injurious behavior is associated with a mutation in a single gene on the $X$ chromosome (Xq26-27) and Rett syndrome (Hagberg et al., 1983), where progressive dementia, apraxia with handstereotypies and extrapyramidal features are associated with a dominant mutation in the MECP2 gene on the $X$ chromosome.

The clinical follow-up of undiagnosed children and adults with MR in serial intervals over time is very important in keeping alert on grouping similar cases together in an attemptt to discover the etiology.

In this study we focus on the Rett syndrome (Rett syndrome), a unique neurodevelopmental disorder almost exclusively affecting girls. They develop a very specific physical and behavioral phenotype. This consists mainly of early infantile stagnation and regression of development, a characteristic loss of intentional grasping into meaningless and stereotypic movement of the hands, and a severe mental impairment. All in contrast with a preserved ability to communicate through the eyes in spite of the progressing motor disability and orthopedic deformation. Rett syndrome is caused by mutations in the $X$-linked gene encoding the methyl-CpG-binding protein 2 (MeCP2).

\section{REFERENCES}

American Psychiatric Assaciation (APA), Diagnostic and Statisticall Manual of Mental Dostrordiers, $4^{\text {th }}$ Edition. Washington, DC: APA, 1994, pp39-46.

Amir R., Van den Veyver I. Wan M., Tran C., Francke U., Zoghbi H. (1999). Rett syndrame is caused by muttations in $x$-linked MECP2, encoding methyl-CpG-binding protein 2 . Nat Genet, 23:185- 188 .

Battaglia A., Bianchimi $E_{2,}$ Carey J. (1999), Diagnostic yield of the comprehensive assessment of developmental delay/mental retardation in an institute of child neuropsychiatry. A.m J Med Genet, 82,60-66.

Batteglia A., Carey JC. (2003). Diagnostic evaluation of developmental delay/mental retardation: An oveniew. Am $d$ Med Genet, 117:3-14

Chelly J., Mandel J. (2004). Monogenic causes of X-Jiked mental retardation. Nat Rew Genet, 9: 6090.80.

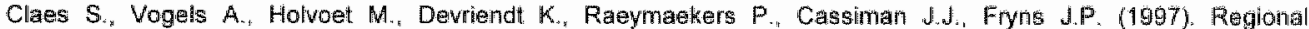
localization of two genes for nonspecific X-linked mental retardation to Xp22.3-p22.2 (MRX49) and Xp11.3-p 1.21 (MRX50). Airm J Med Genet, 73:474-479.

Coffin G. Siris E., Wegienka L. (1966). Mental retardation with osteocartilaginous anomallies. Am J Dis Ghilc, I12:205. 213.

Crawaford D., Meadows K., Newman J., Tafi L., Pettay D., Gold L., Hersey S. Hink le E., Stanfield M., Holmgrean P. Yeargin-Alsiopp M. Boyle C., Sherman S.L. (1999). Prevalence and phenotype consecuence of FRAXA and FRAXE alleles in a large, ethnically diverse, special education-needs population. Aum J Hum Genet, $64: 495-507$.

Curry C., Stevenson R., Aughton D. Byme d, Carey J. Cassidy S., Cunniff C., Graham \., Jones M., Kaback M. Moeschler J. Schaefer G., Schwartz S., Tanleton J., Opitz J. (1997). Evaluation of mental retardation. recommendations of a Consensus Conference: American College of Medical Genetics. An J Med Genet. $72(4): 468-477$

de Vries L. (1997). The fragile X-syndrome. Clinical genetic and large scale diagnostic studies among montally retarded individuals. Thesis, Rotterdam, 1997.

Dingman H. Tarjan 6. (1950). Mentall retardation and the normal distribution curve. Am J Merit Defic, 64: 991 
Eysenck H. Evans D. (1966). De Eysenck 1Q-test voor kinderen. Het Spectrum. Utrecht.

Flint 4 , Yule W. (1904) Behavioral phenotypes, In: Rutter M. Taylor $E$. Hersov LA, eds. Child and adolescent psychiatry modern approaches. Oxford: Blackwell scientific Press.

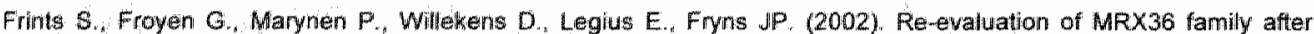
discovery of an ARX gene mutation reweals mild neurological features of Partington syndrome. Am $J$ Med Genet $112: 427-428$.

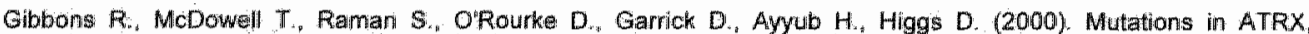
encoding a SWI/SWF-like protein, cause diverse changes in the pattern of DNA methylation. Nat Genet, 24:361371 .

Hagberg B. Alcardi ل. Das K. Ramos O. (1983): A progressive syndrome of autism, dementia, alaxia and loss of purpusstul handuse in girls: Ret's syridrome: report of 35 cases. Ann Neurol, 14:471-479.

Hamel B.(1999) X-linked mental retardation. A clinical and molecular study. (AlkmaarDekave), pp. 1-202.

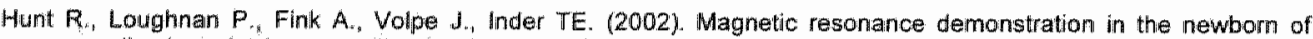
generalized cerebral wenous dilation with spontaneous resolution. Eur J Paediati Meurol, 5:289-92.

Lubs. H. (1969). A marker X chromasome. Arm J Hum Genet, 31:231-244.

Mandel J., Chelly $\mathrm{J}$. (2004). Monogenic X-linked mental retardation: is it as frequent as currently estimated? The paradox of the ARX (Aristaless X) mutations. Eur J Hum Genet, $12: 689-693$.

Martin J. Beil J. (1943). A pedigree of mental defect showing sexalinkage. J Neurol Psychialtr, 6:154-157.

Hartinowich K. Hattori D. Wu H., Fouse S. He F., Hu Y. Fan G., Sun Y. (2003): DNA Methylation-Related Chromatin Rernadeling in Activity-Dependent Bdnf Gene Regulation. Science, 302:890.

Matilainen R:. Airaksinen E. Mononen T., Launialia K, Kaariainen R. (1995). A population-based study on the causes of mild and severe mental retardation. Acta Paediatr, 84:261-266

Moser H. Wolf P. (1971). The nosology of mental retardation: including the report of a survey of 1378 mentally retarded indiwiduals at the Walter E. Fermald School. Birth Defects Orig Artic Ser, 7:1177-137.

OMIM, www ncbi.nim.nih. gov/.

Roeleveld N., Zielhuis G. Gabreels F. (1997). The prevalence of mental retardation: a critical review of literature. Dev Med Child Neurol, 39:125-132.

Schaefer G., Bodensteiner J. (1992). Ewaluation of the child with idiopathic mental retardation. Pediatr Chin North Am $39: 29-43$

Shevell M., Asthwal S., Dontey D., Flini J., Gingold M. Hirz Mainemer A., Noetzel M. Sheth R.; Quality Standards Subcommittee of the American Academy of Neurology; Practice Committee of the Child Neurology Saciety. (2003). Practice parameter; evaluation of the child with glabal developmental delay: report of the Qually Standards Subcominitted of the Child Neurology Saciety. Neurology, 60:367-380

Shoichet S. Hoffmann K. Menzell $C_{\text {. }}$ Trautmann U., Moser B., Hoeltzenbein M., Echenne B., Partington M., Van Bolkhowen H., Moraine C., Fryms JP., Chelly J., Rott H., Ropers H., Kalscheuer V. (2003). Muttations in the ZNF4" gen are associated with cognitiwe deficits: identification of a new cantidate for X-linked mental retardation. Am Hurn Genet. $73: 1341-1354$.

Stayton C. Dabovic B., Gulisano M., Gecz J."Broccoli W. Giovanazzi S., Bossolasco, M., Monaco L., Rastan S Eoncinelli $E$. Bianchi $M$. Consalaz $G$. (1994) Cloning and characterization of a new human $X q 13$ gene, encoding
a putative helicase. Hum Molec Genet, $3: 1957.1964$.

Stromme P., Mangelsdorf M., Scheffer 1., Gecz $\Downarrow$. (2002). Infantile spasms, dystonia, and other X-inked phenotypes caused by mutations in Aristaless related homeobox gene. ARX. Brain Dev, 24:266-268.

Trivier E., De Cesare D., Jacruot S., Pannetier S., Zackai E., Young 1., Mandel J., Sassone-Corsi P., Hanauer A (1996). Mutations in the kinase Rsk-2 associated with Coffir-Lowry syndrome. Nature, 384.567 .570 .

Turmer G. Web T., Wake S. Robinson H. (1996a). Prevalence of fragile X syndrome. Am d Med Genet, 64: 196-197

Turner $G$. (1996b). Intelligence and the X-chromosome. Lancet, 347:1814-1815. 
Van Buggenhout G., van Ravenswaaij-Arts $C_{\text {. }}$, Mietoo H. Syrrotj M. Hamel B., Brumner H. Firno JP. (2001), Dysmorphology and mental retardation: molecular cytogenetic studies in dysmorphis mentally ratarded patients. Ann Genet, 44:89-92.

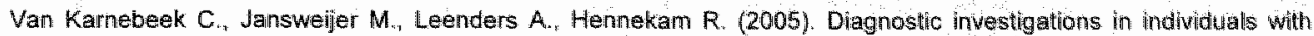
mental retardation: systematic literature review of the usefuness: Eur J Hum Genet 13:6-25.

WHO. Anternational classification of impairments, disabilities and handicaps. Geneve: World Healith Organisation, 1980. 



\section{B. Aims of the study}

From the beginning of my training in pediatrics I was challenged by the developmental disorders in infants and toddlers. Congenital anomalies, neurological impaiments and developmental delay became main points of interest. I had the opportunity to be trained in pediatric neurology and to gather experience as a neuropediatrician working in an institution for severely mentally retarded. Early intervention teams for the infants and children with developmental delay, observation teams for severely retarded persons with behavioral problems were among the new developments of that time. I had the opportunity to learn about the genetics of mental retardation, genetic syndromes and behavioral phenotypes.

The field of clinical genetics expanded rapidly and the combination pediatrics: neuropediatrics with clinical genetics worked well. A lot of the experience was developed in the multidisciplinary approach, the medical, paramedical, psycological and social diagnostic evaluation, of complex multi-impairment and of mental retardation of different etiologies.

My first confrontation with the Rett syndrome happened in 1983 in a 20 months old toddler girl. Since that time, by now over more than twenty years, we have met more then 130 girls and women with Rett syndrome with various histories. However, they all present a specific physical and behavioral phenotype over time with a large clinical variability. This variability is surprising and constitutes a challenge for diagnosis and management of this unique disorder. When the causal mutations in the $X$-linked gene encoding the methyl-Cpg-binding pratein 2 were discovered the study of this clinical variability in relation to the genotype was a clear option.

\section{AIMS OF THE STUDY}

- A detailed clinical and molecular evaluation of a large series of Rett syndrome girls and women known to us from clinical practice over the time period 1983-2003.

- The evaluation of the relationship between clinical severity at the time of examination and the molecular characteristics of the MECP2 mutation.

- Defining subgroups based on the type and localization of the MECP2 mutation in relation to the long-term clinical follow-up. 

A. Rett syndrome a developmental disorder of the brain
B. The Leuven - Maastricht experience
C. Management of Rett syndrome
D. Generall conclusions and future perspectives 



\section{A. Rett syndrome, a developmental disorder of the brain}

\section{HISTORY}

Andreas Rett, a neurologist from Vienna, first recognized the Rett syndrome in 1954. He discovered similarities between several girls with developmental mental regression in early life. They developed typical repetitive hand wringing movements, curious behavioral characteristics, and showed ataxia and apraxia. Through his observations and in comparison with other developmental disorders in children he identified these girls as a distinct syndrame. His publication in the German medical literature in 1966 however remained globally undiscovered (Rett, 1966). In the large textbook series on Neurology by Vincken and Bruyn Rett had written a chapter under the misleading heading of "Cerebral Atrophy and Hyperammonaemia" in a series of 21 girls and women (Rett, 1977). The metabolic finding however could never be confirmed later on. In 1978 Ishikawa et al. described in a short report three Japanese girls with identical symptoms and signs to those reported by Rett (Ishikawa et al., 1978). Also this communication passed mainly unnoticed. Bengt Hagberg, a neuropediatrician from Gothenburg, who had seen these girls in Sweden since the early 60ties recorded 16 girls under the eponym of "Morbus Veslan" and presented them in a survey to the members of the European Federation of the Child Neurology Societies in Manchester in June 1980 (Witt-Engerström, 1990). This finally led to the publication in November 1983 of a collaborative clinical study on 35 girls from Sweden, France and Portugal (Hagberg et al., 1983). The syndrome was thus finally revealled and a rapid recognition occurred by clinicians as well as by parents in children all over the world. Very soon a well organized parental support group started and the International Rett Syndrome Association (IRSA) has now become one of the largest research and parent support foundations in the world, continuously encouraging the medical researchers and clinicians to seek for keys to unlock the biological riddle of the disorder. The diagnosis of Rett syndrome is based on internationally accepted clinical criteria that were developed and adapted over the years as a useful tool for the clinicians that are involved in the diagnostic work-up (Hagberg et al., 1985; Hagberg and Gillberg, 1993" Hagberg and Skjeldal, 1994; Hagberg et al., 2002). The discovery in 1999 (Amir et al., 1999) of the causal relation between the syndrome and a mutation in the X-linked gene encoding the methyl-CpGbinding protein 2 made confirmation of clinical suspicion possible. Rett syndrome is now recognized in all ethnic groups all over the world and in a widening pattern of clinical variability. The study of this surprising variability lead in the meanwhile to the discovery of phenotypes that are perhaps very adjacent to Rett syndrome but of a different genetic origin (Weaving et al., 2004; Tao et all., 2004).

\section{PREVALENCE}

In a large British survey and based on the readily recognizable classic syndrome, the prevalence of Rett syndrome was estimated at 1/10.000 giris at 14 years of age (Kerr. 1992). Other estimates have ranged above and below this figure (Asthana et al., 1990; Kulz et al., 1990; Hagberg and Hagberg, 1997). With the present understanding of classic and variable forms and the sometimes very mild expression of the disorder the overall prevalence is probably higher than the presently accepted minimum. Rett syndrome, next to Down syndrome and Fragile- $X$ - syndrome, might thus well be one of the most important causes of severe mental retardation in females. Most cases of Rett syndrome occur 
sporadic. About $4 \%$ of the British cases had a relative with Rett syndrome. Classic and variant Rett syndrome in severely neurological abnormal boys have been reported in the same kindred (addendum 6).

\section{CLINIICAL FEATURES AND DIAGNOSTIC CRITERIA}

\section{The cascades of symptoms in a staging system}

The early infantile history of a Rett syndrome child is strange and puzzling and clinical recognition of the syndrome under the age of 10 months is very difficult if not impossible. Hypotonia and low intensity in the development of contact are usually present before 6 months of age (Heilstedt et al., 2002). In general the gross and fine motor developmental progress is mostly suboptimal during the first year, but the overall developmental pattern is not obviously disturbed in the beginning. Then the clinical developmental profile becomes more specific for the disorder later on in life. The Rett syndrome staging system delineates the evolving cascades of symptoms of communicative dysfunction, loss of acquired skills and motor performance in the syndrome to a certain pattern at a certain age (Hagberg and Gillberg. 1993, Witt-Engerström, 1990). The four clinical stages are summarized in table 1. and described below.

The early onset stagnation period occurs between 6 months and $11 / 2$ years of age. The main feature at the clinical onset of the disorder is a more ore less sudden change in contact behavior of the infant noticed especially by the mother. Additional abilities are still acquired but somewhat delayed in this period. Up to 10 months of age the infants learn to sit unsupported, but learning to stand upright is delayed or even absent. Instead they choose deviant movement patterns like deviant crawling, shuffling, rolling, or stay immobile. A typical "bottom-shuffling" is very common (fig. 1). Peak optimal development is reached at 11-12 months of age in the majority with pincer grasp or opposed thumbgrasp and new babble or single words may still be learned. The formerly quiet infant may become irritable and parents relate frequent crying to dentition. Diagnostic evaluation is very troublesome to the consulted physician at that time and since the overall developmental pattern of their child is still not apparently abnormal the parents are reassured.

The rapid developmental regression period occurs between 1 and 4 years of age and is characterized by rapid and specific regression of acquired abilities. The lack of speech development in the second year of life, together with the loss of already acquired speech (or babble) and skills, often with the appearance of circulating hand movements and mouthing are the most informative early warning signs for the syndrome. This regression may happen very suddenly and sometimes even with pseudo-toxic symptoms (high-pitched crying, fever and apathy suggesting meningo-encephalitis) often leading to emergency hospitalization. The pediatrician is then left with no clinical explanation because there are no biochemical or microbiological findings. Such an acute onset period can last for days or weeks and after recovery the child's personality has changed completely.

Others present a more gradual decline in their communicative ability and motor performance. Although the eye contact is preserved they show diminished interest in diminishes and in some The facial expression and mimicry in response to affective stimuli the corners of the mouth a mask-like face is present (fig.2). A puzzling muscle twitching at seen, and a convergent or divergen. Often a nystagmus on lateral deviation of the eyes is tired. As acquired babble or deficiency now becomes obvious. Active playing becomes lost in this period mental character. The intentional movement of reaching becomes rare or looses its exploring senseless hair-pulling, head-tapping or hand out for objects and toys ends abruptly in a wrists and fingers apart from the body or together. contact with their daughter as her visual response in this period both parents feel they loose the world". Many girls suffer from recurrent infections changing and she appears to be "off 
at night becomes very common. Febrile convulsions may be present and doubt about epileptic paroxysms may arise. Some of them will start insidiously with panting and hyperventilation. Decline in head circumference in some children becomes a point of concern.

Table 1. The four clinical stages of classic Rett syndrome.

\section{Stage I. Early onset stagnation}

- Duration: weeks to months

- Onset age: $1 / 2-1 / 2$ year

- Developmental progress delayed, with early postural delay

- Developmental pattern still not significantly abnormal but dissociated

- "Bottom- shufflers"

\section{Stage II Rapid developmental regression}

- Duration: weeks-months

- Onset age 1 - 4 years sometimes acute "pseudotoxic"

- Loss of acquired skills: fine finger, babble/words, active playing

- Mental deficiency, eye contact preserved, occasionally "in another world"

- Breathing problems yet modest

- Selzures only in $15 \%$

\section{Stage III Pseudo-stationary period}

- Duration: years to decades

- Onset: after passing stage II

- Apparently preserved walking ability with prominent hand apraxia/dyspraxia

- Inapparent slow neuromotor regression

- "Wake up" period

- Stage III/IV Non ambulant patients

\section{Stage IV Late motor deterioration}

- Duration: decades

- Onset: when stage III ambulation ceases

- Stage IVA: previous walkers, now non-ambulant

- Stage IVB: never ambulant

- Complete wheelchair dependency

- Severe disability: muscle wasting and distal distortions

According to Witt-Engerström (1990) and Hagberg (1993) 

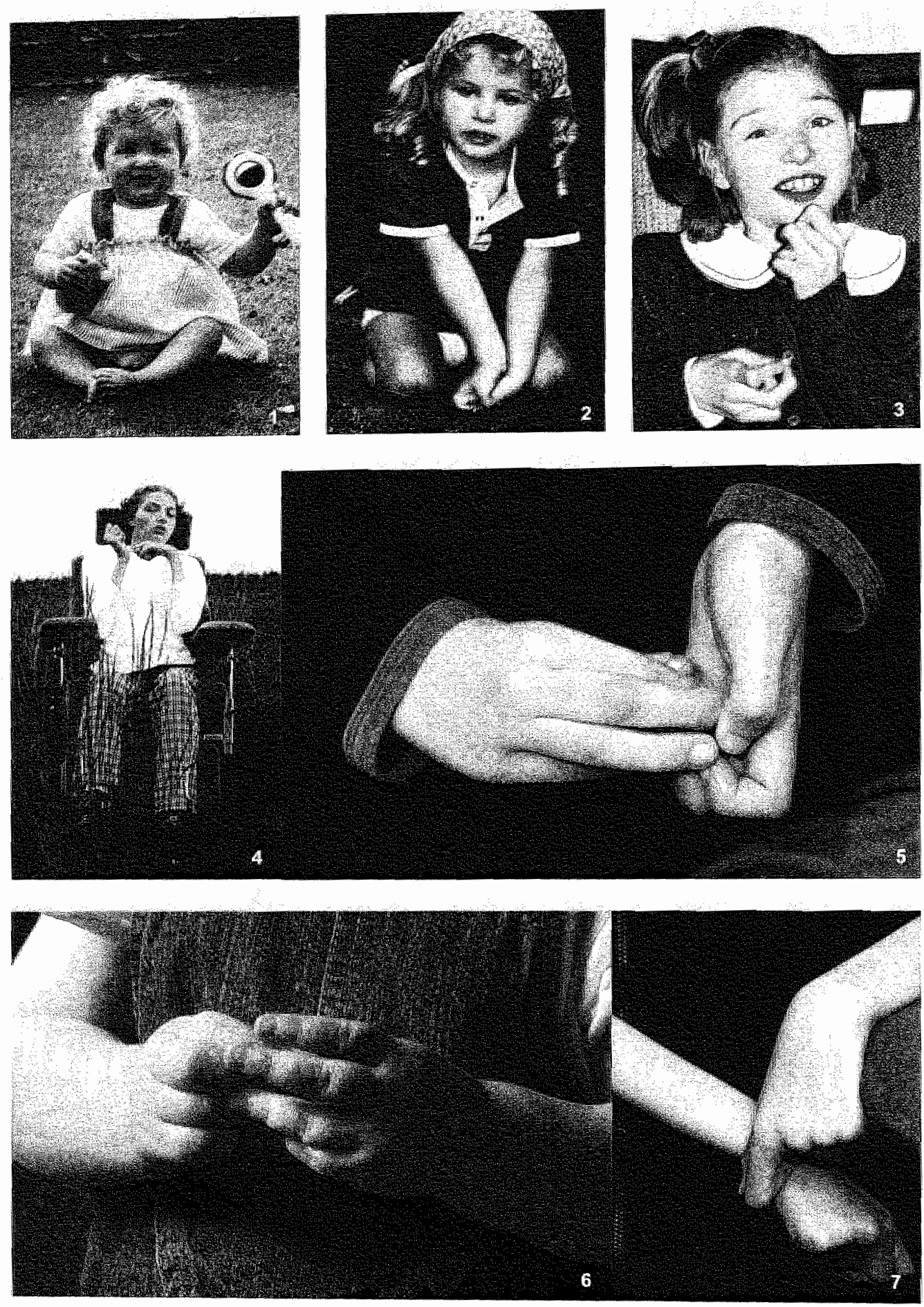

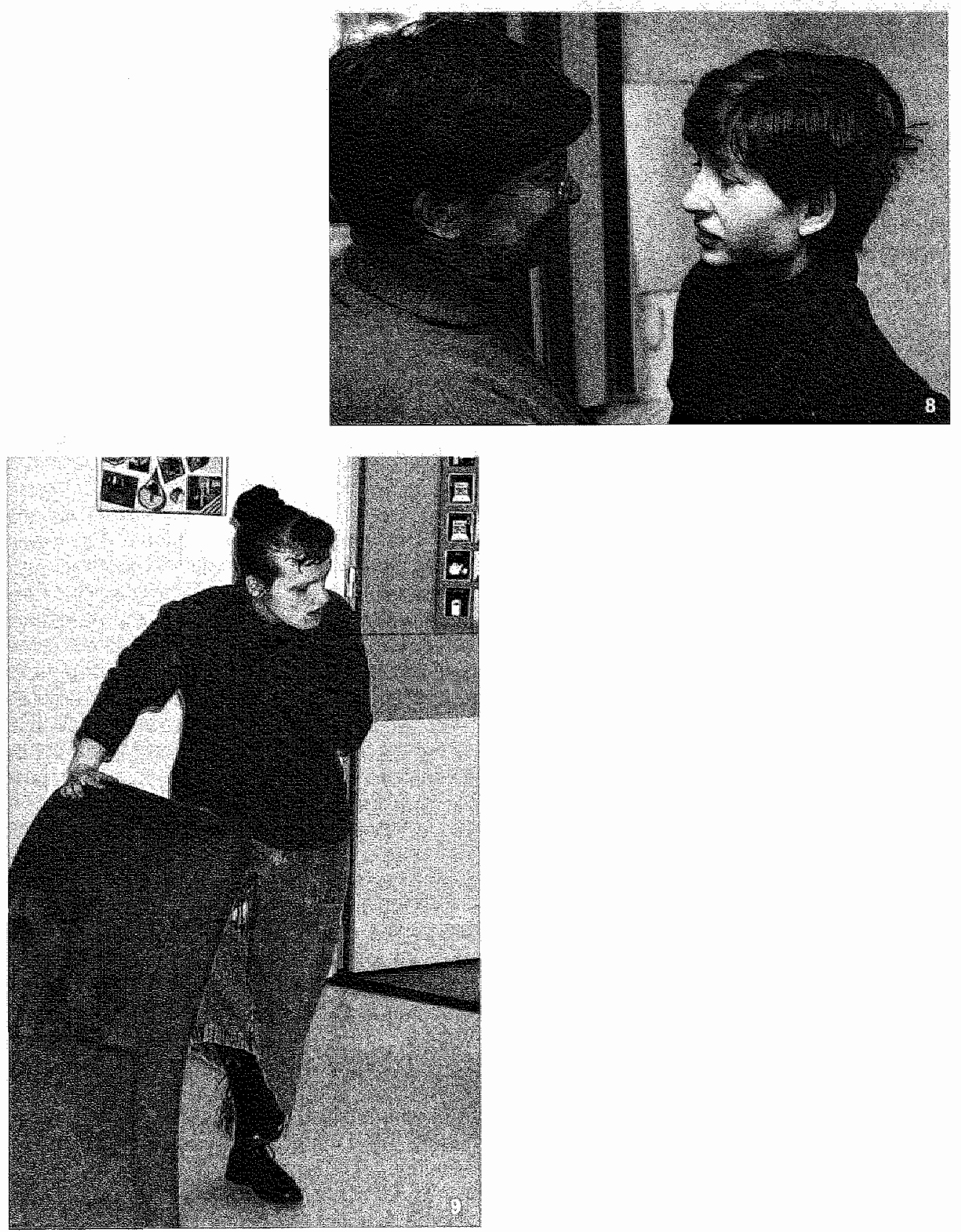
The pseudo-stationary period starts when the regression stage has past. The girl is still able to walk or may even learn this ability in this stage. When they do walk many do so slowly on broad base sometimes swaying the trunk towards the side of the foremost leg. Gait patterns may differ and are defined as gait apraxia. Hand dyspraxia or apraxia now becomes obvious. When they still grasp it is temporarily and with little force. In this stage typical and bizarre handstereotypies appear. They represent a continuous monotonous pattern of repetitive midline movements with hand wringing, -washing, and sometimes gentle hand clapping, and start as soon as the child is awake Others display patting or rolling stereotypies alongside of their bodies with the hands apart, twisting the fingers in the most curious ways (fig 3). A typical visual contact behavior becomes more and more prominent suggesting an "awakening" when some of the personality is manifesting itself again. Their daughter is now more alert and joyful and parents recognize her eye-pointing behavior to express wishes and needs. Breathing irregularities when modestly present in stage II become more prominent in this stage, with or without non-epileptic vacant spells, apneustic breathing, hyperventilation and Valsalva breathing. Unexplained night laughing, frequent daytime sleeping and night-time awakening, crying spells and sudden agitation are other features very demanding for the parents. Many have obvious clinical epilepsy requiring treatment, but many also become seizure free after some time. Dystonic asymmetrical posturing leads to neurogenic scoliosis often rapidly progressive, requiring surgical treatment. Others develop a high kyphosis. The feet and lower limbs are cold with or without color change, with and without atrophic changes. The temperature and color of the lower extremities can change from bluish and cold into red and warm sometimes in relation with the mood they are in. The feet are small and sometimes a shorter fourth toe is seen. Progressive shortening of Achilles tendons in equinus position causes the ankles to deviate in the varus or valgus position. The toes are held more and more in a clenched position. Some of the milder cases have preserved speech and/or hand use. Other girls may say single words or a word sentence many years after the onset of their disorder. Neuromotor regression slowly progresses in this stage that can last for decades. The growth deficit, the gait dyspraxia, the overall rigidity and spine deformation, the muscle wasting and abiotrophic changes in distal limbs and skin make them look like "pre-aging" older women, older than they really are.

The late motor deterioration period starts when walking ceases and the child or adult becomes wheelchair dependent (fig. 4). Severe cases never learn to walk and pass immediately from stage II into stage IVB. This stage is characterized by a severe neurological condition with pronounced muscle wasting and distortion of distal limbs. The feet are cold and discolored with abiotrophic changes, the toes now constantly in the clenched position. The handstereotypies become less intense and simpler with advancing age, and the lack of motor activity in these quadriplegic females leads finally to a state of "frozen rigidity". However a remarkable visual contact and eye-pointing behavior remains present even in the most severe case.

\section{Rett syndrome related manifestations}

Acquired microcephaly: the mean head circumference in classic Rett syndrome tends to fall to -2 SD scores below the mean at the age of 4 years. After the age of 8 it stabillizes close to -3 SD scores. Head growth has decelerated by less than -1 SD in $20 \%$ of the girls at the age of 6 years and in $10 \%$ at the age of 12 years. In form fruste variants, the mean head circumference stays within normal limits, however still significantly below the norm, $-0.8 \mathrm{SD}$ scores. The decline in head growth may thus be very obvious in classic Rett syndrome but is usually not in form fruste variants. Therefore it is no longer regarded as a necessary diagnostic criterion for classic Rett syndrome, nor as a valid one for atypical Rett syndrome (Hagberg et al., 2002). 
Intense handstereotypies such as hand wringing/squeezing, clapping/tapping, mouthing and washing/rubbing in a monotonous pattern constitute the hallmark of the disorder (fig. 5 ). In fact these kinds of midline movements of the hands are similarly present in nomal infants between 9 and 15 months of age (fig. 6). With the insidiously appearing loss of achieved purposeful hand skill between ages $1 / 2-2 \% / 2$ years, they appear at the end of regression stage II and become very obvious and typical in stage 1.1 . Later in stage IV they become less intense and simpler in character (fig. 7).

Intense eye contact-and eye pointing-behavior is the most remarkable feature in stage III. It is the way for them to communicate with their surroundings and to express needs and wishes (fig. 8). Therapists can use this behavior in individual sessions.

Dystomia and abnormal locomotion as a consequence of extrapyramidal deficit in Rett syndrome originates in the basal ganglia, substantia nigra, brainstem and cerebellar vermis. Truncal ataxia in young girls is felt by taking them on the examiner lap. Some are hypertonic, others hypotonic. Intermittent obvious or discrete dystonic posturing of the feet and toes is present even in young Rett syndrome children with milder courses. In ambulant girls there is a broadly based gait "most often with a preferential leg choosing the direction to walk into, causing very awkward walking patterns, all with a basic characteristic of gait dyspraxia (fig. 9)

Spine defomation: hypotonia, neuromuscular insufficiency with muscle wasting and extrapyramidal asymmetry (dystonia) will predispose to severe scoliosis. In ambulant girls it appears unpredictable or may never be present or only develop mildly. In non-ambulant girls with classic Rett syndrome stage IV/B scoliosis will develop in spite of all preventive measures taken. The most frequent curve is S-shaped starting with low lumbar torsion. Others develop C-shaped curves or a high kyphosis.

Autonomic manifestations: irregular breathing in the waking state (hyperventilation "shallow breathing and breath holding, forced expulsion of air or saliva, Valsalva breathing and air swallowing) associated with non-eplleptic vacant spelis is the most distressing feature in Rett syndrome. It reflects the immaturity of the brainstem and may contribute to sudden death. Impaired sleep pattern from early infancy, screaming outbursts and laughing spells, diminished response to pain, poor intestinal motility and constipation, dilated pupils and peripheral vasomotor disturbances with cold, purplish feet are other manifestations of autonomic origin.

Bruxism of the harsh sounding type is very typical, and the extreme bloating of the abdomen is rarely seen to such an extent in other mental retardation syndromes.

\section{DIAGNOSTIC CRITERIA}

The classic and variant Rett syndrome phenotypes are delineated as shown in Tables 2 . and 3. according to the last revision of the clinical diagnostic criteria in 2001 (Hagberg et al, 2002). Fully established Rett syndrome in an older girl or adult can thus be well recognized clinically. 


\section{Necessary criteria}

- Apparently normal prenatal and perinatal period

- Psychomotor development largely normal through the first 6 months or may be delayed from birth

- Normal headcircumference at birth

- Postnatal deceleration of head growth in the majority

- Loss of achieved purposeful hand skill between age $1 / 2-21 / 2$ years

- Stereotypic hand movements such as hand wringing/squeezing, clapping/tapping mouthing and washing/rubbing automatism's

- Emerging social withdrawal, communication dysfunction, loss of learned words, and cognitive impairment

- Impaired (dyspraxic) or failing locomotion

\section{Supportive criteria}

- Disturbances of breathing (hyperventilation, breath-holding, forced expulsion of air or saliva, air swallowing) during the waking state

- Bruxism

- Impaired sleep pattern from early infancy

- Abnormal muscle tone successively associated with muscle wasting and dystonia

- Peripheral vasomotor disturbances

- Scoliasis/kyphosis progressing through childhood

- Growth retardation

- Hypotrophic small and cold feet; small, thin hands

\section{Exclusion criteria}

- Organomegaly or other signs of storage disease

- Retinopathy, optic atrophy, or cataract

- Evidence of perinatal or postnatal brain damage

- Existence of identifiable metabolic or other progiressive neurological disorder

- Acquired neurological disorders resulting from severe infections or head trauma

Hagberg et al., 2002 
The variant types in general are referred to as "form fruste" based on the more slowly and protracted course with more preserved communicative and motor abilities. Clinical diagnosis remains tentative in these girls often up to an age of approximately 10 years. Other variant forms are defined depending on the principal feature dominating the disorder profile (Hagberg and Gillberg, 1993, Hagberg and Skjeldal, 1994).

Table 3. Delineation of variant phenotypes.

Meet at least 3 of 6 main criteria

Meet at least 5 of 11 supportive criteria

\section{Six main criteria}

Absence or reduction of hand skills

Reduction or loss of babble speech

Monotonous pattern of handstereotypies

Reduction or loss of communication skills

Deceleration of head growth from first year of life

Rett syndrome disorder profile: a regression stage followed by a recovery of interaction contrasting with slow neuromotor regression

\section{Eleven supportive criterila}

Breathing irregularities

Bloating/air swallowing

Bruxism, harsh sounding type

Abnormal locomotion

Scollosis/kyphosis

Lower limb amyotrophy

Cold, purplish feet, usually growth impaired

Sleep disturbances including night screaming outbursts

Laughing/screaming spells

Diminished response to pain

Intense eye contact/ eye pointing

Hagberg et all., 2002

The congenital onset variant is rare and difficult to diagnose in an infant or a child. There is marked developmental delay from the beginning without a clear history of stagnation and regression. The preserved speech variant is not so rare and related to an overall better level of development. The late regression variant with Rett syndrome starting at pre-school or early school age is also rare. In the infantile seizure onset variant hypsarrltythmia starting at the age of 2 to 4 months hides the Rett syndrome features in the beginning. When the epileptic encephalopathy stabilizes and is controlled by medication, sometimes only after 
many years, they regain a more or less clear Relt syndrome disorder profile with recovery of interaction. Whether defining the variant forms as such is helpfull in studying the great clinical variability in Rett syndrome remains to be seen and is a point of discussion.

The male Rett syndrome variant, known as one of the MECP2 related disorders is rare (Moog et al., 2003). But since the discovery of the MECP2 mutation more and more disorders in males with mental retardation and associated neurological symptoms have been found. They are discussed in addendum 6 .

\section{PROGNOSIS QUOAD VITAM}

The annual death rate in classic Rett syndrome has been estimated at of $1.2 \%$ in Britain (Kerr, 1992). Most of these deaths clustered between ages 15 and 20 years with causes related to the disorder (wasted condition and poor health, pneumonia, and epilepsy). Poor autonomic control is considered likely to play a significant role (Guideri et al., 1999. Julu et al. 2001). About $25 \%$ however were unexpected and sudden deaths that occurred across the age range. In the general population up to the same age the death rate was $2.3 \%$ (Kerr and Witt-Engerstrôm, 2001).

\section{DIFFERENTIAL DIAGNOSIS}

Children with stagnation and/or regression of devellopment always constitute a challenge for differential diagnosis. Other mental retardation syndromes and neurodegenerative diseases may mimic Rett syndrome in infants and should be rulled out. Since the clinical diagnosis remains vague under the age of 4 years the diagnostic work-up will include neurometabolic screening and neuroimaging among other standard examinations at that time. Nevertheless the clinical Rett syndrome history and presentation are very specific and only confusing with a few other disorders. Infantile neuronal ceroid lipofuscinosis (INCL) has a more rapid progressive and degenerative course with retinal involvement leading to blindness. Nevertheless the differential diagnosis can be difficult in the early stage. Loss of head control and irregular myoclonias are early clues for INCL ( Hagberg and Witt-Engerström, 1990). Myoclonic epileptic encephalopathy of infancy (West syndrome) and childhood (Lennox-Gastaut syndrome) can simulate Rett syndrome in the beginning. Both disorders cause the child to reach a developmental ceiling followed by regression and deterioration in case of therapy resistance. This might also be the case in acquired encepalopathy in infancy (Fiumara et al., 2002). Later in live a more or less Rett syndrome specific profile may become evident. Disintegrative infantile psychosis is sometimes put forward as a diagnosils in Rett syndrome girls with predominant autistic features in the early course of their disorder. Characteristic Rett syndrome features develop later in the course of their disorder. Autism in a young girl without any dyspraxic or dystonic symptom is however rarely associated with Rett syndrome. Mutations in MECP2 do not play a major role in autism susceptibility (Vourc'h et al., 2001; Beyer et al., 2002). Infantile autism and Rett syndrome probably represent two distinct entities at the molecular genetic level (Muhle et al., 2004). Therefore Rett syndrome should never be classified as autistic disorder in the DSM-IV classification
(APA, 1994).

Angelman syndrome (AS) is perhaps the trickiest in differential diagnosis. The pattern of developmental delay at early age is sometimes similar and many of the diagnostic criteria obviously account for Rett syndrome too (Watson et al., 2001). The behavioral phenotype of AS is to our opinion decisive in this matter. The phenotypic resemblance between Rett syndrome and AS is a point of discussion but appears to be rather academic (Allanson et al. 2004). AS methylation test can be performed in MECP2 negative girls with a non-classic Rett syndrome course. A more clear distinction between the two syndromes will evolve over
time (Ellaway' et al., 1998). 


\section{ETIOLOGY, PATHOGENESIS AND GENETICS}

\section{Etiollogy}

Rett syndrome is the result of a mutation in the MECP2-gene (MECP2), located at chromosome Xq28 and encoding the methyl-CpG-binding protein 2 (MeCP2)(Amir et al., 1999). It contains a methyl $\mathrm{CpG}$ binding domain, a transcription repression domain, a nuclear localization signal, and the C-terminal segment. The coding sequence for the methyl-CpG-binding domain is split between exon 3 and 4, while the transcription repression domain lies entirely in exon 4 ( $N a n$ et al. 1996, Nan et al., 1997). For the purpose of discussion we differentiate also between the part of the transcription repression domain including the nuclear localization signal and the part after.

The methyl-CpG-binding domain of the MeCP2-protein (MeCP2) binds specifically to 5methyl-cytosine throughout the genome. The transcription repression domain interacts with histone deacetylase and the transcription silencer co-repressor $\operatorname{Sin} 3 \mathrm{~A}$. The nuclear localization signal mediates the transport of MeCP2 into the nucleus and the C-terminal segment facilitate binding to the nucleosome core (Chandler et al., 1999; Huppke et al. 2000). These interactions result in deacetylation of histones and chromatin condensation, which leads to repression of transcription (Nan et al., 1998; Wan et al., 2001).

Untill now mutation analyses have identified over 200 different causal mutations in classic and variant Rett syndrome, including a number of frequently recurrent missense and nonsense mutations clustering in the functional domains and in the $3^{\prime \prime}-e n d$ of the gene. They are listed in the database accessible through the website of the International Rett Syndrome Association (www.rettsyndrome.org). A mutation detection rate above $80 \%$ accurs in individuals with classic Rett syndrome using standard techniques to analyze the coding region (Cheadle et al., 2000; Smeets et al., 2003). In variant Rett syndrome the incidence of mutations is lower. Recent research (Bourdon et al., 2001; Yaron et al., 2002; Schollen et al. . 2003) established evidence for "gross rearrangements" in the coding region (exon 3 and 4) after MLPA and Southern blot analysis in girls with severe classic Rett syndrome. These gross rearrangements, consisting of larger deletions, are not detected by standard mutation screening techniques (Denaturing high-performance liquid chromatography and sequencing of the coding region). More than $95 \%$ of the MECP2 mutations occur de novo, and almost exclusively on the paternal $X$ chromosome (Girard et al., 2001; Trappe et al., 2001).

\section{Pathogenesis}

MeCP2 is ubiquitously present but particularly abundant in the brain (Amir et al., 1999). It suppresses the transcription of other tissue specific genes whose activity is not or no longer required (Yntema et al., 2002). Loss of function of MeCP2 in cells, especially in differentiated postmitotic neurones, may lead to inappropriate overexpression of these other genes with a potentially damaging effect during central nervous system maturation (Ellaway and Christodoulou, 2001). It's function is also important for the maintenance of the developing brain (Nan and Bird, 2001). Immunoreactive cytometric studies have shown that the presence of MeCP2 in differentiated neurons is diminished in Rett syndrome. This deprivation of MeCP2 probably plays an important role in the pathogenesis of this enigmatic disorder (LaSalle et al., 2001). The knock out mice, deficient in the MECP2 gene, presents several features of the Rett syndrome. The search for target genes that are de-repressed in these deficient mice has not yielded any clear candidates. A genuine candidate is the brain derived neurotropic factor-gene (BDNF). Normal MeCP2 is regulating the expression of this gene that is essential in learning and neural plasticity and might be involved in Rett syndrome (Chen et al., 2003; Martinowich et al. 2003).

The Rett syndrome pathology differs from the other various disorders with mental retardation in that the pattern of dentritic changes in the Rett syndrome brain is unique (Armstrong and Kinney, 2001). Brain weight is reduced in Rett syndrome girls but does not diminish with age. The defined cause of this arrest in brain development and how this results in altered 
neurophysiology is not yet well understood. There is evident failure of the dentritic arborisation in specific sites of the brain correlating with the cortical localization of some of its significant motor and behavioral symptoms. In relation to the peculiar movement disorder in Rett syndrome the substantia nigra, basal ganglia, the cerebellum and spinal cord have been found to show specific alterations. Various neurotransmitter systems have also been studied with various but inconclusive results (Armstrong, 2002). The disturbances in autonomic functions have been studied and related to the immaturity of brainstem autonomic centers resulting in hypersensitivity for sympathetic stimuli with insufficient parasympathetic control (Kerr and Julu, 1999; Julu et al., 2001).

\section{Genetic counselling}

When a MECP2 mutation is found in a girl, the mother should be excluded as an asymptomatic carrier. Until now, in all known familial Rett syndrome cases the mother has been found either to be a carrier of the mutation (Amir et al., 1999; Wan et al., 1999; Cheadle et al, 2000; Orrico et $\mathrm{al}_{\mathrm{n}}, 2000$ ) or to carry a mozaicism for the mutation (Amir et al., 1999). It is speculated that in such cases of maternally inherited MECP2 mutation, the primary mutational event appeared on the mother's paternal $X$ chromosome (Villard et all., 2000; Trappe et al. 2001). Therefore, when the mother is an asymptomatic carrier, the recurrence risk is $50 \%$. This includes the risk of intra-uterine death (Thomas, 1996) or severe neonatal encephalopathy in a male. Recurrence of paternally inherited MECP2 mutation has never been described in familial cases. However, more then $95 \%$ of Rett syndrome mutations occur de novo and almost exclusively on the paternal $X$ chromosome (Kondo et al., 2000). Based on the low likelihood of a gonadal mozaicism, that never can be excluded a priori (Topcu et al., 2002), the recurrence risk in sporadic Rett syndrome is less then $0.1 \%$. The offering of prenatal diagnosis in subsequent pregnancies is therefore debatable and merely done on psychological grounds. For the healthy sister af a sporadic Rett syndrome female the recurrence risk is not enhanced in view of the general population. 
B. The Leuven - Maastricht experience 


\section{MATERIALS AND METHODS}

Between 1983 and 2003107 girls and women, aged between 2 and 60 years, were diagnosed with Rett syndrome and/or re-examined. The clinical diagnosis suspected in infants below 4 years was confirmed above that age according to the intemational criteria. Complete data could be obtained from 103 individuals and most of the adult women were know to us since more than 16 years. They were re-examined in the presence of parents and/or caretakers. This was done either at the clinic, at home or in the institutions and daycare centers. These 103 individuals form the subject of this study. In the clinical evaluation we recorded the personal history of each individual, the age at onset of stagnation/regression, the age at clinical diagnosis, the clinical severity at the age of examination and comments on Rett syndrome manifestations and behavioral characteristics. For the evaluation of clinical severity at the time of examination we applied two scoring systems. Score 1 results from the guidelines for reporting on manifestations common in Rett syndrome (Kerr et al, 2001). The maximum score being 40 , a score above 30 was considered as very severe, a score between 25 and 30 as severe, and between 10 and 25 as mild to less severe. A score less than 10 represents the best clinical condition still recognizabile as Rett syndrome. The different items to score in this system are given in table 1.

We developed a second score system that is shown in table 2 . In this more simplified score system we excluded sleep disorder and mood disturbance, breathing dysrhythmia, muscle tone, involuntary movements, head circumference and other growth parameters, even in females with classic Rett syndrome. In the obviousily milder Rett syndrome, these manifestations are not dominantly present. Therefore, gross motor sitting and walking ability, remaining functional hand use, speech ability, epilepsy, and neurogenic scoliosis were considered more likely to influence the long-term evolution and severity. A score from 0 to 3 was given for these 6 items as shown in Table 2.: 0 for the normal situation; 1 when there was impairment without total loss of motor ability, reduced hand use, some preserved speech, previous epilepsy or seizures well controlled by medication, mild scoliosis/kyphosis; 2 when there was loss of function, apraxia, no speech, uncontrolled epilepsy, severe scoliosis/kyphosis; 3 when the function was never acquired, status epilepticus, surgery for scoliosis. The maximum score is 18 : below 9 the condition was considered as mild to less severe.

All patients had routine cytogenetic studies and molecular examination for exclusion of fragile- $X$, and in the initially mutation negative fermales also for exclusion of Angelman syndrome. Apart from 16 analyses most of the MECP2 mutations were documented at the genetic labs of Leuven and Maastricht.

The routine DNA-diagnostic screening protocol involves DHPLC, DGGE, SSCP, followed by direct sequence analysis of the coding exons and immediate flanking intronic regions of the gene to confirm and identify the nature of the mutation. This approach however does not allow detection of gross rearrangements in the MECP2 gene. For this purpose we analyzed the mutation-negative cases using a multiplex ligation-dependent probe amplification (MLPA) technique to allow the detection of deletions and/or duplications in the MECP2 gene. Rearrangements were subsequently verified and confirmed by Southern blot analysis. $X$-chromosome inactivation (XCI) was studied in 26 adult Rett syndrome females (Schollen et al., 2003; Smeets et al., 2003) 
Table 1. Scoring system for features associated with MECP2 mutations in RTT

A Head circumference during the first year KOther involuntary movements

2 Already below the third percentile at 2 Dominating or constant

birth

1 Normal at birth but decelerating

1 Mild or intermittent

0 Normal at birth with no deceleration

0 None

B Early developmental progress (birth to L Voluntary handuse (eg. self feeding) $12 \mathrm{mo})$

2 No or virtually no progress

1 Suboptimal progress

o Normal progress

C Present head circumference (PC/SD)

2 Below $3^{\text {rd }}$ percentile

13 to $10^{\text {th }}$ percentile

0 Above the $10^{\text {th }}$ percentile

2 None

1 Reduced or poor

o Normal

MOro-motor difficulty

2 Severe (eg. aversion, button fed )

1 Slight(delayed swallowing., chewing, on suppl.)

o None

D Weight $(\mathrm{kg})$

2 Below the $3^{\text {rd }}$ percentille

13 to $10^{\text {th }}$ percentile

N Intellectual disability

2 Apparent profound (infant level)

1 Any except profound

0 No impairment

0 Above the $10^{\text {th }}$ percentile

O Speech

2 Currently uses no real words with meaning

2 Below the $3^{\text {rd }}$ percentile

13 to $10^{\text {th }}$ percentile

0 Above $10^{\text {th }}$ percentile

1 Currently uses some real words with meaning

o Normall speech

F Muscle tone (describe)

2 Severe hypotonila

hypertonia

P Epilepsy

1 Tone mildly abnormal

0 Normal

G Spine posture

2 Severe scoliosis

1 Mild scoliosis

0 No deviation

$\mathrm{H}$ Joint contractures

2 Severe contractures

1 Minor contractures

o None

1 Gross motor function

2 Cannot walk with support

1 Walking impaired

0 Walks normally

JHand stereotypy

2 Dominating or constant

1 Mild or intermittent

0 None

dystonia or 2 Uncontrolled or poorly controlled

1 Previous epileptsy or well controlled on med.

0 Never

Q Disturbed awake breathing rhythm

2 Severe, with vacant spells \& color changes

1 Mild, without vacant spells \& color changes

0 Normal breathing rhythm

$\mathrm{R}$ Peripheral circulation of extremities

2 Cold or discolored with atrophic changes

1 Cold or discolored without atrophic changes

o Normal color and temperature of extremities

5 Mood disturbance

2 Prominent or disruptive agitation/ crying spells

1 Abnormally prone to agitation

0 Normal

I Sleep disturbance (day and/or night)

2 Prominent/disruptive sleeping or night waking

1 Present, not prominent

o Normall sleep pattern

(Kerr et al. 2001) 
Table 2. Simplified severity score

\begin{tabular}{|c|c|c|c|c|}
\hline Score & 0 & 1 & 2 & 3 \\
\hline Sitting & & impaired & lost & never acquired \\
\hline Walking & .5 & impaired & lost & never acquired \\
\hline Handuse & $\stackrel{\text { 胥 }}{=}$ & reduced & lost & never acquired \\
\hline Speech & $\bar{\pi}$ & some words & lost & never acquired \\
\hline Epilepsy & 흔 & controlled & Uncontrolled & status epilepticus \\
\hline Spine deformation & & mild & severe & operated \\
\hline
\end{tabular}

\section{RESULTS}

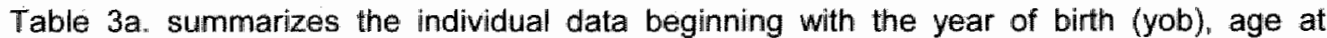
onset, age at diagnosis and age at last examimation; next the clinical delineation as classic (CR) or variant (RV), the molecular findings with the nature, localization and type of the MECP2 mutation, followed by the scores. Table $3 \mathrm{~b}$. comments on their personal history, abilities and behavior. Score 1 resulted from the extensive report on the presence or absence of the different Rett syndrome features, and score 2 resulted from scoring the remaining abilities, the epilepsy and the spine deformation at the time of their last examination. 


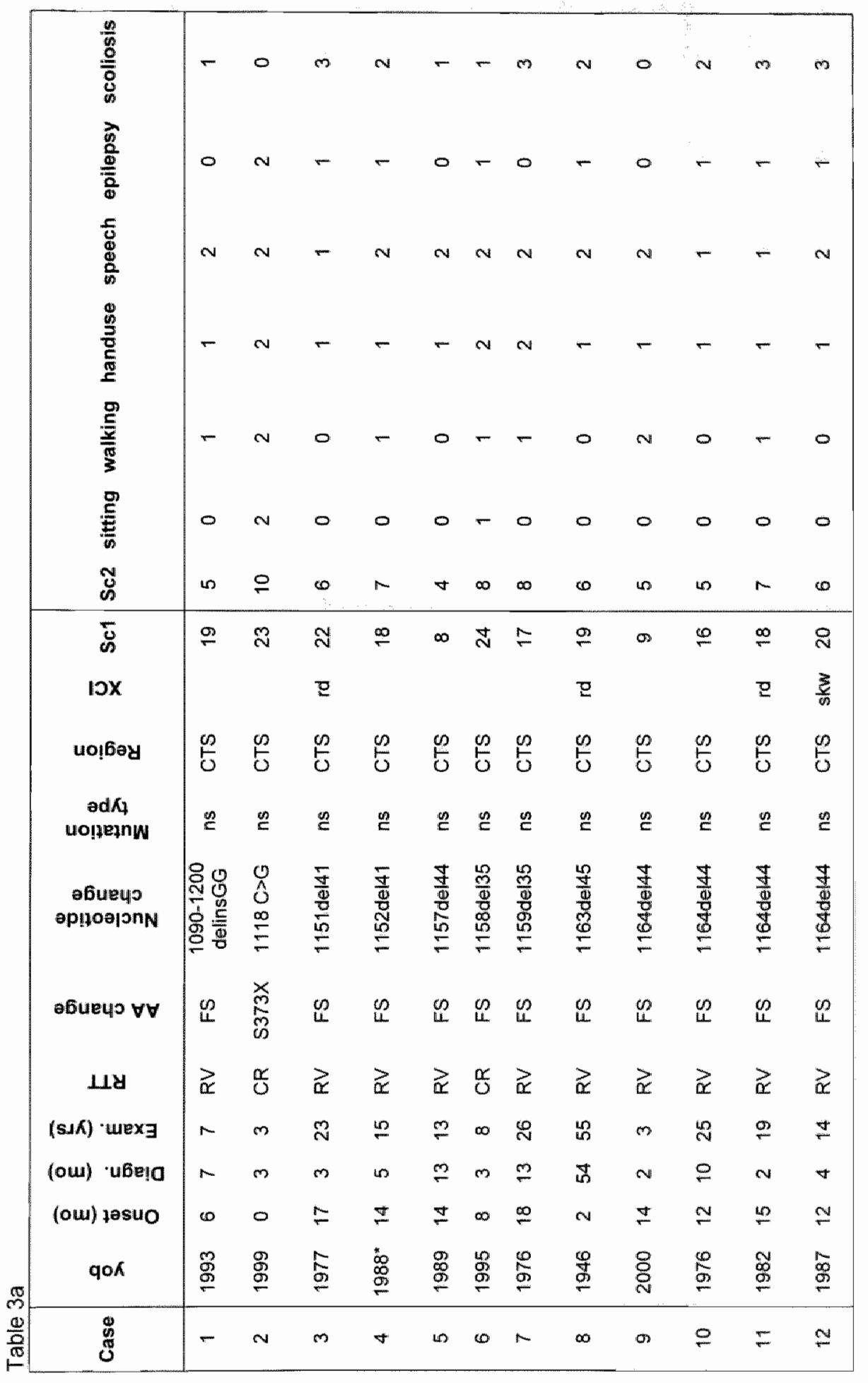




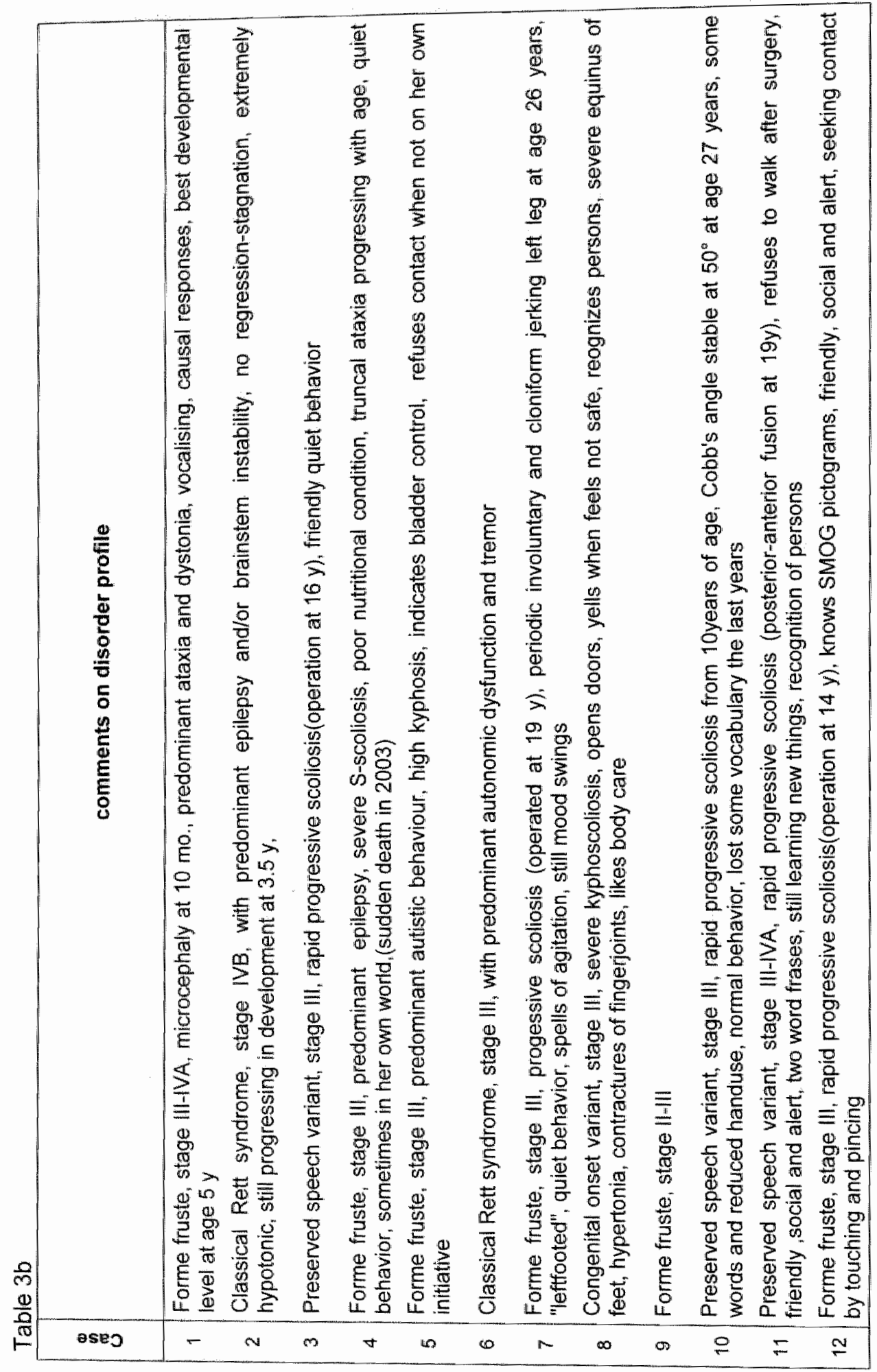




\begin{tabular}{|c|c|c|c|c|c|c|c|c|c|c|c|c|}
\hline$\frac{\stackrel{m}{o}}{\stackrel{0}{0}}$ & 0 & - & - & 0 & 0 & 0 & - & $N$ & - & 0 & - & v \\
\hline$\frac{\vec{y}}{\frac{0}{0}}$ & 0 & - & 0 & 0 & 0 & 0 & $N$ & $N$ & - & - & - & - \\
\hline $\begin{array}{l}\frac{5}{\delta} \\
\Phi \\
\Phi \\
\frac{\alpha}{n}\end{array}$ & $N$ & $N$ & $N$ & N & $N$ & - & $N$ & $N$ & $N$ & $N$ & $N$ & $N$ \\
\hline 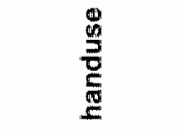 & $r$ & - & - & - & - & - & $N$ & $N$ & - & $\sim$ & - & $N$ \\
\hline$\frac{\text { D }}{\frac{E}{x}}$ & 0 & - & 0 & 0 & 0 & $m$ & N & - & 0 & 0 & 0 & w \\
\hline$\stackrel{\frac{D}{E}}{E}$ & 0 & 0 & 0 & 0 & 0 & 0 & 0 & 0 & 0 & 0 & 0 & - \\
\hline ญै & $m$ & $\omega$ & $\nabla$ & m & 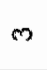 & $\omega$ & $\infty$ & $\infty$ & in & 60 & in & $=$ \\
\hline$\overline{\mathscr{H}}$ & $\infty$ & $\stackrel{m}{\longrightarrow}$ & $\mathscr{\theta}$ & $\stackrel{9}{=}$ & $\infty$ & 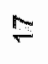 & $\mathbb{N}$ & $N$ & $=$ & $\mp$ & \pm & $\underset{\sim}{\infty}$ \\
\hline $10 x$ & & & $\mathrm{P}$ & & & & & g & $\frac{z}{n}$ & $\mathrm{E}$ & $\mathrm{g}$ & \\
\hline uo!̣6əy & $\stackrel{\infty}{0}$ & $\frac{\infty}{6}$ & 立 & $\sum^{0}$ & 邑 & $\stackrel{9}{\underline{m}}$ & $\stackrel{0}{\stackrel{0}{\mathfrak{m}}}$ & 몰 & 品 & $\frac{0}{2}$ & $\stackrel{p}{\sum}$ & $\frac{0}{2}$ \\
\hline $\begin{array}{c}\text { əd/K1 } \\
\text { uo!̣ejnW }\end{array}$ & 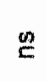 & $\mathscr{m}$ & $\mathscr{E}$ & $\stackrel{n}{E}$ & $\stackrel{m}{E}$ & $\stackrel{\infty}{E}$ & E & $\stackrel{m}{E}$ & $\stackrel{\mathscr{E}}{\mathrm{E}}$ & $\stackrel{M}{E}$ & $\stackrel{w n}{E}$ & E \\
\hline $\begin{array}{c}\text { a6uey } \\
\text { apnoอ|วกN }\end{array}$ & 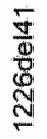 & $\begin{array}{l}\frac{\mathbb{Z}}{8} \\
\frac{\mathbb{g}}{\mathrm{N}} \\
\stackrel{\mathrm{N}}{\sim}\end{array}$ & 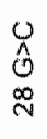 & 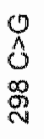 & $\begin{array}{l}\stackrel{M}{O} \\
\frac{\infty}{m}\end{array}$ & $\begin{array}{l}\leftarrow \\
\hat{O} \\
\frac{0}{m}\end{array}$ & $\begin{array}{l}-\widehat{A} \\
\mathcal{O} \\
\text { 品 }\end{array}$ & 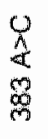 & 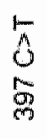 & $\stackrel{\mathrm{O}}{\mathrm{S}}$ & $\frac{\mathrm{B}}{\mathrm{S}}$ & 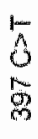 \\
\hline $\begin{array}{c}\text { əธนеนฺ } \\
\forall \forall Z d \supset \exists W\end{array}$ & $\mathbb{Z}$ & $\mathscr{2}$ & $\underset{亡}{\stackrel{g}{\Psi}}$ & $\frac{8}{9}$ & $\frac{3}{0}$ & $\stackrel{\frac{3}{2}}{\frac{2}{\alpha}}$ & $\frac{3}{8}$ & 唄 & $\frac{0}{m}$ & $\frac{\ddot{2}}{2}$ & $\frac{\mathscr{m}}{\frac{m}{x}}$ & $\frac{\mathscr{c}}{\mathscr{m}^{2}}$ \\
\hline LIH & $\gtrless$ & $\not{\alpha}$ & $\vec{\alpha}$ & $\ddot{x}$ & $\gtrsim$ & $\frac{\alpha}{0}$ & $\frac{\alpha}{0}$ & $\vec{z}$ & $\vec{\alpha}$ & 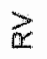 & 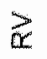 & $\frac{\alpha}{0}$ \\
\hline$(\sin (K) \cdot$ wex 3 & $\stackrel{m}{\sim}$ & $\cong$ & 8 & $\forall$ & $\omega$ & $m$ & $m$ & 8 & $\bar{y}$ & $\stackrel{\infty}{\sim}$ & $\bar{N}$ & $\stackrel{\infty}{\sim}$ \\
\hline (ow) ube!a & $=$ & $\infty$ & 8 & $\nabla$ & $n$ & N & 芦 & $\stackrel{\oplus}{\oplus}$ & F & 2 & $=$ & $\infty$ \\
\hline (oul) jasuo & $\stackrel{\infty}{\rightleftharpoons}$ & $\stackrel{N}{\sim}$ & $\stackrel{N}{\sim}$ & $\stackrel{N}{\sim}$ & 周 & $\infty$ & $\infty$ & $\stackrel{\infty}{q}$ & $m$ & 8 & 芯 & $\infty$ \\
\hline qo $\AA$ & $\underset{\mathscr{\infty}}{\stackrel{\infty}{\circ}}$ & $\begin{array}{l}\stackrel{L}{\infty} \\
\stackrel{\infty}{\sigma}\end{array}$ & $\underset{\nabla}{\sigma}$ & $\begin{array}{l}\infty \\
g \\
\stackrel{9}{2}\end{array}$ & $\stackrel{\leftrightarrow}{\circ}$ & $\begin{array}{l}\frac{g}{g} \\
\stackrel{\alpha}{\sigma}\end{array}$ & 怘 & $\stackrel{\rightleftarrows}{\stackrel{*}{\circ}}$ & * & $\frac{2}{2}$ & $\underset{\sigma}{\sigma}$ & $\stackrel{8}{9}$ \\
\hline 量 & $\stackrel{m}{m}$ & 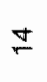 & $\stackrel{m}{2}$ & $\stackrel{\varphi}{\sim}$ & $=$ & $\stackrel{\infty}{\stackrel{2}{2}}$ & on & 요 & $\bar{v}$ & N & $m$ & d \\
\hline
\end{tabular}




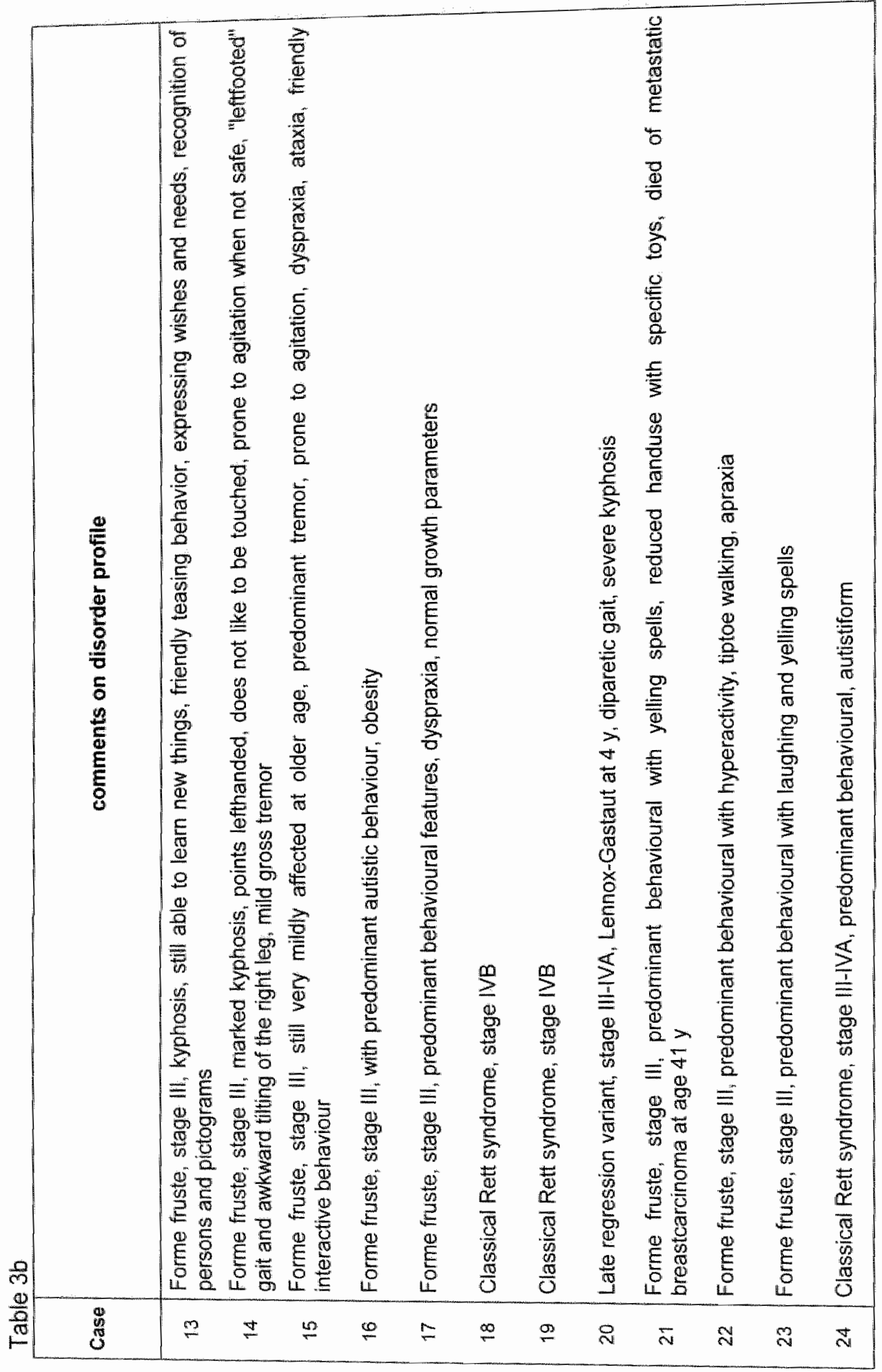




\begin{tabular}{|c|c|c|c|c|c|c|c|c|c|c|c|c|}
\hline 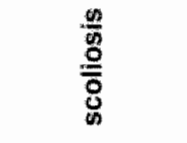 & 0 & 0 & - & 0 & N & $m$ & N & $\infty$ & - & N & - & N \\
\hline 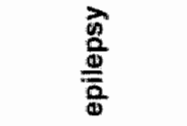 & r & $N$ & N & 0 & N & - & - & - & - & N & n & - \\
\hline $\begin{array}{l}\frac{5}{5} \\
\frac{\mathrm{D}}{5}\end{array}$ & - & n & N & $\sim$ & $\sim$ & N & N & $\infty$ & $\sim$ & N & a & N \\
\hline 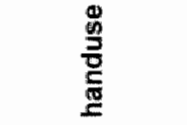 & - & N & - & $N$ & N & N & N & N & N & N & n & N \\
\hline 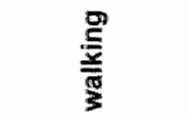 & - & $m$ & o & N & $m$ & N & $m$ & $\sim$ & o & m & n & $m$ \\
\hline 嘉 & 0 & n & - & N & N & N & - & - & 0 & $\circ$ & - & - \\
\hline ్ֶ & ナ & $=$ & r & $\infty$ & $\stackrel{M}{\longrightarrow}$ & $\simeq$ & $=$ & 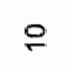 & 0 & $=$ & $\div$ & $=$ \\
\hline $\bar{g}$ & $\sigma$ & $\stackrel{\mathscr{N}}{\mathbb{N}}$ & $\tilde{N}$ & $\stackrel{J}{N}$ & " & $\mathscr{N}$ & \pm & $\dot{N}$ & $\stackrel{\infty}{-}$ & $\bar{n}$ & $\hat{N}$ & I \\
\hline $10 x$ & & & & & $\mathrm{~g}$ & 문 & & $\bar{z}$ & $\frac{\xi}{5}$ & & & \\
\hline uo!̣boy & 㩊 & 品 & 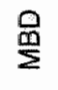 & $\stackrel{\mathrm{m}}{\mathrm{m}}$ & 㩊 & 品 & $\stackrel{\frac{0}{m}}{\Sigma}$ & 誉 & $\frac{\mathrm{O}}{\mathrm{m}}$ & $\stackrel{\mathrm{m}}{\mathrm{m}}$ & $\stackrel{\mathrm{O}}{\mathrm{M}}$ & $\stackrel{\mathrm{g}}{\Sigma}$ \\
\hline $\begin{array}{c}\text { ed } 19 \\
\text { uop̣eynw }\end{array}$ & $\stackrel{\mathscr{L}}{E}$ & $\stackrel{\mathscr{D}}{E}$ & $\stackrel{\mathscr{Q}}{E}$ & $\mathscr{n}$ & $\stackrel{\mathscr{E}}{E}$ & $\stackrel{\mathscr{E}}{E}$ & $\stackrel{\mathscr{O}}{E}$ & $\stackrel{\mathscr{E}}{E}$ & $\mathscr{\mathscr { E }}$ & $\stackrel{n}{E}$ & 哭 & $\stackrel{\mathscr{m}}{E}$ \\
\hline 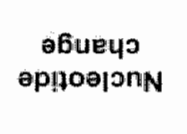 & 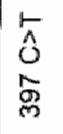 & 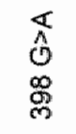 & 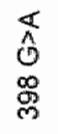 & 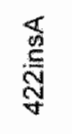 & 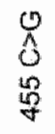 & 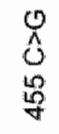 & $\begin{array}{l}0 \\
\hat{O} \\
8 \\
g \\
\end{array}$ & $\begin{array}{l}\stackrel{5}{0} \\
\stackrel{p}{\sigma} \\
\end{array}$ & $\begin{array}{l}\hat{L} \\
\hat{C} \\
\stackrel{g}{G}\end{array}$ & 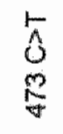 & $\begin{array}{l}\text { 命 } \\
\text { 导 }\end{array}$ & $\begin{array}{l}5 \\
\hat{0} \\
\stackrel{8}{\forall}\end{array}$ \\
\hline $\begin{array}{c}\text { a6ueys } \\
\forall \forall Z d O \exists W\end{array}$ & $\begin{array}{l}\frac{0}{0} \\
\frac{m}{\alpha} \\
\frac{0}{\alpha}\end{array}$ & $\frac{I}{\frac{I}{j g}}$ & $\frac{I}{\frac{I}{m}}$ & $\mathscr{L}$ & 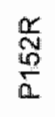 & $\begin{array}{l}\frac{\alpha}{0} \\
\frac{\alpha}{\alpha} \\
\frac{\alpha}{\alpha}\end{array}$ & $\begin{array}{c}\frac{0}{0} \\
\text { on } \\
\frac{0}{\alpha}\end{array}$ & $\begin{array}{l}\text { 离 } \\
\text { 悬 }\end{array}$ & $\begin{array}{l}\text { 离 } \\
\text { 省 }\end{array}$ & $\begin{array}{l}\text { 总 } \\
\text { 莡 } \\
\end{array}$ & 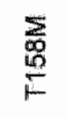 & 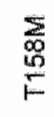 \\
\hline עل & $\stackrel{\infty}{0}$ & $\stackrel{x}{0}$ & $\stackrel{\alpha}{0}$ & $\stackrel{\alpha}{0}$ & $\stackrel{x}{0}$ & $\stackrel{\alpha}{0}$ & 恖 & 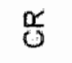 & 앙 & $\stackrel{\circ}{0}$ & $\stackrel{\infty}{0}$ & $\stackrel{\circ}{\circ}$ \\
\hline 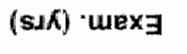 & $\infty$ & $\sigma$ & 0 & n & N & $\stackrel{9}{\longrightarrow}$ & $\begin{array}{c}10 \\
\infty \\
\infty\end{array}$ & y & $\mathscr{\pi}$ & $\stackrel{9}{\square}$ & N & $\bar{\Lambda}$ \\
\hline (ow) u6e!a & $m$ & $N$ & $N$ & N & ส & N & N & $\bar{y}$ & $\infty$ & in & $=$ & $\sigma$ \\
\hline (ow) zasuo & - & 0 & $\cong$ & $\cong$ & o & 운 & a & $\stackrel{\infty}{\sim}$ & A & 0 & $\infty$ & $\sim$ \\
\hline qox & 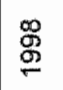 & 䊀 & 絗 & 氮 & 芦 & $\stackrel{\mathscr{\alpha}}{\stackrel{\circ}{\sim}}$ & 兽 & 品 & 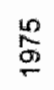 & 喆 & 品 & $\stackrel{\circ}{\stackrel{\circ}{\circ}}$ \\
\hline 总 & $\stackrel{\mathscr{N}}{\sim}$ & $\stackrel{\infty}{\sim}$ & $\hat{N}$ & $\stackrel{\infty}{N}$ & $g$ & 요 & $\bar{n}$ & 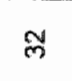 & $\mathscr{\infty}$ & ल & 峞 & $\%$ \\
\hline
\end{tabular}




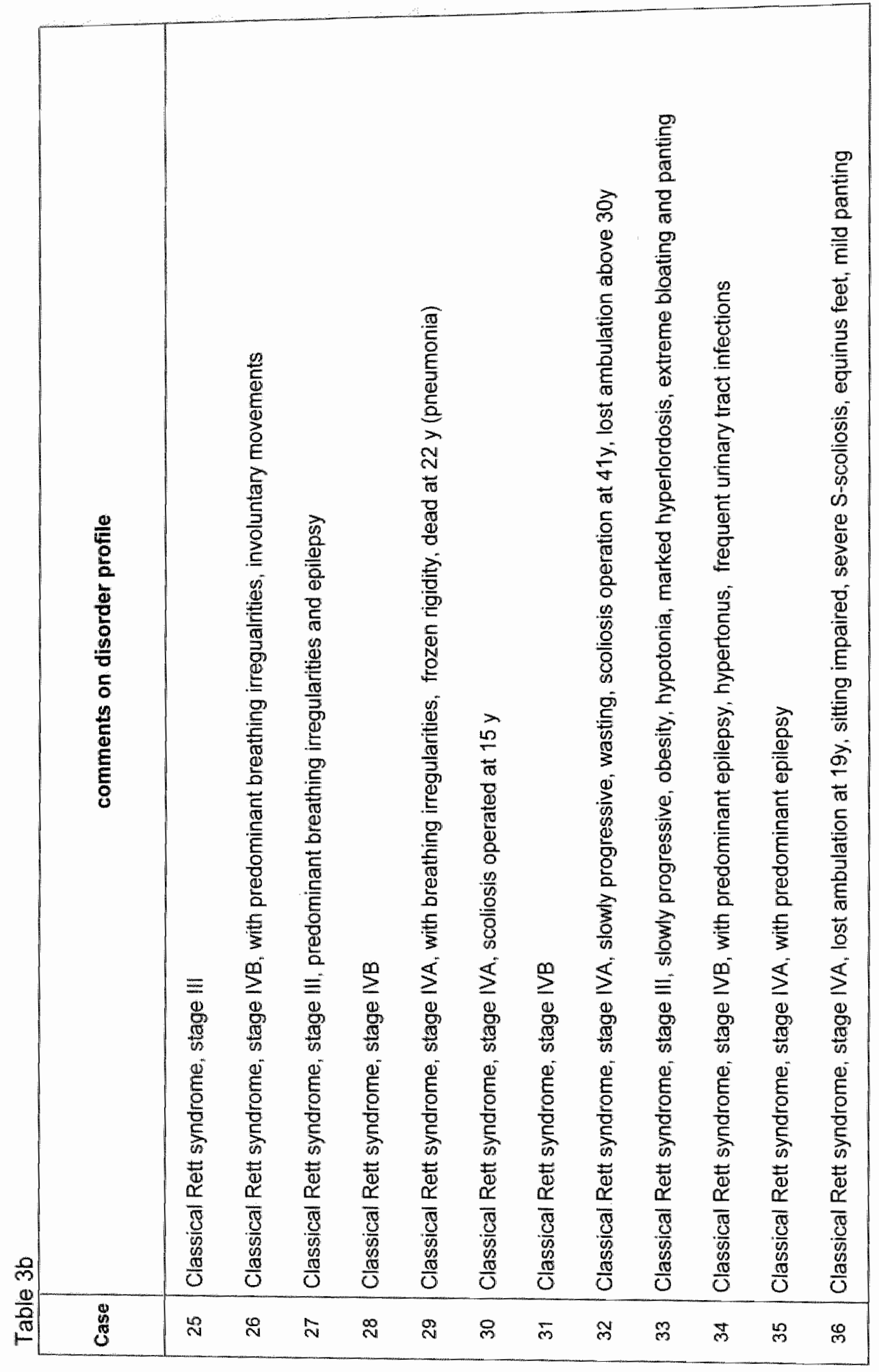




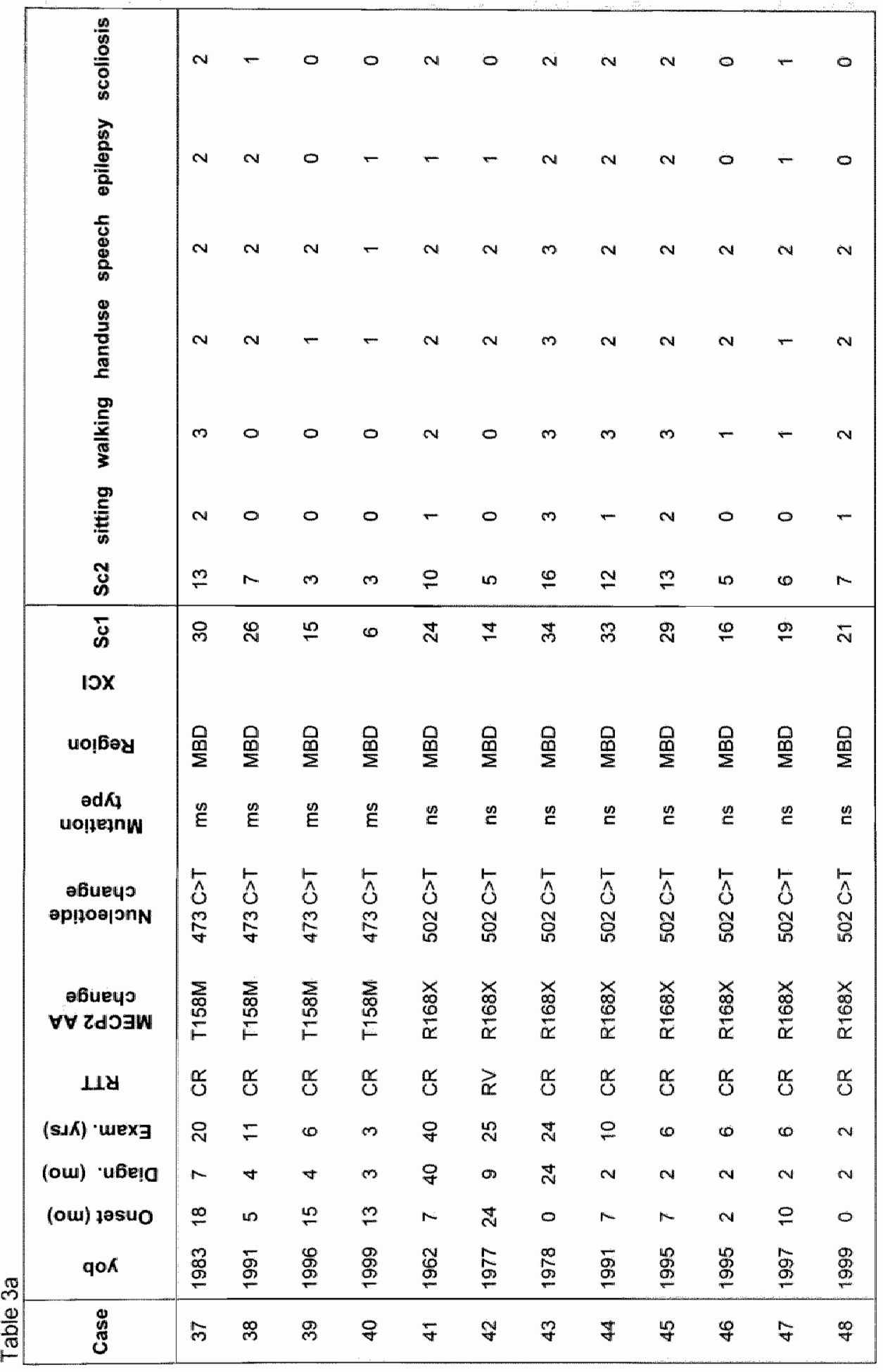




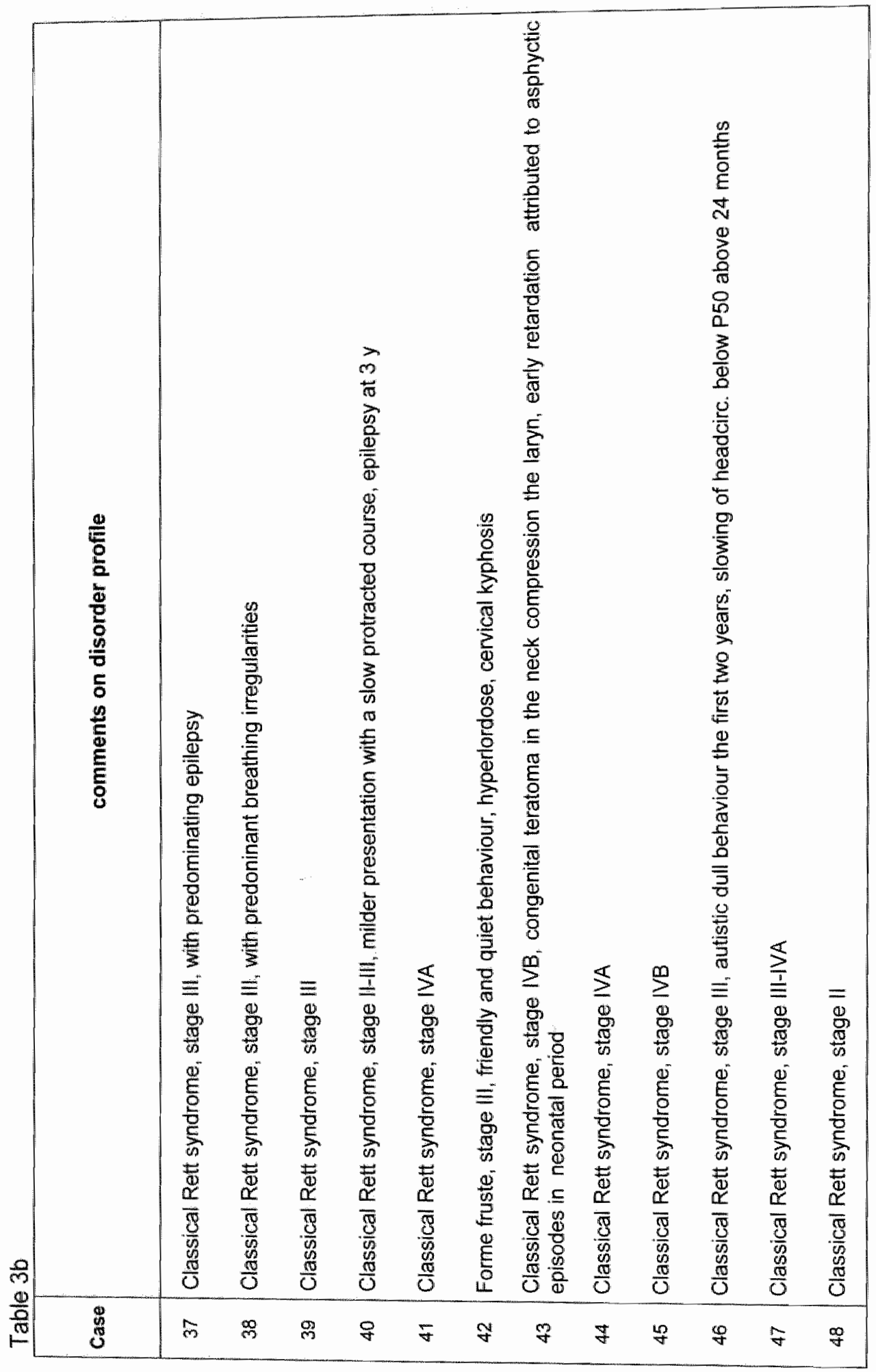




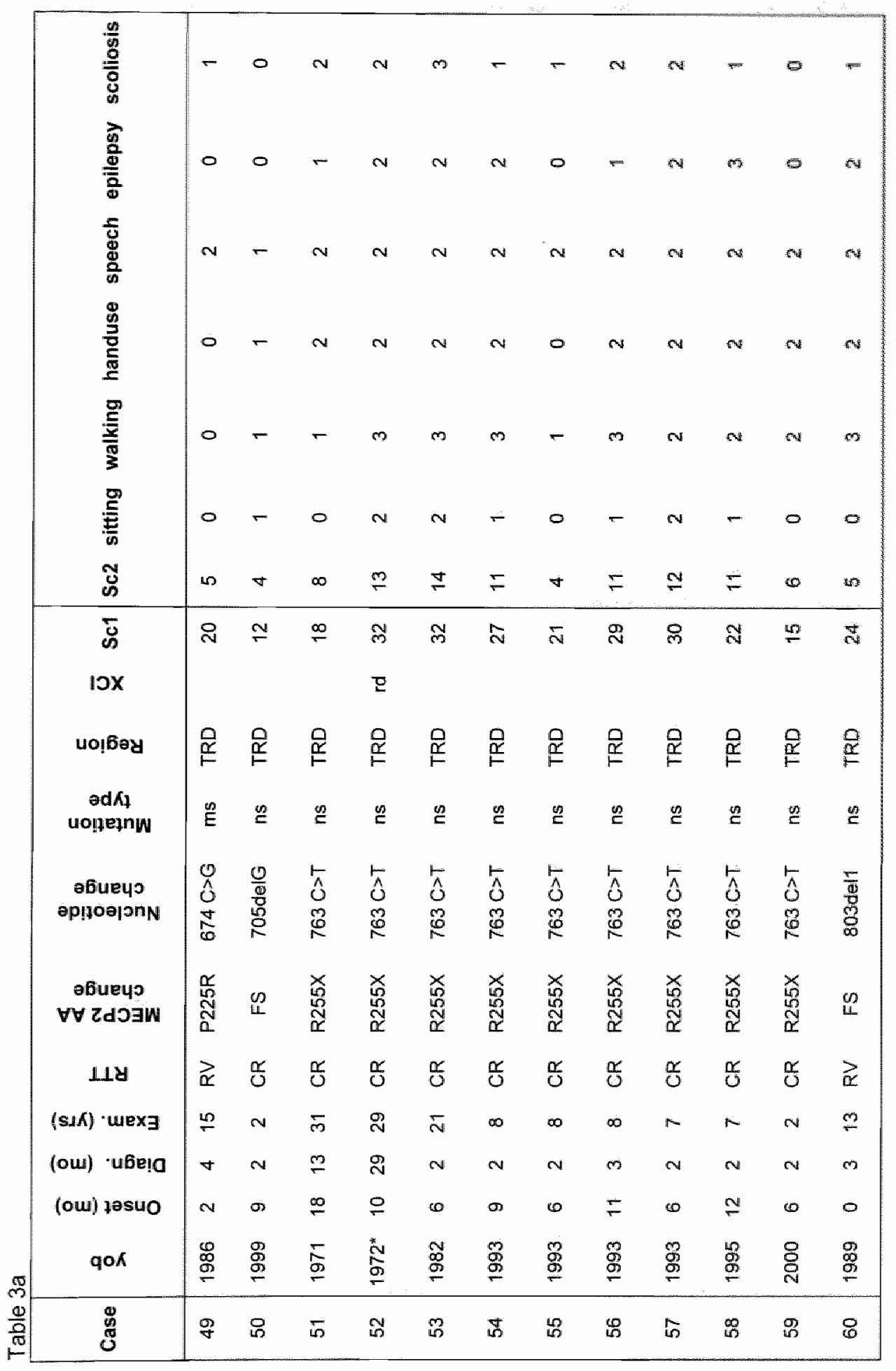




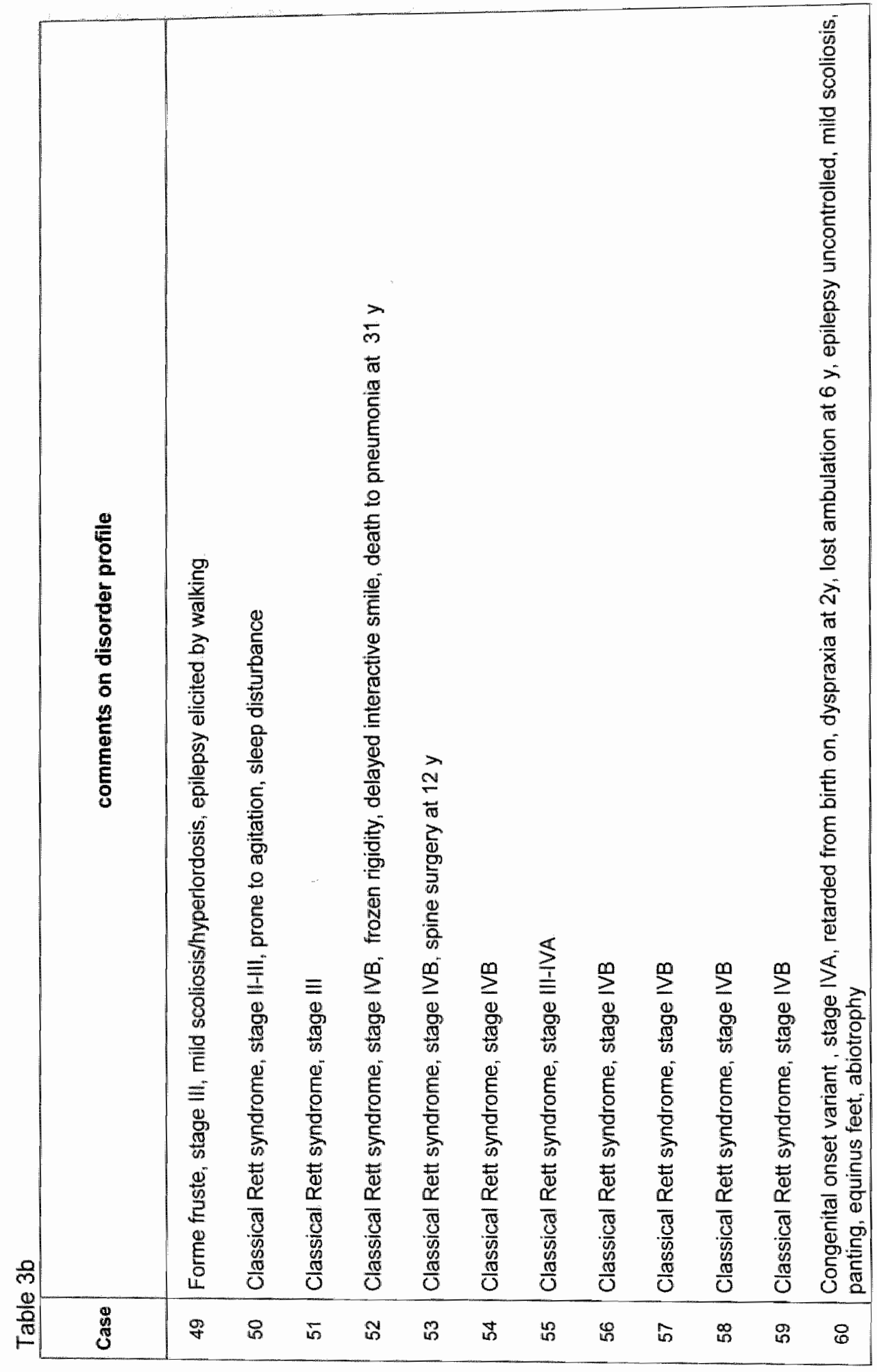




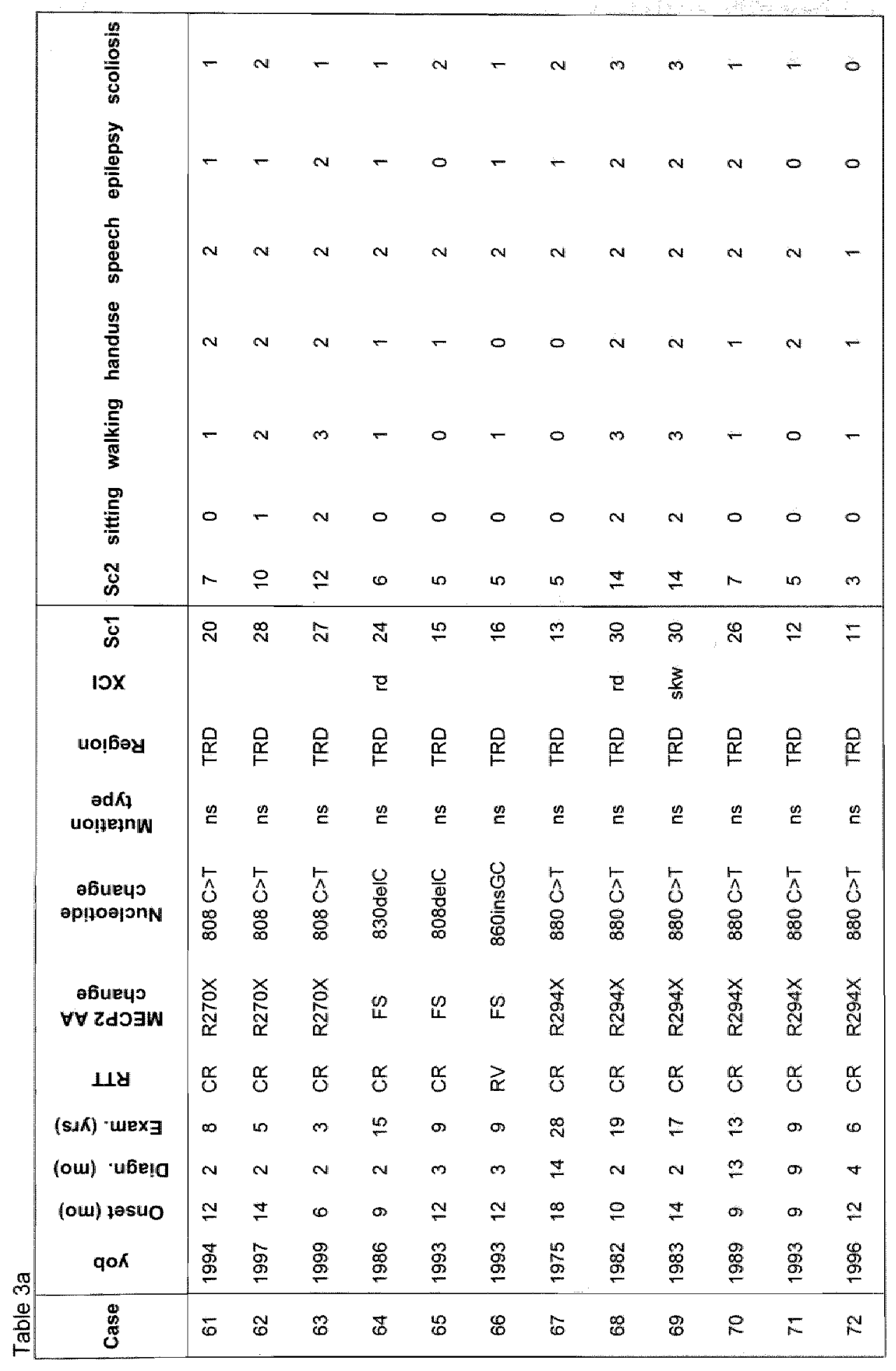




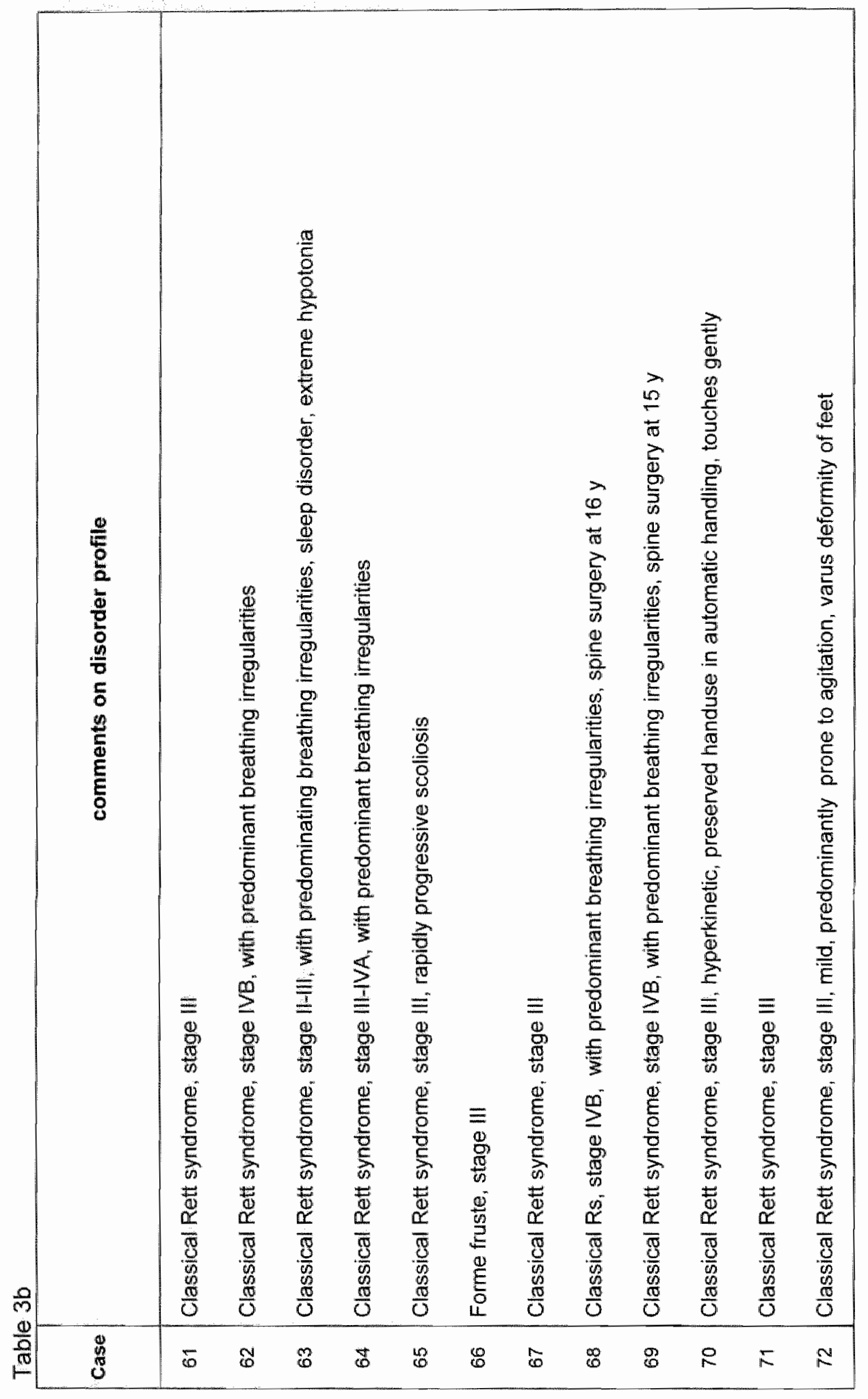




\begin{tabular}{|c|c|c|c|c|c|c|c|c|c|c|c|c|}
\hline$\frac{0}{\frac{0}{8}}$ & 0 & 0 & - & $N$ & $N$ & - & - & 0 & 0 & $N$ & - & - \\
\hline$\frac{\frac{8}{8}}{\frac{2}{2}}$ & - & 0 & 0 & - & 0 & - & 0 & 0 & $N$ & $r$ & N & 0 \\
\hline $\begin{array}{l}\frac{5}{0} \\
\frac{8}{8} \\
\frac{8}{n}\end{array}$ & $w$ & - & $N$ & $N$ & $N$ & $N$ & $N$ & $N$ & $N$ & 0 & $N$ & $r$ \\
\hline 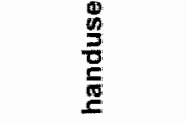 & $N$ & - & - & $\tau$ & $N$ & $N$ & $r$ & $N$ & - & 0 & $N$ & 0 \\
\hline$\frac{\text { 焉 }}{\frac{1}{3}}$ & - & 0 & $r$ & 0 & $\sigma$ & $r$ & 0 & 0 & 0 & 0 & $\infty$ & 0 \\
\hline$\frac{D}{E}$ & 0 & 0 & $r$ & 0 & 0 & - & 0 & 0 & 0 & 0 & 0 & 0 \\
\hline कू & $\omega$ & $N$ & 0 & $\omega$ & $N$ & $\infty$ & $\nabla$ & $\forall$ & $n$ & $m$ & $\sigma$ & $N$ \\
\hline $\bar{\infty}$ & $\bar{v}$ & $\infty$ & $\stackrel{\infty}{\circ}$ & $\stackrel{\infty}{=}$ & $\stackrel{M}{N}$ & N & 으 & \pm & $\stackrel{6}{=}$ & $\stackrel{\infty}{\leftarrow}$ & $\stackrel{N}{N}$ & $?$ \\
\hline $10 x$ & & & $\mathrm{p}$ & $\frac{3}{\infty}$ & & z & $\mathrm{g}$ & & & & & \\
\hline 4u||lby & $\stackrel{\theta}{\underline{\underline{F}}}$ & $\stackrel{0}{a}$ & $\stackrel{Q}{Q}$ & $\stackrel{0}{\stackrel{0}{R}}$ & $\stackrel{0}{\stackrel{\mathscr{C}}{\mathbb{F}}}$ & 扂 & $\stackrel{Q}{\alpha}$ & 啹 & 居 & $\stackrel{\partial}{\stackrel{\rho}{\alpha}}$ & 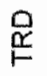 & $\stackrel{Q}{\alpha}$ \\
\hline $\begin{array}{c}\text { adKI } \\
\text { uo!je\}nW }\end{array}$ & $\stackrel{n}{C}$ & $\stackrel{m}{c}$ & $\stackrel{\infty}{E}$ & $\stackrel{\infty}{E}$ & $\stackrel{n}{E}$ & $\stackrel{\varphi}{E}$ & $\stackrel{\infty}{E}$ & $\stackrel{m}{E}$ & $\stackrel{\infty}{E}$ & $\stackrel{m}{E}$ & $\stackrel{\infty}{E}$ & $\stackrel{\infty}{E}$ \\
\hline 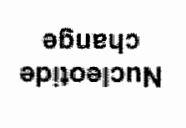 & $\begin{array}{l}\vec{A} \\
\hat{O} \\
0 \\
0 \\
\infty\end{array}$ & $\begin{array}{l}5 \\
\hat{O} \\
0 \\
0 \\
\infty\end{array}$ & $\begin{array}{l}\leftarrow \\
0 \\
\oplus \\
\stackrel{\infty}{\sigma}\end{array}$ & $\begin{array}{l}\leftarrow \\
0 \\
\stackrel{0}{\sigma} \\
\vdots\end{array}$ & 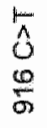 & $\begin{array}{l}5 \\
\hat{0} \\
\qquad 0 \\
\vdots \\
0\end{array}$ & $\begin{array}{l}5 \\
0 \\
\frac{1}{\infty}\end{array}$ & $\begin{array}{l}\frac{t}{0} \\
0 \\
\sigma\end{array}$ & $\begin{array}{l}\leftarrow \\
\vdots \\
\frac{0}{\sigma}\end{array}$ & 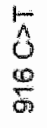 & $\begin{array}{l}\infty \\
\infty \\
\infty \\
\infty\end{array}$ & $\begin{array}{l}1 \\
0 \\
0\end{array}$ \\
\hline $\begin{array}{c}\text { ә6uey } \\
\forall \forall Z d J \exists w\end{array}$ & $\begin{array}{l}\underset{y}{g} \\
\mathbb{N} \\
\mathbb{X}\end{array}$ & 䒽 & $\begin{array}{l}0 \\
8 \\
8 \\
\mathbb{8}\end{array}$ & $\begin{array}{l}0 \\
8 \\
8 \\
01\end{array}$ & \begin{tabular}{l}
8 \\
8 \\
8 \\
\hdashline
\end{tabular} & $\begin{array}{l}y \\
\& \\
\&\end{array}$ & \begin{tabular}{l}
9 \\
8 \\
\hdashline
\end{tabular} & $\begin{array}{l}\mathscr{8} \\
\stackrel{8}{\alpha} \\
\alpha\end{array}$ & 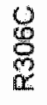 & $\begin{array}{l}0 \\
0 \\
0 \\
0 \\
0\end{array}$ & $\frac{8}{8}$ & $\frac{\mathscr{Q}}{8}$ \\
\hline 피 & $\frac{\pi}{0}$ & $\frac{6}{0}$ & $\frac{\alpha}{0}$ & $\stackrel{\alpha}{0}$ & $\frac{n}{0}$ & $\frac{\alpha}{\delta}$ & $\vec{\alpha}$ & $\vec{x}$ & $\vec{\alpha}$ & $\gtrsim$ & $\frac{\alpha}{0}$ & $\vec{\alpha}$ \\
\hline$(\mathrm{s} / K)$ "uex $\exists$ & $\infty$ & ष & g & $\overline{8}$ & 9 & 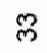 & $\mathfrak{N}$ & N & 워 & $=$ & $F$ & 용 \\
\hline (oul) 'ube!o & $\mathbb{N}$ & $m$ & $\mathscr{q}$ & 웅 & $\mathbb{N}$ & $\stackrel{9}{m}$ & 0 & in & $F$ & $\mathscr{Q}$ & $m$ & $\infty$ \\
\hline (ow) jesuo & $\stackrel{0}{2}$ & $=$ & $\mathbb{N}$ & $\stackrel{\infty}{\leftarrow}$ & $\mathbb{v}$ & $\infty$ & $\stackrel{+}{-}$ & iv & 2 & 8 & N- & 果 \\
\hline qoK & $\stackrel{\mathscr{S}}{\mathscr{S}}$ & $\stackrel{8}{\%}$ & $\stackrel{\mathbb{W}}{\stackrel{\leftrightarrow}{\circ}}$ & $\stackrel{8}{\mathscr{8}}$ & $\stackrel{\mathscr{Z}}{\mathscr{2}}$ & 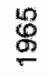 & $\frac{\infty}{\infty}$ & $\frac{\infty}{\infty}$ & 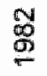 & 范 & $\stackrel{8}{8}$ & g \\
\hline 怘 & $m$ & 吾 & $\stackrel{\mathbb{R}}{R}$ & $\mathscr{R}$ & $N$ & $\infty$ & q & 8 & $\check{\infty}_{\infty}$ & 今 & 2 & 落 \\
\hline
\end{tabular}




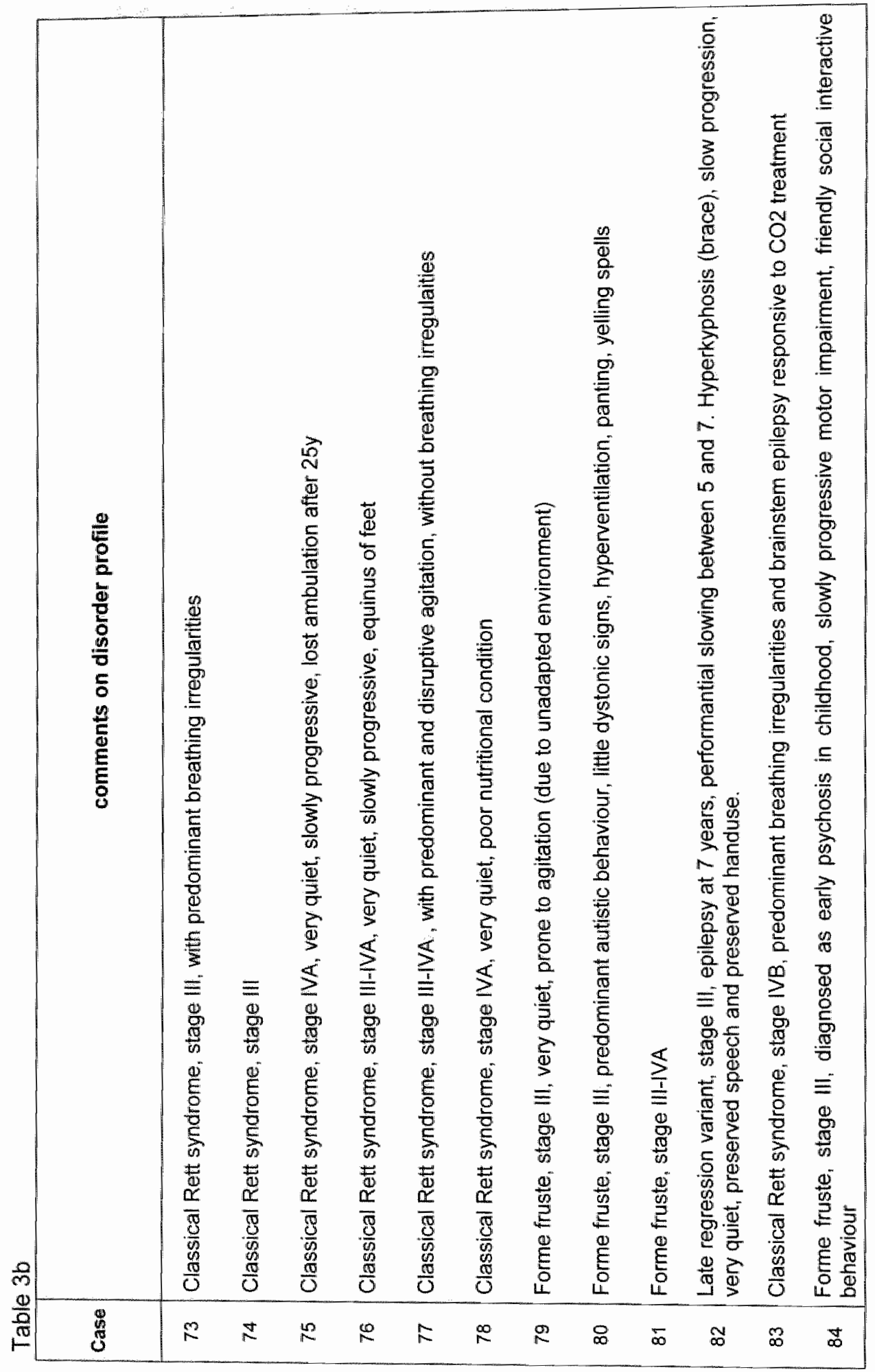




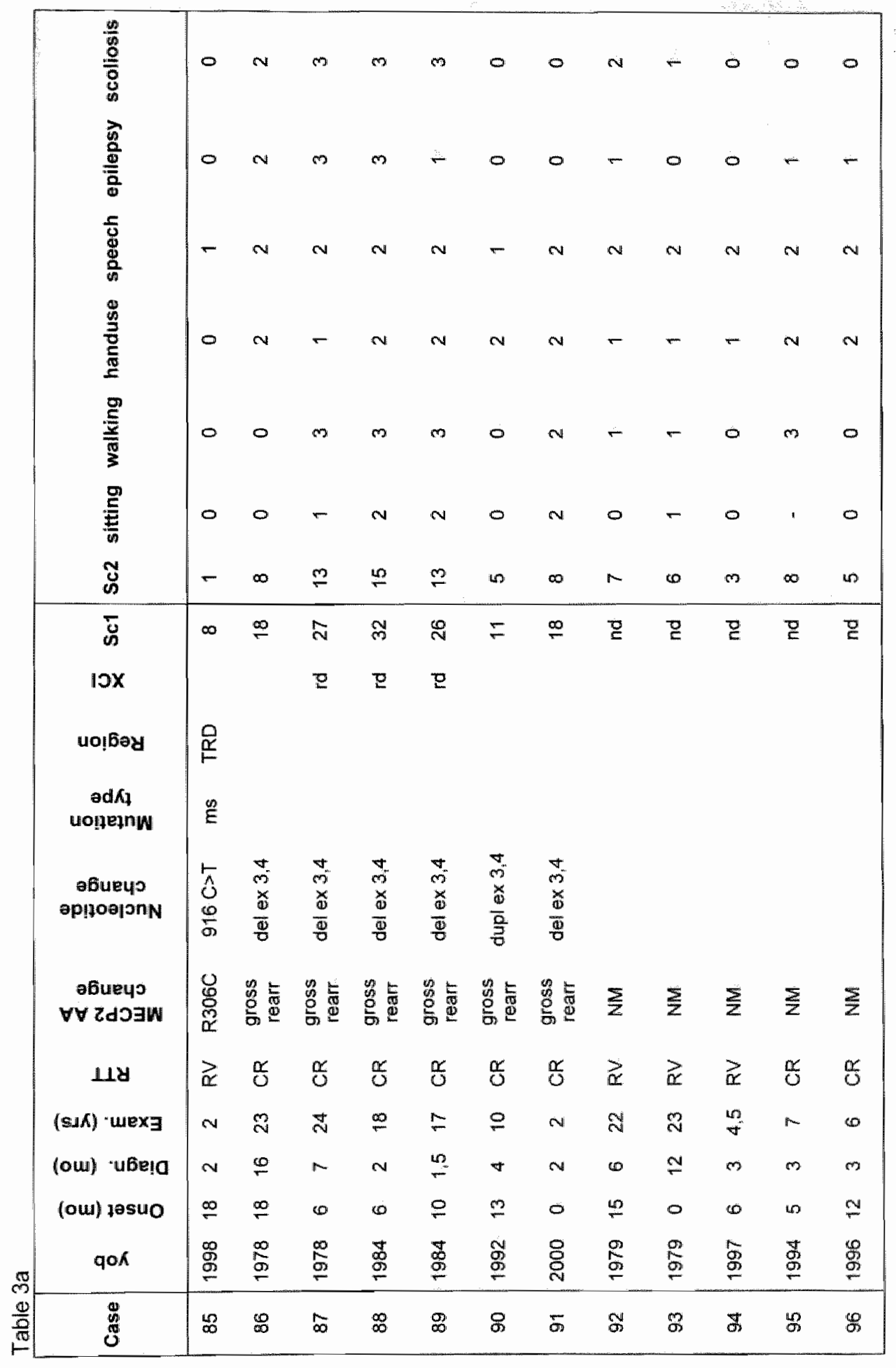




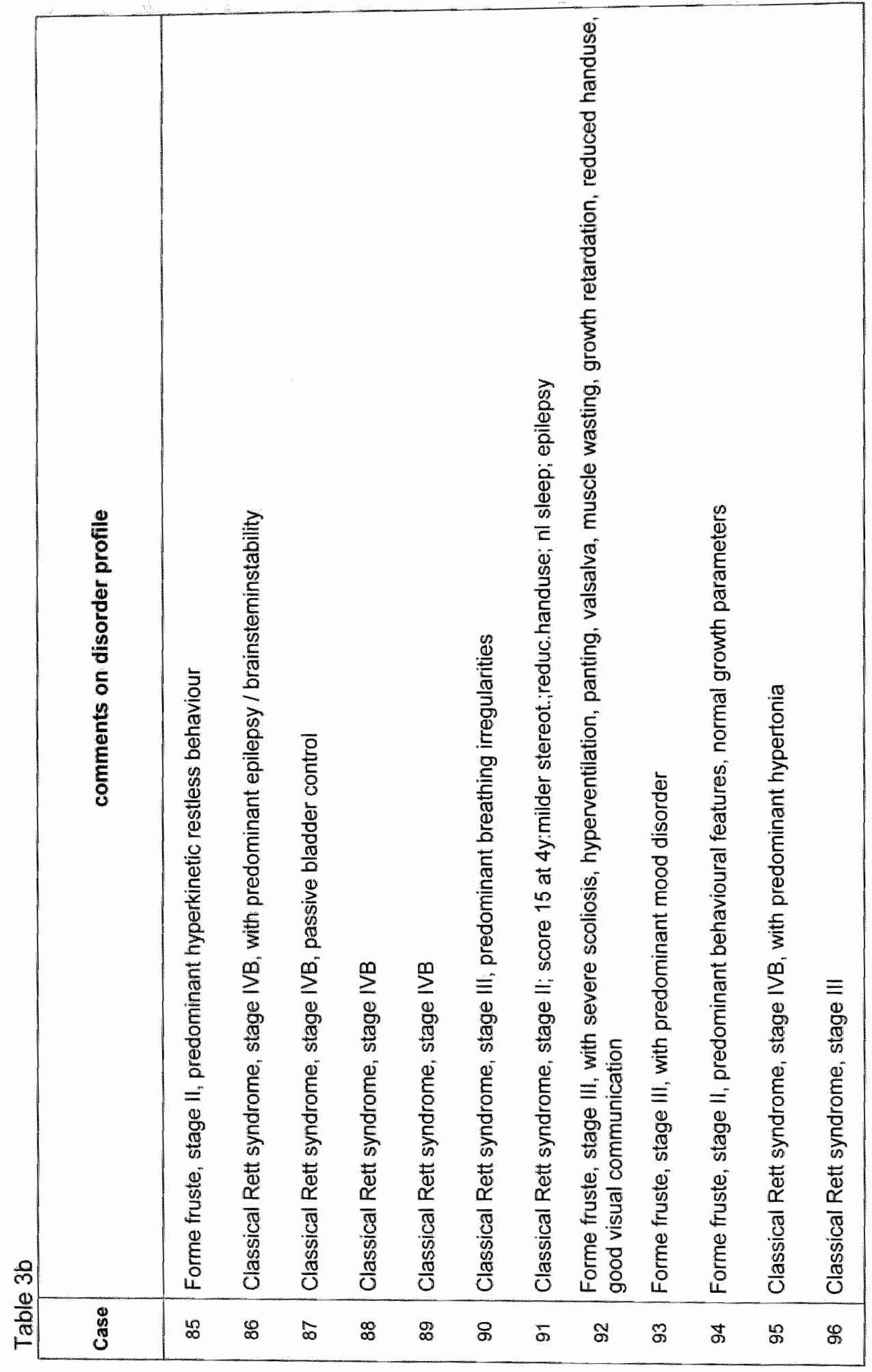




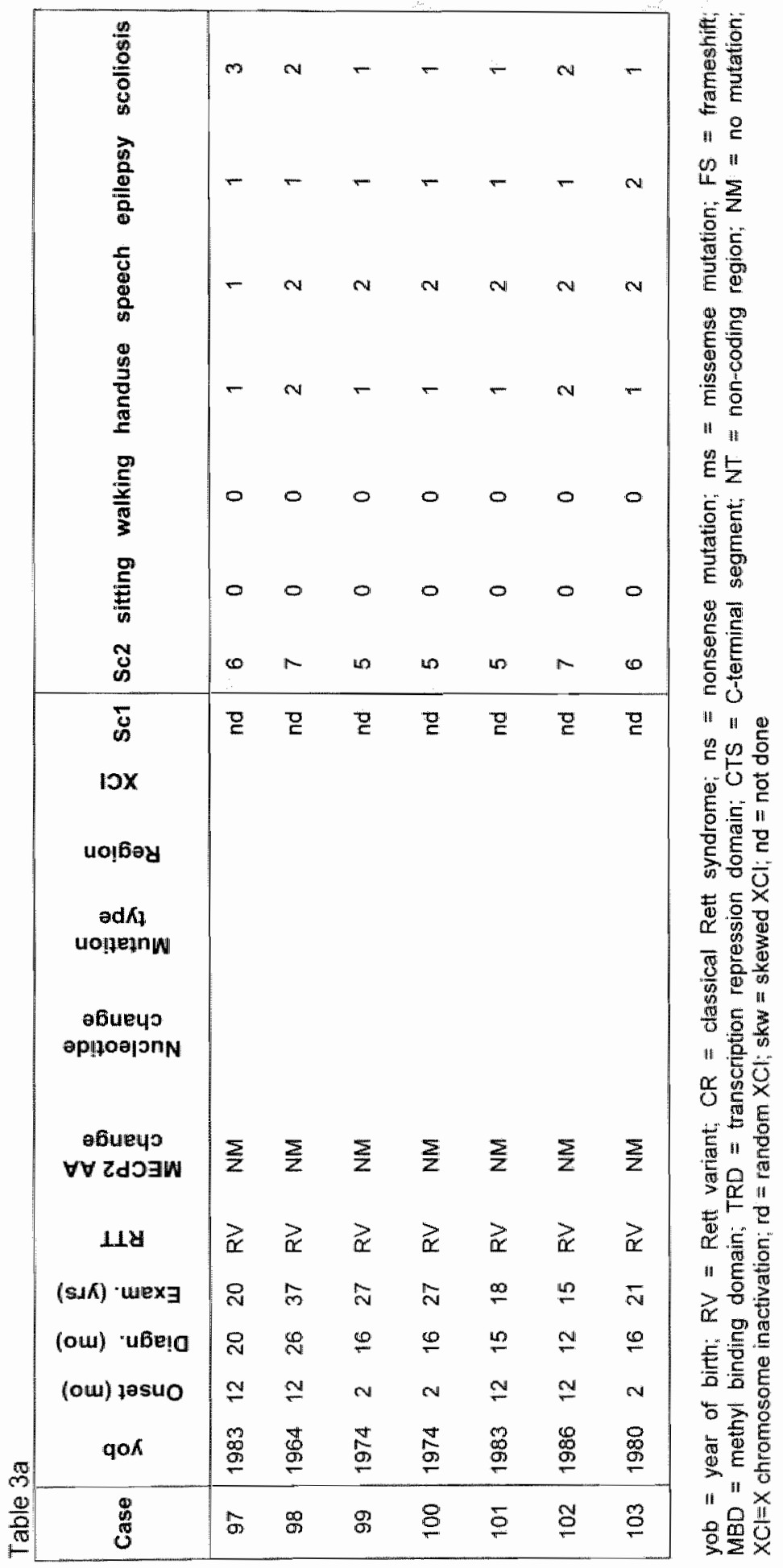




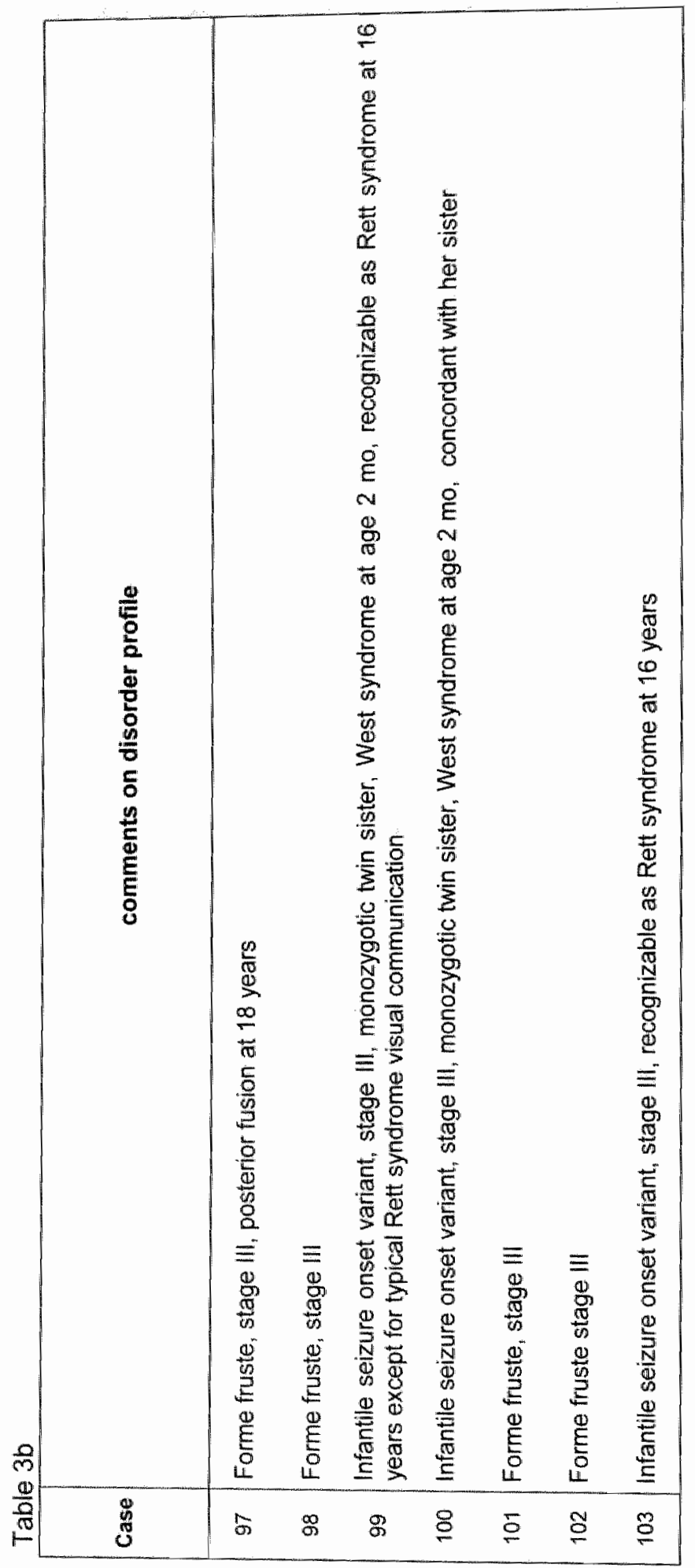


Of the 103 females with clinical Rett syndrome, $64(62 \%)$ had classic Relt syndrome and 39 $(38 \%)$ one of the variant forms. Of the latter 29 had the form fruste, 3 the preserved speech variant, 2 the congenital onset variant, 2 the late regression variant, and 3 the infantile seizure onset variant (of whom two were monozygotic twin sisters). The ages at the time of examination varied between 2 to 60 years, and $54(52 \%)$ were 15 years or older. The mean age was 16.6 years. The age distribution is shown in fig. 1a.

\section{Fig. 1a. Age distribution.}

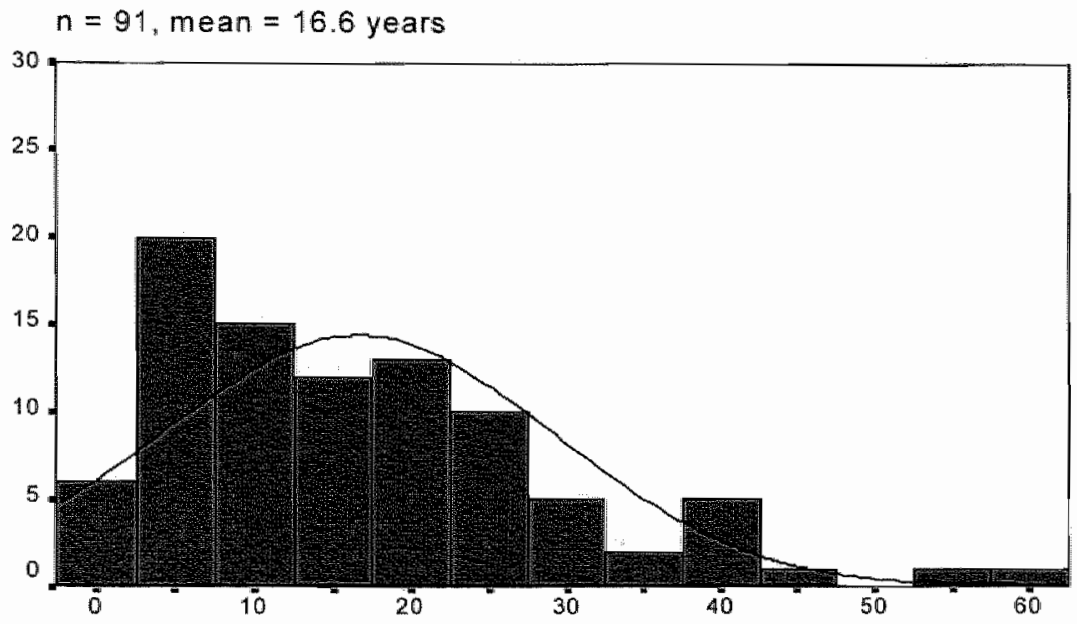

age at examination

The diagnosis of Rett syndrome was made in 52 girls between the age of 2 and 4 years of age, and clinically or molecularly confirmed above that age at follow-up. In the age group between 5 and 14 years 28 females were diagnosed for the first time. In 23 females the diagnosis was made at the age of 15 years or older: 12 with classic Rett syndrome, 2 form fruste, 1 congenital onset variant, 2 late regression variants, and in 6 without a detectable mutation.

Four females died during the periad of this study. Case 4 due to sudden death at the age of 15 years, related to a status epilepticus. Case 21 from complicated metastatic breast carcinoma at the age of 42 years. Cases 29 and 52 suffered from untreatable pneumonia at the age of 22 and 30 years respectively and were both very severely affected Rett syndrome women in a state of "frozen rigidity". 
Table 4. shows the classic and variant Rett syndrome phenotypes with respect to their clinical stage and MECP2-mutation finding, positive $(*)$ or negaitive $(-)$.

Table 4. Classic and variant Rett syndrome female phenotypes in 103 females.

\begin{tabular}{|c|c|c|c|c|c|c|c|c|c|}
\hline & \multicolumn{6}{|c|}{$\begin{array}{l}\text { MECP2 (+) } \\
\text { (n) } 91\end{array}$} & \multicolumn{3}{|c|}{$\begin{array}{l}\text { MECP2 (-) } \\
(\mathrm{n}) 12\end{array}$} \\
\hline & \multicolumn{6}{|c|}{ stage } & \multicolumn{3}{|c|}{ stage } \\
\hline$(\mathrm{n}) 103$ & 11 & $\|11-\| \|$ & 111 & III-IVA & IIVA & INB & 11 & III & IVB \\
\hline CR (in) 64 & 2 & 3 & 18 & 6 & 9 & 24 & & 1 & 1 \\
\hline \multicolumn{10}{|l|}{$R V(n) 39$} \\
\hline $\mathrm{FF}$ & 1 & 1 & $\sqrt{18}$ & 2 & & & 1 & 6 & \\
\hline PSV & & & 2 & 1 & & & & & \\
\hline $\mathrm{COV}$ & & & 1 & 1 & & & & & \\
\hline LRV & & & 1 & 1 & & & & & \\
\hline ISOV & & & & & & & & 3 & \\
\hline
\end{tabular}

All 103 had a normall female karyotype, $46, X X$, and were fragile- $X$ negative. MECP2 mutations were detected in $91(88 \%)$ of the 103 females with Rett syndrome: in $62(96,8 \%)$ of the 64 classilc cases and in $29(74,3 \%)$ of the 39 variant cases (22 form fruste, 3 preserved speech, 2 congenital onset 2 late regression variants).

Of the 12 females without detectable MECP2 mutation, 7 represented a forme fruste in stage II, 2 a classic syndrome in stage II and stage IVB with marked spasticity, and 3 the infantile seizure onset variant in stage III. They all had milder phenotypes with score 2 below 9 . Two infantile seizure onset variants are monozygotic twin sisters with absolute concordant Reft syndrome profile with normal head circumference, less autonomic dysfunction and little dystonic signs, still able to walk independently, but profoundly mentally retarded with poor visual communication.

Table 5. shows the documented types of mutations and their localization within the MECP2 gene. Figure $1 \mathrm{~b}$. Shows the age range according to the mutation type. 
Table 5. Type of mutation and localization in MECP2 in 91 RTT females.

\begin{tabular}{|c|c|c|c|c|c|c|}
\hline \multicolumn{2}{|c|}{ Type of mutation } & NT & $\begin{array}{l}\text { methyl-CpG- } \\
\text { binding } \\
\text { domain }\end{array}$ & $\begin{array}{l}\text { transcriotion } \\
\text { repression } \\
\text { domain }\end{array}$ & $\begin{array}{l}\text { C-terminal } \\
\text { segment }\end{array}$ & (n) 91 \\
\hline \multicolumn{2}{|l|}{ Missense } & $\mathrm{E} 10 \mathrm{Q}(1)$ & $\begin{array}{l}\text { L100V (1) } \\
\text { R106W (3) } \\
\text { Q128P (1) } \\
\text { R133C (5) } \\
\text { R133H (2) } \\
\text { P152R (3) } \\
\text { T158M (9) }\end{array}$ & $\begin{array}{l}\operatorname{P225R}(1) \\
\text { R306C (11) }\end{array}$ & & (n) 37 \\
\hline \multirow[t]{2}{*}{ Nonsense } & $\begin{array}{l}\text { stopcodon } \\
\text { frameshift }\end{array}$ & & $\begin{array}{l}R 168 \times(8) \\
1\end{array}$ & $\begin{array}{l}R 255 \times(9) \\
R 270 \times(3) \\
R 294 \times(8) \\
5\end{array}$ & $\begin{array}{l}13 \text { "hot } \\
\text { spot" }\end{array}$ & $\begin{array}{l}\text { (n) } 29 \\
\text { (n) } 19\end{array}$ \\
\hline & \multicolumn{5}{|c|}{ gross rearrangements encompassing exon 3 and 4} & (n) 6 \\
\hline
\end{tabular}

Figure $1 \mathrm{~b}$. Age range according to mutation type.

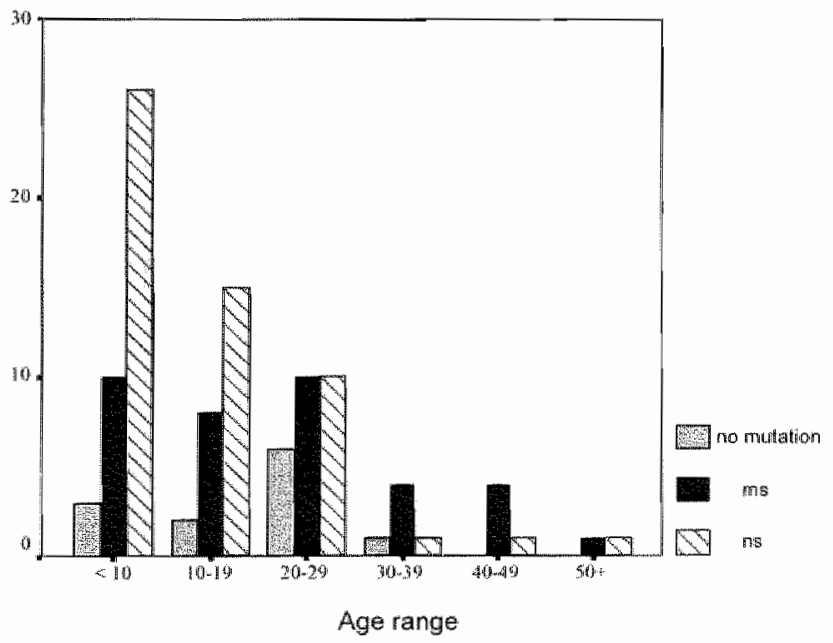


Missense mutations were present in 37 females $(40.7 \%)$ and nonsense mutations in 54 $(59.3 \%$ ). The most frequent were the recurrent mutations $\mathrm{R} 106 \mathrm{~W}(3), \mathrm{R} 133 \mathrm{C}(5), \mathrm{P} 152 \mathrm{R}(3)$, T158M (9), R168X (8), R255X (9), R270X (3), R294X (8) and R306C (11).

The R306C missense mutation was present in $14 \%$, representing the largest group of Rett syndrome females with the same mutation.

There were 13 intragenic deletions in the C-terminal segment $(14.3 \%)$ and 6 single aminoacid substitutions causing a frameshift: 1 in the methyl-CpG-binding domain and 5 in the transcription repression domain.

Gross rearrangements or larger deletion/duplication encompassing exon 3 and mast of exon 4. were documented in 6 individuals with classic Rett syndrome: 3 with severe to very severe Rett syndrome (cases $87,88,89$ )(Schollen et al., 2003) and 3 with a milder course (Cases $86,90,91$ ). Case 90 had a duplication of the region that was deleted in the others. $X$ chromosome inactivation was not studied in them.

X-chromosome inactivation was studied in 26 Rett syndrome adult women with MECP2 mutation. Six patients showed skewed $X$ inactivation with ratio's $<20 \%$ or $>80 \%$. Case 82 , as LRV was the only to present a $100 \%$ skewing. No parental materiall was available to determine which allele was preferentially inactivated in either case. The other 17 patients were classiffed as random $X$ inactivation with ratios between 20 and $80 \%$. Two patients were not informative (case 75,87 ). It was not possible to perform these XCl studies in all cases of the series under study.

In the evaluation of severity according to the obtained scores 1 and 2 only the MECP2 positive females are further discussed.

Table 6. gives an overview of severity score 1 in these 91 Rett syndrome females.

The plots are scattered in fig. 2. for score 1 and in fig. 3. for score 2 . In 11 females a very severe condition was considered because of a score 1 of 30 or more. In 16 females the condition was severe because of a score 1 of $25-29$. In 56 females the condition was mild to less severe with a score 1 between 10 and 24 . In 8 females a very mild condition scored beneath 10 . The results for score 2 were about the same: mild to less severe, < $9: 63$; severe to very severe, $>9: 28$.

Figure 4. shows the results for score 1 for the most frequently recurrent mutations in MECP2: R133C, T158M, R168X, R255X, R270X, R294X, R306C, and the C-terminal
segment deletions (CT). 
Table.6. Severity score 1 in 91 mutation positive females.

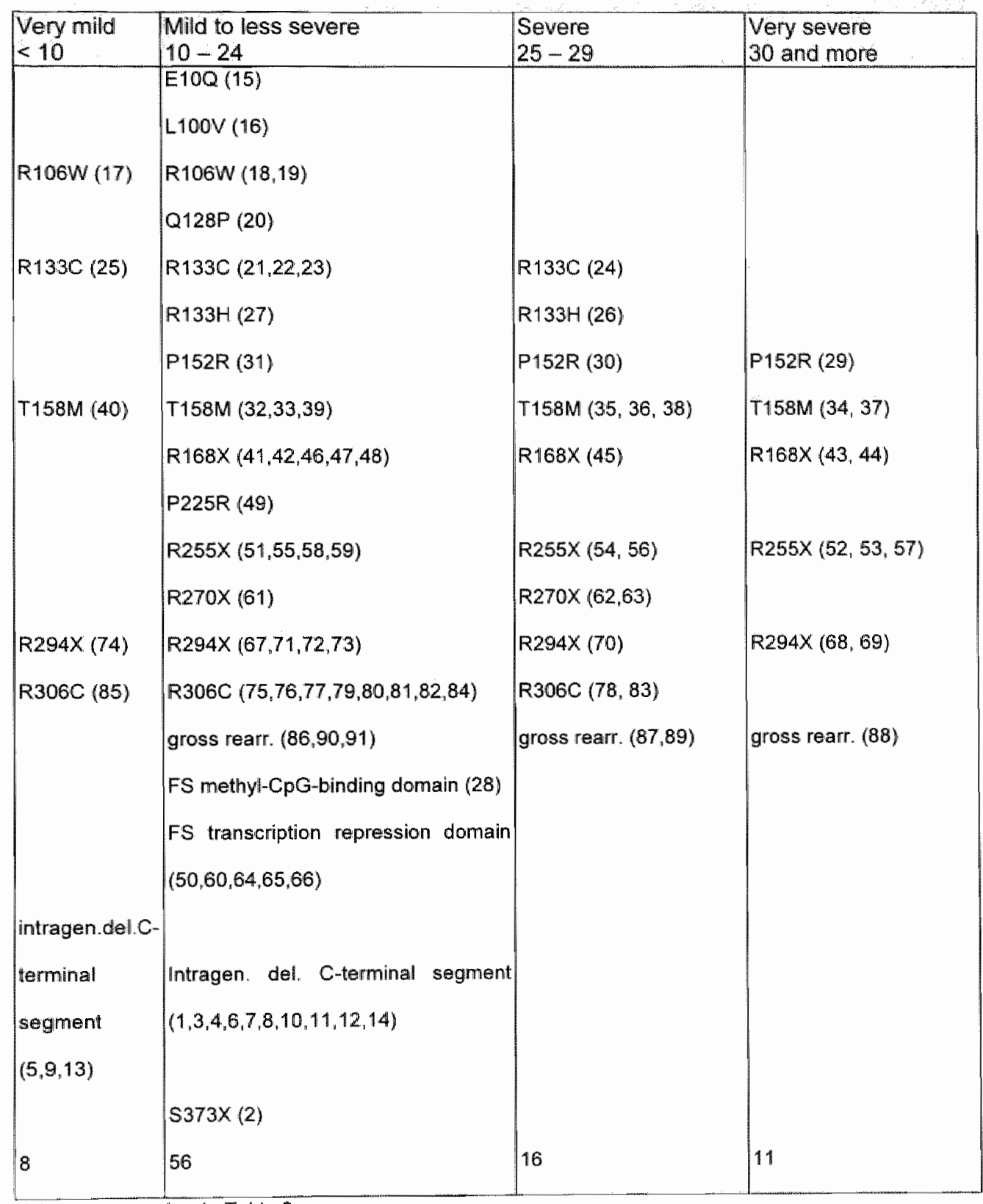

(n) = case number in Table 3 
Fig. 2. score 1 according to the age at examination.

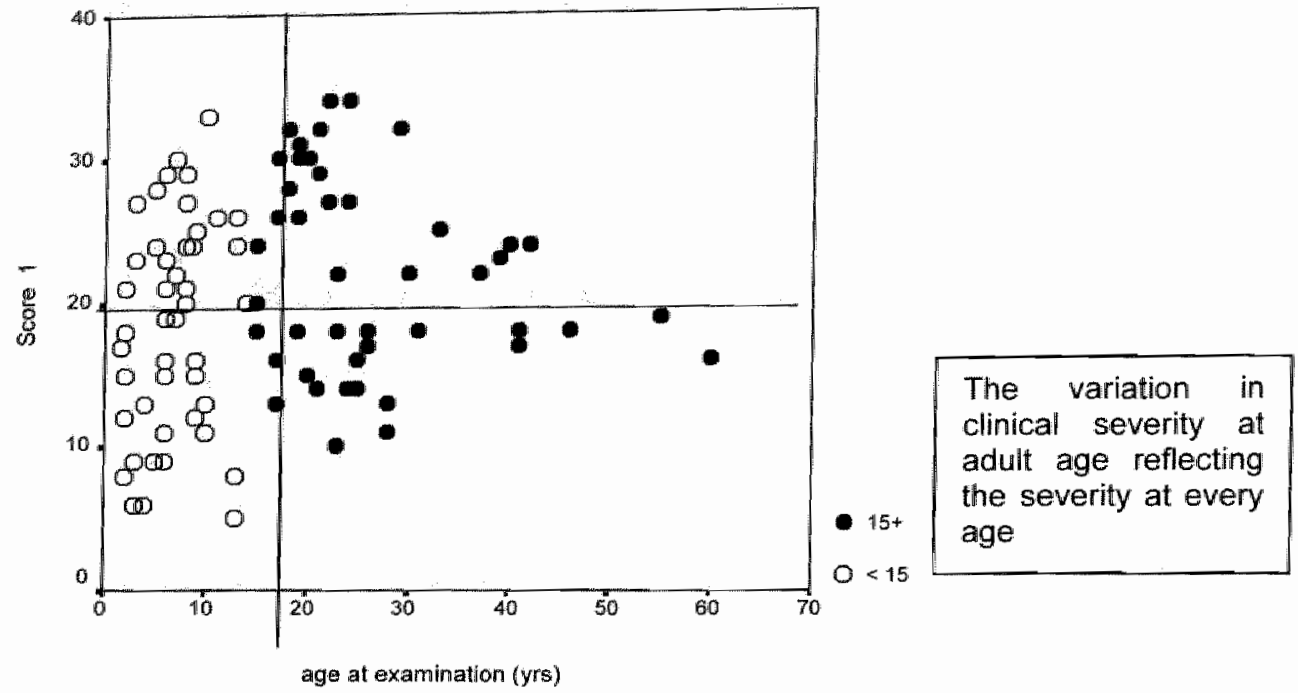

Fig. 3. score 2 according to age at examination.

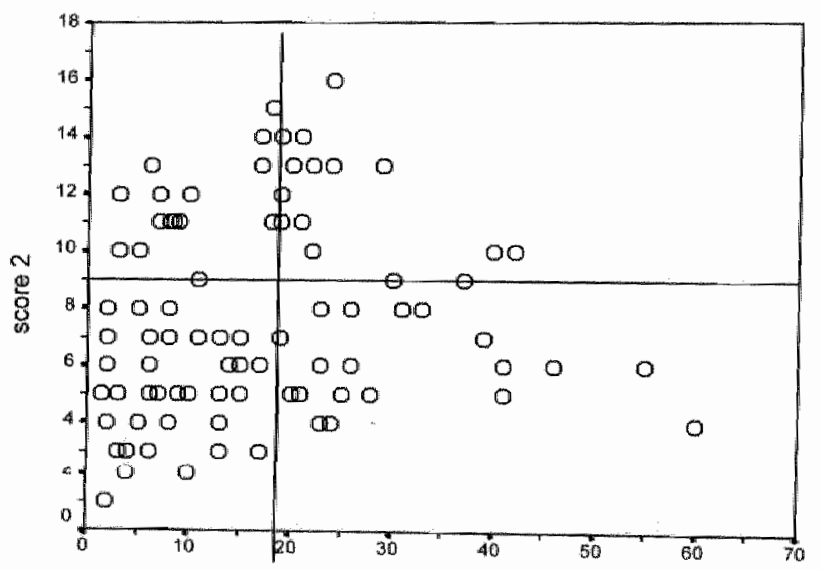

age at examination 
Of the 91 Rett syndrome females with a MECP2 mutation about $60 \%$ still sit and walk. Only $23 \%$ lost ambulation and $17,5 \%$ never walked. Handuse is preserved or reduced in $44 \%$, the remaining having complete apraxia. Speech (meaningful use of words or word sentences) was lost in the majority $(87 \%)_{1}$ and never acquired in only one

Fig. 4. Mean and range of score 1 in recurrent MECP2 mutations

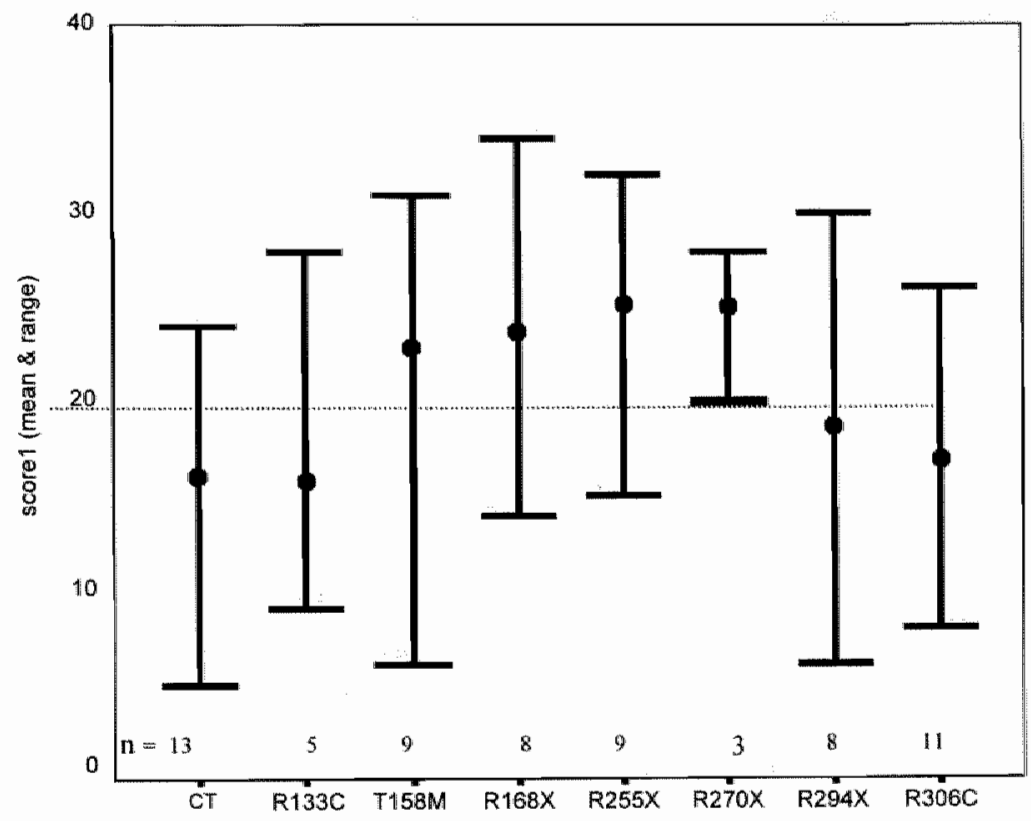


Fig. 5. Prevalence of preserved abilities in $91 \mathrm{RTT}$ females

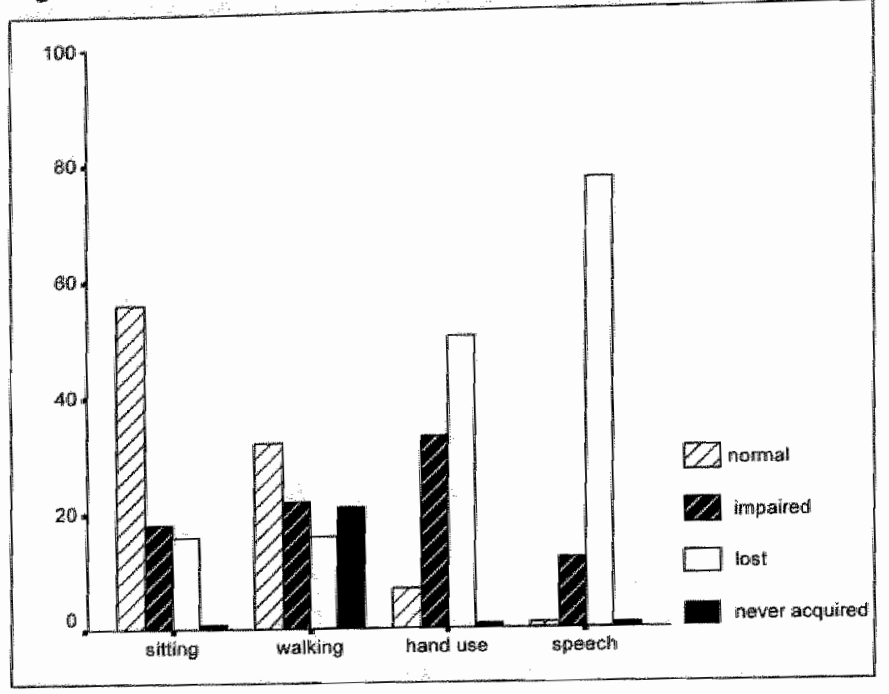

About $60 \%$ still sit and wallk. Only $23 \%$ lost ambulation and $17,5 \%$ never walked.

Handuse is preserved or reduced in $44 \%$, the remaining having complete apraxia.

Speech (meaningful use of words or word sentences) was lost in the majority $(87 \%)$. and never acquired in only one.

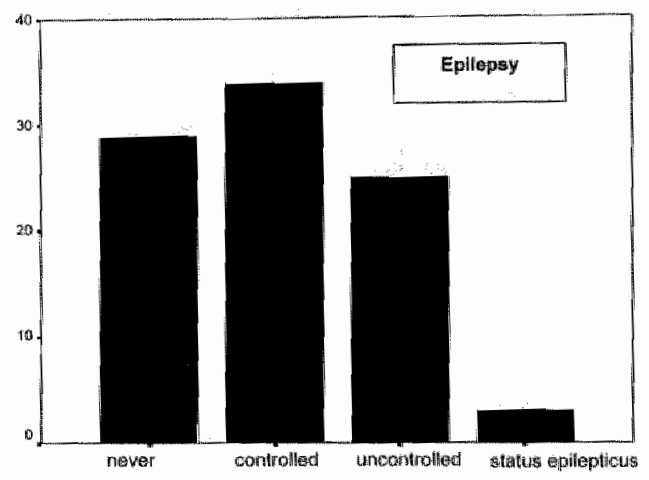

Epilepsy was problematic or uncontrolled in $30 \%$.

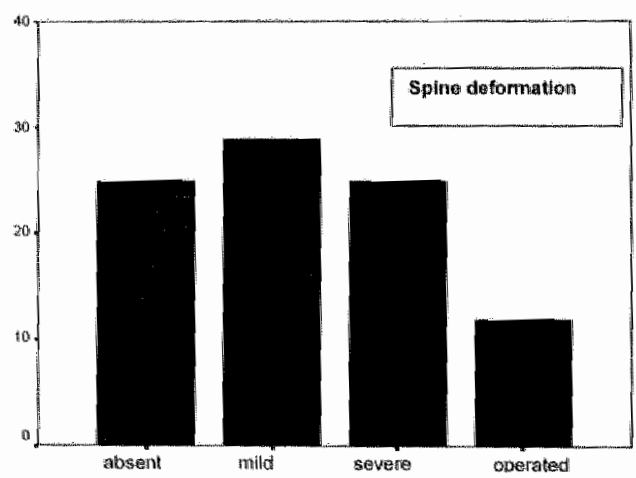

Scoliosis, severe kyphosis or a combination of both was present in $27 \%$, needing surgery in $13 \%$. 


\section{DISCUSSION}

\section{General remarks}

The present cohort of 103 clinically diagnosed Rett syndrome females contains a variation in clinical presentation from classic Rett syndrome (62\%) to variant Rett syndrome (38\%), of different ages and with variable degree of severity. The detection rate for MECP2 mutations in 91 of the 103 females $(88 \%)$ is consistent with other studies (Amir et al., 1999; Sung Jae Lee et al., 2001; Huppke et al., 2002), as is the higher detection rate in classic Rett syndrome versus the lower rate in variant Rett syndrome.

Making the Rett syndrome diagnosis for the first time in 23 females above the age of 15 years is remarkable. It indicates that many adult women with Rett syndrome, who mostly life in institutions or group homes, are either not recognized or still remain undliagnosed. 9 women $(11 \%$ ) were even 30 years or older at the time of diagnosis (cases $8,15,19,21,32$, $41,75,76,78) ; 12$ were older then 30 years at the time of the last examination (cases 8,15 , $19,20,21,32,41,51,75,76,77,78$ ). Since Rett syndrome is only recognized since 1983 some of the older adults may still remain unrecognized. On the other hand many might have not survived into their thirties, because they had been suffering much more the life threatening complications of their disorder prior to clinical recognition.

The plots of severity scores 1 and 2 (fig. 2. and 3.) did not show a big difference in overall severity according to the age at examination. There seems to be a strong linear relation between age and score values for ages under 30 . The correlation however is not that strong probably due to influence of the milder scoring older patients. The persons of adult age have relatively lower scores due to survival in a less severe condition. This supported the clinical experience that, in the long-term evolution of Rett syndrome, preservation of cognitive skills and motor abilities together with milder epilepsy and less severe spine deformation were more determining in the overall clinical severity than the other Relt syndrome manifestations.

There were 12 females, children and adults, remaining without a detectable MECP2 mutation, but with clinical compliance to at least the minimum of the diagnostic criteria. The fact that the 3 ISOV didn't show any kind of MECP2 mutation, even after the most extensive DNA analysis is also found by others (Huppke et al., 2000; Zapella et al., 2001). The ISOV at a certain age is only very similar to Rett syndrome. The future will learn that they are to be considered as a disorder with a different genetic origin (see chapter 6). The other mutation negative classic Rett syndrome and Rett variants obtained also milder to less severe clinical severity scores. They appear clinically as very similar but however different to MECP2 related Rett syndrome, and they were also excluded from Angelman syndrome. Because of a slow protracted course they were defined as form fruste in 7 females. Case 95 is extremely hypertonic but without contractures and never walked. She developed microcephaly "but never presented a problematic epilepsy or any aulonomic dysfunction. Only the 91 females with a documented MECP2 mutation in this cohort will be discussed further.

\section{Grouping by type and localization of the MECP2 mutations}

Since the identification of mutations in MECP2 in girls and females with apparent Rett syndrome, numerous efforts have been made to search for phenotype-genotype rellationships by looking at the type and locallization of these mutations in the gene in relation to clinical severity. Many of the MECP2 mutations in this cohort are recurrent mutations that are listed in the actual database (www.rettsyndrome.org). They account for most of the Rett syndrome cases and consist of missense (single amino acid substitution) and nonsense 
(stopcodon and frameshift that truncate the protein) mutations. Missense mutations cluster in the methyl binding domain and nonsense mulations cluster in the transcription repression domailn.

In general it is indicated that in females with MECP2 mutations missense mutations cause millder phenotypes and nonsense mutations lead to a more severe phenotype. Studies around this correlation however have produced conflicting results (Amir et al., 2000; Cheadle et al., 2000; Hoffbuhr et al., 2001; Monros et al., 2001; Huppke et al., 2002). Some have found more severe Rett syndrome manifestations in children with nonsense mutations but milder expression in the nonsense mutations located at the deletion hot spot in the Cterminal segment (Huppke et al., 2000; Smeets et al., 2005). This is explained by the hypothesis that these "late truncating" mutations do not involve the nuclear localization signal and therefore leave residual function to the protein. Others have not found this difference in severity (Amir et al., 2000).

In this series 1 missense mutation is located in the $\mathrm{N}$-terminal (case 15). The others, except for the R306C, are located in the methyl-CpG-binding domain. They led in general to $a$ milder phenolype even in the adults above 29 years of age. Nevertheless severity ranged through ages from very mild to very severe. The $\mathrm{R} 306 \mathrm{C}$ mutation is the only recurrent missense mutation in the transcription repression domain and the most frequent single mutation in this series (14\%). We will discuss the phenotype further in this chapter. Cliniical severity in the 1 frameshift and the 8 R168X stopcodon mutations, as the only nonsense mutation in the methyl $\mathrm{CP} \odot$ binding domain, varied from mildly affected to very severe in some adult females.

The nonsense mutations $\mathrm{R} 255 \mathrm{X}, \mathrm{R} 270 \mathrm{X}, \mathrm{R} 294 \mathrm{X}$ in the transcription repression domain represent all together $22 \%$ of the MECP2 mutations; all presented with a severe to very severe classic Rett syndrome above 15 years of age, except for case 51 (R255X) and for case 67 (R294X). Other nonsense mutations caused by frameshift mutations in the transcription repression domain were found in 5 children ranging in age from 2 to 15 years. Case 60 and case 64 were on the edge of being severely attended at age 13 and 15 years respectively. It is noted that these nonsense mutations were dropping fast in number above the age of 29 years (fig. 1b). Therefore the severe classic Rett syndrome women with these nonsense mutations probably rarely survived their thirties until now.

The 13 females with intragenic deletions in the C-terminal segment represent the largest group in this series. These deletions cause a frameshift that truncates the protein at its $\mathrm{C}$ terminal and are thus nonsense muttaions. The percentage of $14,2 \%$ is high but also consistent with the finding in literature (Wan et al, 1999) indicating the high mutation susceptibility of this region between position 1050 and 1200 . This region is a "hot spot" in MECP2 for these late truncating mutations. They all showed clinically a very variable but never severe phenotype and are also discussed further.

It was thus unsatisfying, in view of the age range and variable severity scores, to look only at the type and localization of the mutation in MECP2 in trying to establish a clear phenotypelgenotype relationship. Using type of mutation and localization in the gene logether with clinical severity at the time of examination as variables in the study of genotype-phenotype relationship remains particularly troublesome in predicting the outcome of a specific MECP2 mutation found in a young girl. A girl with mild classic Rett syndrome and one with a forme fruste may not differ much at e.g. 4 years, except for the decline in head circumference, and behavior. The variants where age of onset or preservation of speech are dominating the disorder profile may be or become classic in many ways, mildly or severely affected with advancing age. Some of the milder form fruste stay as such far into adulthood, with slow neuromotor impairment, cognitively alert and still learning about their surroundings and new persons they come in touch with (Hagberg et al., 2003; Smeets et 
al 2003 ; Smeets et al., 2005). Severity thus changes with age, but not necessarily for the worst.

\section{Groupüng by long-term disorder profile}

In the present cohort of 103 Rett syndrome females, 91 had a detectable MECP2 mutation. By describing each Rett syndrome individual on the long-term grouping of females with the same MECP2 mutation having a similar disorder profile or a similar if not the same disorder history was a clear option.

The inherent clinical variability in Rett syndrome combined with the inconsistent application of diagnostic criteria for classic Rett syndrome and the subjective application of scoring systems in females of different ages complicates the comparison of data between studies. This makes it difficult to distinguish more specific genotype-phenotype relationships. The milder or less severe classic and variant Rett syndrome at adult age reflect the variation in clinical severity in presentation at all ages, and probably have different courses throughout childhood into adult life. The fact that milder or variant forms of Rett syndrome until now are defined according to preservation of skills or to time of onset seems not helpful in understanding this variability or why they evolve as such. Since Rett syndrome "whether congenital or as late onset, with or without limited speech, still is recognizable as Rett syndrome, and may even be found to become "classic" at a certain stage or age. Therefore the complete depiction of each individual with all of its manifestations on the long term and by grouping them according to this profile, will contribute more to our understanding of the phenotypic severity and the ongoing pathology in relation to the kind of MECP2 mutation. More over it might help to distinguished between or to discover other" etiologies of "new" developmental disorders that are similar or very adjacent to the Rett disordler.

Some profilles are given below as examples of this approach.

The R255X, R270X and R294X stopcodon mutations, as nonsense mutations in the transcription repression domain, cause a classic Rett syndrome history and profile. The highest mean score 1 was obtained in the R255X and R270X, and the range in severity score 1 was larger in the R294X. Numbers are probably to small to distinguish between nonsense mutations that include the nuclear localization signal, (TRD-NLS) like the R255X and the $R 270 X$, and those in the rest of the transcription repression domain (R294X and Cterminal segment deletions). Although a milder disorder profile is said to be found in the R294X- transcription repression domain - mutation (Colvin et al., 2004), we could not confirm this. We prefer to define them all as typical examples of a classic Rett syndrome disorder profile. Survival beyond 30 years in this group of stopcodon mutations is rare. They present many if not all the characteristic manifestations of the syndrome. Clinical diagnosis is often suspected before the age of 2 years and confirmed by rapidly increasing clinical severity with advancing age.

The same long-term profile of severe classic Rett syndrome is also present in the three females with the P152R missense mutation located in the methyl-CpG-binding domain. This mutation causes classic Rett syndrome becoming severe in young adolescence. It was encountered in three females with severe classic Rett syndrome at adult age. Case 29 could still walk when she was institutionalized at age 6 years. At the age of 16 years she was bedridden with severe scoliosis and recurrent pulmonary infections and distress. She died when she was 22 years old in at state of frozen rigidity. Case 30 was diagnosed at the age of 2 years and developed severe classic Rett syndrome, stage IVB at age 19 years. Case 31 was diagnosed in infancy as classic Rett syndrome at the age of 2 years. She lost ambulation by the age of 5 years. Her Rett syndrome manifestations, scoliosis and irregular breathing, are rapidly evolving. We did not encounter females above 22 years with this mutation. The P152R missense mutation in the methyl-CpG-binding domain is responsible for a severe classic Rett syndrome, as severe as the nonsense mutations R255X, R270X and $R 294 \times$ located in the transcription repression domain. 
The T158M missense mutation in methy CPG binding domain was present in 9 children and adults and is very common in Rett syndrome. All were very lively with hyperactive and odd behaviors in childhood with a relatively slow protracted course into adolescence. Ambulation is relatively well preserved far into adulthood in spite of persistent axial hypotonia and slowly developing kyphosis and/or severe scoliosis. Case 32 lost ambulation when she was 30 years of age and was operated for scoliosis when she was first diagnosed at age 41 years. She did not regain walking after surgery. Very little was known about her history, since her parents had demented, and she had posttraumatic cataract due to automutilation. Case 33 was initially diagnosed as brain damaged due to lead poisoning. As a hyperactive toddler she bite the paint from the doors. In 1983 she was diagnosed as classic Rett syndrome. They all have predominant eplepsy and/or obvious breathing irregularities but no vacant spells. Sewerity scores slowly climb higher with advancing age and ambulation is lost in adulthood. The profile in infancy is more atypical becoming classic in adolescence.

The R133C genotype is the best known to cause often very mild Rett syndrome. The 5 females in the series of this study had a predominantly behavioral phenotype. All but one (case 24 ) remained milder attended. As infants they were suspected of a pervasive developmental disorder with hyperactivity and autistiform behavior. In childhood dystonic features were discrete and they we defined as forme fruste because of normal head circumference and slow protracted course. Their behavior remained hyperkinetic, playful and joyful, with bouts of unexplained yelling, and with the preservation of a good general physical condition. Except for case 24 suffering from severe scoliosis that could not be treated causing her to loose postural control as an adult. Case 21 died from metastatic breast carcinoma. None used words or phrases but apparently understood some of the routine conversation. None presented visible breathing irregularities or other signs of autonomic dysfunction. Epilepsy was either never present or well controlled by medication. They obtained the lowest scores because of their good clinical history and physical condition still recognizable as Rett syndrome. Others described the milder phenotype in females with this R133C missense mutation presenting more preserved hand use and speech ability (Zapella et al., 2001; Leonard et al., 2003). Case 21 showed skewed $X$-inactivation (XCI) but did clinically not differ in severity from case 22 and 23 that had random patterns of $X \mathrm{Cl}$.

The R306C missense mutation is very common in Rett syndrome and the only recurrently occurring in the transcription repression domain. Females with this mutation have a most interesting profile since they are often defined as forme fruste in childhood and as classic Rett syndrome in adulthood. The main characteristic seems to be the slow progression of neurological signs with marked spasticity in the lower limbs, from tiptoe walking in infancy evolving to fixed equinus feet (Smeets et al., 2003; Colvin et al., 2004). They never developed epilepsy or became seizure free on medication. The spine deformation was mild requiring no bracing or surgery. Walking in these women became impaired because of slowly progressive spasticity in the lower limbs causing the spine to bent with severe kyphosis and imbalance at an older age. They remained however, relatively stable through adolescence into adulthood, even above 40 years of age. They are remarkably quiet in their behavior although the youngest was prone to agitation due to an unaccepted surrounding where she had to manifest herself. Case 83 is scoring as severe because of problematic breathing itregularities. Her history and management are described in addendum 3 . But phenotypically she is like the other females with R306C mutation.

The C-terminal segment hot spot deletions represent as a group more then $14 \%$ of this series. The course of their disorder in all cases was more protracted in time, with more preserved cognitive abilities in adolescence and adulthood. Their main clinical problem was a rapidly progressive spine deformation due to dystonia and asymmetrical posturing from childhood on. With advancing age they became imore impaired in walking, at least slower and more passive in general motor performance. They developed more inappropriate hand use and tended to use less verbal expression (in presenved speech variants). This slow neuromotor regression together with the smaller stature (as expected in classical Rett 
syndrome), the rigid posturing with pronounced kyphosis or scoliosis, the abtotrophic changes in skin and underlying muscles, gave them a "pre-aging appearance" at least llooking older than their chronological age. In contrast with this decline in motor performance was the preservation of simple communicative and cognitive abilities. These females were still able to recognize and to learn about new persons and situations in their daily surrounding far into adult life. Hagberg et al. (2003) described such a single case of CTS hot spot deletion and refers to the ongoing neuromotor impairment as a decline "at the outputside" in contrast to a better functioning "at the input-side". This may account however for every Rett syndrome person, but becomes more surporising in the initialy milder, atypical cases. The long-term profile of these CTS intragenic deletions is furhter described and discussed in more detail in addendum 2.

\section{CONCLUSION}

Application of the international diagnostic criteria by clinicians involved in the clinical evaluation is primordial not only for diagnosis and follow-up but also for the implementation in larger phenotype-genotype studies as well. Clinical diagnosis remains however difficult in infants and young children and needs confirmation by evolution according to these diagnostic criteria that can only be fulfilled around the age of 4 years. The availability of molecular testing may however lead to early confirmation of clinical suspicion of Rett syndrome in an infant.

The guidelines for reporting on the manifestations common in Rett syndrome is a practical tool in the evaluation of severity in clinically diagnosed Rett syndrome females. It is recommended that it should be used uniformly by all clinicians involved in the study of Rett syndrome to facilitate comparison between different studies Nevertheless this scoring system, as all others $_{n}$ is prone to subjective interpretation. On condition that the same experienced clinician does the successive evaluations it contributes to a uniform approach in clinical follow-up. Scoring only the preservation or loss of gross motor abilities, speech and hand use, and secondary manifestations like epilepsy and spine deformation (score 2) is sufficient for the evaluation of overall severity at the time of examination between the different Rett syndrome females with different MECP2 mutations. It is however of lesser value in predicting the outcome or the prognosis of single mutation types that may lead to a higher death rate above the age of 30 years in some specific mutation types.

Older Rett syndrome women above the ages of 30 to 40 years have survived longer because of a milder disorder profile we do not know enough about yet. One should be aware that they still remain underdiagnosed. The clinical presentation of Rett syndrome symptoms in these women becomes less dominant or simpler, and problems with epilepsy and breathing irregularities have become less prominent. The awareness of clinical variability should bring a higher diagnostic yield in this age group througl MECP2 analysis (addendum 1). We did not encounter Rett syndrome in females above 33 years with stopcodons and frameshifts as nonsense mutations, apart from the CTS intragenic deletions.

In the present cohort of 103 females with clinical Rett syndrome the MECP2 detection rate was high in both classical and variant phenotypes. We confirm that Rett syndrome females with nonsense mutations in general have the more severe and classic Rett syndrome phenotype, already at younger age. And most of the Rett syndrome females in relatively good physical and neurological condition at adult age had missense mulations of different locations in the gene or deletions in the C-terminal segment as late truncating nonsense mutations.

We discovered further that different profiles in development and behavior existed by describing the clinical history and behavioral manifestations as accurate as possible, and by comparing the individual clinical and molecular data according to this long-term history. Therefore grouping of individuals with the same mutation (type and localization) and according to the long-term history learns more about the phenotype-genotype relationship. 
than looking only at type and localization of the mutation in the gene. The females with the frequently recurrent $\mathrm{R} 133 \mathrm{C}$ and $\mathrm{R} 306 \mathrm{C}$ missense mutations and those with intragenic deletions in the C-terminus of MECP2 deserve more attention in larger studies because they seem to develop differently on the long term and stay "milder" far into adult life. This accounts also for the missense mutations P152R and $T 158 \mathrm{M}$ that lead to classic Rett syndrome very fast and severe in the first and more protracted in the latter. 
Early intervention and comprehensive life long management has a significant impact on the health and longevity of affected Rett syndrome individuals. Good management requires the involvement of a multidisciplinary team consisting of many different medical and paramedical specialists and the development of an individualized approach. Parents are critical members of this team, as they become the greatest experts concerning their own child's history, behavior and needs.

Many of the suggestions and recommendations described below are the result of over 20 years personal experience together with a review of international scientific expertise (Smeets and Schrander-Stumpel, 2005). 


\section{GROWTH AND FEEDING}

Physical growth retardation and feeding problems are common features of Rett syndrome. Height, weight for height and head circumference are important parameters to follow up on standard growth charts. Affected girls have a birth weight and length within the normall range for gestational age. Deceleration of linear growth happens during the first two years of life. Later on, height and/or weight for height often fall 2 standard deviations below those of healthy children. The mechanisms causing this growth failure are poorly understood and the role of MeCP2 in physical growth is yet to be investigated. Both nutritional and nonrutritional factors are thought to contribute and it has not been possible to develop efficacious intervention strategies (Reilly and Cass, 2001). There is no evidence that growth retardation in Rett syndrome is caused by growth hormone deficiency, although disturbed hypothalamic control cannot be excluded (Huppke et al., 2001). No treatment of growth retardation is indicated as it is genetically determined and influenced by the neurodevelopmental condition. The rate of hand and foot growth , particularly the latter, of girls with Rett syndrome is slower than that of the normal female (Schultz et al., 1998). The fourth toe is often seen as shortened or higher implanted (fig. The small stature in adult Rett syndrome women, together with the dyspraxic gait, the spine deformity with kyphoscoliosis, the muscle wasting and the abiotrophic aspect of the skin and subcutaneous tissue makes them actually look older than they really are. And in many instance one can get the impression that they seem to age more rapidly (Hagberg, personal communication; Smeets et al. 2005). This suspected relation between MECP2 and "pre-aging" in Rett syndrame needs further attention.

Girls with Rett syndrome love to eat. They like to watch when meals are prepared and are very alert at feeding time. Some girls, especially the younger ones, will even have a tendency to overweight and need monitoring of weight because of inadequate or excessive intake. The development of primary mouth functions like chewing and swallowing is often delayed and problematic. Most of the girls have reduced movements of the mid- and posterior tongue, with premature spill over of food and liquid from the mouth into the pharynx (Motil et al., 1999). They also show delayed pharyngeal swallow, but otherwise pharyngeal problems are minimal. Those individuals with the most neurological impairment tend to have the worst feeding problems and become prone to malmutrition. Assessment of caloric intake is therefore important, and the influence of involuntary movement activity, abnormal breathing patterns and epilepsy on the balance between nutritional intake and energy expenditure should be considered. Various nutritional intervention strategies should be investigated to reduce and if possible, prevent malnutrition and wasting in affected persoms. Gastro-esophageal reflux is frequently present, and together with air swallowing and constipation, interferes with effective oral feeding. When severe swallowing problems and/or insufficient intake is present, affected females often require a gastrostomy-button for feeding or are put on caloric supplements. Because of the greater time spent in involuntary motor movement, energy expenditure associated with activity is greater in girls with Relt syndrome and the energy balance is less positive.

\section{DEVELOPMENT AND BEHAVIOR}

Commumication: all girls with Rett syndrome are mentally retarded. The absence of speech in most of them, the dyspraxia and the short attention span with lack of interest in play, make developmental testing a difficult task. They are more interested in persons than in objects and seem to perform better with music therapy. Formal developmental assessment needs more time than usual because of the latency period they need in producing a reaction. Evoked response study through auditory and visual stimuli has clearly established 
the difference in processing especially through the visual pathway were Rett syndrome girls produce a latent response, a latency that seems to expand in the adult (Stauder et al., submitted 2004). In the long lasting stage III of "wake-up" and "pseudo-stabilization", parents become experts in understanding and recognizing the needs and wishes of their daughter. Evaluation of communicative abilities should include careful observation and questioning of parents and caretakers. Affected children try to establish wisual contact by intense staring. They look at you and want to be looked at. Young girls may even force the parents to turn their face towards them. They "speak" to each other "through" the eyes. Girls with Rett syndrome are able to make choices and take causally related action. Therefore parents and caregivers should be aware that the time they require to show what is wanted or to produce an answer to a specific situation is prolonged. This intense eye contact behavior is further accentuated in older affected females in a typical eye-pointing behavior that expresses needs and wishes. It remains present even in the most severely affected female. This intense eye contact and eye-pointing behavior is very distinct and separates Rett syndrome from other severely mentally retarded or autistic females. Alternative communication methods are used to capitalize on this visual communicative ability. During therapy sessions agitation and distraction are to be avoided as much as possible and gently immobilizing the hands may contribute to quality of the interaction. Some girls have preservation of speech or use words and sentences in a meaningful way. Some of them continue to learn new words and names far into slage III and into adulthood. Gradual loss of this speech ability usually coincides with the point at which walking stops and transition is made into stage IV. It is the overall impression of parents that their daughters actually understand more of the ongoing conversation than is generally considered possible. In relation to their significant retardation of development, this comprehension is probably situation-based or related to the facial expression and emotional attitude of the adult. Girls and adults in stage III! are joyful and alert. Some of them like to tease people and to gently feel with hands and feet in playful body contact. Others reject physical touch of particular body parts. Some get agitated when they feel unsafe. Their preference for male caretakers or visitors is well known and confirmed by the parents. In some of the females with variant Rett syndrome autistic features predominate. Odd behavior, attention deficit and hyperactivity are common, but after careful observation these behavioral characteristics are found in combination with an apparent change in muscle tone or hidden dystonic features.

Intense handstereotypies disturb communicative interaction through distraction and agitation. They cause difficulty in concentration on objects for a long time. By forcing the girls to stop the arm and hand movements by gently fixing the elbows or by bracing them during sessions of interaction, the child will appear more quiet and concentrated. In this way, some girls will be more cooperative in the individual occupational sessions. Braces in soft but resisting materials can be used. In case they cause agitation, they are to be abandoned.

Screaming spells. Some toddlers, teens and even adults experience periodic sudden violent screaming. They are often associated with extreme pain but no specific organ pathology is present and thorough examination does not reveal any somatic abnormality. This is not an epileptic phenomenon but rather is defined as "brain-pain-crying", and can last for hours. Others are abnormally prone to agitation and scream when they do not feel safe for whatever reason. The situation returns to normal when moments of rest and peace are given. Reflux esofagitis or constipation should be ruled out and eventually treated in case of discomfort.

Sleep abnormalities. Disturbed sleep is more or less pronounced and a constant fealure of Rett syndrome. Night laughter, prolonged wakefulness or early morning waking causes great concern for the parents, especially in young preschool girls. These problems may persist into adult life. Night laughter clearly does not disturb the child. The fact that affected children and adults are prone to short periods of daytime sleeping is seen as a need for recovery. The mechanism behind this disruptive night awakening and daytime sleeping is not yet well understood. It might be related to the other autonomic dysfunctions that are 
associated with midbrain and brainstem immaturity. Melatonin appeared to improve total sleep time and sleep efficiency in the girls with the worst baseline sleep quality (McArthur and Budden, 1998; Miyamoto et al., 1999). Pipamperon can be used as a regulator of circadian thythm (personal experience) with little sedative side effects. It mainly acts as a serotonin-antagonist, with litte adrenolytic and antidopaminergic action.

Impaired nociception. Insensitivity to pain is often seen in Rett syndrome, and is sometimes confined to specific body parts. Rarely, the skin can present with easy bruising and blister formation, especially in severe classical Rett syndrome. These lesions are different from decubitus wounds. Impairment of pain perception probably explains this delayed sensitivity to pain.

\section{EPILEPSY}

Epilepsy is present in up to $80 \%$ of affected girls at some time in their lives (Steffenburg et al., 2001). It usually starts after age 4 years and tends to diminish in severity in adulthood. Many become seizure free for 5 years or more. The most common seizure types are partial complex, tonic-clonic, tonic and myocionic seizures. Although about $50 \%$ of seizures can be controlled by medication, intractable epilepsy occurs significantly more frequently in girls with obvious deceleration of head growth. The electroencephalogram is usually abnormal in Rett syndrome, but there is no diagnostic pattern. Electroencephalogram patterns frequently seen in Rett syndrome include generalized slowing, monorhythmic theta waves and, focal and generalized spikes and sharp waves. Many paroxysmal events in Rett syndrome have been found to be non-epileptic in origin but are difficult to interpret as such by parents and care takers. On the other hand clinical events correlating with epileptic discharges on electroencephalogram are sometimes not recognized. Faciall twitching with or without sudden changes in attention and eye deviation should not be a priori interpreted as epileptic paroxysms in a young child. This reflects more the ongoing process of immature brainstem activity and is not influenced by anti-epileptic drugs. The age of onset of seizures is later than in severe mental handicap in general $(0.8 \mathrm{y})$. It is surprising that most of the children with Rett syndrome, although severely impaired, only experience the onset of epilepsy in stages III and IV and not in the rapid regression stage II. Rarely, infantile seizures, variant infantile spasms or other intractable seizures are present before the appearance of classical Rett syndrome features. In spite of this early and severe onset of epilepsy no negative effects on the long-term course and prognosis of Rett syndrome has been identified. The course of epilepsy tends to decrease after age 20. Many girls become seizure free or are well controlled by medication (Steffenburg et al., 2001). Status epilepticus does not occur more often than in severely mentally retarded children in general. The probability of death associated with epillepsy is estimated at $9 \%$. Rett syndrome individuals are sensitive to antiepileptic drugs and have a tendency to be easily over sedated, cognitively depressed and confused. Polypharmacy should be avoided as much as possible, and one constantly needs to consider the withdrawal of anti-epileptic medication when they become seizure free.

\section{DEFORMATION}

Scoliosis develops in early school age with various degrees of severity. Sometimes the progression is very rapid depending on asymmetry in muscle tone and the degree of dystonia and muscle wasting. In ambulatory girls, scoliosis appears umpredictable. It may never be present, only develop to a small extent or stabilize on an acceptable degree. In non-ambulatory girls with classical Rett syndrome stage IVB scoliosis develops in spite of all preventive measures. Most commonly a double curve develops with a longer upper part (most frequently concave to the right) and a shorter lower part (concave to the left). When there is no neurological asymmetry the spine deformity is usually much more benign. 
Periodic radiographs of the spine are recommended to establish the degree of scoliosis and its progression. Good posturing, eventual casting and early surgical intervention, if needed, are important options in long-term habilitation concerning this deformation.

Kyphosis occurs more in girts that continue to walk. It may be related to the degree of extension in the ankle muscles. Tiptoe walking in girts with Rett syndrome, contrary to other circumstances with neurologic deficit, is more a preferential posturing related to uncertainty and anxiety about falling. Girls gain support and stability by bending forward on stiff legs that gives them more balance against gravity. While sitting and drowsy, girls tend to drop their heads forward causing more bending of the cervical and high thoracic vertebral column. A high kyphosis is therefore not uncommon in the many millder forms of Rett syndrome. It rarely needs an intervention.

The foot deformities most common in Rett syndrome are equinus and equinovalgusivarus positions. As long as the Achilles tendon can be flexed over 90 degrees with the knee in extension, normal walking remains possible. Further shortening of the Achilles tendons is then compensated for by an "escape" of the feet in the valgus or varus position. Young girls do not suffer from this and continue to develop walking ability. If there is hyperextension of the ankles, the need for compensation through flexion rises to the knees, the hips and the spine, threatening the balance and making walking very difficult if not impossible. Rett syndrome girls develop a preferential leg, putting it forward in every step and using the other leg in support and balance. Direction is chosen through the preferential leg. Sometimes the other leg is placed more to the side causing her to walk in circles; sometimes the girl tilts it high up and then forward simulating an involuntary movement. With careful follow up of muscle tone and posture, especially of the spine and feet, and with corrective measures taken in time, walking can be preserved for a long time. Abnormal muscle tone in the flexor/adductor muscles of the hip can lead to dislocation especially in non-walking girls. Observation of gait patterns and patterns of preferential posturing may be useful in evaluating the need for correction of a foot deformity. Then surgicall intervention e.g. arthrodese may lead to refusal of walking again afterwards. The approach to orthopedic deformities in Rett syndrome requires input from parents, therapists, pediatrician, orthopedic surgeon and a rehabilitation specialist in order to find a treatment goal related to the individual's level of function in daily life activities. Botox treatment of spasticity can be used in Rett syndrome as in spasticity in general, in consultation with the rehabilitation specialists and the orthopedic surgeon (Flett, 2003). Results depend on good selection of patients in advance. The effect however is limited in time. Braces or orthoses are used for the spine, the foot and the ankle to prevent further deformation or to support walking. Early casting of the trunk as a conservative treatment will not prevent surgical intervention in progressive cases. Surgical lengthening of ankle muscles may be considered for shortened Achilles tendons. Surgical lengthening of flexorladductor muscles may be needed if hip dislocation is imminent. Surgical treatment of scoliosis with spinal fusion should be considered using the same criteria as in the general population. Spinal surgery might be limited to posterior fusion without combined anterior fusion when the intervention is not prosponed to long in severely evolving cases.

\section{Orodental}

Rett syndrome girls present frequent digithand sucking and/or biting, mouth breathing and drooling. The characteristic teeth grinding or bruxism may lead to dental attrition. There are no anomalies of tooth number, size, form, structure or eruption (Ribeiro et al., 1997; Friedlander et al, 2003).

\section{Gastrointestinal}

In Rett syndrome there is a higher incidence of gastro-esophageal reflux and decreased intestinal motility resulting in constipation. When in Valsalwa breathing they press air over a closed glottis into the stomach. The resultant bloating of the abdomen can be extreme and 
of a degree that is not encountered in other mental retardation disorders or syndromes. These clinical features may interfere with normal feeding and with general comfort. Gastroesophageal reflux is conservatively treated as in the general population. Surgical treatment is rarely needed. A conservative approach should be used to treat constipation with dietary measures, sufficient fluids and, eventually, the use of enemas. There is no specific treatment for air swallowing with bloating of the abdomen.

\section{Cardiovascular}

Rett syndrome females have a higher incidence of prolonged QT interval, and heart rate variability is diminished. Imbalance between preserved sympathetic tone and insufficient parasympathetic control is known to cause cardiac arrhythmia. Individuals with prolonged QT intervall associated with abnormal breathing pattern are particularly at risk for cardiac arrhythmia. There is no specific treatment of prolonged QT. Avoidance of certain medications such as cisapride, and tricyclic antidepressants, among others, is indicated, as they can provoke prolonged QT interval.

\section{Ophthalmologic}

Visual sensory function is the strength of people with Rett syndrome and care should be taken to preserve it. There is no specific ophthalmologic pathology although strabismus is very common. Acquired cataracts may occur after self-injurious tapping in association with behavioral agitation. Retinal changes are not present. Our personal experience with visual and auditory evoked responses is presented in addendum $E$.

\section{Autonomic breathing dysfunction}

Irregular breathing in the waking state associated with non-epileptic vacant spells is the most distressing and sometimes problematic feature in classic Rett syndrome. It reflects the immatturity of the brainstem and may contribute to sudden death (Kerr and Witt-Engerström, 2001). Low resting cardiac vagal tone and weak vagal response to hyperventilation and breath holding suggest inadequate parasympathetic control. Neurophysiological studies have shown that these baseline brainstem functions are affected in Rett syndrome, while the baseline sympathetic tone is preserved. Recent insight into these phenomena has introduced new terminology such as "brainstem storm" and "brainstem epilepsy" as a description of spontaneous but exaggerated excitation of the brainstem associated with the altered breathing patterns (Julu et all., 2001). Other autonomic manifestations in Rett syndrome include disrupted sleep staging, agitation, pupilary dilatation, and cold extremities. Hyperventilation is known as a presenting feature in the panic disorder, and in disorders of brain stem function, whether developmental, vascular, traumatic, toxic, metabolic, degenerative or neoplastic in origin. The clinical inaccessibility of the brain stem makes that these phenomena remain poorly understood in terms of etiology and pathogenesis. E.g. in the Joubert syndrome (Joubert et al., 1969), with documented vermis hypoplasia and cyst in the fourth ventricle the exact pathophysiology of the characteristic breathing ataxia is unclear. The effects of hyperventilation are more or less known to clinicians: respiratory alkalosis and diminished oxygen delivery to the brain, reduction in ionized calcium, tingling sensations, tetany and secondary epileptic seizures or epileptogenic EEG changes and cardiac repolarisation abnormalities (like ST depression and T wave inversion).

In Rett syndrome respiration during the waking state has usually become irregular by the end of stage II of regression, with breath holding, panting, shallow or deep breathing. During sleep the respiratory pattern is usually normal. Abnormal breathing starts as soon as the girls are awake and the patterns remain and evolve with time. Most of them show several of the abnormal respiratory patterns switching between them, apparently at random. Why these breathing phenomena arise is not yet clear but it reflects the immaturity of brainstem function comparable with at a neonatal immature breathing in premature infants (Armstrong. 2002). In Retl syndrome children serotonin (5'HT) receptors are increased in the brainstem, 
and levels of Substance P, wich co-localizes with serotonin in central and peripheral nervouls system, are reduced remaining at the level appropriate for a 2 -month old child. Serotonin is a neurotransmitter playing an important role in brain development and mature functioning. Substance $P$ is involved in pain transmission (Riikonen, 2003).

Reduced expression of neuropeptides can be related to respiratory disturbiances in Rett symdrome (Saito et al., 2001). Irregular breathing as a consequence of immature brainstem function has been explicitly described by Julu et al. (2001). Abnormal spontaneous brainstem activation (ASBA) leads to phenomena like "brainstem epilepsy" and "brainstem storm", describing the neurophysiology behind the vacant spells as a consequence of sympathetic overactivity with insufficient parasympathetic control.

The history and management of a Rett syndrome girl with sleep disturbance and severe abnormal breathing with secondary events is described and discussed in addendum 3 . 

D. General conclusion and future perspectives. 
Reit syndrome is a wery specific disorder of neurodevelopment that presents itself almost exclusively in girls. The pattern of clinical manifestations is unique and the variety in clinical severity, evolving over time, is very wide. The differential diagnosis with other disorders is rather limited. It is e.g. quite different in presentation and evolution from the autism spectrum disorders and should in fact never be clasisfied as such.

The diagnosis of Rett syndrome can now be confirmed by DNA analysis of MECP2 in the majority of cases. In spite of this progress in molecular diagnostics, the diagnosis of future Rett syndrome girls will remain strongly clinically based on diagnostic criteria. However, clinical suspicion of Rett syndrome can now be molecularly confirmed in sometimes very young girls. We recomimend the detailed study of the early infantile signs of the disorder and to eventually include them in the clinical criteria. Clinical symptoms and behavior in childhood Rett syndrome may be initially the same in those that present initially as "atypical" with an ultimately milder and protracted course as in those who will develop severe classic Rett syndrome later in life. In each Rett syndrame girl the evolution is in fact very specific requiring thus specific approaches at all times, even into her adulthood.

The molecular studies, apart from the DHPLC and sequencing techniques, that detect mutations in the majority of clinically diagnosed Rett syndrome females, should be extended with the MLPA or the more difficult Southern Blot technique to detect larger deletions, duplications or other gross rearrangements in MECP2. Our findings warrant further (MLPA) studies to establish the prevalence of large rearrangements in the MECP2 gene in initially mutation negative Rett syndrome cases. The application of the MLPA technique in DNA analysis of MECP2 is therefore recommended in initially mutation negative but clinically obvious Rett syndrome females as a standard procedure.

The differences in $X$-inactivation patterns in this $X$-linked condition needs to be studied to more extent since skewing may be different in the different tissues, including also the brain. Non-random patterns are probably only partially explaining the milder cases (Zoghbi et al., 1990). But $X$-inactivation may be responsible for differences in evolution between cases with the same type and localization of their MECP2 mutation.

In the study of phenotype-genotype relationship it becomes essential that diagnostic criteria and clinical scoring systems become implemented in a uniform way to avoid future conflicting results between studies. In studying the relationship between clinical severity at the time of examination and the molecular characteristics of the MECP2 mutation one needs to be very careful in making conclusions about prognosis of a particular MECP2 mutation. Most studies untill now contain few females above the age of 25 years. It is important that more follow-up data of older Rett syndrome women become available because the variability presenting at older age is reflecting the variability at all ages, and not only survival of milder Rett syndrome.

The precise mechanisms by which fetal, neonatal and infantile brain development becomes disturbed because of deficient function of MECP2 are not yet well understocd. The interaction of MECP2 with other genes involved in this development and in the maintenance of central nervous system functions and the influence of eventual epigenetic phenomena or modulating factors are subject to research. Only a few target genes (like the BDNF 1 gene) are proposed candidates.

The deficit in transcription-repression function of MECP2 leads to a disturbance of development of the central nervous system that is related to a moment time, the brain cells involved, and eventually the status of X-inactivation. It is reasonable to expect that different types and localization of mutations in MECP2 may cause variable and sometimes specific clinical profiles of disturbed development. These profiles when studied over time may contribute in finding the answer why in Rett syndrome the clinicall variability is so large and 
what regions in the brain are as much involved. Apart from the basal ganglia, substantia nigra and brainstem regions known to be involved, the sensory pathways seem interesting in the study of dying-out phenomena of the cortical projections. Studying the effect of MECP2 on other biological organ systems might also contribute to the explanation and understanding of the clinical impression of premature aging in Rett syndrome that we encountered in several of the adolescent and adult females.

One can ask whether the delineation of classic versus variant phenotypes is still useful. Defining "atypical" or "milder" cases as forme fruste or by preservation of speech or age at onset is not helpful in trying to understand the ongoing pathology in Rett syndrome at different ages. It leads also to confusion in the different phenotype-genotype studies. By describing every Rett syndrome girl and women as completely as possible in all of her Rett syndrome manifestations on the long term, will contribute more to this understanding than by defining her to some of its preserved abilities (even if some elements can be corrected for age).

Grouping of individuals with the same mutation (type and localization) together with their long-term disorder profile learns more about the phenotype-genotype relationship and the ongoing pathology of neurodevelopment in Rett syndrome in the different stages of the disorder. Since most series of single mutations are to small for conclusive studies it is recommended that all data of individual Rett syndrome females are collected in a larger database in a uniform way and that long-term follow-up becomes included in the collection of these data. The R133C, T158M and R306C missense mutations, in the methyl-CpGbinding domain and transcription repression domain respectively, and the C-terminal segment hot spot deletions as late truncating, nonsense mutations represent interesting groups of recurrent MECP2 mutations that evolve in a clinically milder or more protracted disorder profile. We believe that this has an impact on the management of certain specific Rett syndrome manifestations and on the decision about symptomatic treatment of secondary deformation, breathing irregularities and epilepsy when they are present in a way beyond expectation. On the other hand the management of Rett syndrome fermales with the nonsense mutations R255X, R270X and R294X needs to become more decisive towards early therapeutic intervention when they develop secondary manifestations in order to achieve a better quality of daily life at all ages, and to prevent early complex multiimpairment or early death.

The "maximal" clinical approach will also contribute in distinguishing better those conditions with mental retardation that are clinically very adjacent to Rett syndrome bul appear to be of a different genetic origin. In the monozygotic and concordant twin sisters with "the infantile seizure onset variant" (cases 99.100) recently a STK9 mutation was established at Xp21 (Kalscheuer et al., 2003; Tao et al., 2004; Weaving et al., 2004). Whether this "Rett syndrome variant" will definitely appear to be caused by mutation in this gene needs further confirmation. Anyway, there is little reason to belleve that in diagnostically well established but MECP2 mutation negative females their disorder is caused by a mutation in another gene (Nielsen et al., 2001).

Whether the contribution of MECP2 mutations, eventually in relation to other genes, is important in the diagnostic yield of MR in males remains to be seen. The true male Rett syndrome is rare in non-familial cases. The prevalence of MECP2 related disorders in cytogenetic normal males is certainly much lower than in females and is probably overestimated. In addition the clinical disorder profile is different from that in females, and there is little evidence for routine testing for MECP2 in non specific mental retardation. The majority of the reported MECP2 mutations in mentally retarded males cause amino acid substitutions and, especially in isolated cases, discrimination between a disease-causing 
mutation and a rare polymorphism is not obvious and the significance of each individual variation should be verffed (Winnepenninckx et al. 2002).

The management of this disorder depends largely on the presence or absence of some of its most distressing manifestations and complications. When looking at the preservation of specific abilities in Rett syndrome, it is remarkable that handuse remains present in $44 \%$, walking and sitting in 60\%, but there is absence of speech in more than $80 \%$.

About $30 \%$ or one third of the indruduals have an uncontrolled eplepsy or status epilepticus. The study of drug treatment of epllepsy needs further attention since it is probably related to symptoms of immature brainstem function and brainstem excitability that doesn't respond to conventional anti-epileptic drugs as was shown in the case report (addendum 3 .).

Remarkable are the figures of $27 \%$ having a severe spine deformation, requiring surgery in about half of them $(13 \%)$. Retrospective evaluation of the effects of spine surgery on the long term evolution in relation to the clinical and molecular findings is very important for future Rett syndrome children that might need spine surgery or not. This is important in the long-term management of this manifestation in Rett syndrome and certainly deserves more attention in terms of habilitation and surgical approach and techniques. Some develop their spine deformity rather quickly, others stabilize at some point. The preservation of ambulation is decisive in the planning of a surgical intervention at a younger age; other habilitation and nursing aspects are decisive at older age or in the non-ambulatory group.

The study of autonomic dysfunction in Rett syndrome, in particular the breathing irregularities, deserves more attention in view of a possible symptomatic treatment. The imbalance between sympathetic stimulation and insufficient parasympathetic inhibition due to brainstem immaturity in Rett syndrome may be responsible for secondary events that may be interpreted as epileptic but are in fact not purely of that origin. The use of drug treatment and inhalation therapy in an attempt to control this imbalance is worth to study since it might be a way to improve on the daily quality of life in Rett syndrome. This study however requires input from different specialists from physiology, pharmacology, neurology, psychology and clinical Rett syndrome expertise. This underlines once again the importance of multisciplinary approach in order to achieve an optimally individualized treatment and long-term habilitation management of the disorder. 


\section{REFERENCES}

Allanson J., Hennekam R. Moog U. Smeets E. (2004). Rett syndrome: a study of the face. Proceedings of the Greenwood Genetic Center, $23: 63-64$.

Amir R., Van den Veyer 1. Wan M., Tran C., Francke U., Zoghbi HY. (1999). Rett syndrome is caused by mutations in

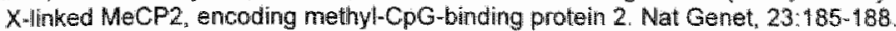

Amir R., Van den Veyer I., Schultz R., Malicki D. Tran C., Dahte E, Philippi A., Timar L., Percy A.. Motil K. Lichtarge O. Smith E. Glaze D., Zoghbi H. (2000). Infiuence of mutation type and $X$ chromosome inactivation on Rett syndrome phenotypes. Ann Neurol, 7:670-679.

Armstrong D. Kinney H. (2001), In: Kerr A. Witt-Engerstrom I, editors. Rett disonder and the deweloping braih. The Neuropathology of the Rett disorder. Oxford, Oxford Uniwersity Press, pp 57-84.

Armstrong D. (2002): Neuropathology of Rett syndrome. MRDD Research Reviews, 8:72.76.

Asthana J., Simha S., Haslam J.S. Kingston H.M. (1990). Survey of adolescents with severe mental handicap. Auch Dis Child, $65: 1133-1136$.

Beyer K., Blasi F., Bacchelli E. Klauck S. Maestrini E. Poustka A. (2002). Hnternationat Mlolecular Genetic Study of Autism Consortium (IMGSAC). Mutation analysis of the coding sequence of the MECP2 gene in infantile autism. Hum Genet, $111(4-5) ; 305-309$.

Bourdon W. Philippe C., Labrune O. Amsallem D. Arnould C., Jonveaux P. (2001). A detailed analysis of the MECP2 gene: prevalence of recurrent mutations and gross rearrangements in Rett syrdrome patients. Hum Genet, $108(1): 43-50$.

Chandler $S_{.,}$Guschin D. Landsberger $\mathbb{N}_{.}$, Wolffe AP. (1999). The methyl-CpG-binding transcriptional repressor MeCP2 stably associates with nucleosomal DNA. Biochem, $38: 7008-7018$.

Cheade J., Gill $H$., Fleming N., Maynard J., Kerr A, Laonard H, Krawczak M., Cooper DN., Lynch S., Thomas N.

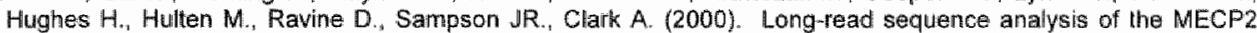
gene in Rett syndrome patients: correlation of disease severity with mutation type and lociallisation. Humm Mol Genet, 9: 1119-1129.

Chen W. Chang Q. Lin Y., Meissner A., West A., Griffith E. Jaenisch R., Greenberg M. (2003). Derepressilon of BDNF Tramscription Involves Calcium-dependent Phosphorylation of MECP2. Science, 302(5646):885.

Colwin L., Leonard $H_{\text {. }}$, de Klerk N., Davis M., Weaving L., Williamson S., Christodoutou J. (2004). Refining the phenotype of common mutations in Rett syndrome. J Med Genet:41:25-30.

Ellaway C. Buchtholz T., Smith A., Leonard H., Christodoutou J. (1998). Reth syndrome: significant clinical overlap with Angelman syndrome but not with methylation status. J Chatd Neurol, 13(9) $448-451$.

Ellaway C., Christodoulou J. (2001). Rett syndrome: clinical characteristics and recent genetic adwances. Disabil Rehabil, 23: $98-106$.

Fiumara A. Polizzi A., Mazzei R., Conforti L., Magariello A. Sorge G. Pavone L. (2002). Rett syndrome phenotype following infantile acute encephalopathy. J Child Neurol. 17:700-702.

Flett P (2003): Rehabilitation of spasticity and related problems in childhood cerebral palsy.

IPaediatr Child Health, 39:6-14.

Friedlander A, Yagiela J, Paterno V., Mahler ME, (2003). The pathophysiology, medical managememt and dental implications of fragile $X$. Rett, amd Prader Wilti syndromes. J Calif Dent Assoc;31:693-702.

Girard M., Couwert P., Carrie $A_{.}$. Tardieu $M$., Chelly J. Beldjond $C$., Bierwenue $T$, (2001). Parental origin of de novo MeCP2 mutations in Rett syndrome. Eur J Hum Genet, 9: 231-236.

Guideri F., Acampa M., Hayek G., Zappella M., Di Peril T. (1999). Reduced heart rate variability in paltents affected with Rett syndrome. A possible explanation for sudden death. Neurepediatrics, $3: 146 \cdot 148$.

Hagberg B. Aicardi 4 . Dias K. Ramos O. (1983). A progressive syndrome of autism, dementia, ataxia and losis of purpusful handuse in girls: Rett's syndrome: report of 35 cases. Ann Neural, 14:471-479 


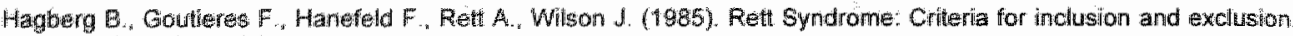
Brain Diev, $7: 372-373$.

Hagberg B. Wht-Engerstrom 1. (1990). Early stages of the Rett symdrome and imfantite neuronal ceroid lipofuscinosisua difficult dfferential diagnosis. Brain Dev, $1990,12(1): 20-22$

Hagberg B.(1993). Rett syrdrome-chinical and biological aspects. Cambrigde: Mackeith Press/Cambridge University Press: Cin Diev Med, 127

Hagberg 13. Gillberg C. (1993). Rett variants-Rettold phenotypsis. In Rett syndrame-efinical and biological aspects. Chapter 5. Cambrigde: Mackeith Press/Cambridge University Press. Clin Dev Med, 127:40-60.

Hagberg B. Sikjeldal O. (1994), Rett Wariants: a suggested model for imclusion criteria. Ped Neurof $11: 5-11$

Hagberg B. Hagberg G. (1987). Rett symdrome: epiderniology and geographical variability. Eur Child Adolesc Psychiatry: 6 suppl 1:5-7.

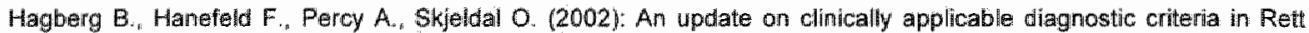
syndrome. Comments to Rett Syndrome Clinical Criteria Consensus Pamel Satellite to European Paediatric Neurology Sorciety Meeting, Baden Baden, Germany, 11 September 2001. Eur J Paediatr Neurol, 6293-297.

Hagberg B. Erlandsson A. Kyllerman $M$, Lairson $G$. (2003). Odd MECP2-mutated Rett variant-long-term follow-up profile to age 25. Eur J Paediati Neurol, $7: 417-421$

Heillstedl H. Shahbazian M. Lee B. (2002). Infantile hypotonia as a presentation of Rett syndrame. Am $₫$ Med Genet; $111: 238-242$

Hoffbuhr K, Devaney J., LaFleur B., Sirianni N., Scacheri C., Giron J., Schuette J., Innis J., Marino M., Philippart M.

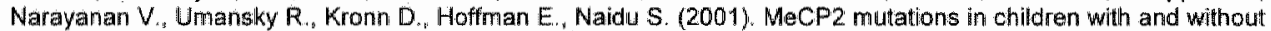
the phenotype of Rett syndrome. Neuralogy. 56:1486-1495.

Huppke $P_{.}$, Laccone F., Kramer N., Engel W., Haneleld F. (2000). Rett syndrome: analysis of MECP2 and clinical characterization of 31 patients. Hum Mol Genet, 9:1369-1375.

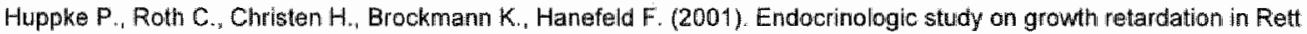
syndrome. Acta Paediatr, 90:1257-1261.

Huppke P. Held M., Hanefeld F., Engel W., Laccone F. (2002). Imfluence of mutation type and location on phenotype in 123 patients with Rett syndrome. Neuropediatrics, $33: 63 \times 68$.

shithawa A., Goto T., Narasaki Ml., Yokochi K., Kitahara H., Fukuyama Y. (1978). A new syndrome (?) of progressive psychomotor retardation with pecullar stereotyped mowements and autistic tendency: a report of three cases. Brain Dev $_{n} 3: 258$.

Joubert M., Eisenning J. Robb J. Andermann F. (1969). Familial agenesis of the cerebellar vermis. A syndrome of apisodic hyperpnea, abnormal eye movements, ataxia, and retardation. Neurology 19: 813-825, 1969.

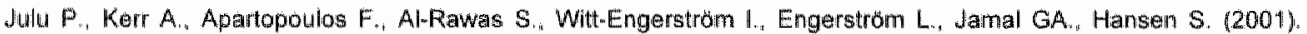
Characterisation of breathing and associated central autonomic dystunction in the Rett disorder. Arch Dis Child. $85 \div 29 \times 37$

Kalecheuer VM, Tau J, Donnelly A, Holway G, Schwinger E, Kubart S, Menzell C, Hoeltzenbein M, Tommerup N Eyre $H_{4}$. Harbord $M_{*}$ Haan $E$, Sutherland GR. Ropers HH, Gecz J. (2003). Disiruption of the serime/threonine kinase 9 gene causes severe X-linked infantile spasms and mental retardation. Am J Hun Genet, 72.1401-1411.

Kerr A. (1992). Rett Syndiome British dongitudinal study (1982-1990) and 1990 survey. (ed. J.J. Foosendaal), pp.1435. Mentail retardation and Medicall Care, 21\%24 April 1991. Uitgeverij Kerckbosch. Zeist ISBN 9067201219.

Kerr A, Julu P: (1999). Recent insights into hyperwentillation from the study of Rett syndrome. Arch Dis Chill, 80.384 387.

Kerr A., Nomura Y", Amstromg D., Anvret M. Belichenko P., Budden: S. Cass H, Christodoulou w., Clarke A., Ellaway C. d'Esposito M. Francke U. Huiten M., Julu P. Leonard H. Naidu S., Schanen C., Webb T., Witt-Engerstrom I., Yamashita $Y$. Segawa M. (2001). Guidelines for reporting clinical features in cases with MECP2 mutations. Brain Dev, 23:208-211.

Kerr A. Witt-Engerstrom 1. (2001). Rett Disorder and the Deweloping Brain, eds. Oxford: Oxford University Press 2001 ISBN 0192630830 . 


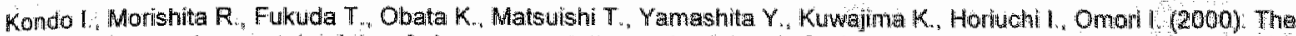
spectrum and parental origin of de novo mutations of methyl-CpG-binding protein 2 gene (MAOPR) in Ret syndrome. Am J Hum Genet, 67 , suppl:2:386.

Kultz J., Rohmann E., Hobusch D. (1990). A study of the Rett Syndrome in the GDR. Brain Dev, 12: 37-39.

LaSalle d., Goldstine J., Baimer D., Greco ClM. (2001). Quantitative localization of heterogeneous methyl-CpG binding protein 2 (MeCP2) expression phenotypes in nomal and Rett syndrome brain by laser scanning cytometry. Hum Mol Genet. 10(17):1729-1740.

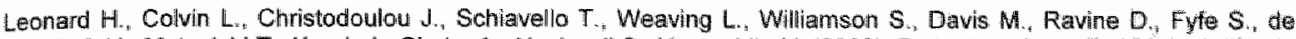
Klerk N. Matsuishi T. Kondo I. Clarke A. Hackwell S. Yamashita Y. (2003). Patients with the R133C mutation: Is their phenotype different from Rett syndrome patients with other mutations? I Med Gemel 40:53.

Martinowich K. Hattori D., Wu H., Fouse S., He F. Hu Y. Fan G., Sun Y. (2003): ONA Methylationwatated Chromatin Remodeling in Activity-Dependent Bdint Gene Regulation. Science, 302:890.

McArthur A., Eudden S. (1998). Sleep dysfunction in Rett syndrome: a trial of axogenous melatonin treatment. Dev Med Child Neuroli:40:186-192.

Mills K. (1997). Serotonin syndrome. Crit. Care Clin, 13, pp. 763-783.

Miyamoto A.s Oki J., Takahashi $S_{\text {, }}$ Okuno A. (1999). Serum melatonin kinetics and long-term melatonin treatment for sleep disorders in Rett syndrome. Brain Dev, 21:59-62.

Moog $U^{*}$. Smeets $E^{\star}$, wan Roozendaal K, Schoenmakers S, Herbergs J, SchoonbrooduLenssen A, Schrander-Stumpel C. (2003). Neurodevelopmental disorders in males related to the gene causing Reth syndrome in females (MECP2). Eur J Paediati Neuro:, 7:5-12.

Monros E., Arrmstrong J. Aibar E. Poo F. Canos I., Pineda M. (2001). Rett syndrome in Spainu mutation analysis and clinical correlation. Brain Dev, 23:251-253.

Motil K., Schultz R., Browning K., Trautwein L., Glaze DG. (1999). Oropharyngeal dysfunction and gastroesophageal dysmotility are present in girls and women with Fett syndrome. J Pediatr Gastroanterol Nutr, 29:31-37.

Muhile R. Trentacoste S., Rapin 1. (2004). The genetics of autism. Pediatrics, 113:e472-486.

Nan $X_{.,}$Tate P., Li E., Bird A. (1996). ONA methylation specifies chromosomal localization of MeCP2. Mol Cell Biol, 10:414-421.

Nan X. Campoy J., Bird A. (1997). MeCP is a tramscriptional repressor with abundant binding sites in genomic chromatin. Cell, $88: 471-481$.

Nan X., Ng H., Johnson C., Laherty C., Turner B. Eisenman R. Bird A. (1998). Transcriptionat repression by the methyl-CpG-binding protein MeCP2 irvolves a histone deacetylas complex. Natura, 393:386-389.

Nan $x$. Bird A. (2001). The biological functions of the methyl-CpG-binding protein MeCP2 and its implication in Rett syndrame. Brain Dew 23 Suppl 1:832-37.

Wielsen ل. Henriksen K. Hansen C., Sitahtaroglu A., Schwartz M. Tommerup N. (2011). MECip2 mutations in Danish patients with Rett syndrome: high frequency of mutations but no consistent correlations with clinical severify or with the $X$ chromosome inactivation pattern. Eur J Hum Gervet, 9:178-184.

Orrico A. Lam C. Galli L. Dotti M. Hayek G. Tong S., Poon M., Zapella M., Federico A. Sorrentino V. (2000). MeCP2 mutation in male patients with non-specific X-linked mental retardation. FEBS Lett; 481:285-281.

Reilly $\mathrm{S}_{.}$Cass H. (2001). Growth and nutrition in Rett syndrome. Disabil Rehabil, 23:118-28.

Reth A. (1966). Uber ein cerebral-atrophisches Syndrom bei Hyperammonämie. Wien Med Wochenschir, 116:723-726.

Rett A. (1977). Cerebral Atrophy assaciated with hyperammomalemia: in Handbook of Clinical Neurology. Ed. By P.J. Vinken and G.W. Bruyn, North Holland publishing company, Amsterdam. New Vork, Oxford. Volume 29, $305-329$.

Ribeiro R., Romano A., Birman E., Mayeir M. (1997). Oral manifestations in Rett syrudrome: ai study of 17 cases. Pediatr Dent:19:349-352. 
Rotonen N (2003). Weurotrophic factors in the pathogenesis of Rett syndrome. I Child Neural, 18:797.

Sato Y. Ho M., Ozawa Y. Matsuighi T., Hamano K., Takashima Si. (2001). Reduced expression of neuropeptides can be related to respiratory disturthances in Rett syndrome. Brain Dev, 23 Suppl 1,5122-126.

Scholen E. Smests E. Deflem E. Fryns J-P. Mathijis G. (2003): Gross rearrangements in the MECP2 gene in three patients with Rett syndrome: implications for routine diagnosis of Rett syndrome. Hum Alut, 22:116-120.

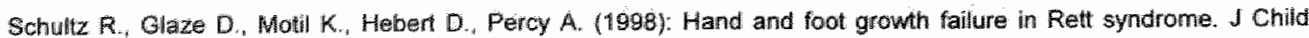
Neuriol $13: 71 \cdot 74$.

Simeets E., Schollen E, Moog U. Mathhijs G. Herbergs J., Smeets H. Curfs L. Schrander-Stumpell C., Fryns J-P. (2003). Rett Syrdrome in Adolescent and Adult Females: Clinical and Molecular Genetic Findings. Am J Med Gen. $1224227 \cdot 233$

Smets E., Terhal P, Casaer P. Peters A, Midro A., Schollen E, van Roozendaal K., Moog U., Mathijs G., Herbergs J., Smeets H. Curfs L., Schrander-Stumpel $C$., Fryns JP. (2005). Rett syndrame in females with CTS hot spot deletions: A disorder profile. Am J Med Genet A. 132A:117-120.

Smeets E. Schrander-Stumpel C. (2005). Ret syndrome. Ir: Preventive Mavagement of Genetic Syndromes. Third Edition, by d. Allanson and S. Cassidy. Wileys - New york.

Stauder J., Smeets E, wan Mil S., Curfs L. The development of visual and auditory processing in Rett syndrome: An event related brain potentlal study. Braim Dev, submitted 2004.

Steffenburg U., Hagberg G., Hagberg B. (2001). Epilepsy in a representative series of Rett syndrome. Acta Paediatr. 90:34-319.

Sung Jae Lee S., Wan M. Francke U. (2001). Spectrum of MECP2 mutations in Rett syndrome. Brain Dev, 23:S138143.

Tao J., Van Esch H., Hagedorn-Gireiwe M., Hoffmann K., Moser B., Raynaud M. Sperner J., Fryns JP., Schwinger E., Gecz J. Ropers H., Kallscheuer V. (2004). Mutations in the X-Linked Cyclin-Dependent Kinase-Like 5 (CDKL5/STK9) Gene Are Associated with Severe Neurodevelopmental Retardation. Am J Hum Genet, 75:1149.w 1154 .

Thomas $G$. (1996). High maleffemale ratio of germ-ine mutations: an altermative explanation for postulated gestational lethality in unales in X-linked dominant disorders. Am J Hum Genet, 58:1364-1368.

Topciu M, Akyerli C, Sayi A, Toruner GA, Kocoglu SR, Cimbis M, Ozcelik T. (2002). Somatic mosaicism for a MECP2 mutation associated with chassic Rett symdrome in a boy. Eur J Hum Genet, 10:77-81.

Trappe R., Laccone F., Cobilanschi J., Meins M., Huppke P., Hanefeld F., Engel W. (2001). MeCP2 mutations in sporadic cases of Rett syndrome are almost exclusively of parental arigin. Am J Hum Genet ${ }_{\mathrm{t}} 68: 1093-1101$.

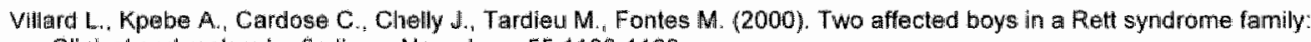
Clinical and molecular findings. Neurology, 55:1188-1193.

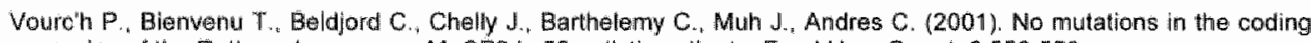
region of the Rett syndrome gene MeCP2 in 59 autistic patlents. Eur J Hum Genet, 9:556-558

Wan M., Lee $S_{1,}$ Zhang X., Houwink-Manwille I, Song H., Amir R., Budden S., Naidu S. Pereira J., Lo 1., Zoghbi H.

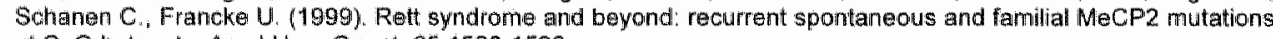
at CPG hotspots, Ant J Hum Genet, 65:1520-1529.

Wan M., Zhao K. Francke U. (2001). MeCP2 truncaling mutations cause histone H4 hyperacetylation in Reft syndrome. Hum Mol Genet, 10:1085-1092.

Watson P., Black G. Ramsden S. Barrow M., Super M., Kerr B., Clayton-Smith J. (2001). Anglelman syndrome phenotype associated with mutations in MeCP2, a gene encoding a methyl CpG binding protein. J Med Genet, $38: 224-228$.

Weaving L., Christodoulou J."Williamson S. Friend K. Mckenzie O. Archer H. Evans J., Clarke A. Peka G., Tam P, Watson C., Lahoot H. Ellaway C., Bennetts B., Leonard H., Gecz J. (2004). Mutations of CDKL5 Cause a Severe Neurodevelopmentall Disorder with Hnfantile Spasms and Mlental Retardation. Am I Hum Genet, 75:1079-1093. 


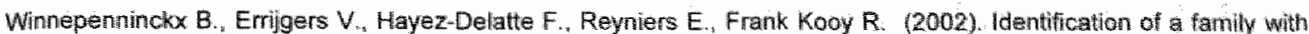
nonspecific mental retardation (MRX79) with the All.0 V mutation in the MECP2 gene: is there meed for routine screening? Hum Mutal, 20:249-252.

Witt-Engerström 1. (1990). Rett Syndrome in Sweden. Acta Paediatrica Scandinawica, suppl.369.

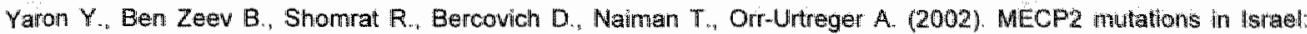
implications for molecular analysis, genetic counseling and prenatal diagnosis in Rett syndrome. Hum Mutat, $20: 323-324$

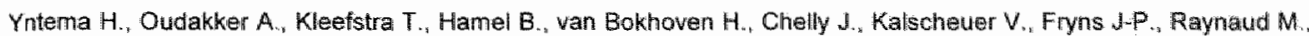
Moizard M., Moraine C. (2002), In-frame deletion in MECP.2 causes mild nonspecific mental retardation. Am I Med Genet, 107:81-83.

Zappella M. Meloni I., Longo I., Hayek G. Renieri A. (2001). Preserved speech variants of the Rett syndrome: moleculair and clinical analysis. Am J Med Genet, 104:14-22.

Zoghbi H. Percy K., Schulz R., Fill C. (1990). Patterns of $X$ chromosome inactivation in the Rett syndrome. Brain Dtew, $12: 131-135$.

\section{WEBSITES ON THE INTERNET:}

InterRett, The IRSA Rett syndrome phenotype database : wuw ichr.uwa, edu au/ret//irsal

The international Rett Syndrome Association IRSA: unw rettsyndrome org

Rett Netwerk Nederiand: www.rett. nil

Belgische Rett syndroom vereniging: www rettsyndrome be

Trefpunt Zelfhulp, patientenverenigingen: www zelfthulp be

Zelfhulp Nederland: www zorgwijzer eigenstart. nl

www.erfelijkheid.nl 

Addenda 



\section{Addendum 1}

Rett syndrome in adolescent and adult females: clinical and molecular findings

Smeets E., Schollen E., Moog U., Matthijs G. Herbergs J., Smeets H. Curfs L., Schrander-Stumpel C., Fryns JP.

Am J Med Genet 2003, 122:227-33. 



\title{
Rett Syndrome in Adolescent and Adult Females: Clinical and Molecular Genetic Findings
}

\author{
E. Smeets ${ }^{4 \prime 2}$, E. Schollen", U. Moog ${ }^{2}$, G. Matthijs", J. Herbergs ${ }^{2}$, H. Smeets ${ }^{2}$, L. Curfs ${ }^{2 / 3}$ \\ C. Schrander-Stumpel ${ }^{2+3}$, J.P. Fryns ${ }^{1+2}$
}

\begin{abstract}
- Deparment of Human Genetics. Uniwersity Hospital Gasthuisberg. Leuven, Belgium: Department of clinical Genetics, Academic Hospital Maastricht, Maastricht, "Research Insitute Growth \& Development (GROW), Maastricht University, Maastricht, The Netherlands
\end{abstract}

\begin{abstract}
Rett syndrome (RTT) is a neurodevelopmental disorder which is diagnosed clinically. We report on 30 adolescent and adult females with classical or atypical RTT of whom 24 have a MECP2 mutation. In these 24 females the clinical manifestations, degree of severity, and disorder profiles are discussed as well as the genotype phenotype correlation. After X-chromosome inactivation study in these cases we found no correlation between skewing and milder phenotype. Three large deletions were found after additional Southern blot analysis in three classical RTT cases. We confirm that early truncating mutations in MECP2 are responsible for a more severe course of the disorder. Three disorder profiles related to the missense mutations $R 133 C$ and $R 306 C$, and to deletions in the $C$ terminal segment are described and are of interest for further clinicall study on larger numbers of cases. The $\mathrm{R} 133 \mathrm{C}$ genotype has a predominantly autistic presentation while the R306C genotype is associated with a slower disease progression. The phenotype of the "hotspot" deletions in the $\mathrm{C}$ terminall segment is predominantly characterized by rapid progressive neurogenic scoliosis. Older women with RTT are underdiagnosed: 7 adults were first diagnosed as having RTT between 29 - 60 years of age, and confirmed on finding a MECP2 mutation. Knowledge of the clinical phenotype of RTT at an adult age is important for all involved in the care of these individuals. The involvement of the parent support group is very important in this matter.
\end{abstract}

\section{INTRODUCTION}

Rett syndrome (RTT) is a worldwide important cause of severe mental retardation affecting mainly females in early childhood. The prevalence is estimated at $1 / 10,000$ girls at 14 years [Kerr. 1992]. It is second only to Down syndrome as the cause of severe mental retardation in females. The syndrome became internationally known in the early 1980 's [Hagberg et al. 1983]. Unaware of Andreas Rett's description [Rett, 1966] Hagberg had diagnosed RTT in Sweden between 1960 and 1982 under the eponym Morbus Veslan [Witt-Engerstrom, 1990].

RTT is a clinical diagnosis made on the basis of internationally accepted clinical criteria [Hagberg et al., 1990, 1993, 1994]. Beside a classical Rett syndrome (CR), several variants. are reported. The forme fruste (FF) runs a milder, incomplete course that is more protracted in time. Developmental deviations are less abrupt or less prominent than in classical RTT. Hand use may be more or less preserved and handstereotypies may be absent or atypical. In this most common form of variant RTT clinical diagnosis remains tentative until age 11-13 years. Other variants include the presenved speech, the congenital onset, the late regression, the infantile seizure onset and the male variant.

Since 1999 , RTT is known to be the result of a mutation in the MECP2 gene at $\mathrm{Xq}_{2} 8$ and encoding the methyl-CpG-binding protein 2 (MeCP2). This ubiquitously expressed DNAbinding protein is particularly abundant in the brain [Amir et al., 1999], and is thought to suppress the tissue specific genes whose activity is not required [Yntema et al. 2001]. It is proposed that loss of function of MeCP2 in cells, especially in differentiated postmitotic neurons, leads to inappropriate overexpression of other genes with a potentially damaging 
effect during central nervous maturation [Ellaway et al., 2001]. MeCP2 contains a 85-amino acid methyl CpG binding domain, a 102-amino acid transcriptional repression domain, wo nuclear localization signals, and a C-terminal segment. The coding sequence for the methyl CpG binding domain is split between exon 3 and 4 , whille the transcription repression domain lies entirely in exon 4 [Nan el al., 1996, 1997]. The methyl binding domain of the MeCP2 protein binds specifically to 5 -methyl-cytosine throughout the genome. The transcription repression domain interacts with histone deacelylase and the transcriptional silencer corepressor $\operatorname{Sin} 3 \mathrm{~A}$. The nuclear localization signals mediate the transport of MeCP2 into the nucleus and the $C$ terminal segment facilitates binding to the nucleosome core [Huppke et al., 2000; Chandler et al.,1999]. These interactions result in deacetylation of histones and chromatin condensation, which leads to repression of transcription [Nan et al 1998; Wan et al., 2001]. Over 185 disorder-related mutations have been described. An $85 \%$ mutation detection rate occurs in individuals with classical RTT, 76-80\% in classical and atypical RTT together; in the familial cases surprisingly only $29 \%$ [Cheadly ef al., 2000]. More than $95 \%$ of mutations occur de novo. The missense mutations seem to cluster in the methyl binding domain. The early truncating mutations are the stopcodon mutations and frameshifts that cluster in the transcription repression domain. Late truncating mutations occur in the $C$ terminal segment of the gene.

The aim of this study was to evaluate the clinical findings in adolescent girls and women with a clinical diagnosis of RTT and a proven MECP2 mutation (Fig. 1). We evaluated whether clinical phenotypes with a recognizable clinical pattern regarding severity and preservation of cognitive and motor functions were related to the type and localization of the mutation in the MECP2 gene.

\section{PATIENTS AND METHODS}

In the period 1985 to 2004 and prior to mutation analysis, the first author clinically diagnosed 30 females with RTT, 13 with classical RTT and 17 with atypical or variant RTT. Of the latter, 10 had the forme fruste, 2 the preserved speech , 1 the congenital onset, 1 the late regression, and 3 the infantile seizure onset variant of whom two were monozygotic twin sisters.

One woman with classical RTT in stage IV has died during this period at the age of 22 years. The other 29 females, born between 1941 and 1987 , were reassessed and scored using 2 scoring systems. Score 1 results from the scoring system for manifestations common in RTT [Kerr et al., 2001]. The maximum score being 40 , a score above 30 is considered as very severe, a score above 25 as severe. A score between 10 and 25 is considered as mild to less severe. A simplified scoring system was devised for our study (score 2) where only gross motor sitting (1) and walking ability (2), remaining functional hand use (3), speech ability (4), epilepsy (5), and neurogenic scoliosis (6) were assessed. In this simplified approach one can obtain a more direct estimation of severity. These parameters were considered to influence the most the clinical degree of severity at the time of our examination. A score from 0 to 3 was given for the different items:

0 for the normal situation;

1 when there was impairment without total loss of motor ability - reduced hand use-some preserved speech - previous epilepsy or seizures well controlled by medication - mild scoliosis;

2 when there was loss of function - apraxia - no speech - uncontrolled epilepsy - severe scoliosis;

3 when the function was never acquired - status epilepticus - surgery for scoliosis.

Walking was considered as not impaired when they could move inside the house or for a short distance, regardless of the degree of equinus or other foot deformity. Automatic hand use like self feeding, opening doors, taking a hand was not considered as this is seen in most of the RTT females with a less severe course. Preserved speech was determined as 
the use of two word phrases and the learning of new words or names. The maximum score is 18 and a total above 9 was considered as severe to very severe.

Mutation analysis on DNA of all 30 RTT females was performed by DHPLC screening followed by sequencing analysis to confirm and identify the nature of the mutation. Exons 3 and 4 of the MECP2 gene were amplified by a standard touch down PCR from genomic DNA in respectively 2 and 5 overlapping fragments, essentially as decribed by Amir et al. [1999]. The fragments were analysed by DHPLC (WAVE system, Transgenomic). Gradient conditions and oven temperatures were determined by the WAVE maker 4.0 sofware. Possible mutations were subsequently identified by sequencing with Big Dye Terminators as described by the manufacturer (Applied Biosystems) and analysed on ABI3100 (Applied Biosystems). In the initially mutation negative subjects, analysis was expanded by complete sequencing and LR PCR. Finally a Southern Blot was performed in 9 fernales as described by $\mathrm{E}$. Schollen et all. [accepted 2003].

X-chromosome inactivation (XCl) was studied essentially as described by Allen et al. [1992]. Briefly, $1 \mu \mathrm{g}$ of DNA (of periferal bload) was digested with Cfol or Hpall prior to PCR amplification. The $C A G$ repeat of exon 1 of the androgen receptor was amplified as described. Amplicons were analysed on a ABI310 (Applera). Peak area's were compared before and after digestion. $\mathrm{XCl}$ was calculated as the ratio of the area under the curve (AUC) of the smallest allel after digestion with the AUC before digestion, taken into account the amplification efficiency of both alleles.

\section{RESULTS}

Mutations were detected in 24 of the 30 females with RTT $(80 \%)$ : in $13 / 13$ of the classical cases $(100 \%)$, in $11 / 17$ of the variant cases $(64.6 \%)(7 / 10$-forme fruste, $2 / 2$ preserved speech, $1 / 1$ congenital onset, $1 / 1$ late regression variant). In the 3 infantile seizure onset variants no mutation was found. Only these 24 cases will be further discussed. Table I summarizes all data, the results of the mutation analysis, the $\mathrm{XCl}$ study and the two scoring systerms. In Table II additional clinical comments are given.

Sixteen subjects had been followed for 10 or more years. In 7 women RTT was first recognized between the age of 29 and 60 years: 5 classical (cases 10, 12, 13, 14, 15) , 2 forme fruste (cases 1,5) and 1 congenital onset (case 19). Most of them had moved into institutions or group homes and only 5 women visited a daycare centre.

Six recurrent mutations were found: $R 133 \mathrm{C}(3), \mathrm{P} 152 \mathrm{R}(2), \mathrm{T} 158 \mathrm{M}(2), \mathrm{R} 255 \times(1), \mathrm{R} 294 \times$ (2) and R306C (4). Three small deletions in the $3^{\prime} U T R$ were identified (1151del41 (1), 1163 del45 (1), 1164 del 44 (2)) as well as three large rearrangements. Three point mutations were not previously reported: $\mathrm{E} 10 \mathrm{Q} \quad(28 \mathrm{G}>\mathrm{C}), \mathrm{Q} 128 \mathrm{P} \quad(383 \mathrm{~A}>\mathrm{C})$ and $830 \mathrm{del} \mathrm{C}$. The missense mutation $E 10 Q$ was found in a woman of 60 years with $F F$. The complete cading region of MECP2 was sequenced in this patient, and no other sequence variations were found. To exclude a large deletion in exon 4 , a long range $P C R$ encompassing the entire exon 4 was performed. The glutamic acid ( $G$ or Glu) at position 10 is downstream of the methyl binding domain and partially conserved (conserved between human and mouse but not rat). No parental material was avallable to check segregation with the disordier. Her older sibs could not yet be examined. At this moment we have no tools to confirm that the E10Q mutation is pathogenic. The Q128P occurred de novo. The glutamate (Q or Glu) at position 128 occurs in the methyl binding domain and is completely conserved. The single base (C) deletion at position 830 in case 18 results in a frameshift at amino acid 277 and a stop codon at position 990 .

$X$-chromosome inactivation was studied in the 24 patients with mutation (Table I). Five patients (cases $5,9,13,16,21$ ) showed skewed $X$ inactivation with ratio's $<20 \%$ or $>80 \%$. No parental material was available to determine which allele was preferentially inactivated. Two patients were not informative (case 12, 24). The other 17 patients were classified as random $X$ inactivation with ratio's between 20 and $80 \%$. 
Of the 30 cases 6 individuals had no detectable mutation. In all the classical RTT females a mutation was found. The technique of DHPLC screening and of sequencing does not detect large deletions in the gene. Cases 6,23 , and 24 were detected after Southern blot analysis as having a large deletion encompassing exon 3 and most of exon 4 [ $\mathbb{E}$. Schollen et al., $2003_{i}$ accepted]. The finding that the 3 cases with infantle seizure onset variant and 3 with the forme fruste did not show a mutation is consistent with previous reports [Monros et al.; 2001]. In the etiology of early infantile epleptic encephalopathy RTT can be considered as a differential diagnosis. Both disorders have a devastating effect on infantile brain development with some recuperation of dentrical and synaptical arborisation in childhood. Therefore it is not unllikely that they mimic each other in disease profile. Whether this is caused by a mutation in the same gene remains to be investigated.

Only the 24 adolescent and adult females with RTT and a MECP2 mutation are discussed further. The individuals were clinically classified as having classical RTT or some variant RTT. The severity of the disorder depended especially on the remaining sitting and walking ability. the degree ofy preserved speech, the variable degree of scoliosis and on the manifestation of other RTT related neurological problems such as epilepsy and symptoms of brainstem overexcitability at the age of examination. Thirteen of the RTT females $(54.1 \%)$ had preserved, $4(16.6 \%)$ had impaired sitting ability and $7(25 \%)$ had lost this ability. Walking ability was preserved in $10(42 \%)$ with score 1 between $10-22$ and score 2 between $4-6$, and considered as having mild RTT. The 7 individuals ( $29 \%$ ) that had never learned to walk had a score 1 from 26 to 34 and a score 2 of $12-15$ and were considered severe to very severe RTT. The 7 individuals $(29 \%)$ with impaired gait or who had lost their walking ability had score 1 between $18-26$ and score 2 between 10-12. Handuse was absent in $54 \%$ and reduced in the remaining $46 \%$. Epilepsy was problematic or uncontrolled by medication in $5(21 \%)$ and $17(79 \%)$ never developed seizures or had previous seizures well controlled by medication. Scoliosis was operated in $10(42 \%) ; 1$ (case 21) at 12 y, 8 in late adolescence or young adulthood (cases $6,7,16,17,20,22,23$, 24), 1 (case 10) at 41 years. They all had a severe dextro-sinistro-convex scoliosis which was especially rapidlly progressive in cases 20,21 , and 22 . In the remaining cases, scoliosis was either absent or mild, or did not progress after adolescence. Case 19 has a severe kyphoscoliosis but was surprisingly stable in her fifties. The decision to operate was taken in function of the degree of the spine deformity in relation to its clinical repercussion on postural and pulmonary functions, and on the basis of preventive management and nursing perspectives.

Classicall symptoms of RTT were less obvious in the older age group. Although constantly present and dominant in childhood, handstereotypies were less intense in the adult group. Sometimes the hands were simply held fixed at the midline without any contracture in the wrists and with very few distortions of the finger joints. Problematic or dominating breathing irregularities with vacant spells and color changes were present only in the 5 cases with $C R$ with the highest score 1 (case $8,15,16,17,23$ ). A score above 30 in the first scoring system reflects an evolution towards a very severe clinical condition or the state of "frozen rigidity" [Hagberg, 1993]. This was demonstrated in cases 8, 15, and 23. A score below 25 reflected a milder to less severe condition at the time of examination.

The frequency and the spectrum of mutations in the MECP2 gene, identified in 21 out of 30 RTT cases is consistent with the general observations [Dragich et al., 2000; Girard et al., 2001; Lee et al., 2001]. We found 3 cases with gross rearrangements and could identify the breakpoints in 2 of them ( $E$. Schollen et al., 2003). We confirm the generally milder course in patients with missense mutations compared to those with early truncating mutations [Cheadly et al., 2000]. The most severe classical RTT females in this series have the early truncating mutations R255X and R294X located in the transcription domain, the P152R missense mutation located in the methyl binding domain, and two out of three females with 
gross rearrangements (case 6,23 ). The third case (case 24) had only milder breathing symptoms and her epilepsy was well controlled by medication. She was passively urinecontinent. The missense mutations in the methyl binding domain and the late truncating mutations in the $\mathrm{C}$ terminal segment leave some residual function of the protein and therefore probably run a more protracted or milder course in time [Huppke et al, 2000].

A relatively low number of cases with early truncating mutations was found in our series. The women above 25 years of age with severe RTT related to these mutations may no longer be alive or not be diagnosed at the time of this study. In the 7 RTT subjects diagnosed above 29 years of age only one (case 15) had an early truncating mutation: Mortality probably is higher in this group because they develop the most life threatening events (severe scoliosis, refractory epilepsy, brainstem instability , SIDS, etc.) from infancy to adolescence. Missense mutations and the late truncating mutations in the CTS may still be responsible for severe and milder RTT phenatypes as well. However the numbers are too small to allow separation into distinct groups.

The five cases. [table I] with skewed $X \mathrm{Cl}$ patterns were clinically not different from the others that showed random XCI patterns. The slight differences in their scores is probably more age related as the disorder evolves in time.

In this group of 24 MECP2 mutation positive females we observed three different groups of atypical RTT on the basis of a particular clinical profile and pattern of evolution.

The first is the forme fruste in cases 3,4 , and 5 with the R133C missense mutation in the methyl binding domain. They had predominantly hyperactivity and autistiform behavior in childhood and stability in evolution over decades in time with well preserved ambulation and few neurogenic signs. A common sign in 2/3 was unexpected yelling or laughing. None used words or phrases but apparently understood some of the routine conversation. None presented with breathing irregularities. Epilepsy was either never present or well controlled by medication. They obtained the lowest scores because of their good clinical condition silll recognizable as RTT, having a profile of hand stereotypes, dyspraxia, and typical visual contact behavior.

The second group consists of cases $11,12,13$ and 14 with the R306C missense mutation in the transcription repression domain. They evolved with a slow progression of neurological signs from infancy (tiptoe walking to equinus feet), no epilepsy or well controlled by medication, and a milder scoliosis requiring no operation. They remained relatively stable through adolescence into adulthood, even above 40 years of age. They were remarkably quiet in their behavior although the youngest was prone to agitation due to an unadapted surrounding. Ambulation in these women became impaired because of slowly progressive spasticity in the lower limbs causing severe kyphosis at an older age.

The third group comprises the variant cases 19,20,21, and 22 with rapidly developing and severe scoliosis (or extreme kyphosis), and secondary foot deformily as signs of marked dystonia. Cases 20 and 22 had some preserved hand use and some preserved speech. Case 19 was retarded in growth and development from birth on and therefore considered as having the congenital onsel variant. She used her hands only to open doors and as a support in transfers. Case 21, diagnosed as a forme fruste, had a protracted course, and used her hands to seek contact or to grab quickly cookies from a dish when allowed by her parent. They all had a deletion in the $\mathrm{C}$ terminal segment of the gene. They presented early as atypical RTT with more preserved functions in adulthood but with a rapid progressive spine deformity that threatened their ambulation and general health. Behaviorally they were curious, alert, friendly, tempting and teasing, but prone to agitation when they did not feel safe.

Based on our observations, one has to be very careful in predicting an outcome of a specific type of mutation in a newly diagnosed RTT girl. This is difficult as parents appeal to the clinicians responsibility for correct diagnostic and therapeutical support for their growing daughter. In order to help organize the lifelong care for people with RTT if is of great 
importance that basic knowledge and understanding of this disorder be transferred between pediatric and adult medicine [Berg, 20011].

\section{CONCLUSION}

RTT remains largely a clinical diagnosis. The scoring list for manifestations common in RTT [Kerr et al., 2001] is a practical toof in the evaluation and follow up of girls with RTT as severily differs in function of age. Preserved motor and adaptive abilities, therapy resistant epilepsy and the degree of scoliosis are the most important features in establishing the degree of severity at an adult age as we assessed in score 2 . Above the age of 25 to 29 years one deals with a survivor group that has a more or less stable condition sometimes for many years to come. Seven were diagnosed and confirmed by mutation finding between 29 and 60 years of age. They were all living in institutions or group homes. Therefore we believe that in the residential care for the mentally disabled the older women with RTT are probably underdiagnosed or at least not clinically recognized as having $\mathbb{R T T}$. In classical RTT with no detectable MECP2-mutation after routine screening and sequencing additional Southern Blot analysis or related techniques are necessary to exclude gross rearrangements in the gene. The confirmation of gross rearrangements in three cases lead to $100 \%$ mutation finding in classical RTT females in this series. In the 24 mutation positive cases there were 5 with skewed $\mathrm{XCl}$ pattern. This could however not be related to the clinical severity in comparison with cases with random $\mathrm{XCl}$.

Continued detailed clinical and molecular studies of the phenotypic effects of MECP2 mutations in RTT are needed to contribute to the knowledge and understanding of this peculliar developmental disorder and to its preventive management on the long term. The involvement of the parent support group is very important and much appreciated in this matter.

\section{REFERENCES}

Allen RC, Zoglhbi HY, Moseley AB. Rosenblatt HM, Belmont JW. 1992. Methylation of Hpath

and Hhal sites near the polymorphic CAG repeat in the humar androgen-receptor gene correlates with $X$ chromosome inactivation. Aim J Hum Gienet. Dec; 51 (6):1229-39.

Amir $R_{\text {: }}$ Van den Veyver I, Wan $M$. Tran $C$. Francke $U_{*}$ Zoghbi $H .1999$. Rett Symdrome is caused by mutations in $X-$ linked LMeCP2, encoding methyl-CpG-binding protein 2. Nat Genet 23:185-188.

Berg M, Hagberg B. 2001. Rett syndrome: update of a 25 years follow up investigation in Sweden sociomedical aspects Brain Dev $23: 224-226$

Chandler SP. Guschin D. Landsberger N. Wolffe AP. 1999. The methyl-CpG-binding transcriptional repressor MeCP2 stably associales with nucleosomal DNA. Blochem 38:7008-7018.

Cheadly Jp, Gll H, Fleming M, Maynard J, Kerr A. Leonard H, Krawczak M, Cooper DN, Lynch S, Thomas W. Hughes H. Hutten M, Ravine D, Sampson. JR, Clark A. 2000. Long-read sequence aralysis of the MECP2 gene in Relt syndronte patients: corrallation of disease severity with mutation be and locallsation. Mum Mol Genet $9: 1119$. 1129.

Dragich J, Houwhk-Manwille I, Schaner C. 2000. Relt syndrome: a surprising result of muation in MeCP2.Hum Mol Gênet $9: 267-2375$

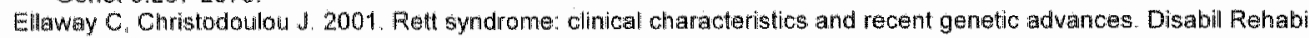
$23: 96-106$.

Girarc M, Gouvert P. Carre A, Tardieu M, Chelly J, Beldjord $C$, Bienwenve T. 2001. Parental origin of de novo MeCP2 mutalions in Rett syndrame. Eur J Hum Genet 9231-236

Hagberg $B$, Alcardi J, Dias $K$. Ramos 0 . 1983. A progressive syndrome of autism, dhementia, ataxia and loss of pulpussful handuse in girls: Rett's syndrome; neport of 35 cases. Ann Neuroll $14.471-79$

Hagberg B, Giberg C. 1993. Relt variants - Rettold types. In Rett Syndrome- Clnical and Biologicall Aspects, Clinics in Developmental Medicine Vol.127. p. 40-60. MacKeith Cambridge University Press. Cambridge, ISBN 052141283 8 .

Hagberg B, Goutieres F, Hanefeld $F$, Rett A, Wilson J. 1990. Rett Syndrome: Criteria for inclusion and exclusion. Brain Dev $12: 47-48$

Hagberg 9. Skeldal O. 1994. Rew Variants: a suggested model for inclusion criteria. Pediatr Neural 11:5-11.

Hagberg B. Hanefeld F. Percy A. Skjeldal O. 2002. An update on clinically applicable diagnostic criteria in Rett syndrome. Comments to Rett Syndrome Clinical Consensus Pamel Satelitite to European Paediatric Neurology Sochety Meating, Baden Baden, Gemany, 11 September 2001. Eur J Paediatt Neurol 6(5):293-7. 
Huppke P. Laccone F, Kramer N, Engel W. Hanefreid F. 2000. Rett syndrome: analysis of MECP2 and chlincal characterization of 31 patients. Hium Mol Genet 9:4359-1375.

Ken $A_{4}$ Witt-Engerström, editors. 2001. Retl Disorder and the Deweloping Brain. Oxford: Oxford University Press 2001 1 ISBN 0192630830

Ker AM, Nomura Y. Armistrong D, Anvret M, Belichenko PV, Bucden S, Cass H. Christodoulou $\Downarrow$, Clarke A, Ellaway C. dEsposito $\mathrm{M}_{\text {" Francke }} \mathrm{u}$. Hutten $\mathrm{M}$, Juk P. Leonard $\mathrm{H}$

Naidu $S$, Schanen $C$. Webb $T$. Engerstrom I, Yamashita Y, Segawa M. 2001. Gudelines for reporting clinical features in cases with MECP2 mutations. Brain Dew 23:2084211.

Kerr, A. 1992. Rett Syndrome British longitudinal study $(1982-1990)$ and 1990 survey. (Editor J.J. Roosendavin, pa. 143. 145. Mental retardation and Medical Care, 21-24 April 1991. Kerckbosch Publisher, 26eist. ISBN 9007201219.

Moinros $E_{2}$ Amstrong J. Aibar $E_{\mathrm{r}}$ Poo P. Canos 1. Pineda M. 2001. Rett syndrome in Spein: mutation analysis and clinical correlation. Brain Dew 23:251-253

Nan $X$. Tate $P$, Li E. Bird A. 1996. DNA methylation specifies chromosomal localization of MeCP2. Mol Cell Blo $10.414-421$.

Nan $X$, Campoy J, Bird A. 1997 . MeCP is a trainscriptional repressor with abundant binding sites in genomic chromatin. Cell $88: 47$ 1 -481 .

Nan X, Ng HH, Johnson CA, Laherty CD, Turner BM, Eisenman RN, Bird A. 1998. Transcriptional repression by the methyl-CpG-binding protein MeCP2 involves a histone deacetylase complex. Nature 393:386-389.

Rett A. 1966. Uber ein cerebral-atrophisches Syndrom bei Hyperammonamie. 1966. Wien Med Wochenschr. 1966 Sep 10,116(37):723-6.

Schollen E. Smeets E, Deflem E. Fryns JP, Matthijs 6.2003 . Gross rearrangements in the MECP2 gene in three pathents with Rett syndrome. Implications for rotitine diagnosis of Rett. Human Mutation. Accepted.

Wan M. Zhao $K_{i}$ Francke U. 2001. MeCP2 truncating mutations cause histone H4 hyperacetylation in Rett 3 wndirome. Hum Mol Genet 10:1085-1092.

Witt-Engerström I. 1990. Rett Syndrome in Sweden. Acta Paediatrica Scandinavica, suppl.369.

Yntema HG, Oudakker AR, Kleefstra T, Hamel BO, van Bokhoven H, Chelly J, Kalscheuer VM, Firyns JP, Raynaud M Moizard MP. Moraine C. 2002. In-frame deletion in MECP2 causes mid nonspecific mental retardation. Am J Med Genet 107(1) 81-3

Zapella $M$, Meloni I, Longo I, Hayek $G$, Renieri A. 20011. Preserved speech variants of the Rett syndrome: maleculair and cinical analysis. Am J Med Genet 104:14-2.2. 
Figure 1. A series of 12 RTI subjects numbered according to table 1. General facial appearance with emphasis on visual response and alertness.
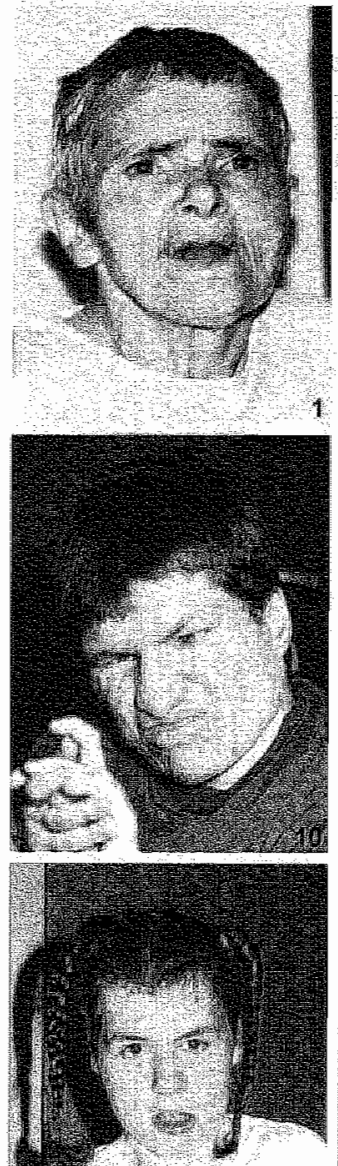

16
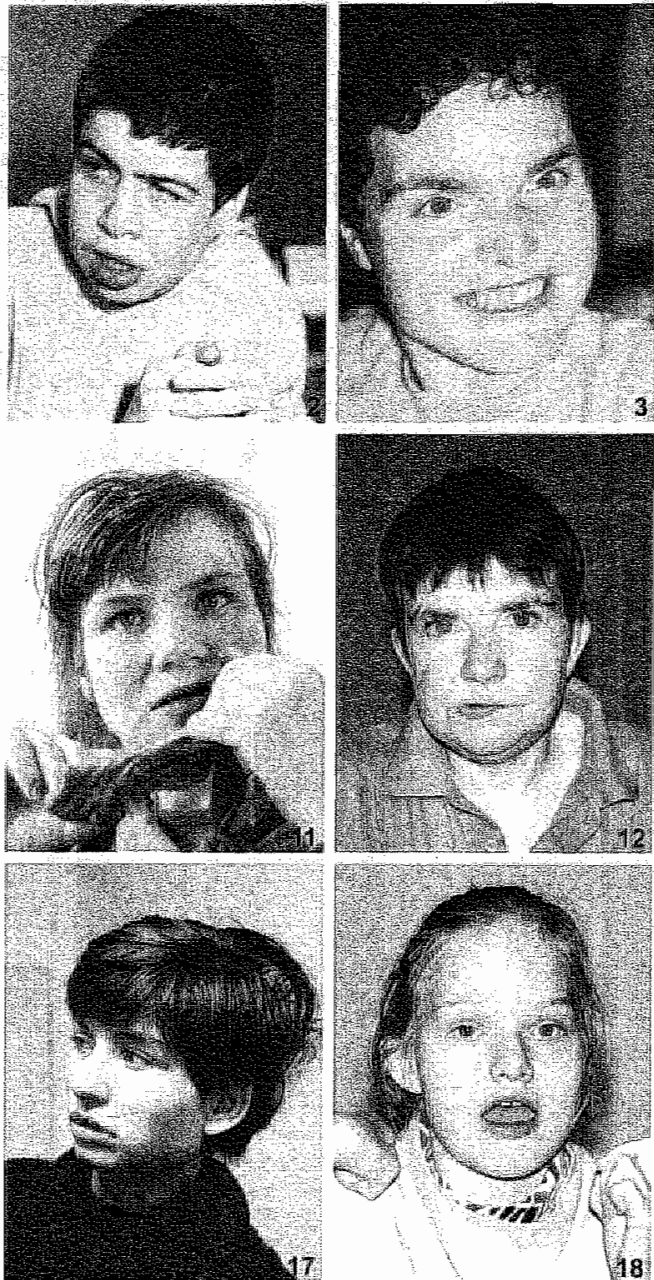
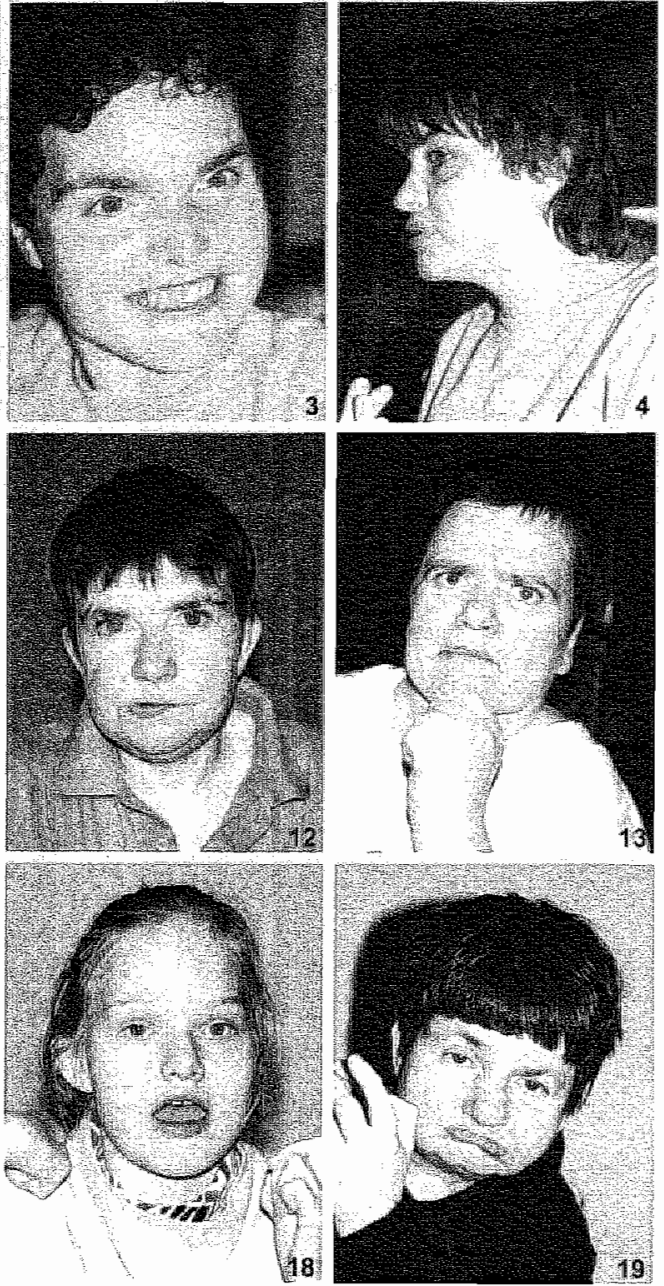


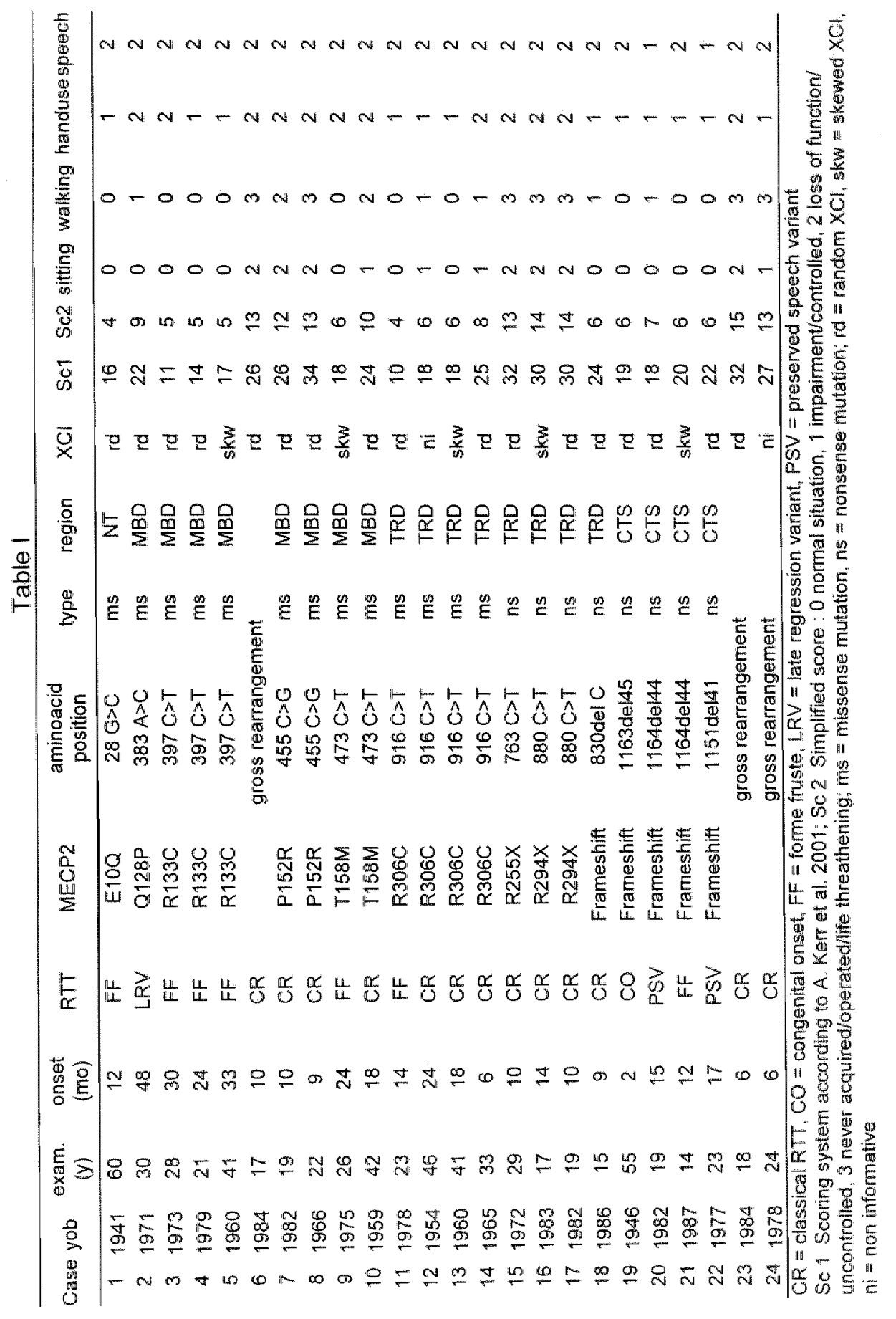




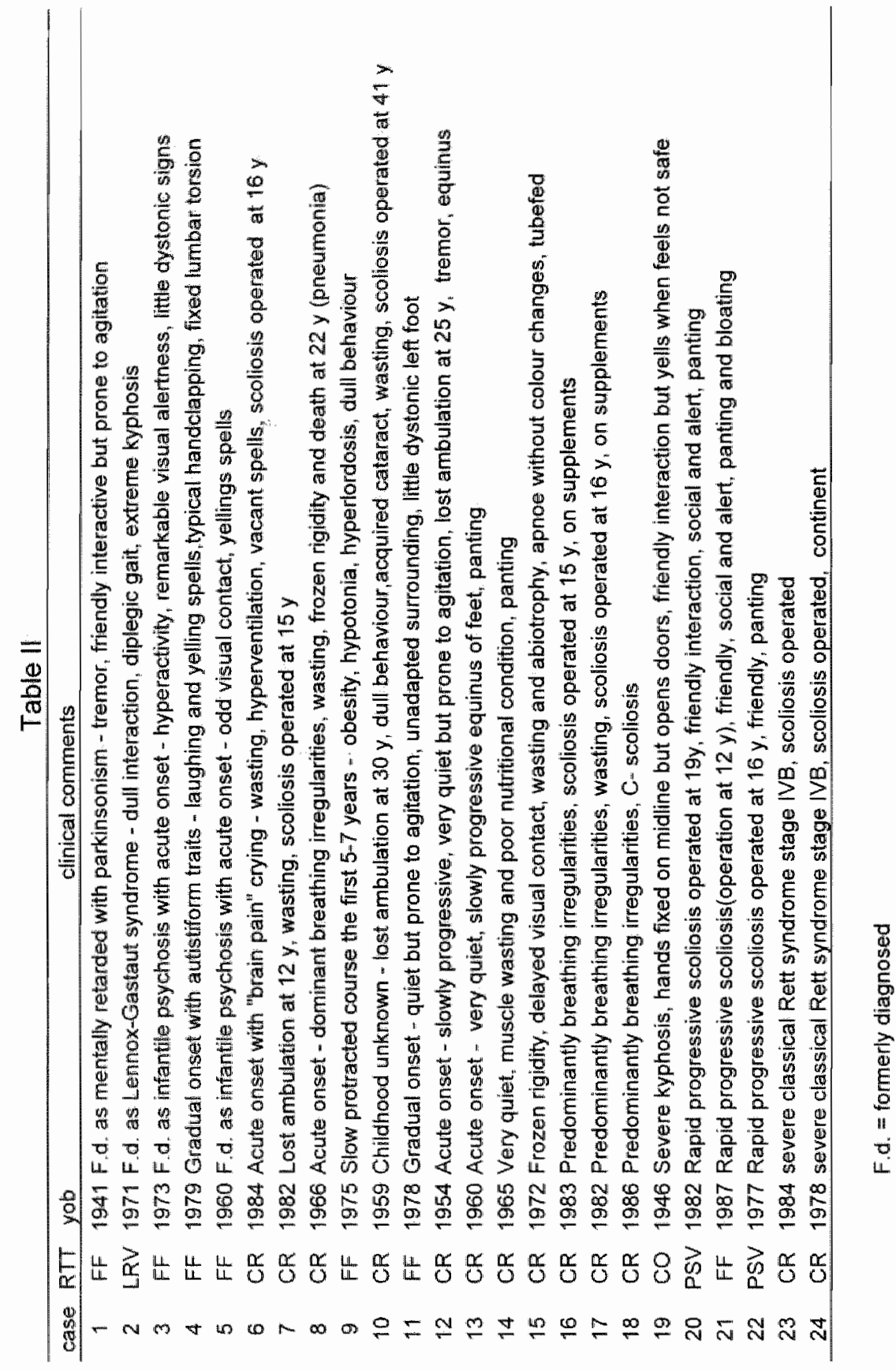


Rett syndrome in females with CTS hot spot deletions: A disorder profile.

Smeets E, Terhal P, Casaer P, Peters A, Midro A, Schollen E, van Roozendaal K, Moog U. Matthijs $G$, Herbergs J, Smeets H, Curfs L, Schrander-Stumpel C, Fryns JP.

Aim J Med Genet 2005, 132:17-20. 


\title{
Rett Syndrome in Females with CTS Hot Spot Deletions: a Disorder Profile.
}

E. Smeets ${ }^{1,2}$, P. Terhal ${ }^{3}$, P. Casaer ${ }^{4}$, A. Peters ${ }^{5}$, A. Midro ${ }^{6}$, E. Schollen ${ }^{1}$, K. van Roozendaal ${ }^{2}$, U. Moog ${ }^{2}$, G. Matthijs", J. Herbergs ${ }^{2}$, H. Smeets ${ }^{2}$, L. Curfs ${ }^{2,7}$, C. SchranderStumpel 2,7 J.P. Fryns,

\begin{abstract}
- Centre of Human Genetics, University Hospital Gasthuisberg, Leuven, Belgium. ${ }^{2}$ Depart. of Clinical Genetics. Academic Hospital Maastricht, Maastricht, The Netherlands ${ }^{3}$ Depart of Medicall Genetics, University Medical Center Utrecht, Utrecht, The Netherlands. "Depart. of Pediatrics, University Hospital Gasthuisberg, Leuven. Belgium." Depart. of Neurology, Unwersity Medical Center Utrecht, Utrecht, The Netherlends. ${ }^{3}$ Depart. of Human Genetics. Medical University of Bialystok, Bialystok, Poland. "Research Institute Growth Q Development, Maastricht University, Maastrictit, The Netherlands
\end{abstract}

ABSTRACT: From a series of 107 females with Rett syndrome (RTT) we describe the longterm history of 10 femalles with a deletion in the C-terminus of the MECP2 gene. We obsenved that their disorder profile is clinically recognizable in time and different from otheir atypical and milder RTT phenotypes. In females with hot spot deletions in the C-terminus dystonia is present from childhood and results more rapidly in a serious spine deformation in spite of all preventive measures. Their adaptive behavior is surprisingly better preserved and in contrast with the decline in motor functioning. The delineaton of disorder profiles by longterm clinical observation can learn more about the genotype/phenotype relationship and eventually about the effect of epigenetic phenomena on the final phenotype.

\section{INTRODUCTION}

Rett syndrome (RTT) is a neurodevelopmental disorder caused by a mutation in the methylCpG-binding protein 2 (MECP2) [Amir et al., 1999]. Classical and variant phenotypes are diagnosed clinically according to international criteria [Hagberg et al., 2001]. Literature data reveal that mutations are found in more than $80 \%$ of RTT cases, with the highest mutation rates in classical RTT and in about $65 \%$ of the variants [Smeets et al., 2003]. More than 200 different mutations have been described in RTT and about 10\% consist of intragenic deletions in the C-terminal segment (CTS) of the MECP2-gene, between nucleotides 1050 and 1200 [Sung Jae Lee et al., 2001]. The aim of the present study was to evaluate the long-term history of 10 females with deletions in this hat spot of the gene with respect to preservation of motor abilities, communication and behavior.

\section{MATERIALS AND METHODS}

Between 1983 and 2002 we examined 107 girls and women, aged between 2 and 61 years, with a clinical diagnosis of Rett syndrome. According to the revised clinical criteria for diagnosis of classical and variant phenotypes [Hagberg et all, 2001] 64 (60\%) presented the classical phenotype (CR) and $43(40 \%)$ one of the RTT variants (RV). We used the clinical scoring system as described by expert clinicians [Kerr et al., 2001] in all females. Each RTT individual was observed for personal abilities and behavioral characteristics and assessed by the first author together with the parents and /or caretakers. A second more simplified score was given leaving out sleep disorder and mood disturbance, breathing dysrhythmia, muscle tone, involuntary movements, head circumference and other growth parameters. In these milder RTT variants these manifestations were not markedlly present and not contributing to the clinical severity. Gross motor sitting, and walking ability, remaining functional hand use, speech ability, epilepsy, and neurogenic scoliosis were therefore considered more likely to influence the long term evolution. A score from 0 to 3 was given for these 6 items as shown in Table I. : 0 for the normal situation; 1 when there 
was impairment without total loss of motor ability, reduced hand use, some preserved speech, previous eplepsy or seizures well controlled by medication, mild scoliosis; 2 when there was loss of function, apraxia, no speech, uncontrolled epilepsy, severe scollosis; 3 when the function was never acquired, status epilepticus, surgery for scoliosis. The maximum score is 18: below 9 the condition was considered as mild.

DNA analysis of the MECP2 gene was performed by DHPLC screening followed by sequencing analysis to identify and confirm the nature of the mutation. Exon 3 and 4 were amplified by a standard touch down PCR from genomic DNA in respectively two and five overlapping fragments, essentially as described by Amir et al. [1999]. The fragments were analyzed by DHPLC (WAVE system, Transgenomic, Crewe, UK). Possible mutations were subsequently identified by sequencing with Big Dye Terminators as described by the manufacturer (Applera, Nieuwkerk a/d I. Jsel, The Netherlands) and analyzed on AB13100 (Applied Biosystems). In the initially mutation negative subjects, analysis was expanded by complete sequencing and LR PCR. Finally, a Southerm Blot and MLPA were performed to establish larger deletions or gross rearrangements as described by Schollen et al. [2003]. Xinactivation was studied in 24 of the 107 females. Tested $X$-inactivation patterns were skewed in five but could not be related to the degree of clinical severity. The overall mutation detection rate in the whole series was $87 \%, 92 \%$ in CR and $79 \%$ in RV. Recurrent mutations were found as well as complex mutations and gross rearrangements [Schollen et al. 2003]. We found 10 variants $(9 \%)$ with deletions in the hot spot of the CTS, all detected by DHPLC screening. Cases 1,5,6,7 and 8 were previously described [Smeets et al ., 2003].

TABLE I. Simplified score system

\begin{tabular}{|c|c|c|c|c|}
\hline score & 0 & 1 & 2 & 3 \\
\hline sitting & normal & impaired & lost & never acquired \\
walking & & impaired & lost & never acquired \\
handuse & & impaired & lost & never acquired \\
speech & & impaired & lost & never acquired \\
epilepsy & & impaired & uncontrolled & status epilepticus \\
scol/kyph & & impaired & severe & operated \\
\hline
\end{tabular}

\section{RESULTS}

Table I. presents the individual data of the 10 females, the molecular findings and simplified score at the time of the last examination. Retrospectively the age at diagnosis was between 3 and $\$ 3$ years in 9 individuals; individual 5 was diagnosed at the age of 54 years. All ten patients were able to sit. Walking was considered impaired in patients 4,7 and 10 . In patient 7 imbalance was due to anxiety after the operation for scoliosis and residual pain. Walking patterns, apart from being broadly based in all cases were particularly awkward in patient 4 and 10. They used their left leg to choose direction of gait tilting the other leg very high up before placing it back onto the floor causing them to walk in circles. Patient 9 (fig. 1.), the mildest in clinical presentation, took short stiff steps like in patients with Parkinson's disease (walking behind the gravity point). She needed orthopedic shoes with an upgrading under her forefoot to help her stop in time at the target. Hand use was reduced in 9 patients, and totally absent in patient 4. Hands were used in automatic handling (e.g. opening doors, clothing, shake hands, self feeding and drinking) as well as in intentional grasping. Intentional grasping is clearly present in most cases, but the reaching out is suddenly interfupted by flexion of the elbow and lost into the characteristic stereotyped movement. The preserved level of grasping "fine motor pincer grasp or gross motor tripod grasp, mimics the grasping patterns of young infants. Hands, fingers (and even feet) were also used in contact behavior for touching, caressing. pitching and skin picking. Speech was present in 
cases 1,6 and 7 with the use of several meaningful words or 2 word phrases in direct communication. This ability seems to fluctuate with age. Parents indicated in cases 1 and 6 that this ability was declining, and in case 7 regaining with advancing age. Epilepsy was uncontrolled by medication in patient 2. The remaining patients had been seizure free for many years or were well controlled by medication. The most remarkable manifestation in this group was their spine deformation. The scoliosis (cases $1,2,4,6,7,8$ ) was $S$-shaped and dextro-sinistro convex. It interfered with walking and pulmonary function necessitating surgical intervention in 4 patients in adolescence. In patient 2 parents refused surgery because of poor nutritional condition. Patient 6 had a severe but stable scoliosis at the time of examination at age 25 years. In the four patients $(3,5,9,10)$ with a high kyphosis the bending with protruding shoulders started in childhood and progressed in adolescence. The associated scoliosis was of the low lumbar torsion type.

Dystonia (or extrapyramidal asymmetry) is a well known manifestation of RTT. In these individuals it is probably the major cause of the spine deformation since hypotionia and muscle wasting were not present at the time of examination. The females with kyphosis might have had axial hypotonia; those with scoliosis more extrapyramidal asymmetry.

Table III. comments on their personal history, abilities and behavior. All females presented as RTT variant or form fruste in infancy except for patient 5 that presented with psychomotor retardation from birth on. She was diagnosed as congenital onset variant but without devastating early epileptic encephalopathy. The behavior of these 10 females can be defined as lively, curious, alert, friendly, tempting and teasing at younger age, and prone to agitation and crying when they feel not safe. Some remain often "in their own world" giving the impression of "autism". All of them used their eyes to express feelings "wishes and needs in the for RTT characteristic way. Many remain able to learn about new situations and persons in their daily surrounding. But in spite of a relatively well-preserved adaptive behavior they became more passive in behavior with lesser facial expression with advancing age.

TABLE II. Clinical and molecular data of 10 females with CTS hot spot deletions

\begin{tabular}{|c|c|c|c|c|c|c|c|c|c|c|c|c|c|}
\hline Case & yob & $\begin{array}{c}\text { nucleatide } \\
\text { chrange }\end{array}$ & $x C l$ & $\begin{array}{l}\text { onset } \\
\text { (mo) }\end{array}$ & $\begin{array}{c}\text { diagn. } \\
(y)\end{array}$ & $\begin{array}{c}\text { exam. } \\
(y)\end{array}$ & $\begin{array}{l}0 \\
\frac{1}{8} \\
0 \\
0\end{array}$ & 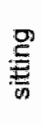 & $\frac{\frac{0}{E}}{\frac{\mathbb{E}}{\pi}}$ & 品 & $\begin{array}{l}\frac{5}{0} \\
\frac{6}{40} \\
\frac{0}{2 n}\end{array}$ & $\frac{\vec{a}}{\frac{a}{a}}$ & $\begin{array}{l}\frac{0}{10} \\
\frac{8}{8} \\
\frac{8}{0} \\
8 \\
0\end{array}$ \\
\hline 1 & 1977 & 1151 del41 & rd & 17 & 3 & 23 & 6 & 0 & 0 & 1 & y & 1 & 3 \\
\hline 2 & 1988 & $1152 \mathrm{de} / 4 \|$ & & 14 & 5 & 15 & 7 & 0 & 0 & 1 & 2 & 2 & 2 \\
\hline 3 & 1989 & 1157 del 44 & & 14 & 13 & 13 & 4 & 0 & 0 & 1 & 2 & 0 & 1 \\
\hline 4 & 1976 & $1159 \mathrm{del} 35$ & & 18 & 13 & 20 & 8 & 0 & 1 & 2 & 2 & 0 & 3 \\
\hline 5 & 1946 & 1163 de 45 & nd & 2 & 54 & 55 & 6 & 0 & 0 & 1 & 2 & 1 & 2 \\
\hline 6 & 1976 & $1164 \mathrm{de} \mid 44$ & rod & 12 & 10 & 25 & 5 & 0 & 0 & $\sharp$ & 1 & 1 & 2 \\
\hline 7 & 1982 & $1164 \mathrm{del} 44$ & rod & 15 & 2 & 19 & 7 & 0 & 1 & 1 & 1 & 1 & 3 \\
\hline 8 & 1987 & 1164 del 44 & skw & 12 & 4 & 14 & 6 & 0 & 0 & 1 & 2 & 1 & 3 \\
\hline 9 & 1989 & $1226 \mathrm{del} 41$ & & 18 & 11 & 13 & 3 & 0 & 0 & 1 & 2 & 0 & 0 \\
\hline 10 & 1985 & 1232 del 44 & & 12 & 9 & 17 & 6 & 0 & 1 & 1 & 2 & 1 & 1 \\
\hline
\end{tabular}

$X \mathrm{Cl}=X$ inactivation; $r d=$ random; skw $=$ skewed 


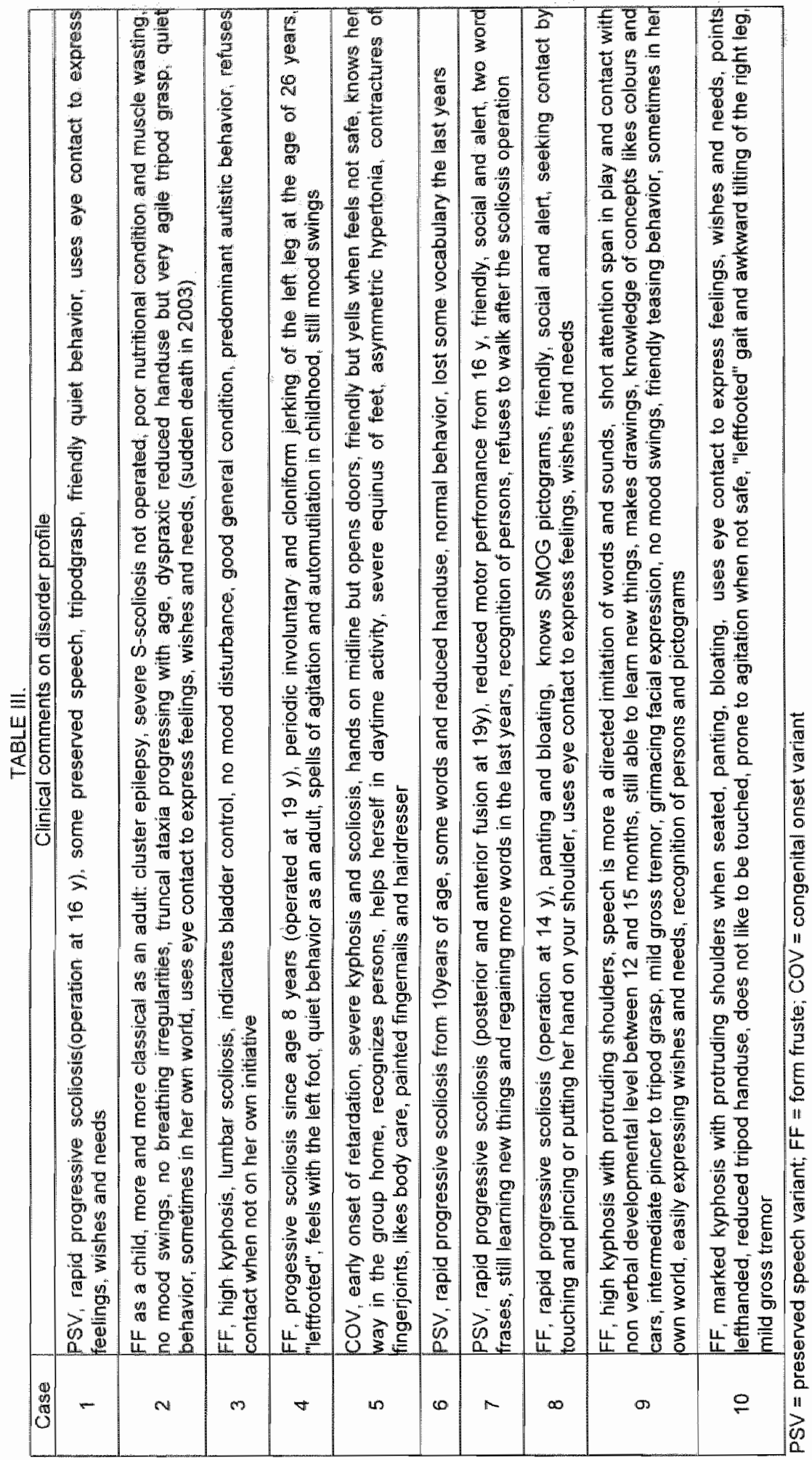




\section{DISCUSSION}

We report on 10 RTT females with an intragenic deletion in the C-terminal segment (CTS) of the MECP2 gene. Although they present as "classical" at older age, in the begining they are like the form fruste as described by Hagberg et al. $[1993,1994]$. The course of the disorder in all of them is more protracted in time, with more preserved cognitive functions in adolescence and adulthoad. Their main clinical problem is a gradual decline of gross motor ability in spite of all preventive measurements, and a rapidly progressive spine deformation as a consequence of marked dystonia that is present from childhood. With advancing age they become more impaired in walking, at least slower and more passive in general motor performance, more inappropriate in hand use and with the tendency to use lesser verbal expression (in the preserved speech variants). The short stature (as expected in classical RTT), the overall rigid posturing with pronounced kyphosils or scoliosis, the abiotrophic changes in skin and under laying muscles and the slowing of motor performance, give them a "pre-aging" appearance. In contrast with this decline in motor capacities is the preservation of simple communicative and cognitive abilities, even still able to recognize and to learn about new persons and situations in their daily surrounding far into adult life. Recently a case report of an odd RTT variant with a CTS hot spot deletion [Hagberg et al, 2003] was described. Her history and disorder profile seems very similar to the patients described in the present report. Hagberg ef al. [2003] refers to the ongoing neuromotor impairment as a decline "at the output-side" in contrast to a better functioning "at the input-side".

Describing disorder profiles, obtained through long-term observation can learn more about the genotype/phenotype relationship and might especially contribute to the understanding of eventual modifying factors [Renieri et all., 2003] or epigenetic phenomena influencing the expression of mutations [Chen et al. "2003, Martinowitch et al., 2003]. XCl patterns were not contributing to the disorder profile but were not studied in all cases. In our series the CTS hot spot deletions represent $9 \%$ of the RTT genotypes. This confirms that they form a major group in the spectrum of recurrent mutations [Laccone et al., 2001, Lee et al., 2000]. Some authors have correlated the type and the location of mutations with the clinical phenotype [Huppke et al., 2002]. They concluded that all mutations that lead to either complete or partial truncation of the region encoding for the nuclear localization signal are associated with a more severe phenotype than other truncating mutations. In addition there is evidence that the carboxyl-terminal segment of MeCP2 facilitates binding to the nucleosome core [Chandler et al.. 1999]. In CTS hot spot deletions truncation occurs beyond the coding regions and is not involving the nuclear localization signal. This might partially explain their atypical or "milder" course that is however in time still clinically recognizable as Rett syndrome.

Fig. 1. Patient 9 . at age 13 years.

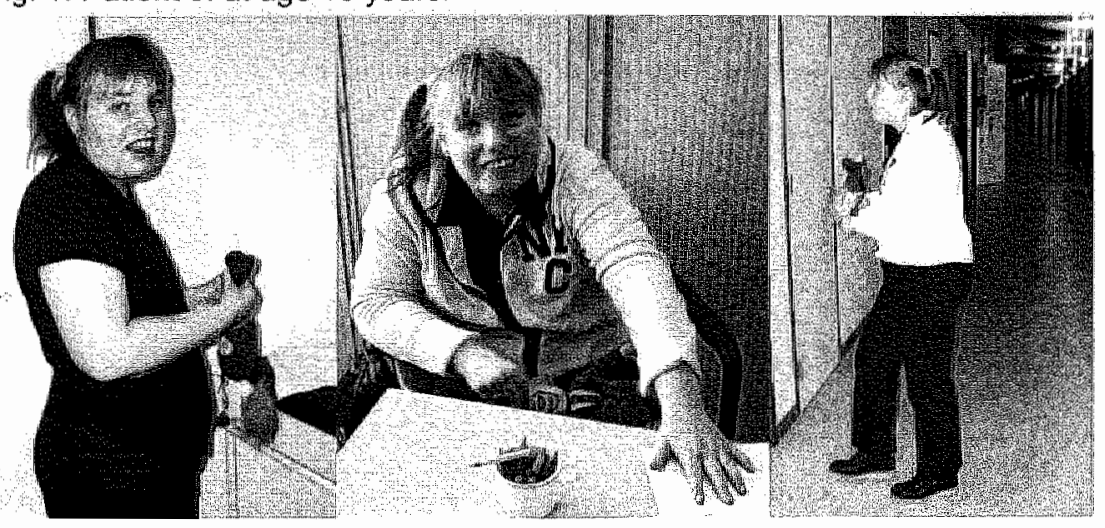




\section{CONCLUSION}

In our experience the CTS hot spot deletion clinically leads to a disorder profile that is recognizable in time and different from other atypical and milder RTT phenotypes. In females with CTS hot spot deletions dystonia produces more rapidly, from pre-school age on, a serious spine deformation in spite of all preventive measures. Their adaptive behavior is surprisingly better preserved and in contrast with a gradual decline in motor performance.

Grouping individual patients by location of their mutation in the MECP2 gene rather then by mutation type will contribute to the actual knowledge about the genotype-phenotype relationship. A long term follow up is important with respect to the development of therapies or rehabilitation measurements to eventually prevent further impairment.

\section{REFERENCES}

Amir Ran den Veywer I, Wan M, Tran C. Francke U, Zoghbi H. 1999. Rett Syndrome is caused by mutations in Xlinked LMeCP2, encoding methyl-CpG-binding protein 2. Nat Genet 23: 185-188.

Chandler SP, Guschini D. Landsberger N. Wolffe AP. 1999 . The methyl-CpG binding transcriptional repressor MeCP2 stably associales with nucleoscmal DNA. Biochemistry 38(22):7008-18.

Chen $W$, Chang $Q_{\text {. }}$ Lin $Y$. Meissner $A$, West $A$, Griffith $E$, Jaenisch $R$, Greenberg $M .2003$. Derepressition of BDNF transcription involves calcilum-dependent phosphorylation of MeCP2. Science 302(5646): 885.

Hagberg $B$, Aicardi $J_{,}$Dias $K$, Ramos 0.1983 . A progressive syndrome of autism,

dementia, ataxia and loss of purposefull hand use in girlsi: Rett's syndrame: report of

35 cases. Anin Neurol 14:474-79

Hagberg B, Gilberg C. 1993 . In: Rett Syndrome, Clinical and Biological Aspects, Rett variants - Rettoid types, Clinilcs in Developmental Medicine Vol 127, MacKeilth Cambridge University Press ${ }_{\text {in }}$ Cambridge, pp 40-60.

Hagberg $B_{3}$ Goutieres $F_{2}$ Hanefeld $F_{*}$ Rett $A$, Witson J. 1990. Rett syndrome: Criteria for inclusion and exclusion. Brain Dev $12: 47-48$.

Hagberg B, Skjeldal O. 1994. Rett variants: a suggested model for inclusion criteria. Pediatr Neurol $\$ 1: 5-11$.

Huppke $P$. Held $M$, Hanefeld $F$. Engel $W$, Laccone $F$. 2002. Influence of mutation type and location on phenotype in 123 patients with Rett syndrome. Neuropediatrics 33(2):63-8.

Kerr $A$, Nomura $Y$, Armstrong D. Anwet $M$, Belichenko $P$, Budden $S$, Cass $H$, Christodoulou J, Clarke $A, E$ Elaway $C$. d. Esposito M, Francke $U$. Hulten $M$, Julu $P$, Leonard $H$, Naidu $S_{x}$ Schanen $C$, Webb $\pi$, Engerstrom I, Yamashita $Y$, Segawa M. 2001. Guidelines for reporting clinical features in cases with MECP2 mutations. Brain Dev 23:208-211.

Laccone F. Huppke P. Hanefeld F. Meirs M. 2001. Mutation spectrum in patients with Rett syndrome in the German population: Evidence of hot spot regions. Hum Mutat 17(3):183-90.

Lee S. Wan M, Francke U. 2001. Spectrum of MECP2 mutations in Rett syndrome. Brain Dew 23:S138-S143.

Leonard H, Colvin L, Christodoulou ل, Schiavello T, Weaving L, Willamson S, Davis MD, Ravine D, Fyfe S, de Klerk N, Matsuishi T. Kondo I, Clarke A, Hackwell S, Yamasthita $Y$. 2003. Patients with the R133C mutation: is their phenotype different from Rett syndrome patients with other mutations? J Med Gemet 40\{5):53.

Martinowch $K$, Hettorl D. Wu H, Fouse $S, H e F$, Fan $G, S$, $Y$. 2003. DNA methylation-Felated chromatin remadeling in activity-dependent Bdnf gene regulation. Science 302(5646): 890.

Renieri A, Meloni I, Longo I. Ariani F, Mari F, Pescucci C. Cambi F. 2003. Rett syndrome: the complex nature of a

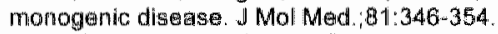

Schollen E. Smeets E, Deflem E, Fryns JP, Mathijs G. 2003. Gross rearrangements in the MECP2 gene in three patients with Relt syndrome: ilmplications for routine ditagnosis of Rett syndrome. Hum Mut 22(2): 116-120.

Smats E, Schollen E. Moog U, Mathijs G, Herbergs J, Smeets H, Curfs L., Schirander-Stumpel C, Fryns $v$ P (2003). Rett syndrome in adolescent and adult females: Clinical and molecular genetic findings. A.MMG 122A:227-233. 


\section{Addendum 3}

Approach and Management of Severe Abnormal Breathing in Rett Syndrome: a Case Report.

Smeets E., van Waardenburg D., Julu P., Witt-Engerstrom I. Hansen S. Apartopoulos $\mathbb{F}_{\text {., }}$ Curfs L. "Schrander-Stumpel C.

Brain Dev (submitted Dec 2004). 


\title{
Approach and Management of Severe Abnormal Breathing in Rett Syndrome: a Case Report.
}

\author{
Smeets $E^{1,5}$, van Waardenburg $D^{2}$, Julu $P^{3}$. Witt-Engerstrom $1^{4}$, Curfs $L^{1,5}$, Schrander- \\ Stumpel $\mathrm{C}^{1,5^{*}}$
}

Department of Clinical Genetics, Academic Hospital Maastricht, Maastricht, the Nethertandls; ${ }^{2}$ Diepartment of Paediatrics, Academic Hospital Maastricht, Maastricht, the Netherlands. ${ }^{3}$ Department of Neurology, Central Moddiesex Hospital INHS Trust, London, "Rett Centre, Fröson, Sweden" Research Institute Growth and Development (GROW). University of Maastricht, Maastricht, the Netherlands

Abstract: Rett syndrome is a neurodevelopmental disorder related to a mutation in methylCpG-binding protein2. Most distressing features are sleep disturbance and irregular breathing in the waking state as signs of brainstem immaturity. We present the clinical and neurophysiological data in a gir' with classic Rett syndrome and severe non-epileptic vacant spells. The rationale of treatment with pipamperon for sleep disturbance and with carbon dioxide inhalation for the autonomic events is discussed in relation to the effect on the quality of life. Key words: Rett syndrome, abnormal breathing, brainstem dysfunction, epilepsy

\section{INTRODUCTION}

Rett syndrome (RTT) almost exclusively affects girls between the age of 6 and 18 months in general, and is diagnosed clinically (Hagberg et al., 2001; Kerr et all, 2001). Recurrent as well as complex mutations and gross rearrangements are found in the gene encoding the methyl-CpG-binding protein2 (Amir et all, 1999, Schollen et al., 2003, Sung Jae Lee et al., 2001). The cascade of evolving clinical symptoms originates in cortical regions (mental retardation), extra pyramidal basal ganglia (dystonia, dysphasia) and brainstem nuclei (autonomic dysfunction)(Armstrong, 2002). Apart from orthopaedic deformation, muscle wasting, epilepsy and prolonged QT-interval, irregular breathing is a problematic feature in some classic RTT girls that might contribute to sudden death (Kerr and Witt-Engerström, 2001). Reduced expression of neuropeptides can be related to respiratory disturbances in Rett syndrome (Saito et al., 2001). Irregular breathing as a consequence of immature brainstem function has been explicitly described (Julu et al.2001). Manifestations like ASBA (Abnormal Spontaneous Brainstem Activation - Abnormal Sensitivity for Brainstem Activity). "brainstem epillepsy" and "brainstem storm", are defined in RTT girls and describe the neurophysiology behind the vacant spells as a consequence of sympathetic overactivity with insufficient parasympathetic control. Other autonomic dysfunctions in RTT are disturbed sleep with frequent daytime sleeping and night awakening, delayed nociception, cold extremities. The history and management of a RTT girl with sleep disturbance and severe abnormal breathing and secondary events are described and discussed below.

\section{CASE REPORT}

A girl born in 1990 was diagnosed as classic RTT by the age of 4 years. DNA analysis established more recently the $\mathrm{R} 306 \mathrm{C}$ missense mutation in the transcription-repression domain of MECP2. As a preschool child she developed hyperventilation and irregular breathing in the waking state. When she was 9 years old, repetitive non-epileptic vacant spells, frequent Valsalva breathing and apnoea with cyanosis became outmost problematic during the day. They also occurred during the night causing abnormal and variable duration of sleep. During two years preceding the assessment and treatment constant supervision from her parents andior co-educators was required. 
Typical vacant spells start with tachypnea, Valsalva breathing and frequent apnoea with cyanosis, with her head turning to the right (Fig.1), wringing hands, gazing upwards, stretching out with large extension movements of the limbs; subsequently becoming rigid and displaying jerky movements of upper and lower limbs and head, the arms being raised and thrown backwards (Fig.2). Her staring eyes remain opened "in panic". Afterwards she becomes quiet and sleepy. These spells may be short lasting or proceed to tonic-clonic seizures. In a more severe spell she also loses consciousness, often with cyanotic lips and is impossible to wake up for several hours. They happened several times during the day and less frequently at night. By defining them as "breathing attacks", the parents underline that these phenomena are different from her epileptic seizures that she had since the age of 6 years.

\section{METHODS}

In an attempt to improve her troublesome situation a planning for assessment and treatment was arganized in three steps: first, pipamperon was added in two daily doses of $20 \mathrm{mg}$ with a 12 hours interval, in order to regulate her circadian rhythm, the main characteristic of this Shydroxytryptophane blocker (Janssen and Awouters, 1994); second, her brainstem function was assessed (Rett Centre, Fröson, Sweden). During this assessment heart rate $(\mathrm{HR})$, systolic (SBP), diastolic (DBP) and mean arterial (MAP) blood-pressure, cardiovascular tone (CVT), baroreflex-sensitivity (CBRS), breathing rate and breathing rhythms, carbon dioxide $\left(\mathrm{PCO}_{2}\right)$ and oxygen $\left(\mathrm{PO}_{2}\right)$ were registered simultaneously both during pipamperon treatment (I and II) and 32 hours after withdrawal of pipamperon (III). Video recording and EEG during the hour of the session were performed simultaneously. Finally, based on the findings of repeated assessments, an inhalation therapy was installed as discussed below.

\section{RESULTS}

With pipamperon she fell asleep easily and slept the whole night without bouts of screaming, without abnormal breathing and without early awakening. During the day and by observation, there was a remarkable reduction in her Valsalva-breathing, the number of vacant spells and secondary events recorded since that time.

The results of the assessment of brain stem function are shown in table I.

During the first two recordings (with pimpamperon treatment) CVT and CBRS were low, in (I) on neonatal values, in (II) slightly better, but still low compared to normal. Blood pressures were within normal limits. The increased heart rates of 92-99 are typical of RTT and are due to decreased vagal tone. The baseline-breathing rate was $20-28 / \mathrm{min}$., with Table I. Monitoring of the cardiovascular system

$\begin{array}{lrrr}\text { Registration } & (1) & (\text { II) } & \text { (III) } \\ \text { CVT } & 2,0 & 4,9 & 4,3 \\ \text { CBRS } & 1,11 & 2,7 & 2,2 \\ \text { SBP } & 140 & 130 & - \\ \text { DBP } & 811 & 72 & * \\ \text { MAP } & 101 & 91 & 93 \\ \text { HR } & 99 & 92 & 96\end{array}$

extended periods of normal breathing allowing good opportunity for baseline values. Five abnormal breathing palterns were observed: Valsalva-manoeuvres, tachypnea, shallow breathing, apnoea (the longest of 67 seconds), and rapid shallow breathing. During periods of normal breathing the transcutaneously measured PO2 was normal and PCO2 below 
normal $\left(<22,5 \mathrm{mmHg}\right.$ ). During periods of Valsalwa breathing and tachypnea $\mathrm{PO}_{2}$ dropped down to $40 \mathrm{mmHg}$ while $\mathrm{PCO}_{2}$ could go down to $15 \mathrm{mmHg}$. When $\mathrm{PCO}_{2}$ decreased below $18 \mathrm{mmHg}$ she became apnoeic until $\mathrm{PCO}_{2}$ climbed up again. During these long apnoeas $\mathrm{PO}_{2}$ decreased as low as $40 \mathrm{mmHg}$. When $\mathrm{PCO} 2$ and $\mathrm{PO} 2$ values were low $A$ SBA nncreased resulting in the sudden activation of the blood pressures, heart rate, cardiovascular tone and central baroreflex-sensitivity.

The third time she was monitored 32 hours after withdrawal of pipamperon. She was more alert during the registration (III) but showed a higher number of Valsalva manoeuvres than in earlier registrations and the $\mathrm{PCO}_{2}$, went even further down. Only once a clinical seizure was documented on EEG. Tremulous movements that were often seen in her muscles did not look like tonic-clonic seizures and never correlated with epileptic discharges on EEG.

Onliy once a clinical seizure was documented on EEG. The tremulous movements that were often seen in her muscles, were different from tonic-clonic seizures and never correlated with epileptic discharges on EEG.

From the results of the brain stem assessment the hypothesis was made that hyperventilation with severe respiratory alkalosis and secondary apnoea with hypoxia were important factors in the origin of ASBA that lead to the severe vacant spells that parents defined as breathing attacks. In order to test this hypothesis she was adimitted to the paediatric intensive care unit and a carbon dioxide/oxygen gas mixture (40\% $\mathrm{CO} 2$ and $60 \%$ 02) at 2 litres/min. was given during daytime by means of nasal prongs. The content of this gas mixture was chosen to result in an estimated inspired $\mathrm{CO} 2$ concentration of approximately $3-4 \%$ in order to prevent hypocapnea and respiratory alkalosis during hyperventilation periods. Before this treatment was started, baseline values of heart rate, respiratory rate, transcutaneous $\mathrm{PCO} 2$ and $\mathrm{PO} 2$, and frequent arterial $\mathrm{PaCO} 2$ and $\mathrm{PaO} 2$ by means of an indwelling arterial catheter, were registered for 48 hours. During this observation period we could confirm the earlier observations of the brainstem function monitoring at the Rett Centre. Severe respiratory alkalosis $(\mathrm{pH}>7.7$, and PaCO2 $<15$ $\mathrm{mmHg}$ ) was repeatedly observed during hyperventilation. During the night her respiratory pattern was normal and normal $\mathrm{PaCO} 2$ values were observed. After CO2-inhalation therapy was installed no differences in $\mathrm{PaCO} 2$ values during normal breathing were observed compared to the baseline values, while during hyperventilation severe hypocapnea and respiratory alkalosis could be prevented $(\mathrm{pH}<7.6$ and $\mathrm{PaCO} 2>22 \mathrm{mmHg})$. More important a striking reduction in the frequency and severity of her "breathing attacks" was observed during a 5-day observation period. After the parents had been instructed how to use the $\mathrm{CO} 2 / 02$ mixture in the home situation she was discharged

Through observation during the next 12 months on diurnal $\mathrm{CO} 2$ inhalation therapy a $50 \%$ reduction in her discomforting breathing attacks was noted in comparison with the year before, and some of the event free periods lasted more than a week. Since we noticed that during the spell she preferentially breathed through her mouth we instructed the parents to use a mixture of $5 \% \mathrm{CO}_{2} 195 \% \mathrm{O} 2$ by facemask during the spell. This led to a further reduction in the number of these events and she could participate again in daily live activities at the day-care centre and at home. This was a big relief for the parents.

After 17 months of $\mathrm{CO} 2$ inhalation therapy we decided to re-evaluate her during a 5 -daly observation period in the paediatric intensive care unit. Baselime values of respiratory rate, heart rate, arterial blood pressures and arterial blood gases were obtained during $\mathrm{CO} 2 / \mathrm{O} 2$ inhalation therapy and were comparablle to those at the end of the first admission. Next the $\mathrm{CO} 2 / \mathrm{O} 2$ inhalation was stopped during 24 hours in which a dramatic recurrence of severe breathing attacks was observed during the waking state, again associated with severe respiratory alkalosis and prolonged intervals in which she lost consciousness.

EKG and echocardiogram were performed to exclude the possibility of secondary pulimonary hypertension or cor pulmonale and were normal. Q-TC intervals were not prolonged on Holter registration. The level of ionic calcium was normal on severall occasions. 


\section{DISCUSSION}

The sleep disturbance, the irregular breathing and especially the secondary events in this RTT girl were severely interfering with normallife.

Pipamperon induced her sleep and she slept through the night for the first time since many years. Also the frequency and intensity of irregular breathing and secondary events during the day were reduced. Pipamperon is a 5 hydroxy-tryptophane blocker with selective serotoninergic activity together with little dopaminergic and adrenergic action. Pipamperone is known to improve disturbed sleep, social withdrawal and other symptoms of chronic schizophrenia in the relative absence of extrapyramidal symptoms (Janssen and Awouters, 1994). Why it diminished the Valsalva breathing in frequency and intensity is not clear. Valsalvas increased considerably when Pipamperon was taken away and caused even lower transcutaneous carbon dioxide levels.

Brain stem function assessment showed that in this child tachypnea and valsalva breathing caused severe hypocarbia. The brainstem reacted with apnoea trying to increase the low $\mathrm{PCO}_{2}$, however at the cost of a severe decrease in PO2. This was followed by lack of contact, sometimes bending forward in her chair, and severe unsteadiness of all the cardiovascular variables. This makes us believe that her so-called "seizures" are in fact autonomic events caused by ASBA and severe derangement of the blood gases. These ASBA periods are a consequence of the immaturity of the brainstem in RTT, but provoked especially by the hypocarbia caused by her irregular breathing with Valsalvas. Valsalva decreases blood pressure and increases heart rate due to the increased intrathoracic pressure, thereby decreasing the return of the blood to the heart. On sudden expiration the blood rushes into the heart, heart rate decreases immediately and blood pressure restores. These swings of pulse and blood pressure may cause dizziness and a panic like "going down in a roller coaster" as described by Julu et al. (2001).

By preventing a fall in $\mathrm{PCO} 2$ the sequence of events as described above did not occur nor proceeded to the full extent of losing consciousness.

Before treatment with pimpamperone and $\mathrm{CO} 2$ inhalation therapy the symptoms in this child were outmost distressing to her and her surroundings. Although she always regained consciousness, even after the longest period of apnoea and cyanosis, for many years her caregivers often feared for her not to survive one of these attacks. Now her situation has much improved and she looks happy and content taking part again in a steady daily family life. To our knowledge she is the first to be treated in this way. The treatment is not a practical one with respect to materials and space occupying gas containers but acceptable for the parents and surroundings of this girl to improve her daily quality of life and appeared to be harmless.

\section{CONCLUSION}

We described the impact of severe non-epileptic vacant spells as clinical signs of brain stem dysfunction in a RTT girl. We could document through monitoring of the cardiovascular variables that these phenomena were based on ASBA. The exact action of pipamperon on improvement of sleep and breathing pattern in this RTT girl is not clear and needs further investigation. The treatment with extra $\mathrm{CO} 2 / \mathrm{O} 2$ mixture is beneficial in this RTT child with predominating autonomic brainstem dysfunction. No side effects were noted after 18 months therapy. 


\section{REFERENCES}

Amir RE, Wan den Veyer IB, Wan M. Tran CQ. Francke U. Zoghbi HY. (1999). Rett symdrome is caused by mutations in X-linked MeCP2, encod ling methyl-CpG-binding protein 2. Nat Genet;23:185-188.

Armstrong DD. Neuropathalogy of Rett syndrome. Ment Retard Dev Disabil Res Rev. 2002,8(2):72*6.

A.zmitia EC. Neuronal instability: implications for Rett's syndrome. Brain Dev. 2001 De0:23 Suppil 1:S\%-\$10.

Hagberg $B_{1}$ Hanefeld $F$, Percy $A$, Skjeldal 0 (2002): An update on clinically appliciable diagnastic criteria in Reft syndrome. Comments to Rett Syndrome Clinical Criteria Consensus Panel Satellite to Eluropeam Paediatric Neurology Society Meeting. Baden Baden, Germany, 11 September 2001. Eur J Paediatr Neurol 6(5),293-7.

Janssen P.A.J. and Awouters F.H.L. Is it possible the clinical effects of newroleptics from animal data? Part V: from halloperidol and pipamperone to risperidone. Arzneim. Forsch./Deug. Res 44 (1994), pp. 269 . 277.

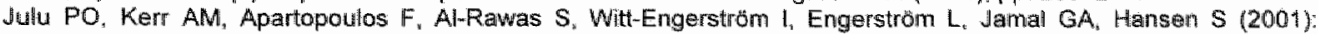
Characterisation of breathing and assaciated central autonomic dysfunction in the Riett disorder. Arch Dis Child $85(1): 29-37$

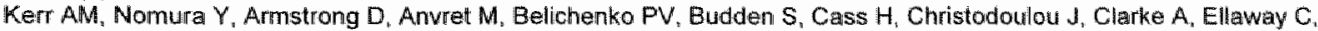
d'Esposito $M$, Francke U, Hulten M. Julu $P$, Leonard $H$, Naidu $S$, Schanen $C$. Webb $T$, Engerstrom M, Yamashita $Y_{3}$ Segawa M. Guidelines for reporting clinical features in cases with MECP2 mutations. Brain Dev 2001:23:208. 211.

Kerr A Witt-Engerstrom I. 200\%. Rett Disorder and the Developing Brain, eds. Oxford: Oxford Uniwersity Press 2001 ISEN 0192630830.

K.C. Mills, Serotonin syndrome, Crit. Care Clin. 13, (1997), pp. 763-783.

Guider $F$, Acampa $M$, Blardi $P$, de Lalla $A$, Zappella $M$, Hayek $Y$. Cardiac dyseutonomia and serotonin plasma lewels in Rett syndrome. Neuropediatrics. 2004 Feb;35; 1):36-8.

Fiikonen R. Neurotrophic factors in the pathogenesis of Rett syndrome. J Child Neuroi. 2003 Niovid 18(11):797

Schollen E, Smeets $E$, Deflem E. Fryns JP, Matthijs $G$ (2003): Gross rearrangements in the MECP2 gene in three patients with Rett syndrome: implications for rautine diagnosis of Rett syndrome. Humi Mut 22(2): $116-120$.

Sung Jae Lee $S$, Wan $M_{1}$ Francke U. 2001. Spectrum of MECP2 mutations in Rett syndrome. Brain Dev 23:S1385143 .

Yoshiaki Saito. Masayuki lto, Yuri Ozawa, Toyojiro Matsuishi, Kenzo Hamano, and Sachio Takashima Raduced expression of neuropeptides can be related to respiratory disturbances in Rett syndrome. Brain Dev. 2001 Dec;23 Suppl 1 : $\$ 122-6$. 


\section{Addendum 4}

The development of visual- and auditory processing in Rett syndrome: An Evoced Related Response study.

Stauder J., Smeets E., van Mil S., Curfs L.

Brain Dev (submitted Dec. 2004). 



\title{
The development of visual- and auditory processing in Rett syndrome: An ERP study
}

\author{
Johannes E.A. Stauder*" "Eric E.J. Smeets ${ }^{1,4}$, Saskia G.M. van Mil ${ }^{1}$, Leopold G.M. Curfs ${ }^{1,2}$ \\ 1 Department of Psychology, Section Nevrocognition, Maastricht Unwersily, Maastricht, the Netherlands: 2 \\ Department of Clinical Genetics. Academic Hospital Maastricht, Maastrich, the Nethertands; 3 Research linstitute \\ Growth \& Development (GROW), Maastricht Uniwersity, Maastricht, the Netherlands 4 Center of Human Geneticsi \\ University Hospital Gasthuisberg, Leuwen, Belgium
}

\section{ABSTRACT}

Rett Syndrome is a neurodevelopmental disorder that occurs almost exclusively in females. It is characterized by a progressive loss of intellectual functioning, fine and gross motor skills, and the development of stereotypic hand movements occurring after a period of normal development. Event-related potentials were recorded to a passive auditory- and visual oddball task in 17 females with Rett syndrome and age matched controls, between 2 and 60 years of age. Overall the participants with Rett syndrome had longer ERP latencies and smaller ERP amplitudes than the control group suggesting slowed information processing and reduced brain activation. Rett females also failed to show typical developmental changes in event related brain activity during childhood and revealed á marked decline in ERP task modulation with increasing age.

Key words: Rett Syndrome, passive oddball task, visual and auditory processing. ERP. lifespan development

\section{INTRODUCTION}

Andreas Rett first described Rett syndrome in 1966. The disorder is characterized by regression of language and psychomotor development at a certain age period, autistic behavior, dementia, unsteadiness, loss of purposeful use of the hands, and seizures $[14,15,27,34]$. Features like breathing dysfunction, electroencephalographic abnormalities. spasticity, peripheral vasomotor disturbance, scoliosis and growth retardation are common manifestations in Rett syndrome, although not all Rett females share these features to the same extent [8]. The syndrome occurs almost exclusively in females and has a prevalence of 1 in 10-15000 live born girls [21]. With the present clinical knowledge and molecular diagnosis the incidence is probably much higher. Therefore Rett syndrome, next to Down syndrome and Fragile-X syndrome, might well be an important cause of severe mental retardation in females. Rett syndrome is usually sporadic and only $1 \%$ of the reported cases are familial. In most cases, Rett syndrome is caused by mutations in MECP2, the gene encoding the $X$-linked methyl-CpG-binding protein 2 (MeCP2) located at Xq28 on the distal part of the X-chromosome. MeCP2 binds methylated DNA and plays an important role in gene silencing processes [8]. Defects in MeCP2 can lead to both an over- and under expression of multiple genes and its biochemical function suggests a critical role in development and maintenance of the nervous system $[29,33]$.

Classic Rett syndrome starts in early infancy and manifests particular symptoms at certain ages. The few studies that used standardized measures of cognitive function reported a mental age below eight months [26]. Hagberg and Witt-Engerström proposed a staging system that divides the natural history of Rett syndrome into four stages $[12,15,34]$. Stage describes the early onset stagnation in the infant between 6 and 18 months of age and is characterized by a developmental arrest, diminished interest in play, and decelerating head growth. Stage 11 is coined the rapid regression stage and starts between 1 and 4 years of age. Its most common features are developmental deterioration, severe dementia, loss of 
hand skills and spoken communication, irregular breathing pattern and appearance of seizures and the characteristic handstereotypies. Stage $\|$ ll starts when regression has stopped usually above 4 years of age and is called the pseudo-stationary stage. It is characterized by some communicative restitution, apparently preserved walking ability, and an unapparent slow neuromotor regression. Finally the late motor deterioration stage (stage IV) sets in when decreasing mobility leads to loss of independent walking. The age of death in Rett syndrome is variable with one third of deaths occurring in the first two decades of life. Some Rett syndrome women live to a relatively advanced age [8].

\section{Event related brain activity}

The electrical activity of the brain can be recorded via electrodes placed on the surface of the scalp. In recording this electrical brain activity during task performance it is possible to extract event-related potentials (ERP's) that are manifestations of brain activities that occur in preparation for, or in response to, discrete events, that can be internal or externall to the subject [10]. An ERP consists of amplitude changes over time characterized by a characteristic polarity (positive or negative peaks), latency and scalp distribution. The names given to the peaks of an ERP waveform usually include descriptors of polarity ( $P$ or $N$ ) and latency or order of appearance. A typical labeling system involves a descriptor of polarity followed by a number. In this case, a P3 refers to the third positive peak within the ERP waveform, while N2 refers to the second negative peak. The timing of a cognitive process modulated by a certain task can be inferred from the latency of the corresponding peak, and the amplitude of or the area under the peak can refer to the degree of activation or strength of the process [24].

The first major positive peak within an ERP is the P1. It is largest at the occipital sites and reflects early visual processing or encoding. Batty and Taylor [2] reported that the P1 amplitude decreases with age during childhood. Kushnerenko et al. [23] examined the maturation of auditory ERP's from birth untill 12 months of age. They found that the P150 amplitude increased during the first three months of life. Thereafter the P150 amplitude remained unchanged from 6 to 12 months of age. The P150 latency steadily decreased from three months of age. It was suggested that the P150 is the precursor of the childhood P100 that develops into the mature adult $P 1$ response by further decreasing in latency and amplitude from 6 to 20 years of age.

The MMN is the earliest ERP activity that indicates that the brain has detected a change in an otherwise invariant background of homogeneous events [11]. To derive the $M M_{1}$, the average waveform elicited by the standard (frequent) stimuli is subtracted from that of the deviant (rare) stimuli. This subtraction yields a negative component with onset latency as short as $50 \mathrm{msec}$ and a peak latency of $100-200 \mathrm{~ms}$. Its amplitude is largest at frontal and central electrode sites. An MMN is elicited whenever the standard and the deviant stimuli are discriminable on any features. The more different the stimuli, the shorter its latency and the larger the MMN amplitude. Since the MMN even appears when a subject is not attending the stimuli, it is likely that the MMN is related to the automatic and preattentive processing of deviant features. Therefore the MMN is used as an index of the operation of an early. preattentive sensory (echoic) memory [10].

The N200 (or N2) appears to reflect the detection of some type of mismatch between stimulus features or between the stimulus and some previously formed template. In other words, it is sensitive to stimulus probability and discrimination difficulty. The difference between the N200 and the MMN is that to evoke a N200 the subject has to attend the task. The visuall $\mathrm{N} 200$ is maximal at occipital sites and the auditory N200 has its maximum at central or at frontal electrode site [10]. The infantile N250 (N2) remains at the same latency in the first year of life and its amplitude greatly increases between 3 and 9 months of age [23]. During chilldhood the N250 amplitude decreases again, but its scalp distribution remains unchanged. [4]. Batty and Taylor [2] concluded that since the N2 latencies and amplitudes decreased with age, categorization processes continue to develop through 
childhood. N2 latency, which is associated with stimulus categorization, reached adult levels at the age of about 9 years.

When subjects attend a task rare stimuli typically elicit a late positive P300 component (also labeled P3 or P3b). The amplitude of the P300 is sensitive to the probability of the stimulus, the rarer the stimulus the larger the P300 amplitude. A stimulus in any modality can elicit a P300. The latency of the P300 is thought to reflect stimulus evaluation or categorization time. This means that when categorization becomes more difficult. latency becomes longer. The amplitude of the P300 is related to the processing resources demanded by a particular task. It has also been suggested that the P300 is a manifestation of a process related to the updating of models of the environment or context in working memory [10]. Besides this classical P300 there is a P300 that is elicited by unexpected novel stimuli that is usually labeled 'novelty P3' or P3a. The latency of this novelty P3 is the same as the latency of the classical P300, but its scalp distribution is more frontal. Fabiani and Friedman [9] showed that all attended deviant stimuli elicit frontal P3s when the stimuli are first presented, for example during a practice block. However " with subsequent repetitions of the same stimuli, the scalp distribution of the P3 reverts to a parietal maximum, which is typical for the classic P300. It has been suggested that the Novelty P3 could reflect involuntary switching of attention to deviant events or inhibition of a response engaged automatically with the detection of the deviance [13].

Jeon and Polich [17] performed a study on the hypothesis that both passive and active paradigms can produce P300 waveforms. They found that the P3a from the novel stimulus was similar in amplitude, scalp topography and peak latency across the passive and the active task conditions. On the other hand, the $\mathbb{P} 3 b$ from the target stimulus demonstrated much smaller amplitude, highly altered scalp topography and longer latency for the passive compared to the active conditions. Application of these passive procedures to elicit the visual P3a should prove useful as a clinical measure of frontal lobe function.

Unlike the frontally oriented P3 found in adults, children do not show a novelty P3 wave to novel stimuli. In children the novelty ERP is characterized by a negative Nc wave at about $400 \mathrm{~ms}$ after stimulus onset and a positive $\mathrm{Pc}$ wave at about $900 \mathrm{~ms}$. The $\mathrm{Nc}$ is developmentally the first to emerge, followed by the PC wave and later still, by $P 3$ waves. The transition from childhood to adulthood wave forms is gradual and is not 'complete' until after the mid-teens [5]. The amplitude of the $\mathbb{N C}$ and $\mathrm{PC}$ components is maximal at central and frontall scalp sites. Courchesne speculated that this age-related morphological difference in the ERP waveform implied that the children and adults processed the infrequent novel information differently. Nc waves reflect the perception of attention-getting or interesting events that require further detailed processing and assessment [5]. In other words, the Nc wave can be seen as a sign of enhanced auditory and visual selective attention to surprising, interesting, or important stimuli [6]. Children do show the classical P3 component, although its latency is 300 ms longer than in adults $[31,32]$.

To date only two reports addressed information processing in Rett syndrome using ERP's In using auditory- and visual evoked potential paradigms Bader et al. [1] reported a P3 activity in nine girls with Rett suggesting remaining perceptual and discrimination properties. McCulloch et al. [25] investigated basic visual function in 11 girls and young women (age range 5-24 years) of which three subjects participated in a 'face discrimination paradigm', and four subjects in a 'face recognition paradigm'. Unlike the study by Bader et all. [1] they were not able to identify any ERP components.

Other developmental disorders have been studied more extensively with ERP's. Ikeda et al. [16] examined a group of mentally retarded persons with an auditory oddball task. They found that the mismatch negativity showed smaller amplitudes and greater latencies for retarded persons as compared to non-retarded adults. The P3a on the other hand, was comparable for both groups. Their conclusion was that there is a dysfunction of automatic auditary processing in mentally retarded persons, although this dysfunction appears to thave less influence on their passive attention to the deviant stimuli. Kemner et al. [20] compared 
autistic children to children with MCDO (Multiple Complex Developmental Disorder) and a normal control group. They found that the central and the occipital P3 are smaller and the parietal P3 larger in children with autism compared to the MCDD children. Compared to the normal controf group, the MCDD group showed larger P3 amplitudes at $\mathrm{Cz}$ and smaller amplitudes at $\mathrm{PZ}$. The autistic children differed from the control group showing smaller occipital P3 amplitudes. Courchesne found that the Nc response is entirely absent or strikingly aberrant in infantile autism [6]. Karrer et al. [19] studied six-months-old infants with Down syndrome during a visual recognition memory task. They found that infants with Down syndrome had larger NG amplitudes as compared to infants without Down syndrome. Both the infants with as without Down syndrome showed larger NC amplitudes to rare stimuli. In a study that compared children with fetal alcohol syndrome (FAS) to children with Down syndrome and controls it was found that the morphology of the waves of the FAS children was very poorly formed. P300 latencies were delayed in all cortical sites in Down syndrome children, whereas FAS children had prolonged P300 latencies only in the parietal region compared to the normal controls: In addition. Down syndrome children were found to have larger P300 amplitudes than FAS or control children at frontal sites [18]. In adults with Prader-Willi syndrome (PWS) and normal controls event-related brain activity was recorded in a visual and auditory oddball task [30]. The event-related brain activity in the PWS group revealed an abnormal deflation of the P300 component in the visual and even to a larger extent, in the auditory oddball tasks. The data support the notion that auditory modality is more affected than visual modality and that short-term memory in persons with PWS is possibly impaired.

The former studies demonstrate that ERP's may reveal interesting insights in developmenta: disorders at all levels of functioning. The two mentioned ERP studies involving Rett females suggest that ERP components like the P3 may be recorded in Rett girls in simple auditory and visual tasks but not in complex visual tasks. The present study presents a life span approach to study the development of auditory and visual processing using simple oddball paradigms in 2 to 60 years old females with Rett syndrome and age matched controls.

\section{MATERIALS AND METHODS}

\subsection{Participants}

In the 17 persons with Rett syndrome age ranged from 2 to 60 years with a mean age of 17,5 years. The controll group consists of 18 healthy age-matched girls and women. Their age ranged from 4 to 56 years with a mean age of 15,7 years. The Rett females were tested in several clinics where they lived. The controls were tested at home or at the university. One Rett-girl was excluded for both the auditory and the visual task. One Rett-woman was excluded for the auditory task and another Rett-woman was excluded for the visual task, all because there was to too much noise in the EEG-signal.

In order to grasp any developmental change in ERP the clinical and control group are split up in three age groups of similar size and age range that are presented in table 1 and depicted in Figure 1. 
Table 1: The number of participants $(N)$, mean age in years and are range in years of the 3 age groups $(I, I I, I I)$ for the participants with Rett symdrome and normal Controls.

\begin{tabular}{|l|l|l|l|l|l|l|}
\hline & \multicolumn{4}{|l|}{ Rett } & Control \\
\cline { 2 - 7 } & Group I & Group II & Group III & Group I & Group II & Group III \\
\hline $\mathrm{N}$ & 4 & 5 & 6 & 4 & 7 & 7 \\
\hline Mean age & 4.4 & 8.7 & 31.1 & 4.4 & 9.0 & 28.8 \\
\hline Age range & $2.1-5.7$ & $6.1-11.5$ & $15.5-60.1$ & $4.0-5.3$ & $6.1-11.9$ & $15.1-55.6$ \\
\hline
\end{tabular}

\subsection{Experimental tasks}

During EEG recording a visual- and an auditory oddball task were presented. Stimulus presentation and behavioral data acquisition were automatically controlled by Experimental Run Time System (ERTS) software. Participants were seated $50 \mathrm{~cm}$ in front of standard $15^{\circ \prime}$ monitor that was used for visual presentation and auditory stimuli were presented via headphones. In the passive oddball tasks there was no instruction and for the visual oddball task the experimenter checked constantly whether the participant was watching the center of the screen. Both tasks were preceded by a practice session of 15 items.

The visual oddball stimuli consisted of a green circle on a black background or a red square on a black background. There are also 'novel' pictures. These latter are unique and random configurations of small colored blocks on a white background that was different for each novel stimulus. The visual stimuli were presented one by one in two sessions during 1000 ms with an inter-stimulus-interval of $1500 \mathrm{~ms}$. Each session contains a randomized sequence of 80 frequent items (green circle), 20 rare items (red square) and 15 novels.

The auditory oddball task presented two pure sinus tones with a clearly distinguishable pitch of respectively 440 and $880 \mathrm{~Hz}$. The tones were presented in two sessions of each eighty $440 \mathrm{~Hz}$ tones and twenty $880 \mathrm{~Hz}$ tones. They were randomly presented one during $300 \mathrm{~ms}$ with an inter-stimulus-interval of $1100 \mathrm{~ms}$.

\subsection{Procedure}

At arrival of the participant the procedure was explained to the parents, companion and/or the participant, followed by placing of the electro-cap and EOG electrodes. During task performance two experimenters stayedi in the same room as the participant. One observed the participant and the other monitored the EEG signall on the laptop computer. The visual task was always presented first because focusing on the screen may imply more effort than passive listening to tone sequences. Between the sessions there were breaks in which the participant could loosen up and move around freely. The entire experiment lasted about one and a half hour.

\subsection{EEG recordings}

The neuroscan NuAmps DC amplifiers record the EEG and EOG signals. The NuAmps is a small portable amplifier with 40 channels of which 36 channels were used to record $E E G$ and EOG. The electro-cap comprised 31 tin electrodes (Electro-cap inc. USA): $F Z, C Z, P Z$,

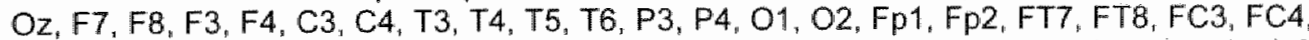
TP7, TP8, CP3, CP4, FCZ, CPz and a ground. The reference electrode is placed at the left mastoid. To measure EOG, four electrodes are used. For the vertical EOG, there are electrodes above and beneath the left eye, and for the horizontal EOG two electrodes are placed on the outer canthi of both eyes. The electrode impedance is kept below $5 \mathrm{k} \Omega$, and for the EOG ellectrodes below $8 \mathrm{k} \Omega$. The impedance is measured with a portable impedance meter (F-EZM4A, Grass inc. USA). Before EEG recording the impedance is also checked with impedance meter of the NuAmps amplifiers. EEG acquisition is controlled by Neuroscan 4.2 software with a band-pass filter of $0.05-30 \mathrm{~Hz}$ continuous sampling rate. The 
presientation of the stimuli is controlled by ERTS (Version 3.18, BeriSoft Cooperation, Germany).

\subsection{EEG anallysis}

Based on the simultaneous EOG recordings the EOG artifacts are removed from the EEG by means of linear regresseion Next the EEG data are epoched off line with a $100 \mathrm{~ms}$ prestimulus and $1000 \mathrm{~ms}$ post-stimulus period after which a baseline correction is performed with a pre-stimulus interval of $100 \mathrm{~ms}$. EEG epochs containing data of which the absolute voltage in any channel exceeded $\pm 350 \mu \mathrm{V}$ for the Rett patients and $\pm 250 \mu \mathrm{V}$ for the controls were omitted from the ERP average for each stimulus condition. For statistical analysis the maximal/minimal ERP peaks are scored within a certain time window resulting in a (peak-) amplitude and a (peak-) latency after stimulus onset. The used intervals used are presented in tabile 2 .

Table 2: The time windows used for determining the (peak-) amplitude and latency for each of the ERP components and age groups $(\mathrm{I}, 1 \mathrm{I}, \mathrm{III})$ of the participants with Rett and controls.

\begin{tabular}{|c|c|c|c|c|c|c|c|}
\hline & \multicolumn{3}{|c|}{ Visual task } & \multicolumn{3}{|c|}{ Auditory task } \\
\hline & & peak P1 & $\begin{array}{l}\text { peak } \mathrm{Ncl} \\
\text { Nowelty } \mathrm{P} 3\end{array}$ & area & $\begin{array}{c}\text { peak } \\
\text { N2MMMN }\end{array}$ & peak P3 & area \\
\hline \multirow{3}{*}{$\begin{array}{l}\text { 焉 } \\
\underline{2}\end{array}$} & group I & $\begin{array}{l}50-200 \\
\text { positive }\end{array}$ & $\begin{array}{l}450-900 \\
\text { positive }\end{array}$ & $\begin{array}{l}450- \\
900\end{array}$ & $\begin{array}{l}400-700 \\
\text { negative }\end{array}$ & $X \times x \times x$ & $450-900$ \\
\hline & group II & $\begin{array}{l}100-250 \\
\text { positive }\end{array}$ & $\begin{array}{l}400-800 \\
\text { positive }\end{array}$ & $\begin{array}{l}450- \\
900\end{array}$ & $\begin{array}{l}450-700 \\
\text { negative }\end{array}$ & $x \times x \times x$ & $400-900$ \\
\hline & group III & $\begin{array}{c}0-150 \\
\text { positive }\end{array}$ & $\begin{array}{l}500-700 \\
\text { positive }\end{array}$ & $\begin{array}{l}450- \\
900\end{array}$ & $\begin{array}{l}350-550 \\
\text { negative }\end{array}$ & $\begin{array}{l}450-650 \\
\text { positive }\end{array}$ & $350-650$ \\
\hline \multirow{3}{*}{$\begin{array}{l}\bar{S} \\
\text { E } \\
\bar{D} \\
\end{array}$} & group & $\begin{array}{c}50-300 \\
\text { positive }\end{array}$ & $\begin{array}{l}200-650 \\
\text { negative }\end{array}$ & $\begin{array}{l}250- \\
650\end{array}$ & $\begin{array}{l}350-670 \\
\text { negative }\end{array}$ & $x x x x x$ & $380-670$ \\
\hline & group II & $\begin{array}{l}50.300 \\
\text { positive }\end{array}$ & $\begin{array}{l}200-650 \\
\text { negative }\end{array}$ & $\begin{array}{l}250- \\
650\end{array}$ & $\begin{array}{l}350-670 \\
\text { negative }\end{array}$ & $x \times X X X X$ & $380-670$ \\
\hline & group III & $\begin{array}{l}50-250 \\
\text { positive }\end{array}$ & $\begin{array}{l}200-650 \\
\text { positive }\end{array}$ & $\begin{array}{l}250- \\
650 \\
\end{array}$ & $\begin{array}{l}300-500 \\
\text { neglative }\end{array}$ & $\begin{array}{l}450-650 \\
\text { positive }\end{array}$ & $350-650$ \\
\hline
\end{tabular}

\subsection{Statistical analysis}

To reduce the number of analyses only the midline electrodes $(F z, F C z, C z, C P z, P z$ and $\mathrm{Oz}$ ) were included because they revealed the most interesting task modulations. $A$ regression analysis across all age groups was performed resulting in a Pearson's Product Moment Correlation Coefficient for each relation. All individual latency and amplitude data were included in these calculations, except for the novel component (Nc) that was only present in the two youngest groups and for the Novelty P3 and auditory P3 that were only present in the oldest group. The regression analyses were performed using SPSS (version 11) and two-tailed significance levels $(p \leq .05)$.

\section{RESULTS}

Figure 1 depicts the ERP's to the auditory tasks of the frequent (solid line) and rare (dotted line) stimulus condition for three age groups. The controls show the typical age changes with a decrement in absolute amplitudes and shortening of the peak latencies of the ERP components. In the Rett group there is not only much less change with age but also a strongly reduced ERP difference between the stimulus conditions. In addition does the morphology of the ERP waveform differ considerably between the groups. For the visual task (Figure 2) one can observe similar group differences than in the auditory task, suggesting that both modalities are severely anomalous in Rett females. 
Only the significant regressions with age are reported next.

\section{Auditory N2-latency}

The N2 latency decreases with age for the control group and the Rett group. The control group showed significant effects on the entire midline for both the rare and the frequent conditions. The Rett group shows significant effects on $\mathrm{Fz}, F C Z, C z$ and $\mathrm{Pz}$ for the rare condition and on $\mathrm{FCz}, \mathrm{Cz}, \mathrm{CPz}, \mathrm{Pz}$ and $\mathrm{Oz}$ for the frequent condition.

\begin{tabular}{|c|c|c|c|c|c|c|c|c|c|c|c|c|}
\hline & \multicolumn{2}{|l|}{$F z$} & \multicolumn{2}{|l|}{$\mathrm{FCZ}$} & \multicolumn{2}{|l|}{$\mathrm{Cz}$} & \multicolumn{2}{|l|}{ CPZ } & \multicolumn{2}{|l|}{$P z$} & \multicolumn{2}{|l|}{$\mathrm{Oz}$} \\
\hline & corr. & p-val. & corr. & $\mid p$-val. & corr. & p-val. & corr. & p-val. & corr. & p-val & corr. & p-val \\
\hline $\mid \begin{array}{c}\frac{a}{w} \\
\frac{\pi}{\alpha}\end{array}$ & -0.714 & $0.001^{*}$ & -0.692 & $0.001^{*}$ & -0.639 & $0.004^{*}$ & -0.633 & $0.005^{*}$ & -0.583 & $0.011^{*}$ & -0.534 & $0.022^{*}$ \\
\hline 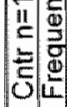 & -0.674 & $0.002^{*}$ & -0.664 & $0.003^{*}$ & -0.653 & $0.003^{*}$ & -0.650 & $0.003^{*}$ & -0.656 & $0.003^{*}$ & -0.668 & $0.002^{*}$ \\
\hline 这 & -0.683 & $0.005^{*}$ & -0.690 & $0.004^{*}$ & -0.549 & $0.034^{*}$ & -0.451 & 0.092 & -0.557 & $0,031^{*}$ & -0.369 & 0.176 \\
\hline 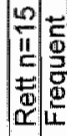 & -0.508 & 0.053 & -0.521 & $0.046^{*}$ & -0.618 & $0.014^{*}$ & -0.565 & $0.028^{*}$ & -0.638 & $0.010^{*}$ & -0.580 & $0.024^{*}$ \\
\hline
\end{tabular}

\section{Auditory N2-amplitude}

The control group shows a decrease in amplitude with age. This means that the amplitude becomes less negative when age increases. This trend is significant for the rare and the frequent condition on the entire midline. Although it looks like that the Rett group shows a similar trend, the correlations did not reach significance.

\begin{tabular}{|c|c|c|c|c|c|c|c|c|c|c|c|c|c|}
\hline & \multicolumn{2}{|l|}{$\mathrm{Fz}$} & \multicolumn{2}{|c|}{$F C z$} & \multicolumn{2}{|l|}{$\mathrm{Cz}$} & \multicolumn{2}{|c|}{$\mathrm{CPZ}$} & \multicolumn{2}{|l|}{$\mathrm{Pz}$} & \multicolumn{2}{|l|}{$\mathrm{Oz}$} \\
\hline & & 总 & $\stackrel{\vec{m}}{\dot{d}}$ & 8 & गें & 8 & 恶 & 言 & 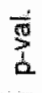 & 5 & $\begin{array}{l}\overrightarrow{\mathrm{T}} \\
\frac{1}{a}\end{array}$ & 8 & $\begin{array}{l}\frac{5}{50} \\
1 \\
1\end{array}$ \\
\hline \multirow{2}{*}{$\frac{\infty}{\frac{\infty}{11}}$} & 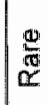 & 号 & 总 & $\frac{8}{\stackrel{8}{+}}$ & $\begin{array}{l}\text { 年 } \\
8 \\
8 \\
0\end{array}$ & $\frac{\infty}{60}$ & 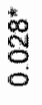 & $\begin{array}{l}\infty \\
8 \\
0 \\
0 \\
0\end{array}$ & $\frac{n}{\bar{y}}$ & $\begin{array}{l}0 \\
0 \\
0 \\
0\end{array}$ & 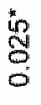 & 赑 & 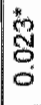 \\
\hline & 莺 & $\begin{array}{l}0 \\
0 \\
0 \\
0\end{array}$ & ${ }_{8}^{*}$ & $\begin{array}{l}10 \\
0 \\
0 \\
0\end{array}$ & $\begin{array}{l}\text { 管 } \\
\text { 号 } \\
\text { 。 }\end{array}$ & $\frac{m}{6}$ & $\begin{array}{l}\text { 웅 } \\
\stackrel{8}{0}\end{array}$ & 足 & $\frac{*}{0}$ & $\begin{array}{l}13 \\
10 \\
0 \\
0 \\
0\end{array}$ & ${ }_{0}^{k}$ & 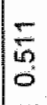 & $\begin{array}{l}0 \\
0 \\
0 \\
0\end{array}$ \\
\hline \multirow[b]{2}{*}{$\left|\begin{array}{c}\frac{1}{2} \\
\text { il } \\
\frac{5}{ \pm} \\
\alpha \\
\alpha\end{array}\right|$} & $\frac{\Delta}{\frac{a}{\alpha}}$ & 品 & ণ্ & 今్ & $\begin{array}{l}\infty \\
\infty \\
N \\
0 \\
0\end{array}$ & 足 & $\stackrel{m}{0}$ & 变 & $\frac{1}{2}$ & $\frac{\pi}{0}$ & $\begin{array}{l}8 \\
8 \\
0\end{array}$ & $\begin{array}{l}8 \\
8 \\
0 \\
0\end{array}$ & $\begin{array}{l}\frac{1}{2} \\
0 \\
0\end{array}$ \\
\hline & 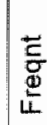 & $\frac{n}{\frac{1}{0}}$ & $\frac{M}{2}$ & $\begin{array}{l}N \\
m \\
0 \\
0\end{array}$ & $\frac{\frac{1}{2}}{0}$ & 焉 & $\begin{array}{l}8 \\
0 \\
0 \\
0\end{array}$ & ज़ & $\frac{N}{0}$ & $\stackrel{N}{\mathcal{N}}$ & 芯 & $\begin{array}{l}\mathrm{N} \\
\mathrm{w} \\
0 \\
0\end{array}$ & 题 \\
\hline
\end{tabular}




\section{Auditory P3-aimplitude}

Again, only the oldest group participated.

For the controls $(n=7)$, no trend is seen in the rare condition. Instead, for the frequent condition the amplitude increases with age. Significant trends are seen on $\mathrm{Fz}(r=0.770$, $p<0.05$, wo-tailed), FCz ( $r=0.805, p<0.05$, two-tailed), $C z(r=0.808, p<0.05$, two-tailed), CPz $(r=0.026, p<0.05$, two-tailed $)$ and $P z(r=0.037, p<0.05$, two-tailed $)$.

For the Rett group $(n=6)$, no significant effects are found:

\section{Visual P1-latency}

For the controls, the latency gets longer with age. The rare stimulus shows a significant positive correlation between age and latency at $\mathrm{Oz}(\mathrm{r}=0.601, \mathrm{n}=18, \mathrm{p}<0.01$, two-tailed). No such trend was found in the Rett group.

\section{Visual P1-amplitude}

The amplitude becomes smaller with age for the control group. There is a significant negative correlation between age and amplitude for the novel condition on $\mathrm{Oz}(r=-0.558$, $n=18, p<0.05$, two-tailled). Again, no such trend was found for the Rett group.

\section{Visual Nc-amplitude}

The control group ( $n=11)$ shows a decrease in amplitude with age which means that the amplitude becomes less negative when age increases. This correlation was significant on $\mathrm{Cz}(r=0.758, p<0.01$, two-tailed $), C P z(r=0.760, p<0.01$, two-tailed $)$ and $P z(r=0.752, p<0.01$, two-tailed). There was no such effect in the Rett group $(n=9)$.

Thus the only significant changes with age in the Rett group are found for N2 latency as can also be appreciated in Figure 1.

\section{DISCUSSION}

The present study investigated age related changes of the auditory MMN "N2 and P3 components and the visual P1, Nc and novelty P3 components in 17 girls and women with Rett syndrome and on 18 healthy age-matched controls. Overall the controls showed shorter ERP latencies and larger ERP amplittudes than the Rett group, suggesting that the Rett patients need more time to process information and have less or less concentrated processing in response to visual and auditory stimulation. The finding that the ERP traces in Rett females seem to become more irregular with increasing age hints to the fact there may be no leveling or improvement in information processing with growing age.

For the visual P1 component there was an increase in ERP latency and a decrease in ERP amplitude with age for the control group that was comparable to the results reported by Batty and Taylor [2]. The Rett females did not show such trend. The latter suggests that for Rett females this early visual processing or encoding does not become easier with age and reduced amplitudes suggests that the process of encoding is less strong the Rett group.

The N2 is thought to reflect the detection of some type of mismatch between stimulus features or between the stimulus and some previously formed template and is sensitive to stimulus probability and discrimination difficulty [10]. Batty and Taylor [2] found that N2 latencies and amplitudes decreased during childhood and reached adult levels at the age of 9 years. In the present study the $\mathbb{N} 2$ latencies decrease with age for both the control and the Rett group. This was the only significant change with age for the Rett group and hints that the detection of a mismatch and stimulus probability also becomes faster in persons with Rett. For the controls also the N2 amplitude decreases with age, which means that the amplitude became less negative when the subjects get older. Such an amplitude trend with age was not found in the Rett group, suggesting that in Rett syndrome the detection of a mismatch between stimuli and stimulus probability does not become more efficient with age. 
The Nc and novelty P3 components are known to reflect some kind of novelty. The Nc component is seen as a sign of enhanced auditory and visual selective attention to surprising, interesting, or important stimuli [6] and the novelty P3 is thought to reflect the involuntary switching of attention to deviant events, or distraction from the primary task [13]. Control children do not show a positive novelty $\mathrm{P} 3$ wave when confronted to novel stimuli, but instead show negative Nc wave occurring at about $400 \mathrm{msec}$ after stimulus onset. The amplitude of the Nc wave is largest in young children and decreases quickly with age to finally emerge as an adult novelty P3. Courchesne speculated that this age-related morphological change in ERP waveform implied that the children and adults process novel information differently. For the control group we found a decrease in amplitude with age, meaning that the amplitude becomes less negative when the children get older. This is in accordance with earlier developmental studies on the Nc component [7]. However, where contral children have a $\mathrm{Nc}$ component do Rett children show a positive going novel component that looks more like a delayed adult novelty P3. This is in contrast with research on children with Down syndrome where Karrer et al. [19] reported even larger No peak amplitudes compared to infants without Down syndrome. Children with autism, on the other hand do show an absent or strikingly aberrant Nc response [6] that is closer to our findings in Rett children. Finally the adults with Rett do not reveal any novelty P3 like activity to novel stimuli (See Figure 2), instead they show a very early positive peak before $150 \mathrm{~ms}$ that is unlike any known ERP modulation to novel stimulation. These markedly aberrant ERPs to novel stimulation in the Rett group paints at a disturbed processing of novel and unexpected stimulation that might constitute one of the key abnormalities in deviant information processing in Rett syndrome, since it is one of the most robust ERPs effects that can even be observed in infants.

The auditory P3 was only visible in the oldest group. Since the spreading of age in the adult group is smaller than in the whole life span group no major correlations with age were expected for the component. Nevertheless there was a significant correlation for P3 amplitude with age in our control group where the amplitude of the frequent stimulus increases with age. This suggest that is when people get older it becomes harder to process auditory stimuli and therefore need more activation. The Rett group did not show any latency or amplitude age changes because of the absence of any identifiable P3 like activity. This seems to suggest that adults with Rett process the rare and frequent tones as if there are no differences between them. The difficulty of detecting any ERP components in Rett patients was also reported by McCulloch et al. [25]. The present study partially confirms this difficulty for the adults with Rett, but children with Rett reveal ERP components and even differences between task conditions (see Figures $1+2$ ) that are clearly identifiable. The failure to identify amy ERP components in the McCulloch et al. [25] study was thus probably due to the age of their participants and, more important, because of a higher lask complexity in their visual face discrimination/recognition paradigm. In using a simpler oddball paradigm like in the present study some ERP activity can be identified in adults with Rett, especially in the auditory oddball task. In the visual task only the ERP to the novel condition shows a clear positive pealk in the Rett group, albeit completely dissimilar from the adult controls.

Taken together there are major differences in ERP found between the Rett group and the controls at any age level. In general Rett females show slower and reduced and irregular information processing in both the visual- and auditory modality when compared to the control group. In addition do the ERP's in Rett females become more deviant from normal controls with increasing age. The small number of participants in each age group did not allow for more profound statistical analyses of the ERP effects and therefore only descriptive statistics were used. Nevertheless, the present study points al several interesting particularities of information processing in Rett's developmental disorder that may guide more extensive evaluations in future research. 


\section{REFERENCES}

11) Bader GG. Wht Engeritram I, Hagbeng B. Neurophysiological findings in Rett syndrome, Il: visual and auditory brainstem, modde and late evolked potentials. Brain Dev, $1989,1 / 110-114$

(2) Baty $M$, Taylor Maj. Visual categorization during chifdhood. An ERP study. Psychophys 2002,39:482-490.

(3) Berg $M$. Hagberg B. Rett syndrome: Update of a 25 years follow up investigation in Sweden, sociomedical aspects. Bain Dev $2001: 23: 224226$

[4] Ceponient R. Rinne T, Natatanen R. Maturation of contical sound processing as indexed by eventretated poteritials. Cin Neurophys 2002;113:870-882

[5] Courchesne $E$. Neurophiysirlogical carralates of coginitive development changes in long-fatemcy ewentrelated potentials from childhood to adufthood. Electroencephatography and Clim Neurophys 1978:45:468-482.

[0] Courchesne $E$ Chronology of posthatal human brain developinent: event-related potential, positron emission, tomography, stryelinogenes;s; and symaptogenesis studies. In Rohrbaugh JW, Prarasraman $R$ \& Johnson $J r$ R. Event-related brain potentials: basic issues and applications; New York: Oxford University Press; 1990 p. 210.241.

(7) Cycowicz VM, Friedman D. Rothstein M. An ERP dewelopmental study of repetition priming by auditory nowel stimuli. Psychophys. 1996,30,680 690

IBI Ellaway C, Christodoulou I. Ret syndrome: clinical characteristics and recent genetic advances. Disab Rehab $2001123.98-106$.

[9] Fabiani $M$, Friedman D. Changes in brain actuvity patterns in aging: The novelty oddball. Psychophys 1995:32:579594.

[10] Fabiani M, Gratton $G$, Coles MGH. Event-related potentials: Methods Theory, and applications. In: JT Cacioppo, LG Tassinary, GG Berntson (Eds.). Handbook of Psychophysiology (2 ed ed.) Cambiridge: University Press. 2000 p. $53-84$.

[11] Friedman D, Cycowicz YM, Gaeta $H$. The nowelty P3: an event-related brain potential (ERP) sign of the brainis evaluation of novelly. Neurasc Blobehav Fev 2001;25:335 373.

[12] Glaze DG. Neurophysiology of Reft syndrome. Mental Retardation and Developmental Disab Res Rev 2002;8:6671

[13] Goldstein A. Spencer $\mathrm{KM}_{\mathrm{B}}$ Donchim $E$. The influence of stimulus deviance and novelty on the P300 and Novelly $\mathrm{P} 3$. Psychophys 2002;38:781-790.

[14] Hagberg $B_{a}$ Alcardi J. Dias $K$. Ramos $O$. A progressive symdrome of autism, dementia, ataxia and loss of purposaful handuse in girls : Rett's syndrome : Report of 35 cases. Ann Meurol 1983;14:471-479.

[15] Hagberg B. Cinical Manifestations and Stages of Rett symdrome. Ment Retard Dev Disab Res Rew 2002;8:61-65.

[16] Ikeda K, Okuzumi H. Hayashi A, Hashimoto S. Kanno A. Automatic auditory processing and event-related brain potentials in persons with mental retardation. Perc Mot Skil 2000:91:1145-1150.

[17] Jeon $Y$ "Polich J. P3a from a passive wisual stimulus task. Clin Neurophys 2001:112:2202-220:3.

[H8] Kaneko WM, Ehlers CL. Philips EL, Rilley EP. Auditory Event-Related Potentials in Fetal Alcohol Symdrome and Down's Syndrome Children. Alcoholism: Clin Exp Res 1996;20:35-4.2.

[19] Karrer $J H$, Karrer $R$. Bloom $D$, Chaney $L$, Davis $R$. Eventrelated brain potentials during an extended visual recognition memory task depict delayed development of cerebral inhilitory processes among 6-months-old infants with Down syndrome. Int J Psychophys 1998;29:167-200.

[20] Kemrer $C$, van der Gaag RJ, Verbaten $M$ \& van Engeland $H$. ERP Differences among Subtypes of Perwasiwe Developmental Disorders. Biol Psychiat 1999;46:781-789.

(21) Kerr A, Wit-Engerstrom I (eds.). Rett disorder and the developing brain. Oxford: Oxford University Press 2001

[22] Kumandas S. Çaksen $H_{*}$ Ciffç $A$, Oztürk $M_{n}$ Per $H$. Lamotrigine in wo cases of Rett symdrome. Brain Dev $2001 ; 23: 240,242$

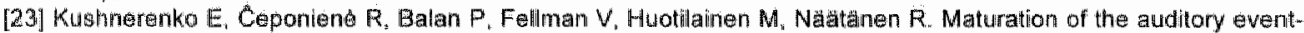
related potentials during the first year of life. Neurorep 2001:13:47-51.

[24] Kutas M . Date A. Electrical and magnetic readings of mental functions. In. Rugg MD (ed) Cognifive Neuroscience. Sussex Psychology Pross 1997 pp. 197-237).

[25] McCulloch DL, Henderson RM, Saunders KJ. Walley RM. Vision in Rett syndrome: studies using evoked potentäls and eventiralated potentals. In: Kerr A \& Witt-Engersitrom I. Rett disorder and the deweioping brain. Oxford: Oxford University Press 2001 pp. $343-348$

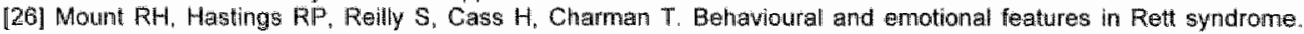
Disab Rehath 2001;23:129-138.

[27] Rett A. Uber ein cerbbral-atrophisches Syndrom bei Hyperammonamie. Wien Med Wochenschr 1966;116723726 .

[28] Schanen C. Rethinking the fate of males with mutations in the gene that causes Rett syndrome. Brain Dev $2001: 23: 1,44146$

[29. Schwartzmam IS, Bernardino $A$, Nishumura A, Gomes RR, Zatz M. Retl syndrome in a Boy with a $47 . X X Y$ Karyotype Cainfirmed by a Rare Mutation in the MECP2 Gene. Neuroped 2001:32:162 164.

[30] Stauder JEA. Brinkman MJ, Curfs LGM. Multi-modal P3 deflation of avent-related brain activity in Prader -Wuilli syndrome. Neurosai let 2002;327:99-102.

[31] Stauder JEA. Molenar PCM. Molen van deir MW. Event related brain potential analysis of the conservation of liquild quantity. Child Dev 1993;64:769-788.

[32] Stauder JEA, Molen wan der MW. Molenaar PCM. Age, intelligence and event-related brain potentials during late childhood: A longitudinal study. Inteligence $2003 ; 31: 257-274$. 


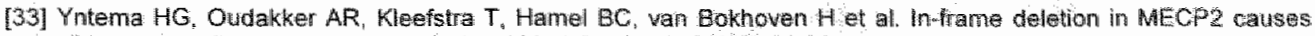
mild nom-specific mental retardation. Am J Mfed Genet 2002, $07: 51-3.3$.

[34] Witt Engerstrom 1. Rett syndrome in Sweden. Acta Paed Scand $1999,369$. 
Figure 1

ERPs to the auditory lask at electrode location ' $\mathrm{Cz}$ '. The horizontal axis indicates the time after stimulus onset in milliseconds (ms) and the vertical axis the ERP amplitude in micro volts $(\mu \mathrm{V})$. The left collumn depicts the Control group, and the right column the Rett group. Age group I is depicted at the top row, Age group II in the middle row and Age group III at the bottom row. The solid line represents the frequent stimulus and the dotted line the rare stimulus. The components that are included in the analyses (MMN, N2, P3) are indicated with an arrow.

\section{Auditory task}

\section{Control}

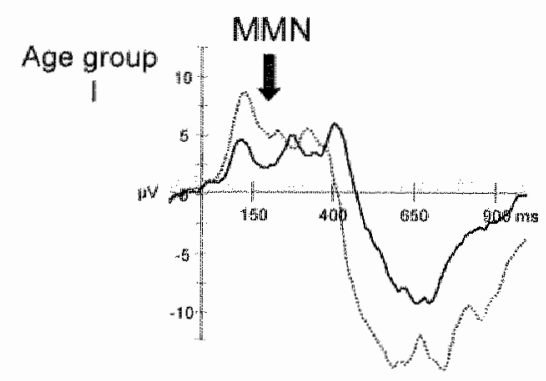

Age group

III
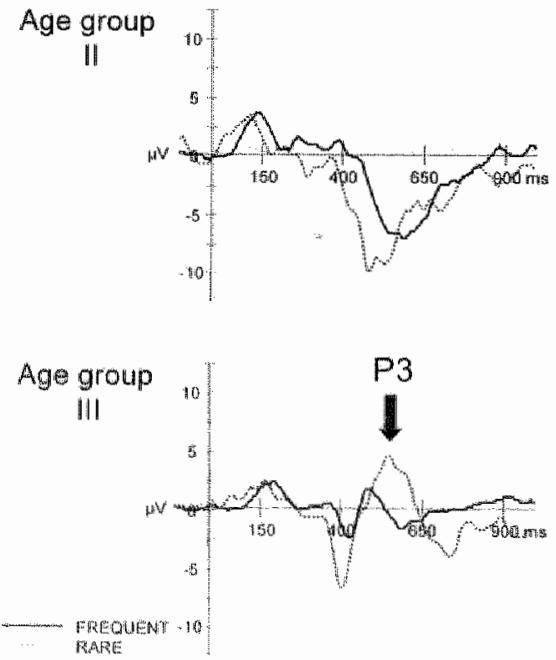

Rett
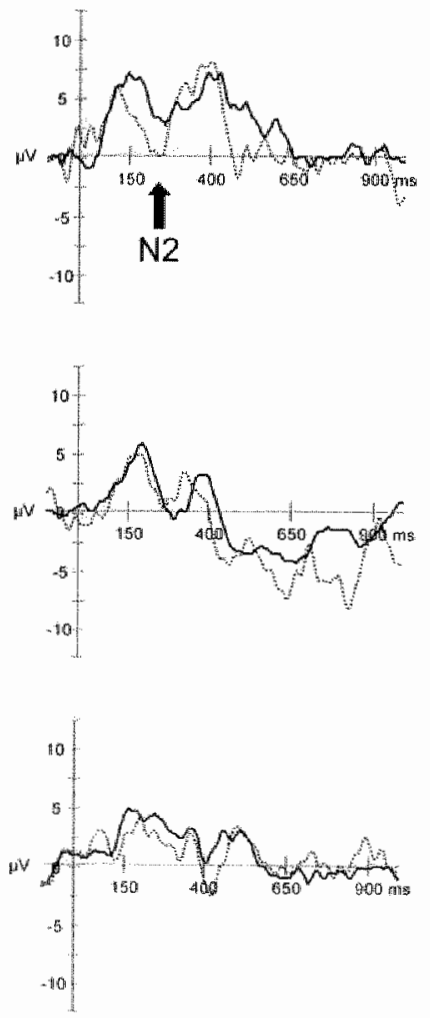
Figure 2.

ERPs to the visual task at electrodle location ' $\mathrm{CZ}$ '. The horizontal axis indicates the time after stimulus onset in milliseconds (ms) and the vertical axis the ERP amplitude in micro volts $(\mu V)$. The left column depicts the Control group, and the right column the Rett group. Age group I is depicted at the top row, Age group II in the middle row and Age group III at the bottom row. The solid line represents the novel stimulus, the dashed line the frequent stimulus and the dotted line the rare stimulus. The components that are included in the analyses ( $P 1, N c_{y}$ novelty $P 3$ ) are indicated with an arrow.

\section{Visual task}

Control
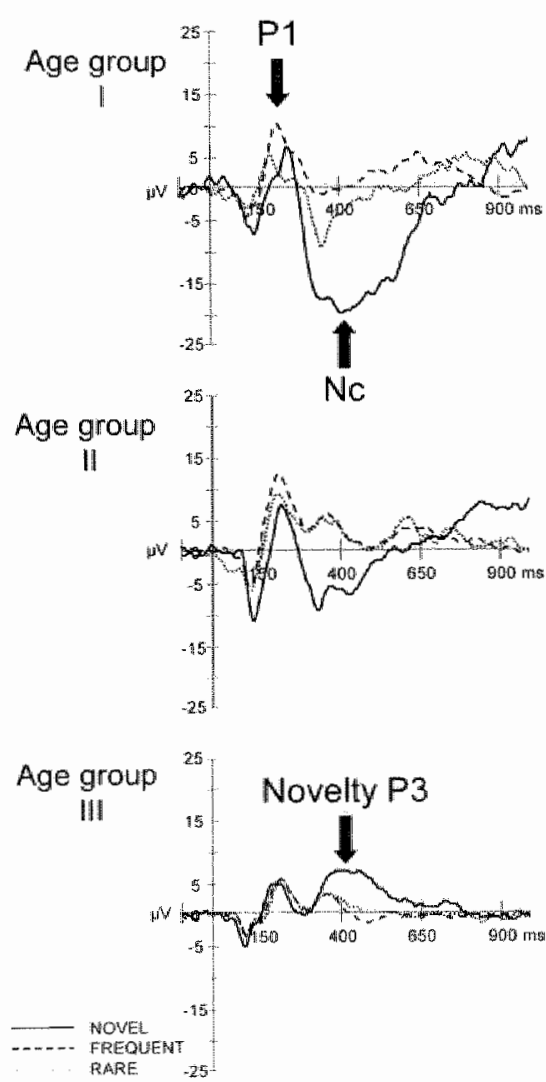

Rett
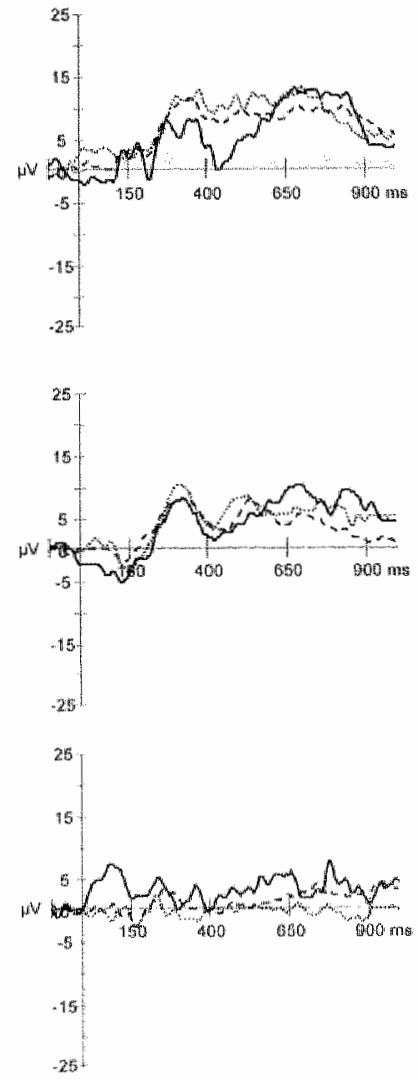


\section{Addendum 5}

Gross rearrangements in the MECP2 gene in three patients with Ret syndrome: implications for routine diagnosis of Rett syndrome.

Schollen E." Smeets E., Deflem E., Fryns JP., Matthijs G.

Hum Mutat. 2000, 22:116-20. 



\title{
Gross Rearrangements in the MECP2 Gene in Three Patients With Rett Syndrome: Implications for Routine Diagnosis of Rett Syndrome
}

\author{
E. Schollen, E. Smeets, E. Deflem, J.P. Fryns, and G. Matthijs \\ Genter for Human Genetics, University of Leuwen, Leuwen, Beigium
}

Communicated by Haig $H$. Kazazian : Since 1999, many laboratories have confirmed that mutations in the MECP2 gene are the primary cause of Rett syndrome (RTT or RS) and identified mutations in 70 to $90 \%$ of the sporadically affected girls. Most of the screenings are PCR-based and restricted to the coding part of the gene and therefore prone to miss gross

rearrangements. By Southern blot analysis we identified large deletions $(41 \mathrm{~kb})$ in three female patients with classical, severe Rett syndrome. Further characterization by semiquantitative PCR and amplification of junction fragments confirmed the presence of a $7.6-\mathrm{kb}$ deletion in one patient and an $8.1-\mathrm{kb}$ deletion in the other patient, both including exon 3 and the coding part of exon 4 . The exact nature of the rearrangement in the third patient remained elusive. These results underline the importance of screening for major genomic rearrangements in Rett syndrome.

\section{INTRODUCTION}

Rett syndrome (RTT or RS; MIM\# 312750) is a childhood neurodevelopment disorder that affects almost exclusively girls in early childhood. A period of apparently normal development (until 6 to 18 months of age) is followed by a stagnation-regression marked in particular by loss of purposeful hand use and speech and a characteristic neurological profile of dystonic motor disability with preserved visual contact behavior [Hagberg et al., 1983]. The clinical phenotype of classical and variant RS are delineated by internationally accepted clinical criteria [Hagberg et al., 1985]. Since 1999, numerous reports support the evidence

that mutations in the Methyl CpG binding protein 2 gene (MECP2; MIM\# 300005) are the primary cause of RS [Amir et al., 1999; reviewed by Mittenberger-Miltenyi and Laccone, 2003]. Mutations are found in 70 to $85 \%$ of patients with classical RS, and to a lesser

extent, in patients with variant RS. Until now there is no clear phenotype genotype correllation [Shahbazian and Zoghbi, 2002]. Recently, multations in MECP2 have also

been found in males with early-onset RS and variable degrees of mental retardation Laccone et al., 2002]. Eight mutations [p.T158M (c.473C4T), p.R168X, (c.502C4T), p.R255X (c.763C4T), p.R270X (c.808C4T), p.R294X (c.880C4T), p.R306C (C.916C4T), p.R133C (c.397C4T), and p.R106W (c.316C4T)] are recurrently found in different populations and account for $56 \%$ of all mutated alleles; another $38 \%$ of the patients carry a deletion in the C-terminal region, ranging from 1 to $338 \mathrm{bp}$ (see RettEASE: http://mecp2.chw.edu.au/) Christodoulou et al, 2003]. In most laboratories, mutation analysis of the MECP2

gene is based on $\mathrm{PCR}$, in combination with screening techniques like denaturing high pressure liquid chromatography (DHPLC), single strand conformation polymorphism (SSCP), denaturing gradient gel electrophoresis (DGGE), or direct sequencing. It is largely limited to the coding region. These screening strategies might miss smaller deletions [Bienvenu et al., 2001] and larger genomic rearrangements. Tens of mutation reports have been published. However, so far, only two groups [Bourdon et al., 2001a; Yaron et al., 2002] reported the use of Southern blot to screen for major rearrangements in MECP2 and 
identified respectively two and one patients. One of these patients carried a 436 -bp deletion within exon $4(c .736$ _ 1772 del), while the deletions in the other wo remained uncharacterized. We performed Southem blot analysis on nine patients with RS (three with classical RS, six with a variant RS). We identified aberrant fragments in the three patients with classical RS. Semi-quantitative PCR with markers within and flanking the gene and long range PCR were used to characterize the rearrangements. Two patients carry a deletion of $47 \mathrm{~kb}$ encompassing exon 3 and the major part of the coding region of exon 4 . The deletion in the third patient is large and not yet fully characterized.

\section{MATERIALS AND METHODS}

\section{Patients}

The three RS subjects described in detail in this study have severe classical RS in stage IVB at adult age and were scored following the guidelines by Kerr and co-workers [Kerr et al., 2001 ]. We consider a score above $25 / 40$ as severe, above $30 / 40$ as very severe. Patient 1 obtained a score of $32 / 40$ at 18 years. She has very severe RS with spastic quadriplegia and dystonia with frozen rigidity and contractures in feet, wrists, knees, elbows, and hips. She was operated on for severe scoliosis when she was 16 years of age. Hand stereotypies were constantly present but simple. Hyperventilation, breath holding, and panting were mild, without vacant spells and color changes. Her epilepsy is well controlled by medication. She presents a friendly visual contact behavior and has no mood disturbance. Growth parameters are below the 3rd centile. The four extremitties show abiotrophic changes. Patlent 2 resented with a gradual onset of RS with sub-optimal progress of development and deceleration of head circumference the first year. At 23 years she obtained a score of $28 / 40$. She was operated on for severe scoliosis at 14 years of age. She has a remarkable eye pinpointing behavior. She has passive bladder control. She developed severe contractions in the knees and hips. Patient 3 presented the first symptoms at 10 months of age with screaming behavior day and night. At 17 years she obtained a score of 26/40. She was operated on for severe scoliosis at 16 years of age. She still has prominent agitation with crying spells and

disruptive daytime sleeping/night time awakening behavior. Hyperventilation, breath holding, and panting are milldy present without color changes. Growth parameters are between the 3 rd and 10 th centile. Her epilepsy is well controlled by medication. The four extremities show temperature, color, and trophic changes.

\section{Screening of MECP2}

For routine diagnosis, exons 3 and 4 were screened by DHPLC. The exons are amplified in respectively 2 (Ex3F1; Ex3F2) and 5 (Ex4F1, Ex4F2, Ex4F3, Ex4F4, Ex4F5) fragments, essentially as described by Amir et al [1999]. Details on primers and DHPLC conditions can be obtained on request. Base vartations were confirmed and identified by direct automated sequencing with Dye Terminator Ready Reaction mix (Applera, Nieuwerkerk a/d lisel, The Nethertands) and analysis on a $A B \| 310$ or $A B \mid 3100$ (Applera). Large deletions, overlapping several PCR primer sites in exon 4, were excluded by long-range PCR essentially as described by Cheadle et al. [2000] with the forward primer of Ex4F1 and the reverse primer of Ex4F5. The complete coding region (exon 2, 3, and 4 and the flanking intronic sequences) was analyzed by direct sequencing for patients with a typical RS phenotype and no mutations after DHPLC screening. 


\section{Southern Blot Analysis}

Genomic DNA (10 mg) was digested with $40 \mathrm{U}$ Sacl, Bglll, BamHI EcoRl, Hindlll, or Pstl (Roche, Vilvoorde, Belgium) and separated on a $0.8 \%$ agarose gel. The probe was amplified from genomic DNA with primers 3UTR (GCO AGT TTG CTC TCA GAG CAT) and EX4F1 (ACG TTT GTC AGA GCG TTG TCA CC) using buffer 3 of the Expand Long template PCR system (Roche). An aliquot was labeled with [a-32P]-dCTP using random primer labeling and Southern blotting was performed essentially as described by Sambrook et al. [1989].

Semi-Quantitative PCR A semi-quantitative PCR was developed for a multiplex of 6 genomic fragments: two published STS markers G54853 (primers forward CAC AAC TGC CCT CTT CCA GT; reverse ACC TCC CAG CTG GAG TTT CT) and stSG43248 (primers forward GGG AGT CCC TTG AAC TAC TGG; reverse TGC CTC CAT GGC CTC TAG); and four of the fragments used for routine screening (EX3F1, Ex4F1, Ex4F3, and EX4F5). The fragments were amplified in a $50 \mathrm{ml}$ reaction volume with $200 \mathrm{mM}$ dNTP's, 1 Buffer (Roche), $1 \cup$ Taq DNA polymerase (Roche), 50 ng DNA, and respectively $5.0 ; 5 . \overline{0} ; 7.5 ; 10.0$; 5.0 ; and 7.5 pmol of each primer for the different fragments. A touch-down PCR program was used with 13 cycles of 2000 at $951 \mathrm{C}, 3000$ at $651 \mathrm{C}$ minus $11 \mathrm{C}$ each cycle, and 3000 at $681 \mathrm{C}$, followed by 12 cycles of 2000 at $951 \mathrm{C}, 3000$ at $521 \mathrm{C}$, and 3000 at $681 \mathrm{C}$. Amplicons were sized and quantified on an ABI310 (Applera). Areas under the curve were calculated using Genescan software (Applera).

\section{Amplification of the Junction Fragment}

To amplify across the deletion breakpoint, the reverse primers of 654853 and of Ex4F5 were used for an expanded long template PCR (Roche) reaction and subsequently sequenced.

\section{X-Chromosome Inactivation ( $\mathrm{XCI}$ )}

XCl was studied essentially as described by Allen et al. [1992]. Briefly, $1 \mathrm{mg}$ of DNA (of peripheral blood) was digested with Cfol or Hpall prior to PCR amplification. The polymorphic CAG repeat of exon 1 of the androgen receptor was amplified as described. Amplicons were analyzed on a $\mathrm{ABI} 310$ (Applera). Peak areas were compared before and after digestion.

\section{RESULTS}

In a screening of 30 well wharacterized adult RS patients, mutations were found in 21 of them by routine screening (10/13 females with classical RS, $11 / 17$ with varian $R S$ ) [Smites et al. 2003]. In Patient 3 of this study, a previously unidentified base variation (c.439 G4A), resulting in a missense mutation p.D147N, was identified in an apparently homozygous condition. The mother was carrier of this variation but not the father; hence the variation was present in a hemizygous condition. Although D147 is phylagenetically conserved, it was concluded that p.D147N is not a causal mutation. Actually, this observation pointed to the existence of a deletion on the paternal allele. In an attempt to identify the mutation in the remaining nine patients, we performed Southern blot analysis. Genomic DNA was first digested with Sacl, Bglll, and BamHI (Fig. 1 and data not shown). A probe of 2,223 bp was amplified from genomic DNA. It spans 103 bp of intron 3 , the coding part of exon 4 and 909 bp of the 30UTR. Aberrant patterns were obtained for three patients. The pbservations were confirmed on a second blot with the restriction enzymes EcoRI. HindllI, and Pstl. To identify the nature of the aberrant restriction fragments, a multiplex, semi-quantitative PCR was developed for six. markers covering a region of $17 \mathrm{~kb}$, ranging from intron 3 (IVS3-1.4 kb; G54853) to 665 bp in the 30 UTR (stG43248) and covering markers for exon 3 (Ex3F2) and exon 4 (Ex4F1, Ex4F3, and Ex4F5). Patient samples and 10 normal controls were analyzed 
in duplo. A single dose was observed for markers Ex3F2, Ex4F1, and Ex4F3 in all three patients, and for marker Ex3F5 only in Patient 1. The other markers were present

in two copies, indicating that all three patients carry a deletion covering at least exon 3 and part of exon 4. The exact extent of the deletions was determined by amplification and sequencing of the junction fragments. Fragments of approximately $10 \mathrm{~kb}$ were obtained with primers G54853R and Ex3F5R in Patients 2 and 3 . Sequencing across the breakpoint identified a deletion of 8,136 bp from IVS3-6215 to c.1190 in Patient 2 (g.58906 67041del, with reference sequence NT 025965.8 subset $626543 y 702439$, complement). Patient 3 has a complex rearrangement with a deletion of at least 7,628 bp from IVS3-5690 to c1208 and an insertion of $42 \mathrm{bp} \mathrm{(} 9.5942167059$ delins42). A BLAST genome search located this inserted fragment around $1 \mathrm{Mb}$ distal to MECP2 in the contig NT 029507.1. where it is repeated thiree times. The exact extent of the deletion could not be determined because the 50 breakpoint of the rearrangement is due to an Alu mediated recombination between intron 3 (IVS3-5989 to IVS3-5690) of MECP2 and the distally repeated sequence. We did not succeed in determining the exact features of the rearrangement in Patient 1 . Several PCRapproaches failed. X-chromosome inactivation $(\mathrm{XCl})$ was studied on DNA from peripheral blood. The influence of $\mathrm{XCl}$ on the genotype phenotype correlation is discussed by Smeets et al. [2003]. Patient 2 is not informative for the AR marker. Both other patients show a random distribution of $\mathrm{XCl}$.

\section{DISCUSSION}

We identified large deletions $(47 \mathrm{~kb})$ in three patients with classical severe RS and specified the deletion borders in two of them. The patients were included in a series of 30 adult RS palients presenting with classical RS (13) or variant RS (17) [Smeets et all, 2003]. With the identification of these deletions we confirmed the diagnosis in all patients with classical severe RS, giving a virtual detection rate of $100 \%$. No detectable gross rearrangements were found in subjects with variant RS, leaving the detection rate in that group at $65 \%$ $(11 / 17)$.

Two previous reports identified major rearrangements in 1 out of 47 and 1 out of 17 classical RS patients [Bourdon et al., 2001a; Yaron et al., 2002]. In total, this results in a frequency of approximately $5 \%(5 / 94)$ of the mutated RS alleles. Given the size and the position of the deletions, no functional protein would be expected. With a random $X \mathrm{XI}_{\text {, these major }}$ rearrangements therefore result in severe classical RS. The frequency in the subset of severe RS patients might even be much higher. The viability of MECP2-null mice suggested already that absence of functional MECP2 is compatible with life [Chen et al., 2001; Guy et al., 2001]. The mechanism of these deletions is uncertain. Smaller deletions, insertions, and complex insertionsdeletions (indels) represent 126 of the 262 different disease-causing mutations in the RS database RettBASE and are responsible for $18 \%$ of all mutated alleles.

Remarkably, the 30 junctions of the majority of these deletions are restricted to a region ofB100 bp (c.1150 to $\mathrm{c} .1250$ ). Interestingly, this also applies to the gross deletions identified in this study. Generally, it is assumed that this instability is due to the presence of palindromic

repeats. In contrast, Lebo and co-workers [Lebo et all, 2001] ascribed the deletion hotspots in that region to the presence of polypurine stretches. The deletion in Patient 2 is also compatible with such a mechanism. In Patient 3 , the 30 breakpoint is located in the same region, but the 50 breakpoint may be caused by an Alu mediated meiotic or mitotic recombination. In the case of Patient 3 , we have evidence that the deletion is of paternal origin because of the presence of the maternal polymorphism p.D147N. We did not have access to parental DNA in the other two cases. We cannot explain why we did not succeed in amplification across the breakpoint in Patient 1 ; the semi-quantitative PCR analysis provided evidence for the presence of major deletion, probably extending beyond the 30 UTR in exon 4. It is remarkable that the identification of deletions and gross rearrangements 
in major but recently identified disease genes has been slow. These shortcomings are the result of the fact that many laboratories limit themselves to the use of PCR based methods, while Southem blot has either become obsolete or is hardly ever introduced. In the early days of mutation research, people would not have overtooked deletions; for instance with the

Duchenne muscular dystrophy gene (DMD; MIM\# 300377) [Koenig et al.; 1987]. Later. deletions were more often overlooked when PCR became the preferred tool for molecular analysis, to the extent that it became big news when someone finally found a deletion, such as with the first deletion in the breast cancer gene, BRCA1 (MIM\# 113705) Petrij-Bosch et all., 1997]. Novel techniques like multiplex ligation-dependent probe amplification (MLPA) Schouten et al. 2002] will certainly allow future researchers to avoid these pitfalls. The deletions found in the three patients described in this paper are too small to be detected by FISH analysis as performed by Bourdon et al. [2001b]. Larger deletions cannot be excluded but are probably restricted at the centromeric site due to the nearby presence of the Interleukin-1 receptor associated kinase 1 gene (IRAK1; MIM\# 300283; GenBank NM_001569). Given the frequency of large chromosomal rearrangements

in patients with classical severe RS, we strongly advise the use of Southern blot or alternative techniques like MLPA in routine screening of clinically well delineated RS patients.

\section{REFERENCES}

Allen RC, Zoghbi HY, Moseley AB, Rosenblatt HM, Belmont JW. 1992. Methylation of Hpall and Hhall sites near the polymorphic CAG repeat in the human androgen-receptor gene correllates with $X$ chromosome inactivation. An $J$ Hum Genet 51:1229-1239.

Amir RE, Van den Veyver $B_{3}$ Wan M, Tran CQ. Francke U. Zoghbi HY. 1999 . Rett symdrome is caused by multatlons in $X$-limked MECP2, encading methyl-CpG-binding proteir 2.

Nat Genet 23:185-188

Bierwenu T, Souwitle I, Poirier K, Aquaviva C, Burglen L, Amiel J, Heron B, Kaminska $A_{n}$ Couvert P, Beldjord $C$, Chelly J. 2001 . Five nowel frameshift mutations in exon 3 and 4 of the MECP2 gene identified in Rett patients: consequences for the molecular diagnosis strategy. Hum Mutat 18:251-252.

Bourdon $V_{n}$ Philippe $C$, Labrune $O$, Amsallem $D$. Arnould $C$, Jomveaux $P$. 2001a. A detailed analysis of the MECP2 gene: prevalence of recurrent mutations and gross DNA irearangements in Rett syndrome patients. Hum Genet 108:43-50.

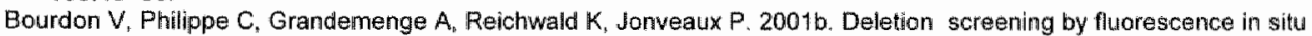
inybridization in Rett syndrome pattents. Ann Genet 44:191-194.

Cheadle JP, Gill H, Fleming N, Maynard J, Kerr A, Leonard H, Krawczak M, Cooper DN, Lymch S. Thomas N, Hughes

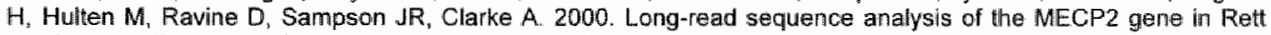
syndrome patients: correlation of wisease severity with mutation type and location. Hum Mol Ge nat $9: 1119-1129$.

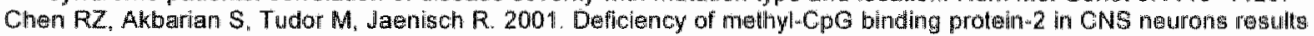
in a Rettlike phenotype in mice. Nat Genet $27 \cdot 327-331$

Christodoulou J: Grimm A. Maher T, Bennetts B. 2003. RettBASE: the IRSA MECP2 variation databasta a new mutation database in evolution. Hum Mutat 21:466-472.

Guy $₫$, Hendirich $B_{4}$ Holmes $M$ Martin JE. Bïrd A. 2001. A mouse Mecp2-nuill mutation causes neurological symptoms that mimic Rett symdirome. Nat Genet 27:322-326

Hagberg $B_{*}$ Aicardi $J$ Dias $K_{2}$ Ramas 0 . 1983. A progressive syndrome of autism, dementia, allaxia, and loss of purposefull hand use im giris: Rett's syndrome: report of 35 cases. Arin

Neuiral $14471-479$

Haglberg B, Goutieres F. Hanefeld F. Rett A, Wilson J. 1985. Rett syndrone: criteria for inclusion and exctul sion. Brain Dev 7:372-373

Kerr AM, Nomura Y. Airmstrong D, Anwret $M$, Belichenko PV, Budden S, Cass $H$, Christodoulou J, Clarke $A$, Ellaway $C$. d'Esposito M. Francke U. Huiten M, Julu P. Leomard H, Naidu S, Schamen C. Webb T, Engerstrom IW, Yamasthita $Y^{\prime}$. Segawa M. 2001. Guidelines for reponting clinical features in cases with MECP2 mutations. Brain Dev 23:208211

Koenig M. Hoffman EP. Bertelson CJ. Monaco AP, Feener C, Kunkel L.M. 1987. Complete cloning of the Duchienne muscular dystrophy (DMD) CDNA and preliminary genomic arganizition of the DMD gene in normal and affected individuals. Cuell $50: 509-517$

Laccone $F$. Zoll B. Huppke P. Hanefeld F. Pepinsiki W. Trappe R 2002 MECP2 gene nueleotide changes and their pathagenicity in males: praceed with caution. J Med Genet 39:586-588. 


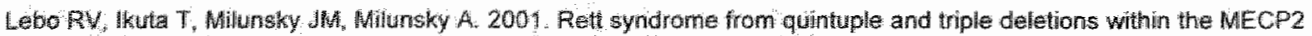
deletwon hotspot region. Clin Genet 59:406-417. Mittenberger-Mitteny $G$, Laccone F. 2003. Mutations aind polymorphims in the human mefhyl CpG-binding protein, MECP2. Hum Mutal 22:107-115.

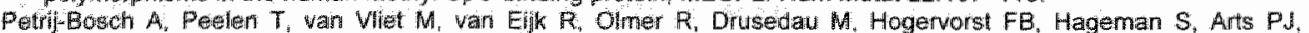

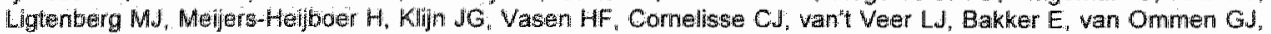
Devile P. 1997. BRCAH genonic deletions are majof founder mutations in Dutch breast cancer patients. Nat Genet $17: 341-345$

Sarnbrook d, Fritech EF, Maniatis T. 1989. Molecular clloning: a laboratory Manual, 2nd ed. Cold Spring Harbor Laburatory Press: Cold Spring Harbor, WY.

Schouten JP, MCElgunn CJ, Waaller R, Zwijnenburg D, Diepivens F, Pals G. 2002. Relative quantification of 40 nucleic acid sequences by muttiplex ligation-dependent probe amplification. Nucleic. Acids Res 30 :e57.

Ghahbazian MDD, ZoghbiHY. 2002. Rett Sysidrome and MeCP2. linking epigenetics and neuronal function. Am J Hum Genet $71.1259-1272$.

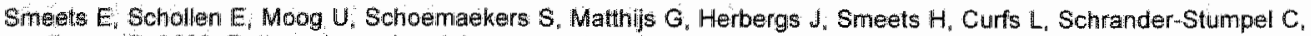
Fryms $\mathrm{JP}$. 2003. Rett syndrorye in adolescent and adulit females:

clinical and molecular genetic findings. An J Med Genet, accepted.

Yaron Y, Ben Zeev B. Shomrat Bi, Bercovich D, Naman T. Orr-Urtreger A, 2002. MECP2 mutations: in Israel: introlicationis for molecular analysis, genetic counselting, and prenatal diagnosis in Rett syndrome. Hum Mutat 20 : $323-324$. 
Neurodevelopmental disorders in males related to the gene causing Rett syndrome in females (MECP2).

Moog U." ,Smeets E.*, van Roozendaal K., Schoenmakers S., Herbergs J." SchoonbroodLenssen A., Schrander-Stumpel C.

Eur J Paediatr Neurol 2003, 7:5-12.

"equal contribution by both authors 



\section{Neurodevelopmental disorders in males related to the gene causing Rett syndrome in females (MECP2)}

Ute Moog "Eric EJ Smeets ", Kees EP van Roozendaal", Sam Schoenmakers", Jos Herbergs ${ }^{3}$. Anneke MJ Schoonbrood-Lenssen ${ }^{2}$, Connie TRM Schrander-Stumpel ${ }^{4,3}$

Department of Cinical Genetics, University Hospital Maastricht, Maastricht, The Netherlands; "Center for People with Intellectual Disability "Pepijm", Echt, The Netherlands; "Resealch institute Griowth Development (GROW), Naastricht University, Maastricht, The Netherlands.

*equal contribution by both authors

\section{ABSTRACT}

Mutations in the MECP2 (methyl-CpG-binding protein 2) gene are known to cause Rett syndrome, which is a well known and clinically defined neurodevelopmental disorder. Rett syndrome occurs almost exclusively in females and for a long time was thought to be an $X$ linked dominant condition with lethality in hemizygous males. Since the discovery of the MECP2 gene as the cause of Rett syndrome in 1999, MECP2 mutations have however also been reported in males. These males phenotypically have classical Rett syndrome when the mutation arises as somatic mosaicism or when they have an extra $X$ chromosome. In all other cases, males with MECP2 mutations show diverse phenotypes different from the classical Rett syndrome. The spectrum ranges from severe congenital encephalopathy, mental retardation with various neurological symptoms, occasionally in association with psychiatric illiness, to mild mental retardation only.

We present a 21 year old malle with severe mental retardation, spastic tetraplegia, dystonia, apraxia and neurogenic scoliosis. A history of early hypotonia evolving into severe spasticity. slowing of headgrowth, breathing irregularities and a good visual interactive behaviour were highly suggestive of Rett syndrome. He has a de novo missense mutation in exon 3 of the MECP2 gene (P225L). The clinical spectrum and molecular findings in males with MECP2 mutations are reviewed.

\section{INTRODUCTION}

Rett syndrome (RTT, MIM *312750) is a progressive neuradevelopmental disorder occurring almost exclusively in females. After an apparently normal development until 6-18 months of age, girls with classical RTT show regression with deceleration of head growth and loss of speech and acquired motor skills, in particular purposeful hand use. They develop stereotypic hand movements, breathing irregularities, ataxia and seizures. After a period of pseudo-stabilisation and then further deterioration, the condition is mostly characterised by severe mental retardation with a relatively spared and often remarkable visuall communicative ability, a progressive scoliasis and a variable degree of spasticity and rigidity often leading to wheelchair dependency. The diagnosis is made clinically in accordance with recognized criteria. ${ }^{1}$ Apart from classical RTT, a forme fruste, a variant with preserved speech, cases with late onset of regression and congenital onset variants are known to occur in females.

In 1999, RTT was reported to be caused by mutations in the gene encoding methyl-CpGbinding protein 2 (MECP2) located at chromosome $\mathrm{Xq28}^{2}$. RTT had been thought to be an $X$-linked dominant condition leading to prenatal lethality in hemizygous males. In recent years however, MECP2 mutations have also been reported in males. These males may present with a RTT phenotype when they have X-chromosome aneuploidy or somatic mosaicism for the mutation. However, when MECP2 mutations occur in non-mosaic form and in chromosomally normal males, they lead to various neurological phenotypes different 
from RTT. We present a 21 year ald male with severe mental retardation and a neurological disorder with features reminiscent of RTT in whom a de novo MECP2 mutation was found, and review reported male patients with a MECP2 mutation.

\section{CASE REPORT}

\section{Patient report}

The patient was born at term with a birthweight of $3900 \mathrm{~g}$. Pregnancy and delivery had been uneventful. He had two older healthy brothers. The family history was negative for mental retardation and neurological disorders. There were no feeding problems. His very early infantile development was reportedlly normal. Head circumference at birth is unknown but was $46.5 \mathrm{~cm}$ at age 11 months and $47.5 \mathrm{~cm} 3$ months later (both slightly below the 50 th centile). Around 3.5 months of age, his mother noticed "a change" in making contact and in behaviour towards her. Shortly thereafter, he began to show axial hypotonia and a marked headlag. His psychomotor development became severely retarded. He never learned to sit alone nor to walk and lost his ability to stand with support at the age of 2 years. However, there was some fine motor adaptive ability. From 2 years on, he showed motor restlessness and developed extrapyramidal symptoms. There was no development of speech. He apparently had epilepsy from infancy to 7 years of age. A video taken at 11 years of age shows his posture in the wheelchair to be hypotonic with severe kyphoscoliosis and pelvic asymmetry. He could turn the pages of photo albums and booklets. His concentration was poor with little attention span. He developed severe spastic tetraplegia. At the age of 16 years, he lost purposeful handuse and became completely apraxic with flexion contractures of the wrists. There were periads of great anxiety, protest and overagitation associated with dysregulation of body temperature.

On clinical examination at the age of 21 years, he was severely mentally retarded and bound to a wheelchair due to severe spastic tetraplegia. His was lean and small statured with a head circumference of $53 \mathrm{~cm}\left(3^{\text {rd }}\right.$ to $10^{\text {th }}$ centile $)$. He had a severe kyphoscoliosis, a hip dislocation on the right side, joint contractures of fingers, wrists, elbows and knees and had warm, sweaty hands and feet. He was abnormally prone to agitation and to repetitive daytime sleeping. Sometimes, he became extremely pale and had shallow breathing interrupted by short apneic periods. He was able to eat mashed food, did not chew and had delayed swallowing. He had a good visual contact, recognizing his parents and caregivers both visually and vocally, but. seemed to be very reserved towards strangers. His parents described him as being emotionally involved in sympathy or antipathy towards other people. He loved music and family soaps on the TV.

Chromosome analysis showed a normal 46, XY karyotype. A CT scan of the brain at 7 years of age and a MRI scan at 12 years of age, an EEG, SSER, BER and EMG were all reported as normal.

\section{MATERIALS AND METHODS}

Genomic DNA was prepared from peripheral blood leukocytes using the Wizard Genomic DNA purification kit (Promega) according to manufacturers recommendations.

The MECP2 coding region was PCR amplified in 8 , mostly overlapping, segments. The obtained PCR products were screened for mutations using bi-directional sequencing utilising the Big Dye 2 Terminator Cycle Sequencing Kit (Perkin-Elmer Biosystems). After anallysis on the ABI PRISM 3100 Genetic Analyzer (Perkin-Elmer Biosystems) the data were analysed using the Vector NTI DNA alignment software.

The presence of the identified putative mutation site in the MECP2 segment ex $3 \mathrm{~b}$ was subsequently assessed using a single-strand conformational polymorphism (SSCP) anallysis approach (GenePhor, Pharmacia Biotech) under the conditions showing an altered 
migration profile when the nucleotide substitution is present. Further to the patient's, his mother's and brothers' DNA, an additional 96 control chromosomes ( 25 female and 46 male) were included in the SSCP study.

\section{RESULTS}

DNA sequence analysis of the MECP2 gene of our index patient revealed the presence of a cytosine to thymidine nucleotide substitution at position 674 of the coding region. This nucleotide substitution (C674T) leads to a proline to leucine amino acid change in the transcriptional repression domain (TRD) at position 225 of the MeCP2 protein (P225L). In contrast, subsequent DNA sequence analysis of the patient's mother and wo elder brothers showed no base alteration in the MECP2 gene. These results were confinmed by SSCP analysis. In comparison to the gel mobility profile of his family members, only the patient's amplified MECP2 segment ex3b DNA showed an altered profile, indicative of the presence of a base change. Similarly, no changed mobility profiles were observed with the SSCP analysis of the 96 control chromosomes.

Consequently, our data indicate that the observed C674T substitution in our patient has arisen de novo and is not to be found in the general population.

\section{Clinical characteristics of MECP2 related disorders in males}

Since 1999, there has been a growing number of publications reporting male patients with a MECP2 mutation. A summary of these cases, their clinical findings, family history and the particular mutation is given in table $1^{3-30}$ The phenotypes cover a huge spectrum of neurodevelopmental disorders, ranging from classical RTT to mild mental retardation only and encompass congenital encephalopathy and mental retardation of different degrees in association with diverse neurological features and/or psychiatric illness.

Male patients who presented with a classical or almost classical RTT phenotype can be divided into two groups: those with aneuploidy of the X-chromosome (patients 1.4 in table 1) and those in whom somatic mosaicism of the MECP2 mutation was found (patients 5-7). In the former group, one mutation is reported as a de novo mutation, ${ }^{5}$ in the other reports this is not specified. The mutations in the latter group arose by definition due to a postzygotic event and thus occurred de novo; The RTT phenotype of both groups can be explained by the presence of a second X-chromosome containing the normal wild type allele as is the case in female RTT. In both groups, patients are not consistently hemizygous for the mutation and thus differ considerably from cases $8-25$ whom may be regarded as having true manifestations of MECP2 related disorders in males.

Five patients (cases 8-12 in table 1) presented with a severe congenital encephalopathy and died during the first two years of life. ${ }^{4,15-19}$ They were all born in families with girls affected with typical RTT and/or a second boy with the same condition. Two of the 5 mothers were identified as asymptomatic mutation carriers with a skewed X-inactivation pattern, , $^{-10}$ and another manifested mild learning disability and mild neurological symptoms. ${ }^{15}$ in the other two mothers, no mutation was found in blood; the recurrence of the mutation in a second child was most probably due to germline mosaicism. ${ }^{18-10}$

Cases 13-18 were all families with several affected males. ${ }^{20-28}$ Most of them presented with a combination of neurological symptoms and mental retardation. The neurological features were very diverse and comprised pyramidal and extrapyramidal symptoms, ataxia, seizures and hypotonia. The degree of mental retardation was severe (case 13 and 14) to mild (case $15+18$ ) and showed intrafamilial variability (case 16). In case 18, no neurological symptoms were associated with mental retardiation. The males described by Klauck et al. (case 17) showed a combination of mental retardation, neurological symptoms (pyramidal signs), psychosis and macro-orchidism, the so called PPM- $X$ syndrome. ${ }^{27}$ In this farnily, the clinical features were variable as there were males with or without a psychiatric illness. One of the affected males of caseffamily 15 had severe behavioural problems. Regarding the 
carrier women, most were asymptomatic (family 16-18, some carriers of family 13 and 15) whereas others showed mild symptoms (borderline intelligence or mild retardation, mill hypotonia, gait disturbance, speech difficulty, tremor). In cases 19-22, only one male was affected due to a familial MECP2 mutation detected also in at least the mother; these female mutation carriers were asymptomatic. In cases 23 and 24, no DNA of the mother was available for mutation analysis. Again, clinical findings comprised mental retardation with (case 19) or without neurological or other features (cases 21-24); unfortunately, the clinical documentation of the latter cases was scant. Case 20 presented with a psychiatric and developmental receptive language disorder. ${ }^{30}$ None of the male patients of cases $13-22$ showed deceleration of head growth which is an obligate feature in classical RTT.

When $X$ chromosome inactivation $(\mathrm{XCl})$ was investigated, symptomatic carrier women had a random $X$ chromosome inactivation (family 13 and 14). In asymptomatic mutation carriers however, both a skewed (case 18) and a balanced $X$ chromosome inactivation pattern (case $13,19,21,22$ ) were found. Thus, the lack of symptoms in carrier women can not consistently be explained by a skewed $\mathrm{XCl}$.

Compared to the whole group of male patients with a MECP2 related disorder, the present case shows some peculiarities. Firstly, the mutation of our patient arose de nowo which was not shown in any of the reported patients. However, the possibility can not be ruled out that the mutation is caused by germline mosaicism in his mother. Secondly, the clinical course and findings were dominated by features characteristic for RTT: a history of early hypotonia evolving into severe spastic tetraplegia and apraxia, slowing of head growth, neurogenic scoliosis and joint contractures, abnormal breathing pattern and a preserved visual interactive behaviour. The major difference with classical RTT is that postnatally, he had only a short period of apparently normal development, that his handuse was relatiely preserved for several years and that he did not develop the characteristic, stereotypic hand movements. The present case expands the described spectrum of MeCP2 related phenotypes in male variants of the Rett syndrome occurring in a chromosomally normal boy.

\section{Molecular genetics}

\section{MeCP2 protein and gene}

MeCP2 is an ubiquitously expressed DNA-binding protein, which is particularly abundant in the brain. It contains a methyl-CpG binding domain (MBD), a transcriptional repression domain (TRD), and a final C-terminal segment. MeCP2 binds with its MBD to methylated DNA throughout the genome, is subsequently involved in deacetylation of core histones and chromatin condensation and thus leads to repression of transcription. Loss of function of MeCP2, especially in differentiated, postmitotic neurons, is predicted to lead to deregulated expression of putative target genes with a potential damaging effect during central nervous maturation.

The gene encoding MeCP2 is located at Xq28 and undergoes X-inactivation. It comprises 4 exons, with the coding sequence in exons 2 to $4 .{ }^{32}$ Over 185 mutations have been reported in RTT patients. About $2 / 3$ are truncating and $1 / 3$ missense mutations, the latter ones occurring mostly in the MBD. ${ }^{33-34} 10 \%$ are intragienic deletions or complex rearrangements leading to frameshifts in the C-terminal segment. The mutation detection rate in sporadic female cases with classical RTT is $70-85 \%$ and lower in Rett variants. ${ }^{34}$

\section{MECP2 mutations in male patients}

Most of the mutations found in patients 1-12 (table 1) who showed a RTT phenotype or had severe congenital encephalopathy, are known to occur in females with classical RTT. It is obvious that mutations leading to classical RTT in females do not necessarily result in prenatal lethality in males; they may be underdiagnosed because of the non-specific congenital onset encephalopathy. ${ }^{35}$ It is also possible that the smaller number of males 
could relate to the paternal origin of the mutation in a large percentage of girls with classical RTT.

However, the relatively milder cases presenting with a spectrum of neurodevelopmental disorders (cases 13-25) were associated with mutations not found in females with classical RTT. In contrast to the MECP2 mutations reported in girls with classical RTT, truncating mutations (frameshift and stopcodon mutations) seem to be an exception in males with a normal karyotype: apart from one (case 13) which is a very late truncating mutation, there are no truncating mutations reported in males. The mutation $\mathrm{A} 140 \mathrm{~V}$ is found in several male patients (cases 14, 17, 20-22) and causes different phenotypes. It is intriguing that in both cases with psychiatric features (case $17+20$ ) this mutation was found. Kudo et al. studied the effect of this and the E137G mutation (case 16) on MeCP2 function as compared to the protein function when a classical Rett mutation is present. ${ }^{36}$ They found evidence for only mild impairment of MeCP2 function in both cases and argued that A140V is unlikely to be a polymorphism. That different mutations cause different functionality of the MeCP2 protein has certainly to be confirmed by future studies.

The described, newly identified missense mutation (P225L) observed in the boy presently reported is located in the TRD and is a highly conserved residue in mouse, chicken and Xenopus sequences. Since this particular mutation was shown to be de novo it is highly probable that the leucine substitution is pathogenic. Moreover, a disease causing missense mutation has previously been identified in several female Rett patients at the same position (C674G) in the MECP2 coding sequence, leading to a proline to arginine substitution. ${ }^{37-38}$ These two amino acid substitutions in the TRD may well have different effects on the function of the MeCP2 protein on basis of their chemical constitution and thus manifest distinct phenotypes.

\section{CRITERIA FOR MECP2 SCREENING IN MALES}

On the basis of our current knowledge of MeCP2 related disorders "DNA analysis of the MECP2 gene in combination with a chromosome investigation should seriously be considered in males with

- Classical Rett syndrome,

- Congenital encephalopathy,

- MR and diverse neurological findings (including MR and neurological findings reminiscent of Rett syndrome) when no other explanation has been found after a careful examination,

- A combination of mental retardation, pyramidal signs, psychosis and macroorchidism (PPM-X syndrome).

So far, it is debatable whether non-syndromic X-linked mental retardation (XLMR) should be added to the list of criteria for DNA testing. In the present series, family 18 is the only example of non-specific MR caused by a MECP2 mutation. Unfortunately, the clinical findings of the 4 sporadic cases 21-24 are too poorly documented to exclude further neurological anomalies or features of $\mathrm{RTT}^{25}$ The mutation in family 18 was detected after the screening of 176 families with MR of (possible) $X$-linked inheritance (material collected by the European XLMR consortium); in $13 / 176$ families, the genetic defect could be linked to $\mathrm{Xq}_{28}{ }^{28}$ A subsequent study reported the occurrence of anly one MECP2 mutation in 500 males with unexplained MR. ${ }^{39}$ The low yield of these studies weaken the result of a previous study which suggested that MECP2 might be highly mutated in X-linked mental retardation and account for $\pm 2 \%$ of MR. ${ }_{40}^{25}$ No MECP2 mutations were detected in 42 autistic males with or without mental retardation. ${ }^{40}$

In conclusion, MECP2 mutations give rise to a spectrum of neurodevelopmental disorders in males which partially depend on the type of mutation and functionality of the protein. ${ }^{36}$ 

criteria for testing.

\section{REFERENCES}

1. The Reth syndrome Diagnostic Working Group. Diagnostic crileria for Rett syndrome. Ann Neural 1988; 23: $425-$ 428 .

2. Amir RE, Van den Veyer ID, Wan M, Tran CQ, Francke U, Zoghbi HY. Rett syndrome is caused by mutations in Xlinked WeCP2, encoding methyl-CpG-binding protein 2. Nat Gener 1999; $23,185-188$.

3. Leonard $H$, Sibersten $\downarrow$, Falk $R$. Houwink-Manwille I, Ellaway $C$. Raffaele LS, Engerstrom IW, Schanen $C$ Decurrence of Rett syndrome in boys. Child Newrol 2001; 16: 333-338.

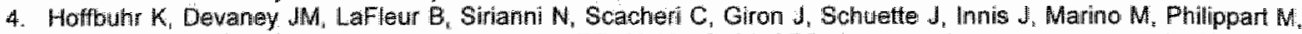
Narayanan $V$. Umansky $R$, Kronn D. Hoffman EP, Naidu S. MeCP2 mutations in chidren with and without the phenotype of Ret syndrome. Neurology 200 $;$; $6: 1486-1495$.

5. Schwartzman JS. Bemardino $A$, Mishimura $A_{\xi}$ Gomes $R_{2}$, Zatz M. Rett syndrome in a boy with a $47, X X, Y$ Karotype. Confirmed by a rare muttation in the MeCP2 gene. Neuroped 2001; 32: $162 \% 164$.

6. Schwartzman J5, Zatz M, Vasquez LR, Gomes RR, Koifmann CP, Fridman $C$, Otto PG. Rett syndrome in a boy with a 47, XXY Karyotype. Am J Hum Genet 1999; 64: 1781-1785.

7. Vorsanowa SG, Yurow YB, Ulas WY. Demidova IA, Sharonin VO, Kolotii AD, Gorbatchewskaia NL, Beresheva AK, Soloviev IV. Cytogenefic and molectlar-cytogenetic studies of Rett syndrome (RTT): a iretrospective analysis of a Russian cohort of RTT patients the investigation of $57 \mathrm{girls}$ and three boys). Brain Dev 2001; 23(Suppl 1) $5196-$ S201.

8. Claylori-Smith d: Watson P. Ramisden $S_{x}$ Black GCM. Somatic mutation in MeCP2 as a non-fatal neurodevelopmental disorder in males. Lancer $2000 ; 356: 830-832$.

9. Watson $P$. Black G. Ramsden S, Barrow M, Stper M, Kerr B, Clayton-Smith J. Angelman syndrome phenotype associated with mutations in MeCP2, a gene encoding a methyl CpG binding protein. $J$ Med Geneil 2001; 38: 224. 228.

10. Armstrong J, Poo P. Pineda M, Aibar E, Gean E, Catala V, Monras E Classicra! Rett syndrome in a boy as a result of somatic mosaicism for a MeCP2 mutation. Ann Nesrol 2001; 50: 692.

11. Topcu $M_{4}$ Akyerli $C$. Sayi $A_{n}$ Toruner $G A$, Kocoglu $S R$, Cimbis M Ozcelik $T$. Somatic masaicism for a MECP2 multation associated with classic Rett syndrome in a boy. Eur ul Hum Genet 2002; 10: 77-81.

12. Wan M, Zhao K, Lee SS, Francke U. MECP2 truncating mutations cause histone H4 hyperacelylation in Rett syndrome. Hum Mol Genet 2001, 10: 1085-1092.

13. Wan M. Lee SS, Zhang X, Houwink-Manville I Song HR, Amir RE, Budden $S$ "Naidu S, Pereira JLP, Lo IFM, Zoghbi HMY, Schanen $C$, Francke U. Rett syndrome and beyond: recurrent spontaneous and familial MeCP2 mutations at CpO hotspots. Am J Hum Genet 1999; 65: 1520-1529.

14. Schanen C. Francke U. A severely affected male born into a Reth syndrome kindred supports $X$-linked inheritance and allows extension of exclusion map. Am J Hum Genet 1998; 63: 267-269.

15. Schanen NC, Kurc.zynski TW, Brunelle D, Woodcock MM, Dure LS, Percy AK. Neonatal encephalopathy in wo male children in families with recurrent Rett syndrome, J Child Neurol 1998; 5: 229-231.

16. Villard $L$, Kpebe $A_{k}$ Cardoso $C$, Chelly J Tardieu $M$, Fontes $M$. Two affected boys in a Rett syndrame family Clinical and moleculai findings. Neurology 2000; 55: 1183-1193.

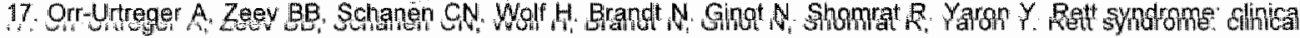
manifestations in malles with MeCP2 mutations, germline mosaicism and implications for genetic counseling and pronatal diagnosis. Eur J Hum Gonot 2001; 9(Suppl 1): 199

19. Zeev BB, Yaron $Y_{n}$ Schanen NC. Wolf H, Brandt N, Ginot N, Shomrat R, Orr-Lrtreger A. Rett syndrome: clinical imanifestations in males with MECP2 mutations. I Child Nownol $2002 ; 17: 20-24$.

19. Geerdink $N$, Rotteveel $J J$, Lammens M, Sistermans EA, Heikens GT. Gabreêls FJM, Mullaart FA, Hamel BCJ. MECP2 mutation in boy with severe neonatal encephalopathy: clinical, neuropathological and molecular findings. Newropediatros 2002: $33: 33-36$.

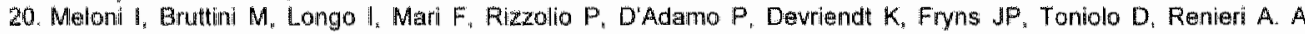
inultation in the Rett Syndrome Gene, MeCP2, causes X-linked mental retardation and progressive spasticity in males. Arm J Hum Ganer 2000; 67: 982-985.

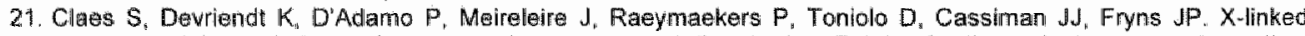
severe mental retardation and a progressive neurological disorder im a Belgian family: clinical and genetic studies. Cin Genet 1997; 52: 155-161.

22. Orrico A, Lam C, Galli L. Dotti MT, Hayek $G$, Tong SF, Poon MK, Zapella M, Federico A, Sorrentino V. MeCP2 mutation in male patients willy non-specific X-linked mental retardlation. FEBS Lett 2000; 481: 285-288.

23. Dott MT, Orrico A, De Stefano N, Battisti $C$, Sicurelli $F$, Severi S, Lam CW, Galli L Sorrentino V, Federico A. A Rett syndrome MECP2 mutation that causes mental retardation in men. Newrolagy 2002; 58: 226-230.

24. Verloes $A_{n}$, Cherif 1 . Briatilt $S_{i}$ Chelly $\mathrm{J}$. MeCP2 mulation in mild non-specific $X$-linked mental retardation family. Eur J Hum Geret 2001; 9(Suppl. 1): 185.

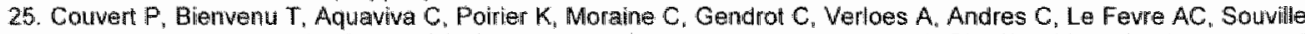
1. Steffann, Des Portes $W$, Ropers HH, Yntema HG. Fryns JP, Briault S, Chelly J, Cherif B. MeCP2 is highly muted in X-linked mental retardation. Hum Mof Genet 2001; 10; 9411.946. 


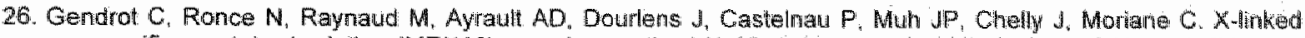
monspecilic mental retartation (MRX16) mapping to distal $\times 2028$. linkage study and neuropsychotogical data in a llarge family. Am II Mod Genet 1999; $83 ; 411418$

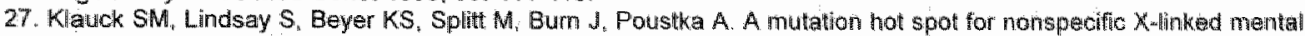
retardation in the MECP2 gene causes the PPW-X syndrome. Am J Hum Gener 2002; 70: 1034-1037.

28. Yntema HG, Oudakker AR, Kleefstra $T$, Hamel BC, Boklwoven HV, Chelly J, Kalscheuer VM, Fryns JP, Raynaud

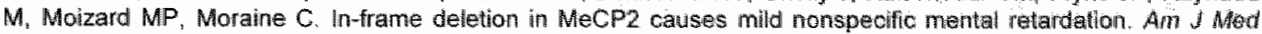
Genet 2002; 107: 81:83.

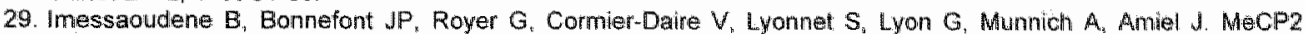
mutations in mon-fiatal, non-progressive encephatopathy in male. J Med Genet 2001: 38; $171 \times 174$

30. Cohen D, Lazar $G$, Couvert $P$, Desportes $V$, Lippe D. Maet P, Heron D. MECP2 mulation in a boy with languag disorder and schizophreni:. Am If Psychatry 2002: 159: 148-149 (Letter).

31. Ellaway $C_{1}$ Christodoulou J. Rett syndrome: clinical characteristics and recent genetic advances. Disabil Rehabil $2001: 23: 98-106$.

32. Dragich J, Houwink-Manwille I Schanen C. Rett syndrome: a surprising result of multation in MeCP2. Hum Mol Gener 2000; $9: 2365-2375$.

33. MeCP2 Mutation Database of the Rett Symdrome Research Foundation (http / /Www.rirforg/)

34. Lee SSJ, Wan M. Francke U. Spectrum of MeCP2 mutations in Rett syndrome. Brain Dev 2001; 23(Suppl. 1): S138-\$143.

35. Schanen C. Rethinking the fate of males with mutations in the gene that causes Rett syndrome. Bram Dev 2001 23(Suppl. 1): S144-S146.

36. Kudo $S$, Nonura $Y$. Segawa M. Fuita N, Nakao M, Hammer S, Schanen $C_{t}$ Terai I, Tamura M. Functional characterisation of MeCP2 mutations found in male patients with $X$ linked mental retardation. J Med Gonet (Letter) 2002; 39: 132-136.

37. Cheadie JP, Gill H, Fleming N, Maynard, , Kerr A, Leonard H, Krawczak M, Cooper DN, Lynch S, Thomas N, Hughes $H_{\text {, Hulten } M}$, Ravine $D$, Sampson JR, Clarke A. Long-read sequence analysis of the MECP2 gene in Rett syndrome patients: correltation of disease severity with mutation type and location. Mum Mol Genet 2000; $9: 1119$. 1129.

38. Amir RE, Van den Veyer IB. Schultz R, Malicki DM, Tran CQ, Dahle EJ, Philippi A, Timar L, Percy AK, Motil KJ. Lichtarge $O$, Smith EO, Glaze DG, Zoghbi HY. Influence of mutation type and $X$ chromosome inactivation on Rett syndrome phenotypes. Ann Nourol 2000; 47:670-679.

39. Yntema HG, Kleefstra T, Oudakker AR, de Vries. BBA, Nillesen W, Sistermans EA, Brunner HG, Hamel BC.J, Wan Bokhowen $\mathrm{H}$. Low frequency of MECP2 mutations in mental retardation of unknown origim: implicaltions for routine DNA diagnostics Eur J Hum Genet 2002; 10(Suppl 1): 229(A).

40. Vourch $P$, Bhenwenu $T$, Beldjord $C$, Chelly J, Barthelemy $C$. Muh JP, Andres $C$. No mutations in the coding region of the Rett syndrome gene MeCP2 in 59 autistic patients. Eu J Hum Genet 2001: 9: $556-558$ 


\begin{tabular}{|c|c|c|c|c|c|c|c|c|c|c|}
\hline$\underline{\tilde{E}}$ & & & $\begin{array}{l}6 \\
6\end{array}$ & 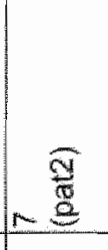 & $\begin{array}{l}10 \\
100^{\circ}\end{array}$ & 으 & $E$ & 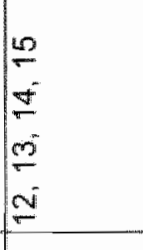 & $\mathscr{\theta}$ & a \\
\hline 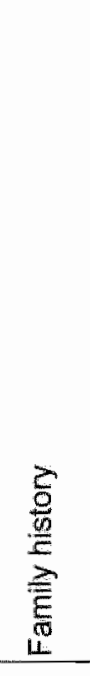 & & & 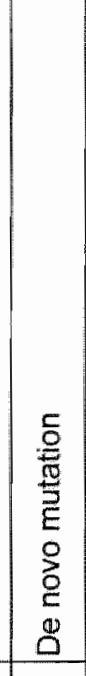 & 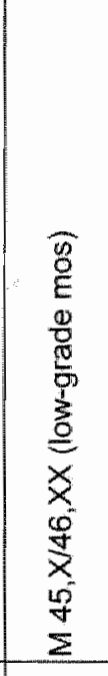 & & & & 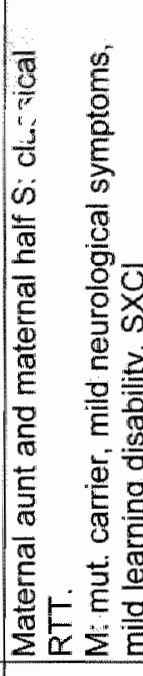 & 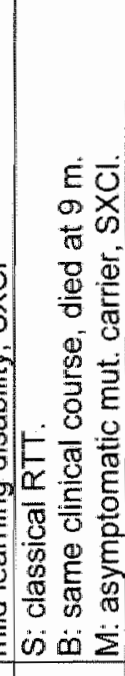 & 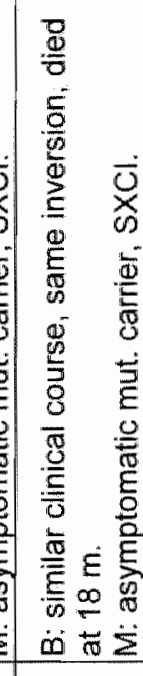 \\
\hline 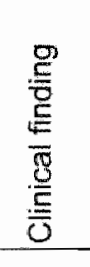 & 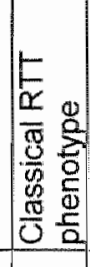 & 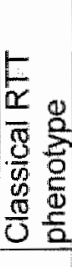 & & 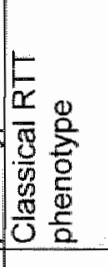 & 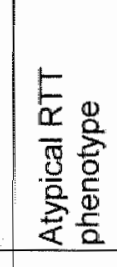 & 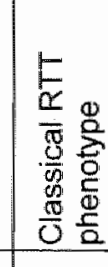 & 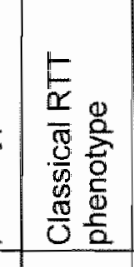 & 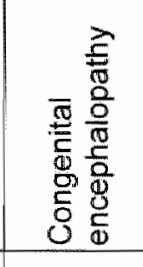 & 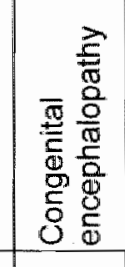 & 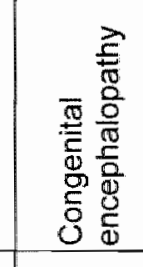 \\
\hline$\stackrel{g}{\&}$ & a & $\stackrel{\vec{m}}{=}$ & in & 点 & $\overrightarrow{0}$ & $\underset{\forall}{\nexists}$ & $\stackrel{\vec{N}}{\stackrel{v}{*}}$ & 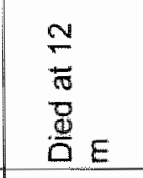 & 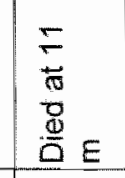 & 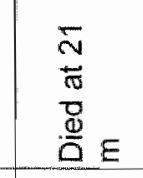 \\
\hline 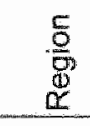 & 睘 & 品 & 誉 & 总 & 品 & $\frac{\mathrm{O}}{\Sigma}$ & $\underset{\mathbb{R}}{\stackrel{p}{1}}$ & 足 & 畐 & $\stackrel{\infty}{0}$ \\
\hline 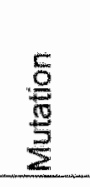 & 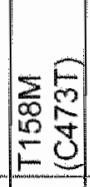 & & 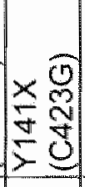 & 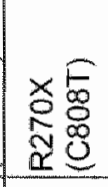 & 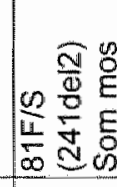 & 甹 & 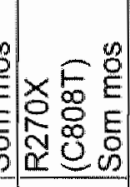 & 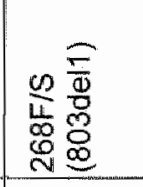 & 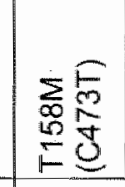 & 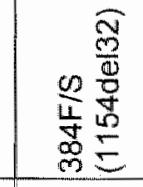 \\
\hline $\begin{array}{l}\text { 总 } \\
\text { 商 } \\
\text { 总 }\end{array}$ & 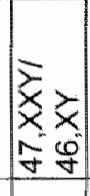 & 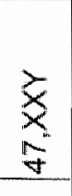 & $\mid \begin{array}{l}\vec{x} \\
x \\
\vec{y}\end{array}$ & 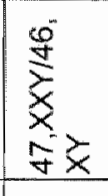 & $\begin{array}{l}x \\
x \\
0 \\
y\end{array}$ & $\begin{array}{l}x \\
x \\
0 \\
0\end{array}$ & $\begin{array}{l}x \\
x \\
0 \\
0\end{array}$ & $\begin{array}{l}\grave{x} \\
0 \\
g \\
y\end{array}$ & $\begin{array}{l}x \\
x \\
0 \\
0 \\
y\end{array}$ & 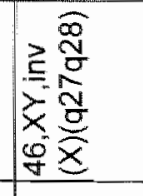 \\
\hline 之 & -1 & $N$ & $m$ & J & $w$ & $\omega$ & N & $\infty$ & $\infty$ & 우 \\
\hline
\end{tabular}




\begin{tabular}{|c|c|c|c|c|c|c|c|c|c|}
\hline $\begin{array}{l}\bar{\Phi} \\
\end{array}$ & $\begin{array}{l}\hat{\underline{\mathbb{S}}} \\
=\infty\end{array}$ & 은 & $\mid \begin{array}{l}\bar{N} \\
\bar{N} \\
\bar{N}\end{array}$ & $\mid \begin{array}{l}\vec{N} \\
\mathcal{N}\end{array}$ & $\begin{array}{l}\dot{s} \\
\stackrel{N}{N}\end{array}$ & $\mid \begin{array}{l}0 \\
w \\
w\end{array}$ & $\hat{a}$ & 102 & 9 \\
\hline 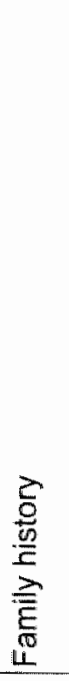 & 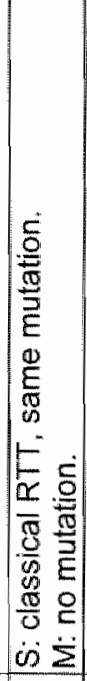 & 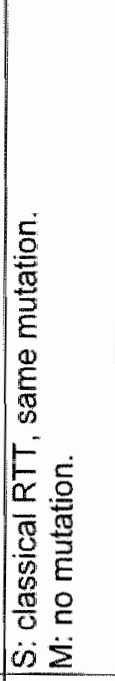 & 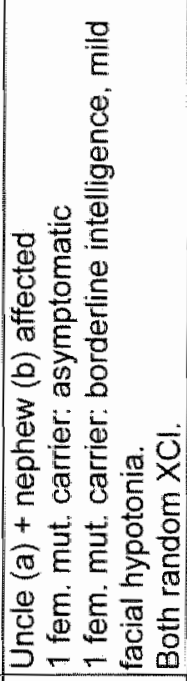 & 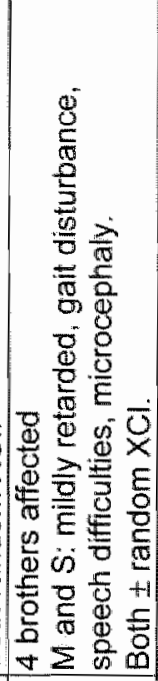 & 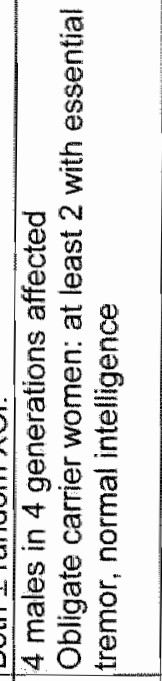 & 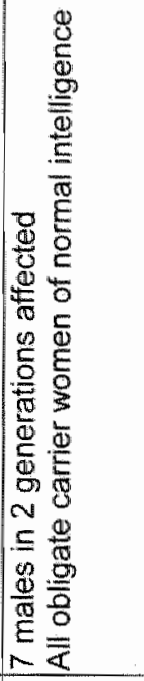 & 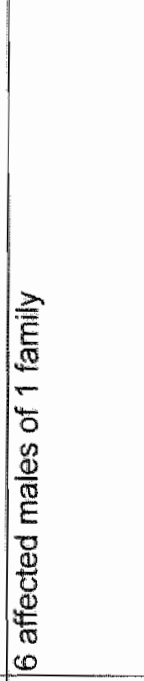 & 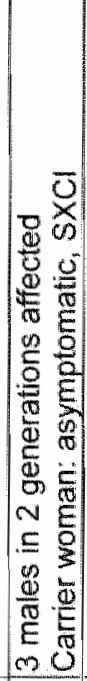 & 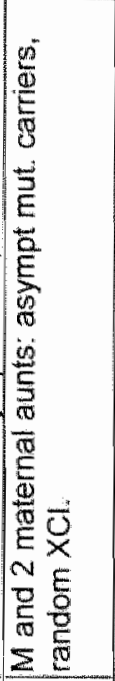 \\
\hline 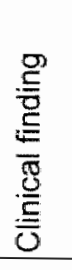 & 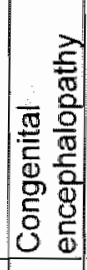 & 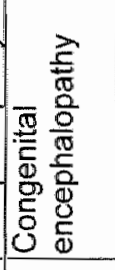 & 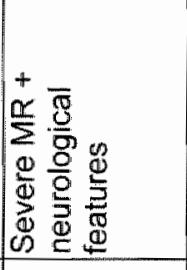 & 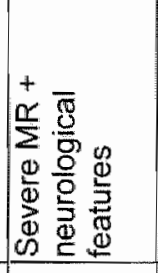 & 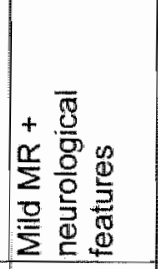 & 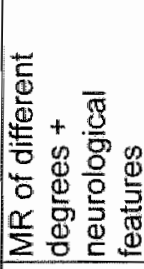 & 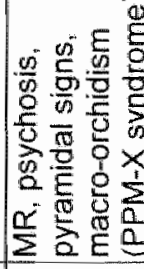 & $\mid \frac{\alpha}{2}$ & 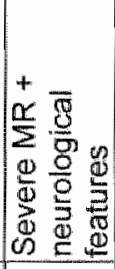 \\
\hline$\stackrel{\mathscr{g}}{\mathbb{L}}$ & 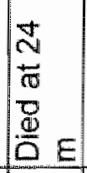 & $\begin{array}{l}\frac{m}{2} \\
\frac{\pi}{\pi} \\
\frac{0}{0} \\
\frac{0}{0} E\end{array}$ & 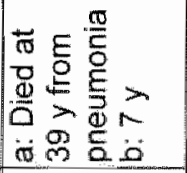 & a & $\begin{array}{l}2 \\
8 \\
0 \\
0 \\
0\end{array}$ & 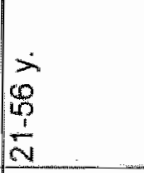 & 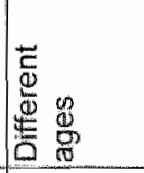 & $E$ & $\infty$ \\
\hline 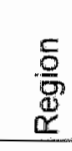 & $\stackrel{a}{\underline{\alpha}}$ & 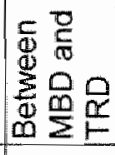 & $\frac{5}{0}$ & $\sum^{0}$ & 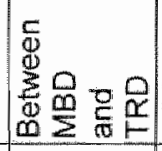 & $\sum^{0}$ & $\underline{0}$ & $\frac{\omega}{b}$ & 5 \\
\hline 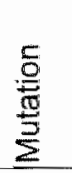 & 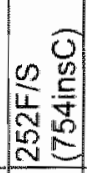 & 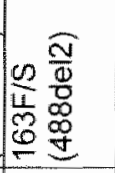 & 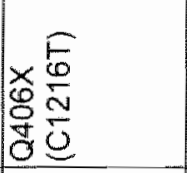 & 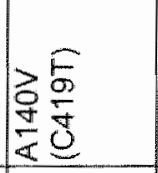 & 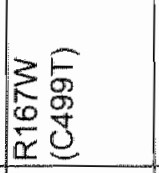 & 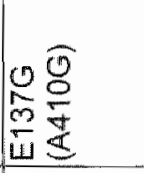 & 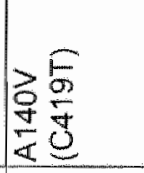 & 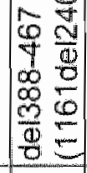 & 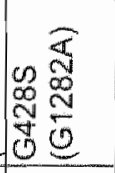 \\
\hline 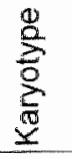 & 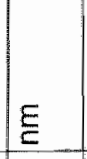 & $\begin{array}{l}x \\
0 \\
g^{\circ}\end{array}$ & 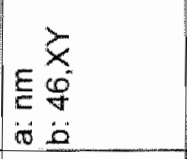 & & & & $\underline{E}$ & & $\begin{array}{l}x \\
0 \\
q\end{array}$ \\
\hline 之 & $E$ & $\stackrel{N}{2}$ & $\stackrel{2}{2}$ & $1 \pm$ & 15 & $\stackrel{10}{2}$ & $F$ & $\infty$ & $\sqrt{2}$ \\
\hline
\end{tabular}




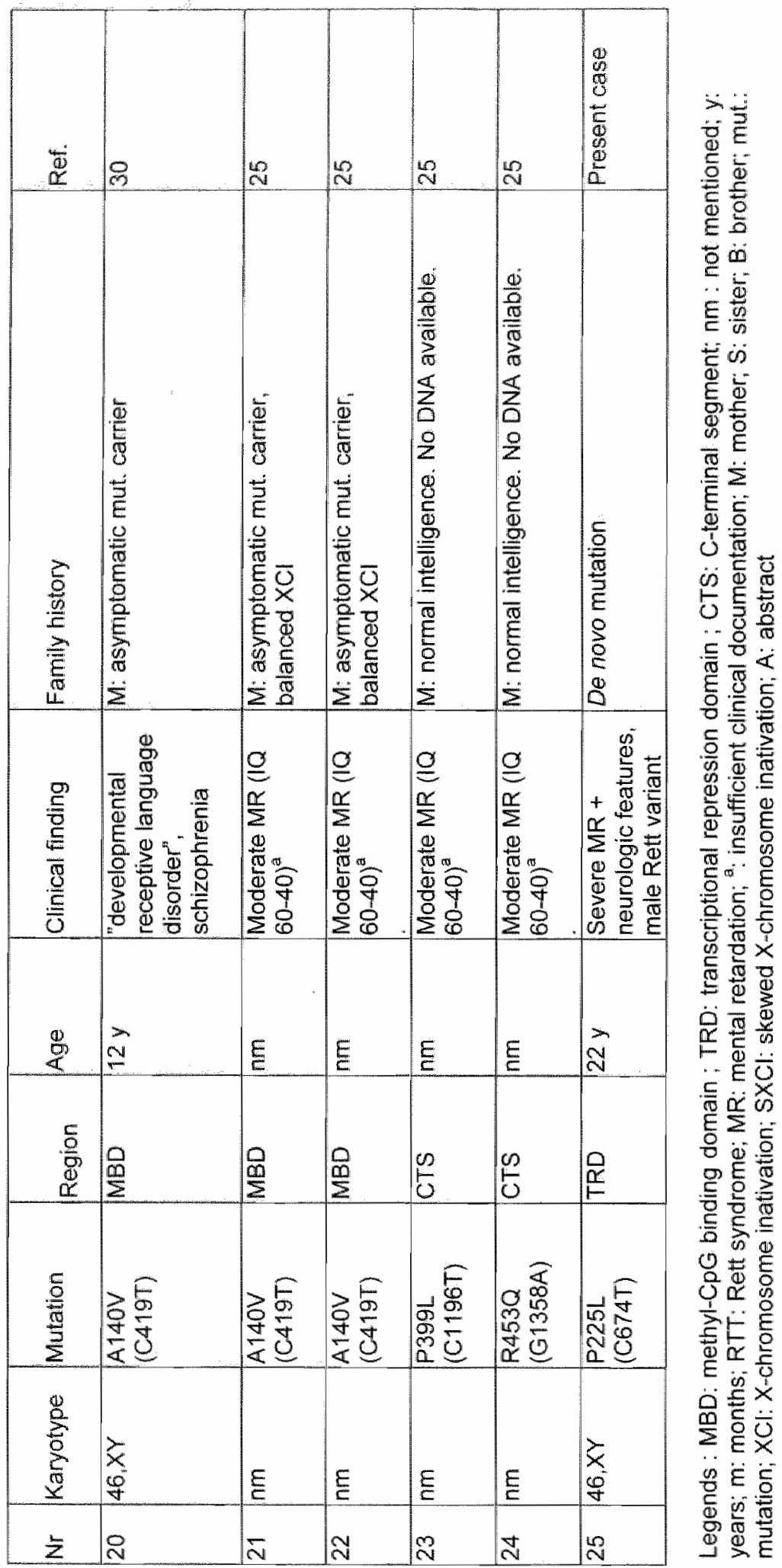




\section{Summary}

Rett syndrome is worldwide an important cause of severe mental relardation affecting females in early childhood. After an apparently normal infantile development stagnation appears followed by neurological regression. This results in a pattern of characteristic manifestations that is unique in human pathology. Loss of speech and purposeful use of hands followed by the appearance of characteristic stereotypic hand movements and mental deficiency together with the partial recovery of mainly visual interactive communicative ability form the diagnostic hallmarks of this disorder. The disorder finally leads to severe multi-handicap with complete dependency for all the activities of daily living. Rett syndrome is caused by mutation in the MECP2 gene encoding the methyl-CpG-binding protein 2.

The first part of this thesis contains the general introduction, presenting the medical and psychosocial diagnostic approach of developmental delay and mental retardation and the outline of the aims of the study. The second part contains four chapters.

In chapter A. the Rett syndrome in females is described historically and clinically, with the staging system and diagnostic criteria, followed by annotations about etiological, pathogenic and genetic aspects of this neurodevelopmental disorder.

In Chapter B. the Leuven-Maastricht experience with Rett syndrome is presented. Materials, methods and results of the study are presented and discussed in a series of 103 females of different ages with a clinical diagnosis of Rett syndrome. Their clinical severity was compared with the nature of the MECP2 mutation involved. Comparing the long-term evolution with the type and localization of the MECP2 mutation involved seems to contribute more to the understanding of genotype-phenotype relationship in Rett syndrome than to look at the type and localization of the mutation alone. Different disorder profiles could thus be recognized and illustrated that defining classic and variant forms as such is not contributing to the understanding of the ongoing pathology of disturbed neurodevelopment.

Chapter $\mathrm{C}$. concerns the management of Rett syndrome in all of its most important features and underlines the importance of the multidisciplinary approach. Some of the findings of this. study about the clinical variability within the syndrome are important in the individualized approach of each girl or adult and for the future management of Rett syndrome in general.

Chapter D. concludes with a general discussion and future developments that we expect in the clinical approach and management of Rett syndrome.

Finally, there are six addenda:

1.) about adolescent and adult females with Rett syndrome, 2.) about the "hot spot" deletions in the C-terminus of MECP2, 3.) a case report as an original article about the management of severe breathing irregularities in a girl with Rett syndrome, 4 .) the results of a visual and auditory response study in girls and fremales with Rett syndrome, 5.) about the MLPA technique in finding gross rearrangements in MECP2, and 6.) gives a review of the $M E C P 2$ related disorders in males with mental retardation. 
Rett syndroom vormt wereldwijd een belangrijke oorzaak van ernstige mentale retardatie dat zich vrijwel uitsluitend manifesteert bij meisjes in hun kinderleeftijd. Na een ogenschijnlijk normale vroegkinderlijke start leiden stagnatie in de ontwikkeling en een neurologische achteruitgang tot een patroon van afwijkingen dat uniek is in de menselijke pathologie. Verlies van spraak en doelmatig handgebruik, met het optreden van karakteristieke stereotype handbewegingen en mentale retardatie, gepaard met een gedeeltelijke recuperatie van een hoofdzakelijk visuele communicatieve interactie vormen de hoofdkenmerken. Er bestaat een grote variatie in ernst van het klinisch beeld dat in zijn klassieke vorm leidt tot ernstige motorische en mentale handicap met totalle afhankelijkheid in de activiteiten van elke dag. Rett syndroom wordt veroorzaakt door mutatie in het MECP2 gen dat codeert voor het eiwit methyl-CpG-bindend proteine 2.

Deel 1 behandelt in de eerste paragraaf de benadering van ontwikkelingsachterstand bij kinderen en mentale retardatie in het algemeen vanuit medisch en psychosociaal oogpunt. In de tweede paragraaf worden de doelstellingen van deze thesis over het Rett syndroom uiteengezet. Deel 2 bevat vier hoofdstukken.

Hoofdstuk $A$, is de inleiding tot het Rett syndroom en beschrijft de geschiedenis, de prevalentie, de klinische symptomatologie en diagnostische criteria, de etiologische. pathologische en genetische aspecten van het Rett syndroom bij meisjes.

Hoofdstuk B. omvat de Leuven - Maastricht ervaring met Rett syndroom. De methode de resultaten en bevindingen worden uitvoerig beschreven aan de hand van het onderzoek dat verricht werd bij 103 meisjes en vrouwen met klinisch Rett syndroom. De klinische ernst (fenctype) werd dan vergeleken met de aard van hun MECP2 mutatie (genotype). Hieruit bleek dat het type en de lokalisatie van de mutatie in het gen als variabelen, samen met de lange termijn evolutie het meest leert over de voortschrijdende pathologie van deze ontwikkelingsstoornis. Het definiëren van Rett syndroom "varianten" als dusdanig lijkt van minder belang te zijn dan het herkennen van bepalalde profielen van ontwikkelingsstoornis eigen aan bepaalde mutaties in MECP2.

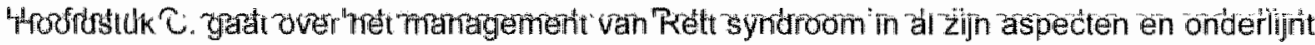
het belang van de multidisciplinaire samenwerking. Een aantal van de bevindingen rondom de klinische variatie binnen het syndroom zijn van belang voor de begeleiding en de aanpak voor ieder meisje of volwassen vrouw afzonderlijk en voor het toekomstig beleid rondom Rett syndroom in het algemeen.

Hoofdstuk $\mathrm{D}$. bevat de algemene besluiten van deze thesis waarbij enkele toekomst perpectieven worden onderlijnd.

Tenslotte zijn er 6 addenda: 1.) over adolescente en volwassen vrouwen met Rett syndroom, 2.) een aparte beschouwing van de "hot spot" deleties in het C-terminale deel van MECP2, 3.) over de benadering en de aanpak van ernstige ademhalingsonregelmatigheden aan de hand van een case report, 4.) de resultaten van een studie over visueel en auditief geévokeerde potentialen bij meisjes en vrouwen met Rett syndroom, 5.) de MLPA analyse lechniek ter opsporing van grote deleties in MECP2, en tenslotte 6.) een overzicht van ontwikkelingsstoornissen met mentale retardatie bij mannen welke gerelateerd zijn aan een MECP2 mutatie. 
Eric E.J. Smeets werd geboren te Hasselt op 03 februari 1951, als zoon van een befaamd jeneverstoker. Hij studeerde Geneeskunde alan de Katholieke Universiteit te Leuven. specialiseerde zich in de Kindergeneeskunde met bijzondere bekwaming in de Kinderneurologie, en is erkend als Revalidatiearts in de Functionele Revalidatie.

Hij was verbonden als Kinderarts aan het Maria Ziekenhuis Noord-Limburg te Neerpelf van 1982 tot 1999 , en aan het Dienstencentrum voor ernstig mentaal gehandicapte kinderen en volwassenen, St-Oda te Overpelt van 1982 tot 1995.

Hij werd staflid van de Klinische Dienst Genetica, Centrum Menselijke Erfelijkheid, van het Universitair Ziekenhuis Gasthuisberg te Leuven in januari 1990, en wan de afdeling Klinische Genetica van het Academisch Zlekenhuis Maastricht te Maastricht in juli 1999.

$\mathbb{H i j j}$ is auteur en mede-auteur van verscheidene medische publiciaties en lezingen.

Hij is vader van vijf kinderen, Wouter, Arne, Joris, Simon en Maren, en grootvader van JensLouis. Hij houdt van paarden, leest en reist graag met en naar zijn vrienden, en om het evenwicht te bewaren beoefent hij het hard lopen. Als liefhebber van het buitenleven, en als verdediger van het socio-economisch belang ervan, is hij coördinator van de bosgroepering Galgenberg-Tegenschuer, secretaris en werkend lid van de Bosgroep Zuid-Limburg, en voorzitter van de vzw Ontwikkeling Vijvergebied Midden-Limburg in Belgisch Limburg. 


\section{List of publications}

Smeets E., Terhal P. Casaer P. Peters A., Midro A., Schollen E., van Roozendaal K., Moog U., Matthijs C. Herbergs J., Smeets H., Curfs L., Schrander-Stumpel C., Fryns JP. (2005). Rett syndrome in females with CTS hot spot deletions: A disorder profile. Am J Med Genet, $132: 117-120$.

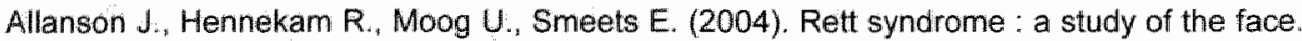
Proceedings of the Greenwood Genetic Center, $23: 63-64$.

Hoedemaekers $Y_{.}$De Kleine M. Stevens-Kroef M., Smeets $E$., Schrander-Stumpel $C$. (2004). Hypotriploidy 68,XX: a new case report and review of earlier cases. Genet Couns. 15:329-333.

Moog U.*, Smeets E. , van Roozendaal K., Schoenmakers S., Herbergs J., SchoonbroodLenssen A., Schrander-Stumpel C. (2003). Neurodevelopmental disorders in males related to the gene causing Rett syndrome in females (MECP2). Eur J Paediatr Neurol, 7:5-12.

Smeets E., Schollen E., Moog U., Matthijs G., Herbergs J., Smeets H., Curfs L., SchranderStumpel C. Fryns JP. (2003). Rett syndrome in adolescent and adult females: clinical and molecular genetic findings. Am J Med Genet, 122:227-233.

Schollen E., Smeets E., Deflem E., Fryns JP., Matthijs G. (2003). Gross rearrangements in the MECP2 gene in three patients with Rett syndrome: implications for routine diagnosis of Rett syndrome. Hum Mutat, 22:16-20.

Lukusa T., Smeets E., Vermeesch J., Fryns JP. (2002). Small terminal 10q26 deletion in a male patient with Noonan-like stigmata: diagnosis by cytogenetic and FISH analysis. Genet Couns, $13: 417-425$.

Smeets E., Vandenbossche L. Fryns JP.(2001). Partiall distal trisomy 3p. A partial autosomal trisomy without major dysmorphic features. Genet Couns, $12: 85-89$.

Lukusa T., van den Berghe L., Smeets E., Fryns JP. (1999). Proximal trisomy 13q and distal monosomy $8 \mathrm{p}$ in a dysmorphic and mentally retarded patient with an isodicentric chromosome $13 \mathrm{q}$ and a $13 \mathrm{q} / 8 \mathrm{p}$ translocation chromosome. Ann Genet, 42:215-220.

Fryns JP., Smeets E. (1998). "Cataplexy" in Coffin-Lowry syndrome. J Med Genet, 35:702.

Fryns JP., Smeets E., Devriendt K., Petit P. (1998). Wolf-Hirschhorn syndrome with cryptic 4 p16.3 deletion and balanced/unbalanced mosaicism in the mother. Ann Genet, 41:73-6.

Frints S., Schrander-Stumpel C., Schoenmakers E., Engelen J., Reekers A., Van den Neucker A., Smeets E., Devlieger H., Fryns JP. (1998). Strong variable clinical presentation in 3 patients with $7 q$ terminal deletion. Genet Couns, 9:5-14.

Frints S., Schoenmakers E., Smeets E., Petit P., Fryns JP. (1998). De novo 7 q36 deletion: breakpoint analysis and types of holoprosencephaly. Am J Med Genet, 75:153 158. 
Smeets E. Fryns JP., Van den Berghe H. (1996). The Floating-Harbor syndrome: report of another patient and differential diagnosis with Shprintzen syndrome. Genet Couns, $7: 143$ m 146.

Fryns JP., Smeets E., Van den Berghe H. (1995). On the nosology of the "primary true microcephaly, chorioretinal dysplasia, Iymphoedema" association. Cin Genet $48: 131-133$.

Zwamborn-Hanssen A. Schrander-Stumpel C., Smeets E. Decock P. Fryns JP. (1995). FG syndrome: the trias mental retardation, hypotonia and constipation reviewed. Genet Couns, 6:313-319.

Smeets E., Fryns JP., Van den Berghe H. (1994). Melkersson-Rosenthal syndrome and de novo autosomal $t(9 ; 21)(p 11 ; p 11)$ translocation. Clin Genet, $45: 323-324$.

Smeets $E_{n}$, Fryns $\mathbb{U}$., Cohen M. Jr (1994). Regional Proteus syndrome and somatic mosaicism. Am ل Med Genet, 51:29-31.

Fryns JP., Smeets E., Thiry P., Geutjens J., Vinken L., Van den Berghe H. (1994). Ectomorphic habitus, severe mental retardation and characteristic face: a new MCA/MR syndrome? Am J Med Genet, 49:91-93.

Fryns JP., Thiry P., Geutjens J., Smeets E., Vinken L., Van den Berghe H. (1993). Profound mental retardation, characteristic facies with midfacial hypoplasia and premature frontotemporal balding, muscular hypotrophy, and small patellae in two unrelated male patients. J Med Genet, 30:319-321.

Volcke P., Soekarman D., Vandenbussche P. Haegeman J., Smeets E., Thiry P., Fryns JP. (1993). Macrocephaly and mental retardation. The unique association with short stature, spastic paraplegia and CNS malformations. Genet Couns, 4:47-50.

Fryns JP. Kleczkowska A., Smeets E., Van Den Berghe H. (1992). Transmission of ring chromosome $1846, X \times / 46, X X, r(18)$ mosaicism in a mother and ring chromosome 18 syndrome in her son. Ann Genet, 35:121-123.

Grubben C., Fryns JP., Smeets E., Van den Berghe H. (1991). Noonan phenotype in the basal cell nevus syndrome. Genet Couns, 2:47-54.

Brichard B., Smeets E., Withofs L., Gillerot $Y$., Battisti O. "Langhendries JP, Bertrand JM. (1990). Tracheal agenesis: an exceptional cause of neonatal respiratory distress. Pediatr Pulmonol, 9:119-120.

Fryns JP., Kleczkowska A. Smeets E., Thiry P., Geutjens J., Van den Berghe H. (1990). Cohen syndrome and de novo reciprocal translocation $t(5 ; 7)(q 33.1 ; p 15.1)$. Am J Med Genet. $37: 546-547$

Fryns JP., Kleczkowska A., Smeets E., van den Berghe H. (1988). A new centromeric heteromorphism in the short arm of chromosome 20. J Med Genet, 25:636-637.

Borghgraef M., Fryns JP., Smeets E., Marien d. van Den Berghe H. (1988). The 49, $\times \times \times \times \times$ syndrome. Clinical and psychological follow-up data. Clin Genet, 33:429-434.

Fryns JP., Kleczkowska A. Smeets E., Van den Berghe H. (1987). Distal 11q deletion: a specific clinical entity. Helv Paediatr Acta. 42:91-94. 
Fryns JP. Kleczkowska A., Vinken L., Geutjens J., Smeets E., Van den Berghe H. (1986). Acrocentric/18p translocation in two mentally retarded males. Delineation of the adult phenotype. Ann Genet, 29:107-111.

Eggermont $E$., Vanderschueren-Lodeweyckx M., De Nayer P., Smeets $E$., Vanacker G. Comette $C_{.}$, Jaeken J., Devlieger $H_{\text {. }}$, Eeckels $R_{\text {. }}$ Beckers $C$. (1984). The thyroid-system function in pretem infants of postmenstruall ages of 31 weeks or less: evidence for a "transitent lazy thyroid system". Helv Paediatr Acta, 39:209-222.

Casteels-van Daele M. Standaert L., Boel M., Smeets E., Colaert J., Desmyter J. (1981). Basilar migraine and viral meningitis. Lancet, 1(8234):1366.

Eggermont E., Dewlieger H., Marchal G., Jaeken J., Vandenbussche E., Smeets E., Vanacker G., Corbeel L. (1980). Angiographic evidence of low portal liver perfusion in transient neonatal hypermmonaemia. Acta Paediatr Belg, 33:163-169.

Fryns JP., Smeets E., Eggermont E., Delire C., Van den Berghe H. (1978). Partial trisomy 9q-in a polymalformed new-born infant Karyotype: $47, X_{1}+$ del (9) (q33). Acta Paediatr Belg, $31: 237-240$. 
Mijn bijzondere dank gaat uit naar mijn opleiders in de Kindergeneeskunde: Prof. R. Eeckels, Prof. L. Corbeel, Prof. E. Eggermont en Prof. M. Casteels-van Daele, die mij vanuit het niets de kwalen en kommer van het kind leerden kennen; Professor P. Casaer die bij mij de interesse voor de ontwikkelingsineurologie losmaakte en mij in de kinderneunologie opleidde: Prof. Jean-Pierre Frijns en Dr. Lambert Vinken, huisarts en arts verstandelijk gehandicaptenzorg, die mij het kijken, meten en vergelijken hebben voorgedaan.

Het was een uitermate klinisch gerichte opleiding die mij via die interesse voor het kind met ontwikkelingsstoornissen en complex meervoudige handicap terug binnen de muren van de Alma Mater op de afdeling Klinische Genetica bracht in 1990 toen Prof. J.P. Frijns mij in 1990 in zijn toen nog kleine schare van medewerkers heeft opgenomen. Het was een voorrecht om met hem te werken en de ewolutie van de klinische en moleculaire genetica van de laatste decennia van nabij te mogen meemaken en al de nieuwe krachten en jonge wetenschappers te zien komen en groeien in het vak.

Een bijzonder woord van waardering en dank gaat uit naar Professor Bengt Hagberg en zijn echtgenote. Wij kennen elkaar vooral sedert de fameuse "Rett-weeks" in Gotenburg in 1989 en van vele ontmoetingen nadien in Zweden of elders in de wereld onderweg. Bengt heeft mij steeds gefascineerd door zijn diagnostische benaderingen, zijn kennis en kracht om mensen te motiveren en niet in het minst rondom het Rett syndroom. Professor Alina Midro ontmoette ik in 2000 en onze samenwerking, ook met de Poolse Rett Oudervereniging. groeide, op een vaak zeer hartelijke manier, uit tot een onlosmakelijke band. Dr. Peter Julu leerde ik kennen in 2001 tijdens een bezoek aan het Rett centrum in Frösön, Zweden. Zijn uitbundigheid heeft mij niet meer losgelaten, en zijn neurofysiologische vaardigheid is indrukwekkend. Met al deze collega's en vrienden hoop ik nog lang te mogen samenwerken. Voor mijn promotoren Professor Connie Schrander-Stumpel en Professor Jean-Pierre Frijns, voor al de hulp en sturing, de aanmoediging en ondersteuning die zij mij gaven bij de realisatie van deze thesis, mijn oprechte en welgemeende dank. Jullie hebben mij het vertrouwen gegeven en ruimte en tijd gelaten.

Ik wens ook mijn waardering uit te spreken voor de verpleegkundigen van de kinderafdelingen waar ik door de jaren heen gewerkt heb, voor de sociaal-pedagagische en paramedische medewerkers van St-Oda en van diverse andere centra voor verstandelijk gehandicapten. Ook voor de collega's en medewerkers van het Centrum voor Menselijke Erfelijkheid te Leuven en van de afdeling Klinische Genetica te Maastricht mijn harteiijke dank. We hebben op elkaars professionele golflengtes leren praten, elkaar leren begrijpen, hetgeen de multidisciplinaire benadering van ontwikkelingsstoornissen op een hoog niveau bracht en bijdroeg tot de teamspirit die voor iedereeen zo belangrijk is om goede resultaten te bekomen. En het leidde ook tot de kameraadschap zoals die tussen velien van ons is ontstaan.

We doen het tenslotte voor het kind, zijn ouders en de families. Zij weten onze inzet het meest te waarderen en geven daarvoor ook veel terug. Mijn dank gaat dus ook naar hen, voor hun samenwerking, voor hetgeen wij van hen geleerd hebben in de consultwoering en vaak ook op persoonlijk vlak.

Tenslotte bedank ik ook Karel en Francis voor de fotografische ondersteuning. Mickey Chenault voor de statistische uitwerking. Denise, Rita en Ivette en iedereen van de beide secretariaten voor de hulp en het geduld dat ze met mil gehad hebben.

De tandem Kindergeneeskunde met Klinische Genetica loopt goed voor mij en ik hoop nog genuime tijd door te fietsen. 